\title{
TOMOGRAFÍA DE ONDAS SUPERFICIALES EN SUDAMÉRICA: ESTRUCTURA LITOSFÉRICA EN LA CUENCA CHACO-PARANÁ
}

\author{
MARÍA LAURA ROSA
}

\author{
Directores \\ Marcelo Sousa de Assumpção \\ Nora Cristina Sabbione
}

Tesis presentada para optar por el grado de DOCTOR EN GEOFÍSICA

Noviembre de 2015 
Tomografía de Ondas Superficiales en Sudamérica: Estructura Litosférica en la Cuenca Chaco-Paraná

\author{
María Laura Rosa
}

\title{
Directores:
}

- Dr. Marcelo Sousa de Assumpção

Instituto de Astronomía y Geofísica. Universidad de São Paulo.

- Dra. Nora Cristina Sabbione

Facultad de Ciencias Astronómicas y Geofísicas. Universidad Nacional de La Plata

Tribunal examinador:

- Dr. Danilo R. Velis (presidente del Tribunal)

Facultad de Ciencias Astronómicas y Geofísicas. Universidad Nacional de La Plata

- Dra. Patricia Alvarado

CIGEOBIO. Universidad de San Juan

- Dr. José I. Badal

Facultad de Ciencias. Universidad de Zaragoza. 
"Nothing, not even the wind that blows, is so unstable as the level of the crust"

C. Darwin 
A Nicolás, Ignacio, Santiago y Pablo 


\section{Agradecimientos}

A la Universidad Nacional de La Plata y a la Facultad de Ciencias Astronómicas y Geofísicas por permitir formarme profesionalmente.

A mis directores Marcelo y Nora por la infinita paciencia que han sabido tenerme todos estos años, por su generosidad, por su cariño y por su entera dedicación a mi formación como investigadora.

A mis amigos del Departamento de Sismología y Meteorología Néstor, Miguel, Celeste, Alberto, Federico, José, Irina, Jorge, Carolina, Horacio, Martín y Augusto que me han acompañado durante todos estos años, haciendo los días más amenos y los asados más sabrosos.

A Gabriela, compinche, compañera y confidente.

A Ruben Martinez un gran amigo, siempre dispuesto a ayudar y siempre con la mejor voluntad.

A Bruno Collaço de la USP y a toda la gente que me recibe con los brazos abiertos, haciéndome sentir muy cómoda cuando estoy trabajando en Brasil.

A mis tesistas Gonzalo, Consuelo y Lucía por la paciencia que me han tenido en estos meses y por enseñarme a enseñarles.

A Graciela Font que lamentablemente no podrá acompañarme en este momento porque la vida así lo quiso.

A toda la gente de la facultad que me acompaña día a día.

A mis padres, Cristina y Héctor por todo el amor que me han dado, por su paciencia y comprensión, por la ayuda que he recibido todos estos años de trabajo y sobre todo por enseñarme a ser una persona feliz.

A mis suegros Celia y Pablo por el cariño recibido, por su infinita ayuda y por estar siempre.

A mi abuela, a mi hermano, a Silvina y a toda mi familia. 
A mi gran amiga de toda la vida, Dolores, que siempre está ahí para escucharme y acompañarme.

A Pablo, mi gran amor, que me ha acompañado todos estos años, por su apoyo incondicional, por sus fuerzas cuando estaba flaqueando, por alentarme, por escucharme y aceptarme como soy y por ser feliz a mi lado.

A mis hijos, Nicolás, Ignacio y Santiago, por ser tan buenas personas, por su cariño, por apoyarme diariamente, por mimarme y acompañarme, por aguantarme, por esperarme, por saber entender el tiempo que no pude dedicarles y por ser mis mejores proyectos. Los quiero mucho.

A mis amigos y compañeros de la vida....

A todos GRACIAS!

María Laura Rosa

19 de Noviembre de 2015 


\section{Resumen}

En este trabajo de Tesis se realiza un estudio de tomografía de ondas superficiales para Sudamérica utilizando curvas de dispersión de terremotos regionales y curvas de dispersión inter-estación obtenidas mediante correlación de ruido ambiental, logrando una mejor cobertura de trayectorias y una distribución acimutal más uniforme, que permite alcanzar resultados con una mejor resolución en comparación con estudios geofísicos, en particular para la cuenca ChacoParaná. Con los mapas tomográficos se determinan los modelos de espesores y velocidad en la región de la cuenca, mediante inversión. Se obtienen las funciones receptoras para tres estaciones ubicadas al este del continente, con las que se aplica un método de stacking que permite obtener valores de la relación entre las velocidades de ondas sísmicas $\mathrm{P}$ y $\mathrm{S}\left(\mathrm{V}_{\mathrm{P}} / \mathrm{V}_{\mathrm{S}}\right)$ y del espesor cortical. Finalmente se realiza una inversión conjunta de funciones receptoras y curvas de dispersión para obtener modelos de velocidad de ondas de corte $\mathrm{V}_{\mathrm{S}}$.

Los mapas tomográficos muestran variaciones laterales significativas en la velocidad de grupo de las ondas superficiales, provocadas por las distintas características geológicas y tectónicas, fortaleciendo los resultados alcanzados en estudios previos. Para la estación sismológica La Plata (LPA) se obtienen valores del espesor sedimentario de $0.5 \mathrm{~km}$ con presencia de arcillas y arenas con un módulo de Poisson de 0.406 , siendo éstos los primeros resultados que definen la estructura local utilizando técnicas sismológicas.

Los modelos obtenidos para la cuenca Chaco-Paraná muestran un espesor cortical entre 33 y $38 \mathrm{~km}$ y confirman la existencia de una zona de baja velocidad de la onda $S(4.4$ a $4.5 \mathrm{~km} / \mathrm{s})$ en el manto superior en la región norte, causada probablemente por una cuña astenosférica menos profunda y más caliente (o mayor contenido de agua en el manto superior en la región de la litósfera). Otro resultado fundamental es la confirmación de la existencia de un área de corteza delgada en la región norte de la cuenca, de aproximadamente 28 a $30 \mathrm{~km}$. Dicha área se extiende hacia el norte, más allá de los límites de la misma, siendo este resultado inédito en un análisis de estas características. 
Agradecimientos $\quad 5$

$\begin{array}{ll}\text { Resumen } & 7\end{array}$

Capítulo 1 Introducción

- 1.1 Introducción 10

- 1.2 Marco geológico 14

- 1.2.1 Sudamérica 14

- 1.2.2 Cuenca Chaco-Paraná 21

- 1.3 Antecedentes $\quad 24$

- 1.4 Objetivos 30

Capítulo 2 Tomografía de Ondas Superficiales

- 2.1 Ondas superficiales 32

- 2.2 Curvas de dispersión 36

- 2.3 Resolución 40

- 2.4 Determinación de las curvas de dispersión 42

○ 2.4.1 Introducción $\quad 42$

○ 2.4.2 Técnica de filtrado múltiple 43

- 2.5 Datos 48

○ 2.5.1 Sismos 48

- 2.5.1.1 Selección de eventos sísmicos 48

- 2.5.1.2 Procesamiento inicial 50

- 2.5.1.3 Curvas de dispersión $\quad 51$

○ 2.5.2 Ruido ambiental 53

- 2.5.2.1 Introducción 53

- 2.5.2.2 Correlación cruzada de ruido ambiental 54

- 2.5.2.3 Curvas de dispersión de ruido ambiental 56

- 2.6 Tomografía de ondas superficiales 58

- 2.6.1 Introducción 58

- 2.6.2 Mapas tomográficos 60

- 2.6.2.1 Método de inversión (suavizado con $1^{\text {er }}$ derivada) 61

- 2.6.2.2 Método de inversión (suavizado con $2^{\text {da }}$ derivada) 62

○ 2.6.3 Resultados y discusión 63 
Capítulo 3. Funciones Receptoras

- 3.1 Introducción 81

- 3.2 Estimación de las funciones receptoras 85

- 3.3 Datos 89

○ 3.3.1 Selección de eventos $\quad 89$

- 3.3.2 Procesamiento inicial 90

- 3.4 Resultados 91

- 3.4.1 Estación sismológica CPUP 92

- 3.4.2 Estación sismológica TRQA 98

- 3.4.3 Estación sismológica LPA 104

- 3.5 Método de Stacking 112

- 3.5.1 Estación sismológica CPUP 114

○ 3.5.2 Estación sismológica TRQA 119

○ 3.5.3 Estación sismológica LPA 124

Capítulo 4 Inversión en Profundidad: Estimación de la Estructura Cortical en la Cuenca de Chaco-Paraná

- 4.1 Introducción 128

- 4.2 Inversión conjunta de funciones receptoras y curvas de dispersión 128

- 4.2.1 Metodología 130

- 4.2.2 Resultados y discusión 139

- 4.3 Inversión de velocidad en capas aplicada a la cuenca Chaco-Paraná 148

- 4.3.1 Metodología 149

○ 4.3.2 Resultados y discusión $\quad 150$

Capítulo 5 Conclusiones

- 5.1 Conclusiones 164

- 5.2 Publicaciones y presentaciones 166

- 5.3 Trabajos a futuro 167

$\begin{array}{ll}\text { Referencias Bibliográficas } & 168\end{array}$

$\begin{array}{ll}\text { Apéndice A } & 179\end{array}$

$\begin{array}{ll}\text { Apéndice B } & 189\end{array}$ 


\section{Capítulo 1}

\section{Introducción}

\subsection{Introducción}

Conocer la estructura interna de la Tierra es un gran desafío. La Sismología es la disciplina de la Geofísica que proporciona la mayor resolución del interior terrestre (Christensen and Mooney, 1995). La ocurrencia de terremotos, su distribución espacio-temporal, el mecanismo y la liberación de energía, ponen de manifiesto los procesos dinámicos activos en la Tierra. El estudio de la propagación de las ondas producidas por los terremotos nos permite revelar la estructura del interior terrestre, las regiones que lo constituyen y la distribución de la densidad y las constantes elásticas. Entender la estructura de la corteza en regiones de tectonismo activo es una componente fundamental en los estudios vinculados a analizar las catástrofes naturales y en consecuencia a proponer herramientas para su mitigación, y es esencial para cualquier interpretación sismológica.

Los métodos sismológicos proporcionan la mejor resolución de la estructura terrestre ya que las ondas sísmicas poseen longitudes de onda cortas y se puede conocer su sensibilidad espacial y temporal en la trayectoria recorrida por la energía. La velocidad de las ondas sísmicas depende de las características elásticas del medio, por consiguiente mediante la observación de los tiempos de recorrido y las amplitudes de estas ondas se puede estudiar la distribución de estas características en el interior de la Tierra. En los últimos años ha habido un gran avance en las metodologías aplicadas para resolver y mapear detalles finos de la estructura de la Tierra (Barmin et al., 2001; Ritzwoller et al., 2002; Rawlinson and Sambridge, 2003; Nolet, 2008; Rawlinson et al., 2010).

Las ondas superficiales muestran las propiedades del medio por el que se propagan a través de su velocidad. Como los parámetros elásticos varían con la profundidad, las ondas superficiales son sensibles a estos cambios presentando el 
fenómeno de dispersión, es decir su velocidad depende de la longitud de onda. La determinación de las curvas de dispersión y su análisis constituyen una herramienta eficaz para estudiar la estructura interna de la Tierra. La forma que presenta la curva de dispersión depende de los espesores de las discontinuidades, sus velocidades de ondas $\mathrm{P}$ y $\mathrm{S}$ y densidades. Conociendo la curva de dispersión para una determinada trayectoria es posible obtener los parámetros mencionados para esa trayectoria (Udías, 1999). Su sensibilidad al espesor cortical se ha aplicado en estudios estructurales, alcanzando mejores niveles de precisión con la aparición de nuevas técnicas para la medición de las ondas superficiales y una mayor disponibilidad de datos (Ritzwoller, 2000). Estas curvas de dispersión se pueden obtener mediante el uso de registros de terremotos o a través de la correlación de ruido ambiental (Lobkis and Weaver, 2001; Wapenaar, 2004).

Los métodos tomográficos de creciente resolución pueden aplicarse tanto a ondas internas como superficiales, proporcionando imágenes en detalle de la estructura de la corteza y del manto. Esta técnica aplicada a ondas superficiales, puede producir mapas de velocidad en dos dimensiones que representan un promedio local espacial de velocidad de grupo o de fase en cada punto del mapa y resumen gran cantidad de información de dispersión de ondas superficiales en una forma que es muy útil y fácil de interpretar. La información de dispersión de los mapas tomográficos puede ser utilizada en numerosas aplicaciones como la inversión 3D para estimar la distribución de la velocidad de corte en profundidad (Pasyanos et al., 2001; Feng et al., 2004).

Por otra parte, hace unas décadas se observó que la componente vertical de los registros sismológicos estaba levemente afectada por la estructura bajo la estación sismológica y mediante la deconvolución entre las componentes vertical y radial, se pudo extraer información de los efectos de esta estructura a partir de los sismogramas registrados. Esto dio inicio a una nueva era de estudios dirigidos a conocer la estructura de la litósfera, ya que esta metodología proporciona una forma de aislar la señal conocida como función receptora. La técnica de funciones receptoras se ha utilizado para analizar la distribución vertical de velocidades de la onda $\mathrm{S}$ debajo de estaciones sísmicas permanentes y temporales en todo el mundo (Langston, 1979). 
La inversión conjunta de las ondas superficiales con otros datos, como por ejemplo las funciones receptoras, pueden reducir la incertidumbre del modelo y mejorar los resultados obtenidos por ambos conjuntos de datos independientemente (Julia et al., 2000). Solas o como parte de un conjunto de datos multidisciplinarios, actualmente las ondas superficiales se están volviendo cada vez más importantes para establecer la imagen sísmica de la corteza y la Moho (Assumpção et al., 2013).

En este trabajo de Tesis se aborda el estudio de las ondas superficiales en Sudamérica mediante una inversión tomográfica 2D de las velocidades de grupo para las ondas Rayleigh entre 10 y 150 segundos y para ondas Love entre 10 y 100 segundos. Para la inversión tomográfica se utilizan curvas de dispersión de terremotos regionales localizados en y alrededor del continente, registrados en estaciones sismológicas ubicadas dentro del continente y curvas de dispersión inter-estación obtenidas mediante la correlación de ruido ambiental para registros de ruidos sísmicos en distintas estaciones. De esta manera se logra una mejor cobertura de trayectorias y una distribución acimutal más uniforme en toda la región, alcanzando una mejor resolución en comparación con trabajos anteriores (Feng et al., 2004; 2007) especialmente alrededor de la cuenca Chaco-Paraná. La inversión se realiza utilizando diferentes criterios de regularización y parámetros de suavizado ( $1^{\text {er }}$ y $2^{\text {da }}$ derivada) para poner a prueba su influencia en los resultados de la inversión de la estructura de la corteza.

Con los resultados obtenidos en la tomografía se determinan los modelos de espesores y de velocidad en la región de la cuenca Chaco-Paraná aplicando un programa de inversión basado en el método de búsqueda de grilla (Pasyanos et al., 2001).

También se obtienen las funciones receptoras usando una técnica en el dominio temporal a partir de registros telesísmicos para tres estaciones ubicadas en el continente, las estaciones LPA (La Plata) y TRQA (Tornquist) ubicadas en Argentina y la estación CPUP (Villa Florida) ubicada en Paraguay, próxima a la cuenca Chaco-Paraná. Se aplica un método de stacking para identificar las distintas fases en las funciones receptoras, permitiendo obtener valores de la relación $V_{\mathrm{P}} / \mathrm{V}_{\mathrm{S}} \mathrm{y}$ del espesor cortical. Se realiza una inversión conjunta de las funciones receptoras y las curvas de dispersión usando una aproximación iterativa 
linealizada para obtener modelos de velocidad de la onda $S$ en profundidad. Estos resultados son complementarios a los modelos de inversión 3D de la tomografía.

Los resultados obtenidos en este trabajo contribuyen al conocimiento de los modelos sísmicos de la región, permitiendo relocalizar hipocentros y localizar sismos futuros con mayor precisión, de manera de mejorar la estimación de la probabilidad de ocurrencia de un terremoto de una cierta magnitud, en un lugar dado.

Esta Tesis se encuentra estructurada de la siguiente manera:

- En las siguientes secciones del capítulo 1 se describe el marco geológico de Sudamérica y en particular de la región de la cuenca Chaco-Paraná, se resumen los estudios realizados hasta el momento en el tema de tomografía e inversión por otros autores y finalmente se plantean los objetivos que motivaron la realización de la Tesis.

- En el capítulo 2 se enuncian las propiedades de las ondas superficiales, se describe la metodología de obtención de las curvas de dispersión para los distintos datos y se detallan los métodos tomográficos y los criterios de aplicación. Finalmente se presentan los mapas de tomografía para Sudamérica y se interpretan los resultados, relacionándolos con la geología.

- En el capítulo 3 se describe la metodología para la obtención de las funciones receptoras y se presentan resultados para tres estaciones ubicadas en el continente, una de ella cercana a la cuenca Chaco-Paraná. Se aplica el método de stacking y se interpretan los resultados de los espesores y relaciones $V_{\mathrm{P}} / \mathrm{V}_{\mathrm{S}}$ obtenidos en cada caso.

- En el capítulo 4 se detallan los criterios de aplicación de los dos métodos de inversión, el método de inversión conjunta de funciones receptoras y ondas superficiales y la técnica de inversión $3 \mathrm{D}$ de mapas tomográficos. Se presentan e interpretan los resultados para la región de la cuenca y se comparan con resultados obtenidos por otros autores. Finalmente se contrastan los resultados de ambas inversiones entre sí, para una estación cercana a la cuenca. 
- En el capítulo 5 se presentan las conclusiones finales de la Tesis haciendo un conciso resumen de los aportes más significativos, se mencionan las publicaciones producidas durante este trabajo de Tesis y las posibles líneas de futuros trabajos.

\subsection{Marco geológico}

\subsubsection{Sudamérica}

Sudamérica es el resultado de una evolución compleja de la litósfera continental que comenzó en tiempos Arcaicos e incluyó períodos sucesivos de separación y posterior unión de masas continentales constituidas por bloques cratónicos y terrenos alóctonos (Ramos, 1988; Rapela y Llambías, 1999; Rapela et al., 2007; Rapela, 2008), que han dejado su huella en el manto litosférico (Heintz et al., 2005). Los procesos dinámicos y de amalgamiento que ocurrieron mayormente desde el Proterozoico hasta inicios de Paleozoico, sufriendo pequeñas alteraciones durante el resto del Fanerozoico (Ramos, 1988), determinaron un continente constituido por un conjunto de distintos tipos de ambientes tectónicos desde escudos precámbricos, provincias basálticas y cuencas sedimentarias hasta cadenas montañosas.

La unión de los cratones sudamericanos y sus homólogos africanos durante el Neoproterozoico llevó a la formación del supercontinente Gondwana. Esta etapa es considerada una de las etapas más importantes en la evolución de la corteza siendo una etapa de transición entre los procesos dominantes de las grandes masas continentales de la era Mesoproterozoica y la tectónica de placas actual (de Brito Neves and Fuck, 2013).

El borde oriental de la placa Sudamericana forma un margen divergente de más de $10.000 \mathrm{~km}$ de largo, que se desarrolló como resultado de la separación de las placas Sudamericana y Africana desde el Mesozoico, a través de la apertura del Atlántico Sur y la ruptura de Gondwana (Engler, 2006). Los márgenes norte y sur de la placa se desarrollaron a lo largo de fallas transformantes en un régimen tectónico transcurrente debido al contacto entre la placa Sudamericana y las placas del Caribe por el norte y de Scotia por el sur (Engler, 2006). 
Las tres provincias tectónicas más grandes de Sudamérica incluyen a la Plataforma Sudamericana, la Plataforma Patagónica y la Cordillera Andina (Fig. 1.1); las dos primeras son consideradas estables mientras que la última es el resultado de un margen activo en convergencia (Cordani and Britos Neves, 1982).

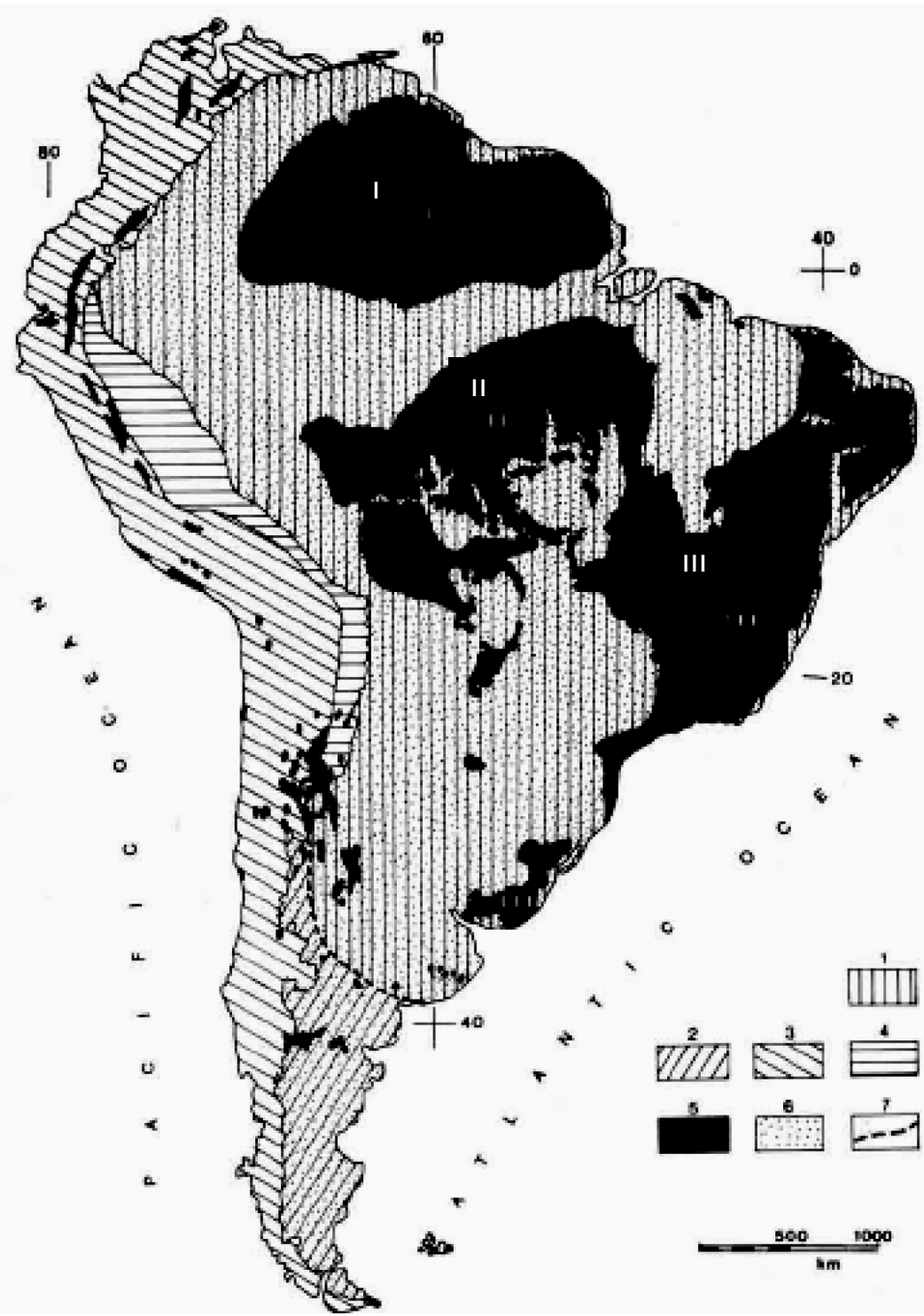

Figura 1.1: Las principales unidades geotectónicas de Sudamerica. 1- Plataforma Sudamericana. 2-

Plataforma Patagónica. 3- Coordillera Andina. 4- Cuencas Subandinas. 5-Basamento; en la plataforma Sudamericana (I) Escudo de Guyana, (II) Escudo de Guaporé, (III) Escudo del Atlántico. 6- Sedimentos Fanerozoicos. 7- Limite sur de la plataforma Sudamericana (extraído de Almeida et al., 1976).

La plataforma Sudamericana es la provincia tectónica más antigua y estable de Sudamérica. Está ubicada en el centro y este del continente, limitada por los 
Andes al oeste y por el océano Atlántico al este. La plataforma se consolidó durante el Proterozoico superior hasta comienzos del Paleozoico, en el curso del ciclo orogénico Brasiliano/Panafricano, durante la formación del supercontinente Gondwana (Engler, 2006). Consiste esencialmente de un basamento precámbrico cubierto en gran parte por rocas volcánicas y sedimentarias del Fanerozoico. Incluye tres grandes escudos que exponen rocas arcaicas y proterozoicas bien preservadas: los escudos de Guyana en el norte, de Guaporé en el centro y del Atlántico en el este.

El escudo de Guyana está constituido por una fina cubierta post-paleozoica asentada sobre rocas ígneas y metamórficas de edad precámbrica. La región central y oriental está compuesta de granulitas y gneisses variando entre 3700 y $3400 \mathrm{Ma}$ (De Souza and Mitchell, 1998). El escudo de Guaporé está compuesto de rocas precámbricas de hasta $2500 \mathrm{Ma}$, cubiertas por depósitos fanerozoicos. El escudo del Atlántico está caracterizado por una cubierta compleja de granito-gneiss con rocas de hasta $3400 \mathrm{Ma}$ (Almeida et al., 1981) y abarca cuatro provincias estructurales: el cratón de São Francisco ubicado al sudeste de Brasil y las provincias plegadas de Borborema, Tocantins y Mantiqueira (Fig. 1.2).

Los escudos de Guyana y Guaporé son considerados los dos bloques principales del llamado cratón Amazónico y están ubicados al norte y al sur de la cuenca Amazónica (Fig. 1.2). Probablemente estos escudos, que incluyen terrenos de la misma edad y naturaleza, formaron un único cratón antes del episodio de rifting amazónico (Cordani and Brito Neves, 1982; Tassinari et al., 2000). Así, la evolución de la corteza en ambos cratones es similar entre los 3000 y $1700 \mathrm{Ma}$, sugiriendo que posiblemente estaban contiguos conformando un supercontinente Paleoproterozoico (Cordani and Sato, 1999).

De acuerdo a Almeida et al. (1981), la plataforma Sudamericana está conformada por una cuarta región cratónica: el cratón del Río de La Plata. Este cratón, cubierto en su mayor parte por sedimentos fanerozoicos, constituye una provincia austral tectónicamente estable, que no ha sufrido deformaciones mayores desde el Precámbrico. Según Almeida et al. (1976) la relación entre este cratón y el cratón Amazónico está oculta bajo la cubierta sedimentaria, aunque posiblemente podrían ser parte de una única gran unidad. Determinaciones radiométricas en el 
basamento indicaron que el área cratónica se consolidó al final del ciclo Transamazónico (Almeida et al., 1981).

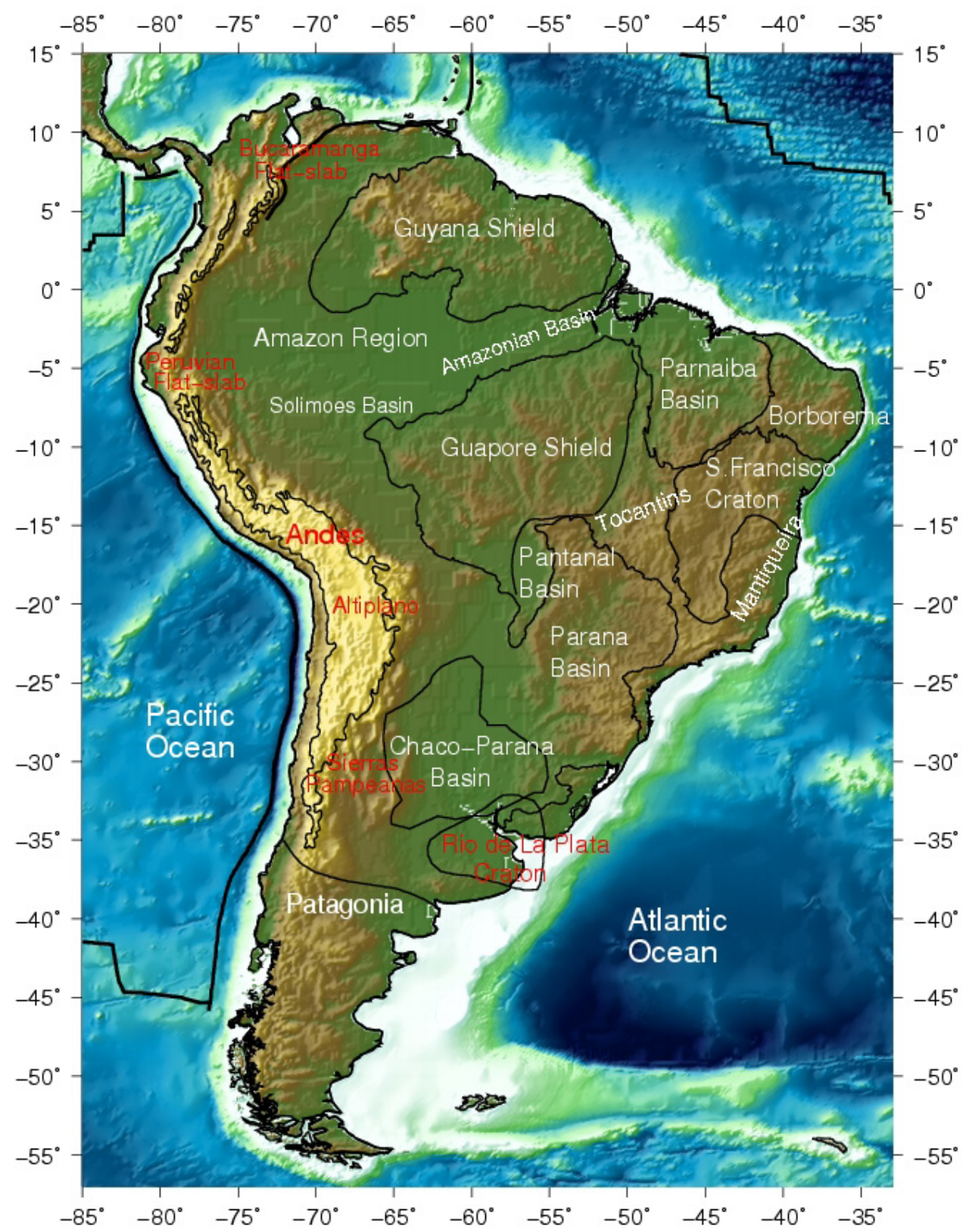

Figura 1.2: Mapa geotectónico de Sudamerica. Los límites de la cuenca Chaco-Paraná corresponden a Dragone et al. (2012), los límites del cratón del Río de La Plata corresponden a Ramos (2000) y Cingolani and Dalla Salda (2000), los límites de las restantes provincias geológicas corresponden a Feng et al. (2004).

Las rocas más antiguas del cratón, migmatitas, granitos, gneisses y esquistos, constituyen el basamento metamórfico del Paleoproterozoico inferior 
(entre 1600 y $2500 \mathrm{Ma}$ ). Estas rocas se encuentran por debajo de la pila sedimentaria, a diferentes profundidades debido al fallamiento diferencial que las afectó como consecuencia de las fuerzas endógenas a las que estuvieron sometidas en diferentes momentos de su larga historia y hasta tiempos bastantes recientes (Urien y Zambrano, 1996). Como consecuencia de ese fallamiento diferencial, es posible observar el basamento metamórfico aflorando en territorios de la República Oriental del Uruguay, en la Isla Martín García, en Tandilia y en las Sierras Australes.

Los procesos de sedimentación paleozoica de la plataforma Sudamericana se preservan en cuatro cuencas: del Amazonas, Parnaíba, Paraná y Chaco-Paraná (Fig. 1.3). Estas cuencas se encuentran sobre una corteza continental o cuasi continental (Milani and Zalán, 1999).

La cuenca del Amazonas es una cuenca alargada con sedimentos marinos paleozoicos de comienzos del Silúrico o del Ordovícico Superior. Se compone de la cuenca de Solimões en la parte occidental de la región del Amazonas y su contraparte la cuenca Amazónica ubicada en la parte oriental, con aproximadamente 4 y $6 \mathrm{~km}$ de sedimentos respectivamente, a lo largo del eje central (Milani and Zalán, 1999).

La cuenca de Parnaíba se encuentra en su totalidad en el norte de Brasil. Es casi de forma circular y con elevaciones menores a $600 \mathrm{~m}$ (De Souza and Mitchell, 1998). Su subsidencia comenzó en el Ordovícico Superior o comienzos del Silúrico, después de la erosión de las rocas del basamento precámbrico. Según Almeida et al. (1981), la región se vio afectada por varios episodios de sedimentación marina y continental con edades que van desde el Devónico inferior hasta principios del Pérmico.

La cuenca de Paraná representa una de las provincias ígneas (LIP: Large Igneous Province) de mayor tamaño en el mundo. Junto a su contraparte africana la provincia de Etendeka, está asociada a la expresión superficial de la pluma del manto Tristan da Cunha (Turner et al., 1994). Se formó en respuesta a la estabilización geológica que siguió al ciclo Brasiliano (Beri et al., 2010). Su subsidencia comenzó en el Ordovícico medio a superior en el interior cratónico de Gondwana, por tal motivo es vista como una cuenca intracratónica (Milani e 
Ramos, 1998) que se rellenó con secuencias sedimentarias desde el Ordovícico hasta el Cretácico con intercalaciones de flujos basálticos entre 137 y $127 \mathrm{Ma}$. Según Almeida et al. (1981) la evolución de la cuenca se caracteriza por episodios de sedimentación marina durante el Devónico y Carbonífero y sedimentación continental durante el Pérmico, con $4.2 \mathrm{~km}$ de sedimentos depositados.

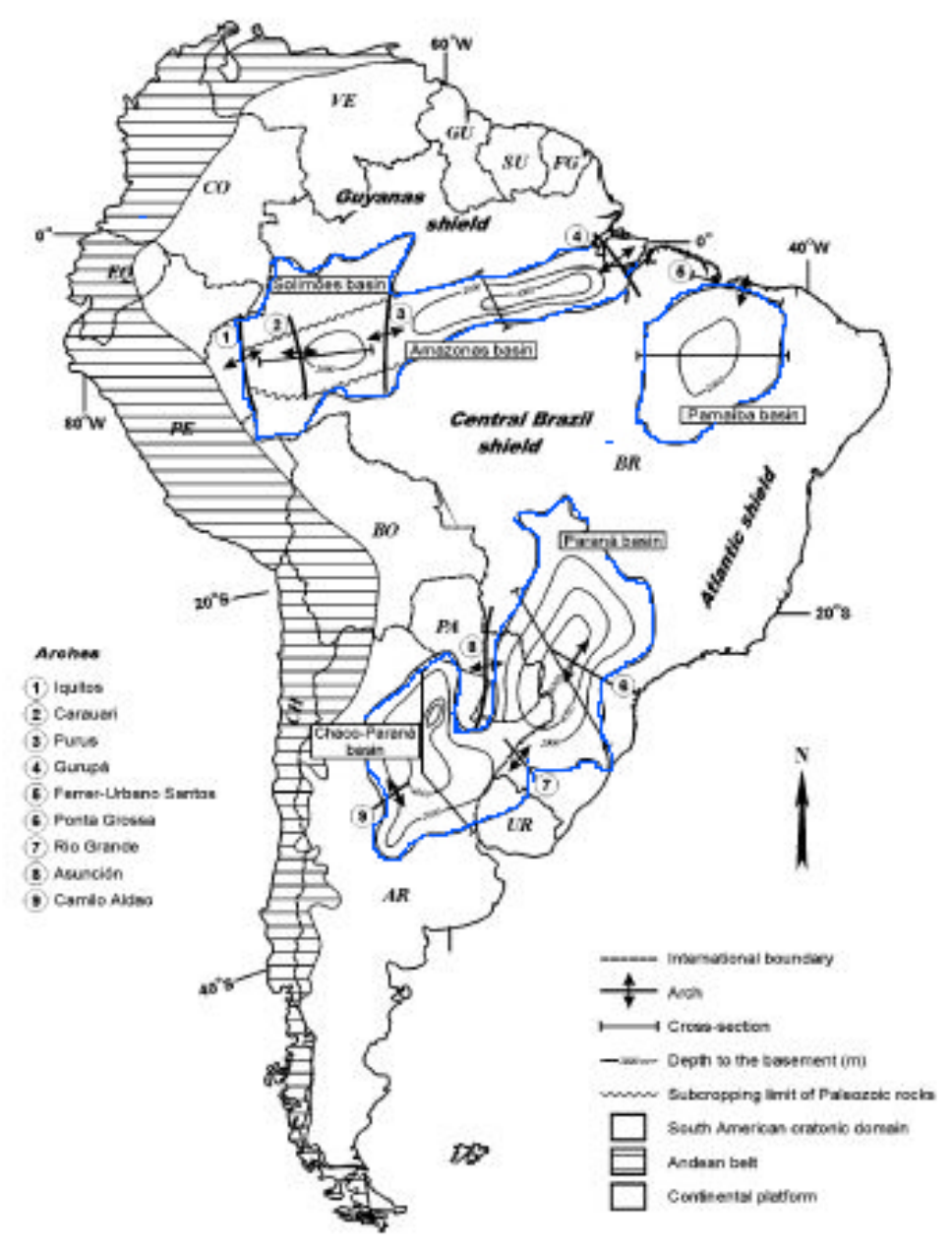

Figura 1.3: Cuencas intracratónicas de la plataforma Sudamericana (extraído de Milani and Zalán, 1999).

Durante la separación de América del Sur y África en el Jurásico Superior, la provincia fue ampliamente cubierta por sedimentos continentales de $0.4 \mathrm{~km}$ de espesor, así como por los flujos de basalto que pudieron alcanzar $1.5 \mathrm{~km}$ de espesor en la parte centro-norte. Milani e Ramos (1998) sugieren que la configuración actual de la cuenca es el resultado de seis episodios de 
sedimentación separados geográfica y temporalmente en tres cuencas diferentes, cada una con su propia geometría.

La cuenca Chaco-Paraná ocupa la parte sur y sudoeste de la plataforma Sudamericana. Se caracteriza por ser una cuenca paleozoica intraplaca marcada por diversas fases de hundimiento y elevación a lo largo de la historia. Se distinguen los ciclos deposicionales Cambro-Ordovícico, Siluro-Devónico, Neopaleozoico, Mesozoico y Cenozoico (Pezzi y Mozetic, 1989).

La plataforma Patagónica es la segunda mayor provincia tectónica de Sudamérica (Fig. 1.1). Es mucho más pequeña que la plataforma Sudamericana y se encuentra en el extremo sur del continente donde limita al oeste con la cordillera Andina y al este con el océano Atlántico. Tiene su origen en el Paleozoico tardío. Las rocas del basamento dominadas por grandes granitoides paleozoicos con terrenos proterozoicos, están cubiertas por sedimentos y rocas volcánicas del Carbonífero y Jurásico (De Souza and Mitchell, 1998).

Otra provincia tectónica de Sudamérica es la cordillera Andina, formada por el levantamiento de rocas del Precámbrico y Paleozoico durante el Mesozoico y Cenozoico (Dalziel, 1986). Este orógeno se extiende por todo el margen occidental de Sudamérica y está relacionado a la subducción de la placa de Nazca bajo la placa Sudamericana con una velocidad de convergencia de 7.8 - $8.4 \mathrm{~cm} / a n ̃ o$ (DeMets et al., 1990). Presenta tres regiones donde la subducción es horizontal: Bucaramanga que se encuentra al norte de $5^{\circ} \mathrm{N}$, el segmento de Perú entre $5^{\circ} \mathrm{S}$ y $14^{\circ} \mathrm{S}$ y el segmento Pampeano que se encuentra entre $30^{\circ} \mathrm{S}$ y $33^{\circ} \mathrm{S}$ (Cahill and Isacks, 1992; Ramos, 1999; Alvarado et al., 2009). Estas tres regiones están caracterizadas por una gran liberación de energía sísmica y una ausencia de actividad volcánica comparada con las regiones de subducción normal (Fig. 1.4). La formación de la Cordillera de los Andes comenzó en el Triásico medio a superior en el norte y en el Jurásico medio a superior en el sur. La sedimentación mesozoica se produjo a lo largo de la cadena montañosa con depósitos marinos intercalados con rocas volcánicas. La subsidencia durante el Jurásico y comienzos del Cretácico afectó toda la cordillera andina. Durante el Cretácico medio, los depósitos situados a lo largo del margen occidental de Sudamérica fueron levantados y deformados por la compresión tectónica. Entre el Cretácico superior y 
el Cenozoico el lugar de la actividad magmática andina emigró hacia el este (Gansser, 1973).

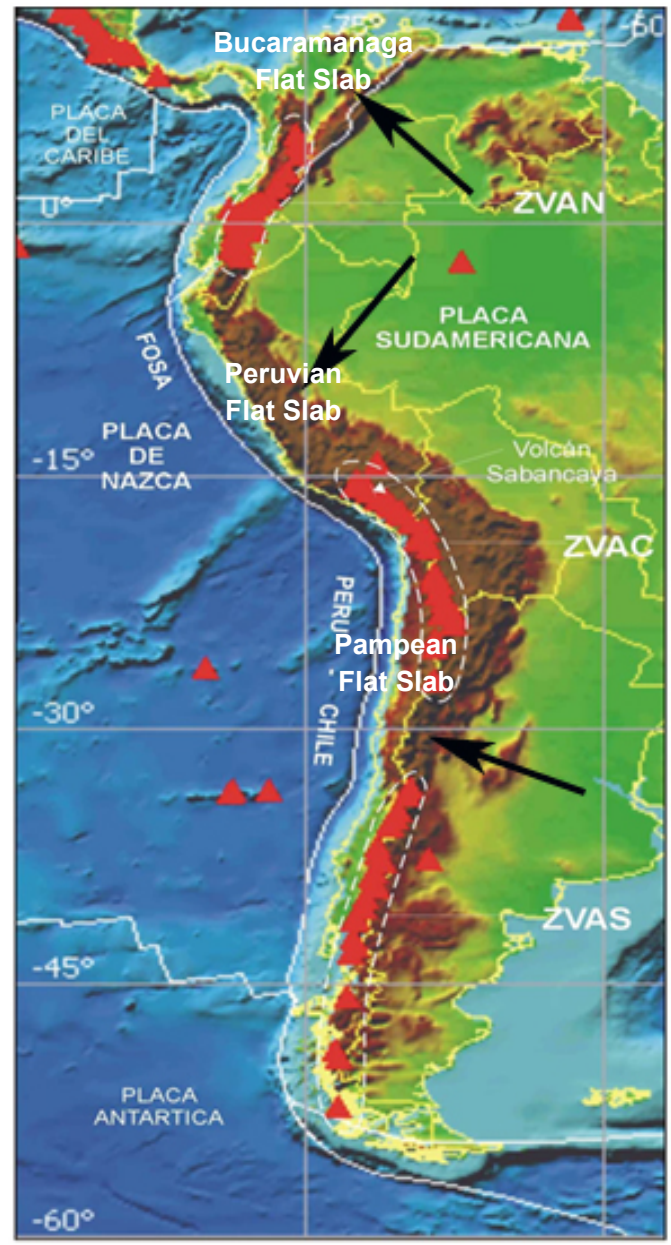

Figura 1.4: Regiones de subducción horizontal donde se observa la ausencia de actividad volcánica (modificada de Antayhua y Tavera, 2003).

\subsubsection{Cuenca Chaco-Paraná}

La cuenca Chaco-Paraná está ubicada en la plataforma Sudamericana ocupando la parte sur y sudoeste (Fig. 1.5). Esta cuenca se encuentra incluida en la denominada planicie Chacopampeana, que es una llanura cubierta por sedimentos cuaternarios provenientes de los Andes (Chebli et al., 1999). Sus dimensiones no están bien definidas, pero se desarrolla principalmente en el noreste de Argentina. Es una cuenca aproximadamente elíptica cuyos ejes se orientan ENE-WSW, con depocentros semicirculares (Barredo y Stinco, 2010). Se 
extiende al oeste del extremo sur de la cuenca de Paraná y está separada de ella por los arcos de Asunción y Río Grande (Fig. 1.5). Está limitada por la cordillera Oriental en el oeste, por el escudo Brasileño en el este y noreste y por el cratón del Río de La Plata en el sur (Fig. 1.2). La región se caracteriza por la ausencia de grandes eventos tectónicos recientes y pocos afloramientos (Russo et al, 1986; Pezzi y Mozetic, 1989; Chebli et al., 1999), impidiendo el análisis directo de las secuencias sedimentarias previas al Cuaternario o del basamento, dependiendo en consecuencia el análisis sólo de los pocos datos de pozos o sondeos geofísicos. El estilo estructural de la cuenca está relacionado con fallamiento extensional principalmente en dirección N-S en correspondencia con antiguas zonas de debilidad del basamento Precámbrico reactivadas por movimientos compresivos recurrentes (Chebli et al., 1999). Asimismo, diversas fallas de rumbo (la mayoría de origen regional) se encuentran en toda el área (Torra, 2006).

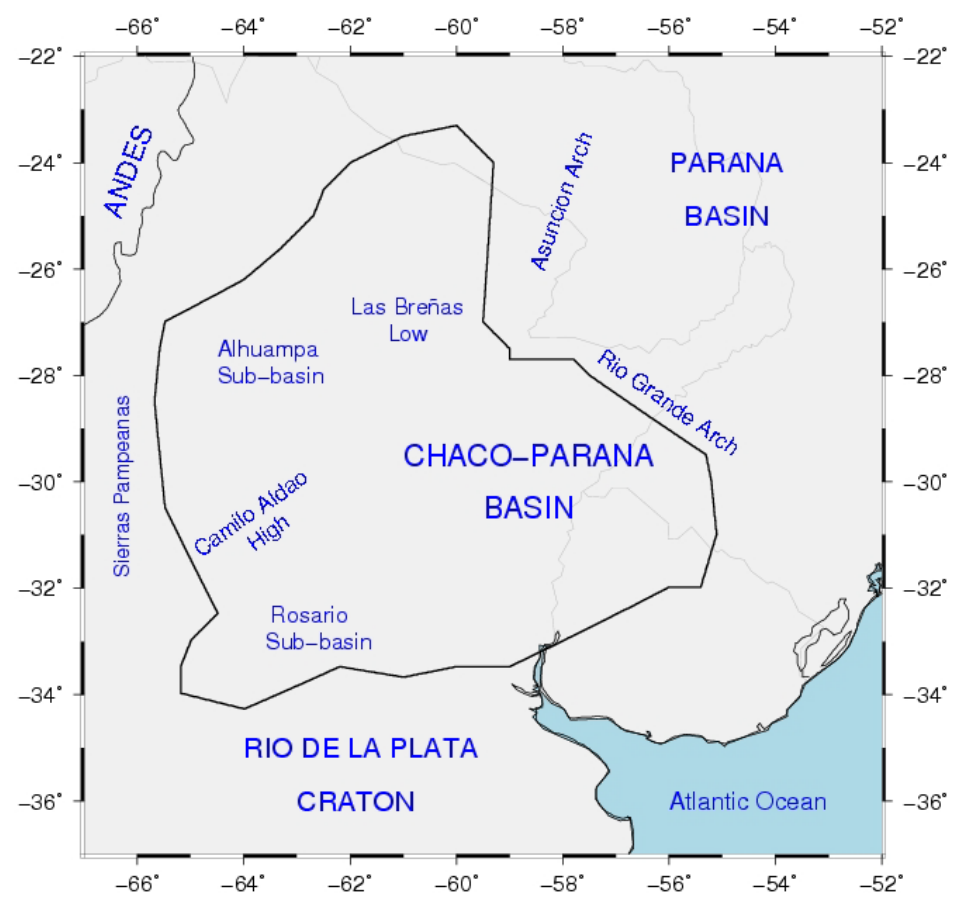

Figura 1.5: Mapa de la cuenca Chaco-Paraná. Los límites de la cuenca corresponden a Dragone et al. (2012).

Se divide en dos subcuencas separadas por el Alto de Camilo Aldao: la subcuenca Rosario en el sudeste y la sub-cuenca Alhuampa en el noroeste delimitada por las Sierras Pampeanas en el oeste y por basaltos cretácicos en el noreste (Fig. 
1.5). Un depocentro cambro-ordovícico profundo con dirección NE-SW, el bajo de Las Breñas, se ubica en la parte centro norte de la cuenca (Pezzi y Mozetic, 1989). Este depocentro se muestra como un graben asimétrico con inclinación estructural del basamento hacia el NW (Milani and Zalán, 1999).

La evolución geológica de la cuenca fue compleja. Su registro litológico fue testigo de varias etapas de su historia, cada una controlada por distintos factores climáticos y tectónicos. La cuenca está aparentemente sustentada por basamento cratónico de composición granítica que se extiende desde el Precámbrico hasta el Paleozoico inferior (Winn and Steinmetz, 1998). Se conjetura la presencia del cratón del Río de la Plata en algunas regiones; según Rapela et al. (2007) el límite oeste del cratón sigue la falla principal de orientación NE-SW que limita el bajo La Breñas.

La cuenca contiene estratos paleozoicos de comienzos del Silúrico o del Devónico, una gruesa sección clástica y volcánica con grandes volúmenes de roca magmática del Mesozoico al Terciario (Milani and Zalán, 1999) y una cubierta de sedimentos Cenozoicos Cuaternarios. La sedimentación Silúrica y Devónica expandió el área deposicional de la cuenca más allá de su extensión (Grahn, 2003). Este paquete sedimentario fue depositado en una cuenca de antepaís para algunos autores (e.g., McQuarrie et al., 2005; Prezzi et al., 2014), mientras que para otros, en un hundimiento de margen pasivo o cuenca intracratónica (e.g., Winn and Steinmetz, 1998; Grahn, 2003; Limarino and Spalletti, 2006; Barredo y Stinco, 2010; Vitorello et al., 2011).

La región de Chaco-Paraná sufrió diversos episodios de subsidencia relacionados a los procesos termomecánicos que tuvieron lugar en una litósfera relativamente rígida y fría, que interactuó con un manto convectivo (Barredo y Stinco, 2010). El área que incluye la cuenca de Paraná se sometió a extensión de retroarco en el Ordovícico y Silúrico. Chaco-Paraná sufrió subsidencia nuevamente como parte de una cuenca de antepaís comenzando probablemente a finales del Silúrico y continuando en el Devónico (Winn and Steinmetz, 1998). El episodio de rifting en el sudoeste de Gondwana durante fines del Paleozoico generó grabens y horsts en la región (Winn and Steinmetz, 1998). A partir del Triásico la cuenca adquirió rasgos de una cuenca de rift continental (Barredo y Stinco, 2010) asociada a extensión cortical. Desde el Carbonífero superior al Cretácico inferior, comparte 
una historia sedimentaria con la cuenca de Paraná (Milani and Thomaz Filho, 2000). Así, a pesar de compartir parte del desarrollo Paleozoico y Mesozoico con la cuenca de Paraná, difiere ampliamente en sus secuencias cambro-ordovícica y cenozoica (Russo et al., 1986; Pezzi y Mozetic, 1989; Chebli et al., 1999; Ramos, 1999; Milani and Thomaz Filho, 2000). Otra actividad de subsidencia extensional ocurrió desde el Jurásico superior al Cretácico inferior. La diferencia notable con la cuenca de Paraná es su mayor subsidencia y sedimentación cenozoica, correspondiente a depósitos de una cuenca de antepaís distal (Ramos, 1999), siendo los sedimentos más jóvenes del Cuaternario Holoceno (Torra, 2006).

\subsection{Antecedentes}

La estructura sísmica de la corteza y el manto superior bajo Sudamérica es considerada una de las regiones menos estudiadas de la Tierra, en particular en la zona central y oriental del continente. Sin embargo en los últimos años se han instalado nuevas estaciones sismológicas banda ancha temporales y permanentes, con el apoyo de agencias internacionales (IRIS, GSN, GEOSCOPE), contando, de esta manera, con nuevos datos disponibles para Sudamérica.

A continuación se citan los trabajos de investigación realizados mediante tomografía de ondas superficiales para Sudamérica, y en particular aquellos trabajos en los que se obtuvieron modelos sísmicos para la región de la cuenca Chaco-Paraná. La mayoría de los resultados se presentan a través de los mapas obtenidos por los distintos autores y luego se consideran en la discusión final de los resultados alcanzados en este trabajo de Tesis.

En lo que respecta a los primeros estudios de inversión en la región de la cuenca Chaco-Paraná, Snoke and James (1997) encontraron a partir de la inversión de ondas superficiales de un sismo andino, la profundidad promedio de la discontinuidad de Mohorovicic (Moho) bajo la cuenca de Chaco de $32 \mathrm{~km}$ y bajas velocidades de onda $S$ en el manto superior $(4.2 \mathrm{~km} / \mathrm{s}$ aumentando sólo a $4.3 \mathrm{~km} / \mathrm{s}$ a $150 \mathrm{~km}$ de profundidad). Vdovin et al. (1999) realizaron una tomografía de la velocidad de grupo para Sudamérica para períodos entre 20 y 150 s para la onda Rayleigh y entre 20 y 100 s para la onda Love, encontrando cuatro anomalías de baja velocidad en los mapas de $20 \mathrm{~s}$ una de ellas coincidente con la región de la 
cuenca de Chaco-Paraná. Van der Lee et al. (2001) obtuvieron la estructura de velocidad de la onda $S$ en el manto superior para la región central y occidental del continente para profundidades entre 30 y $400 \mathrm{~km}$ a partir del análisis de ondas Rayleigh, encontrando bajas velocidades en la cuenca de Chaco y al oeste de la cuenca de Paraná (Fig 1.6).
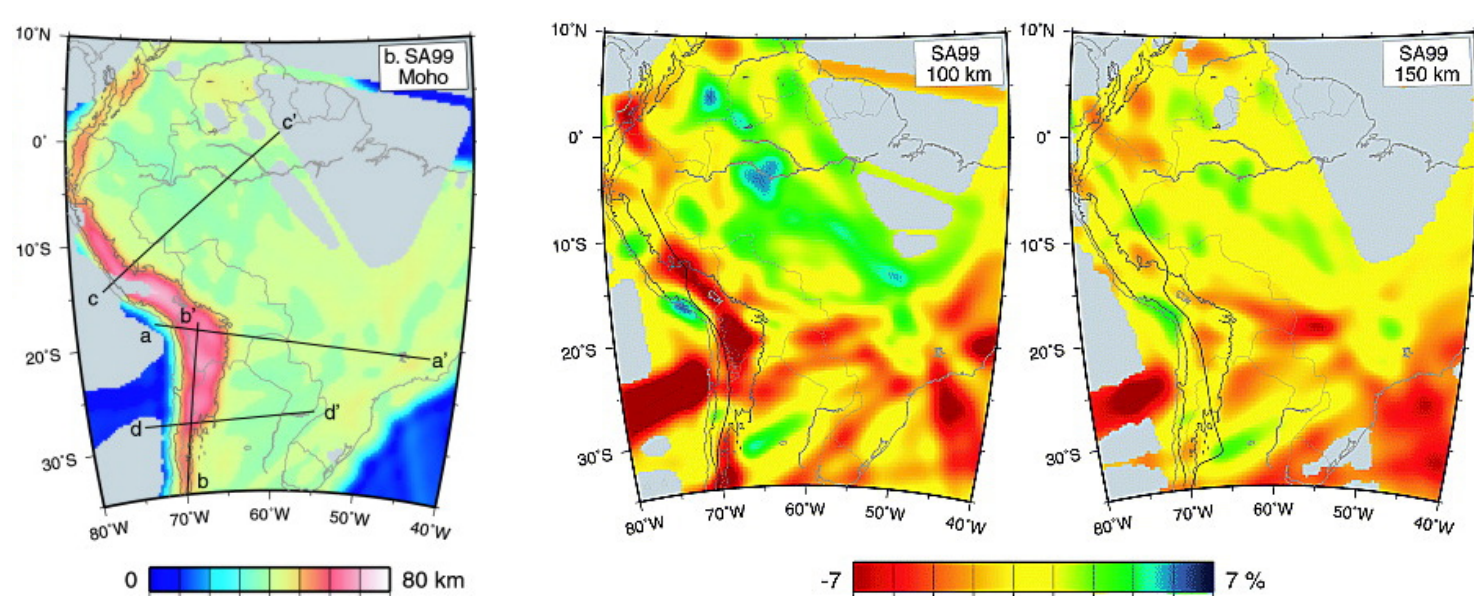

Figura 1.6: Modelo SA99 de la profundidad de la discontinuidad de Mohorovicic y modelos de la distribución de velocidades de onda $S$ relativas a las velocidades de onda $S$ de iasp91, para el manto superior para 100 y $150 \mathrm{~km}$ obtenido por Van der Lee et al. (2001). Las áreas grises corresponden a datos con escasa resolución.

En un perfil E-W de los Andes, Yuan et al. (2000) sugirieron, usando funciones receptoras, que la profundidad de la Moho se vuelve superficial (30 km) en la llanura chaqueña. Feng et al. (2004) obtuvieron la estructura 3D de velocidad de onda S para profundidades entre 30 y $150 \mathrm{~km}$ a partir del análisis de ondas Rayleigh y Love (Fig. 1.7) y encontraron pronunciadas anomalías de baja velocidad en el manto superior hasta $150 \mathrm{~km}$ de profundidad, bajo la cuenca de Chaco.

Heintz et al. (2005) presentaron un modelo 3D de velocidad de ondas Sv para el manto superior a partir de la tomografía de ondas Rayleigh para los modos fundamental y superiores. Los autores encontraron que la cuenca de Chaco se caracteriza por velocidades bajas hasta los $200 \mathrm{~km}$ de profundidad, como se observa en la Fig. 1.8. 

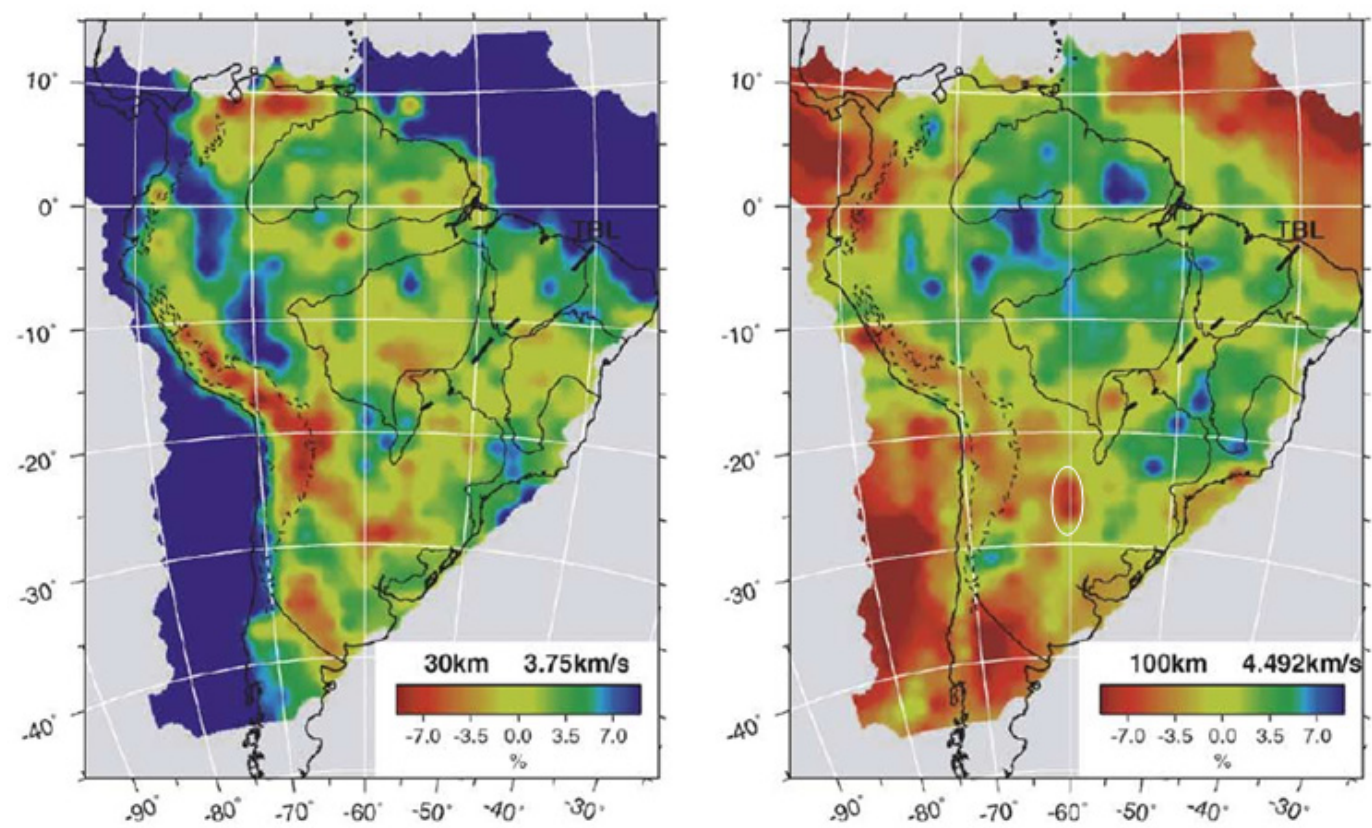

Figura 1.7: Modelos 3D de velocidad de onda S relativos al modelo IASP para 30 y $100 \mathrm{~km}$ obtenidos mediante datos de velocidad de grupo de ondas Rayleigh y Love según Feng et al. (2004). La elipse blanca indica la anomalía de baja velocidad bajo la cuenca de Chaco.
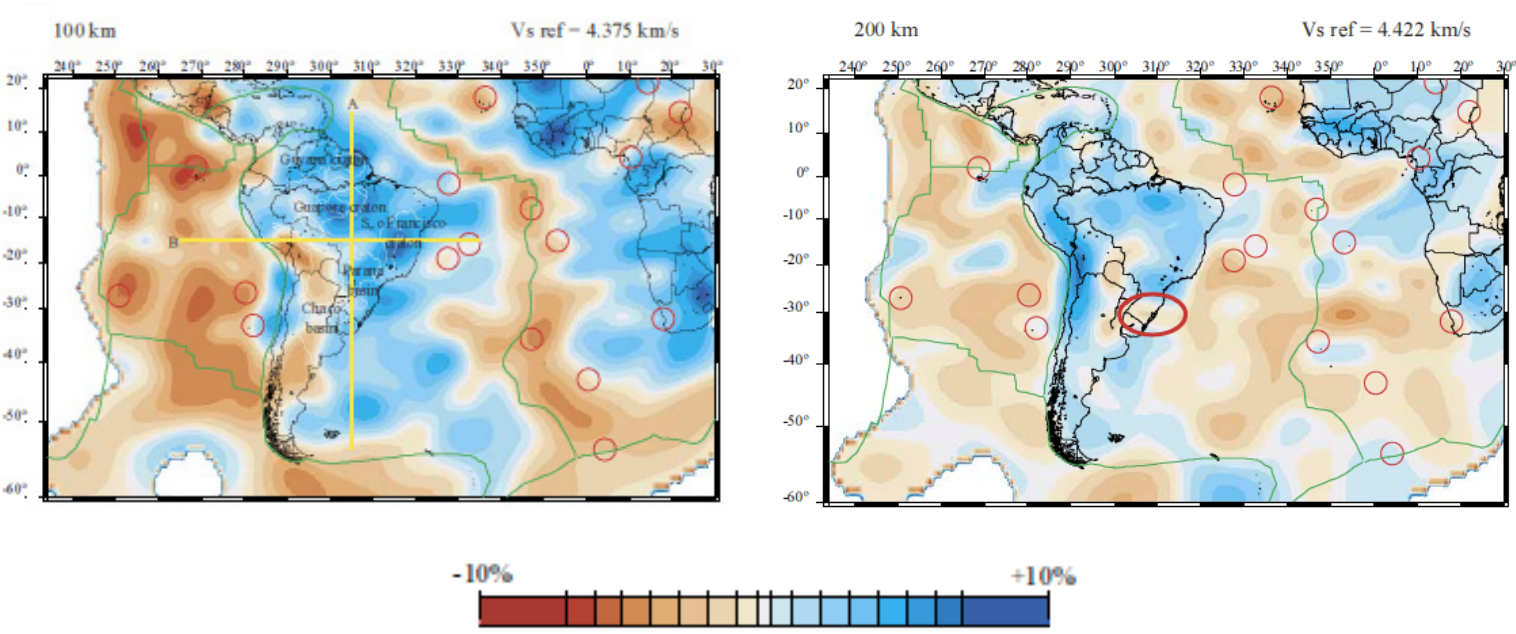

Figura 1.8: Mapas de heterogeneidades de la onda Sv para 100 y $200 \mathrm{~km}$ de profundidad obtenidos por Heintz et al. (2005). Las variaciones de velocidad se representan mediante una barra de colores que las relaciona con una velocidad de referencia indicada en cada mapa. Los círculos rojos corresponden a puntos calientes y las placas tectónicas están delimitadas por líneas verdes.

Posteriormente, Feng et al. (2007) utilizando la inversión conjunta de formas de onda y velocidades de grupo de ondas Rayleigh, obtuvieron un nuevo modelo 3D de velocidad de onda $S$ para el manto superior y un modelo de la Moho para 
Sudamérica (Fig. 1.9), estimando la profundidad de la Moho de $30 \mathrm{~km}$ en el centro de la cuenca Chaco-Paraná, así como la existencia de una anomalía de baja velocidad en el manto litosférico.
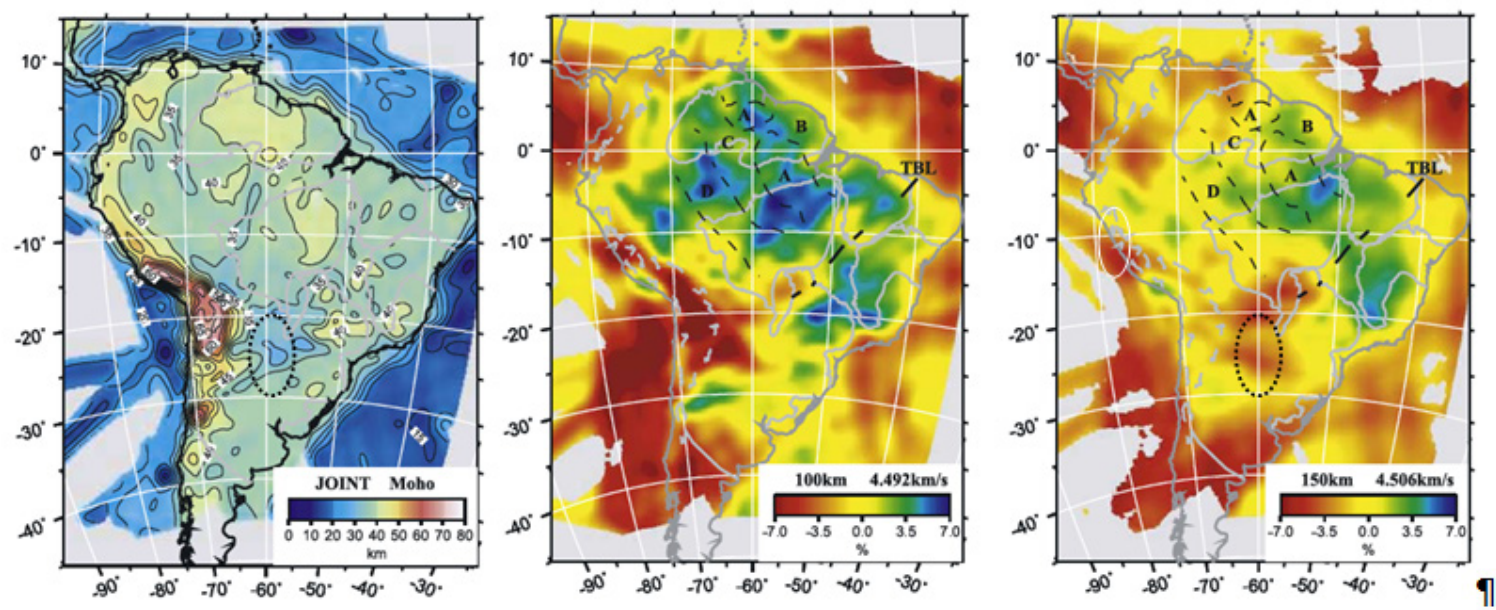

Figura 1.9: Modelo de profundidad de la discontinuidad de Mohorovicic (contornos de profundidades cada $5 \mathrm{~km}$ ) y modelos de velocidad de onda $S$ relativos al modelo IASP para 100 y $150 \mathrm{~km}$ obtenidos por Feng et al. (2007).

En 2010, Lloyd et al. presentaron un mapa de la Moho obtenido a partir del análisis de funciones receptoras y ondas Rayleigh, con mejor resolución en la región oriental del continente (Fig. 1.10). Ellos obtuvieron una Moho de aproximadamente $30 \mathrm{~km}$ en el norte de la cuenca Chaco-Paraná y en la región occidental de la cuenca de Paraná, utilizando básicamente el mismo conjunto de datos que Feng et al. (2007) para las ondas Rayleigh.

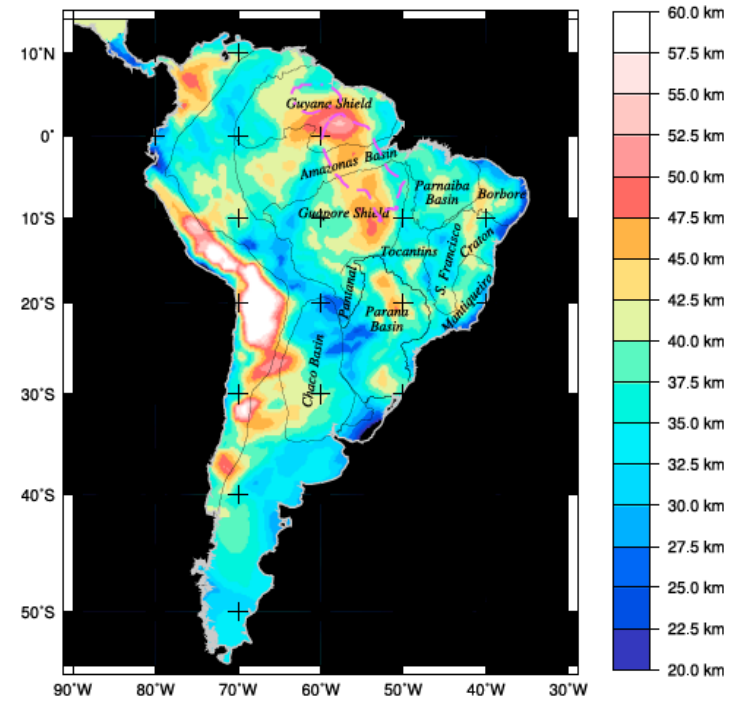

Figura 1.10: Mapa de la Moho obtenido por inversión conjunta de funciones receptoras y ondas Rayleigh (Lloyd et al., 2010). 
Corchete (2012) determinó la estructura de velocidades de ondas S para profundidades entre 0 y $400 \mathrm{~km}$ a partir de la regionalización e inversión de ondas Rayleigh para 287 trayectorias obtenidas en diversas estaciones del continente, encontrando la existencia de un canal de baja velocidad de la onda $S$ entre $180 \mathrm{y}$ $280 \mathrm{~km}$ de profundidad. Chulick et al. (2013) presentaron mapas de contorno y análisis estadísticos de la estructura sísmica de la corteza y manto superior, basados en datos de refracción sísmica, datos de tomografía sísmica, análisis de ondas superficiales y funciones receptoras (Fig. 1.11).

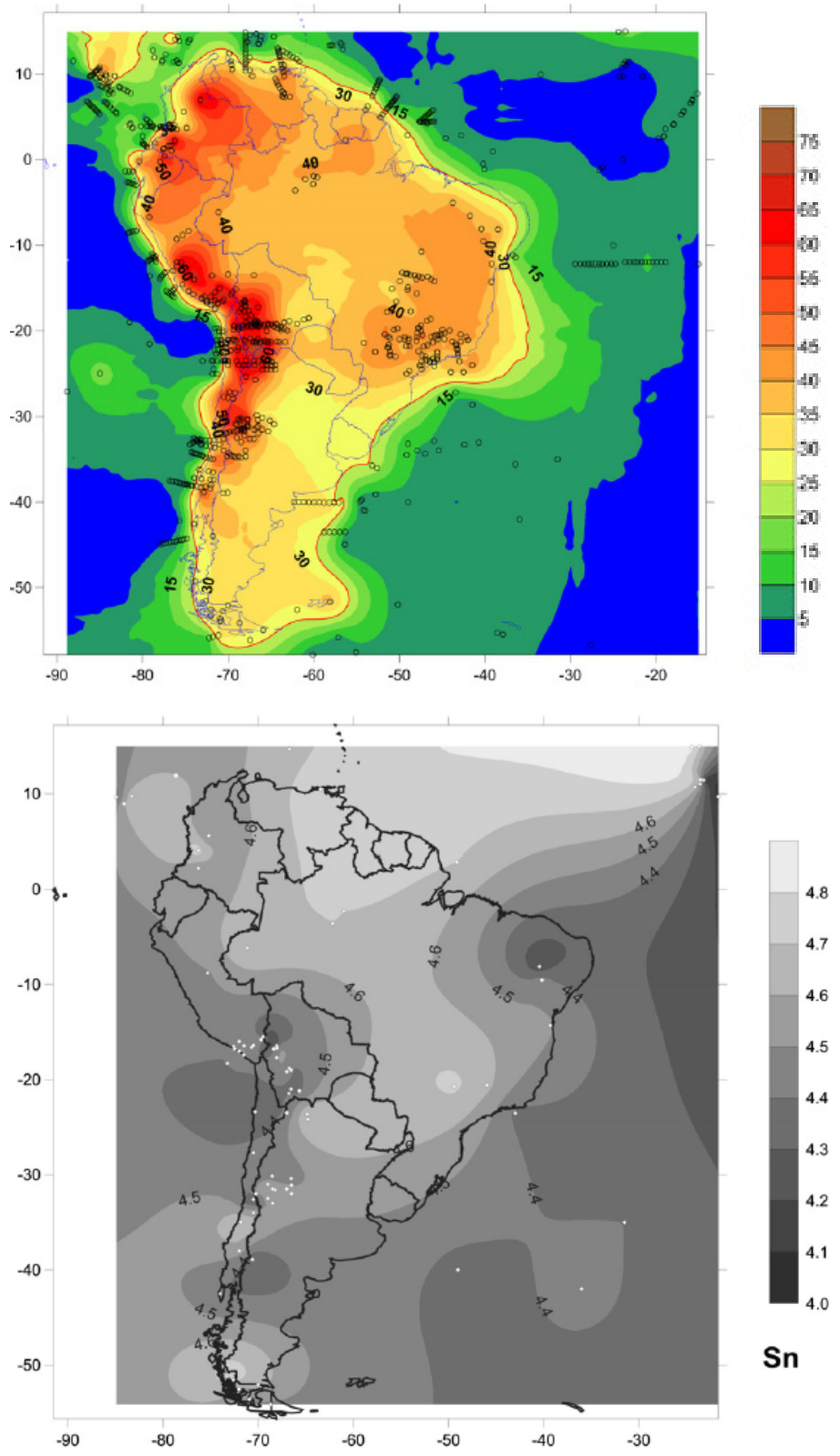

Figura 1. 11: Mapa de contornos del espesor cortical en $\mathrm{km}$ y mapa de velocidades promedio de la onda S bajo la discontinuidad de Mohorovicic (Sn) en km/s, obtenido por Chulick et al. (2013). 
Recientemente, Assumpção et al. (2013) presentaron modelos de espesor de la corteza en América del Sur mediante la compilación más actualizada de espesores corticales (principalmente de funciones receptoras), con una inversión conjunta de dispersión de ondas superficiales (incluyendo velocidades de grupo obtenidas de la correlación cruzada de ruido ambiental y datos de dispersión de terremotos proporcionados por este trabajo de Tesis) y modelado regional de formas de onda. Estos autores también utilizaron algunas estimaciones del espesor cortical a partir de modelos de gravedad para completar áreas que no fueron muestreadas directamente por las funciones receptoras. En la parte central del continente (Fig. 1.12), en particular a lo largo de las cuencas que conforman el antepaís andino, se ha observado que el espesor medio de la corteza es inferior a $35 \mathrm{~km}$ y en la parte norte de la cuenca de Paraná el espesor de $40 \mathrm{~km}$ disminuye a menos de $35 \mathrm{~km}$ en el extremo sur, continuando en la cuenca Chaco-Paraná. La corteza delgada hallada en los modelos tomográficos se basa principalmente en datos de ondas superficiales.
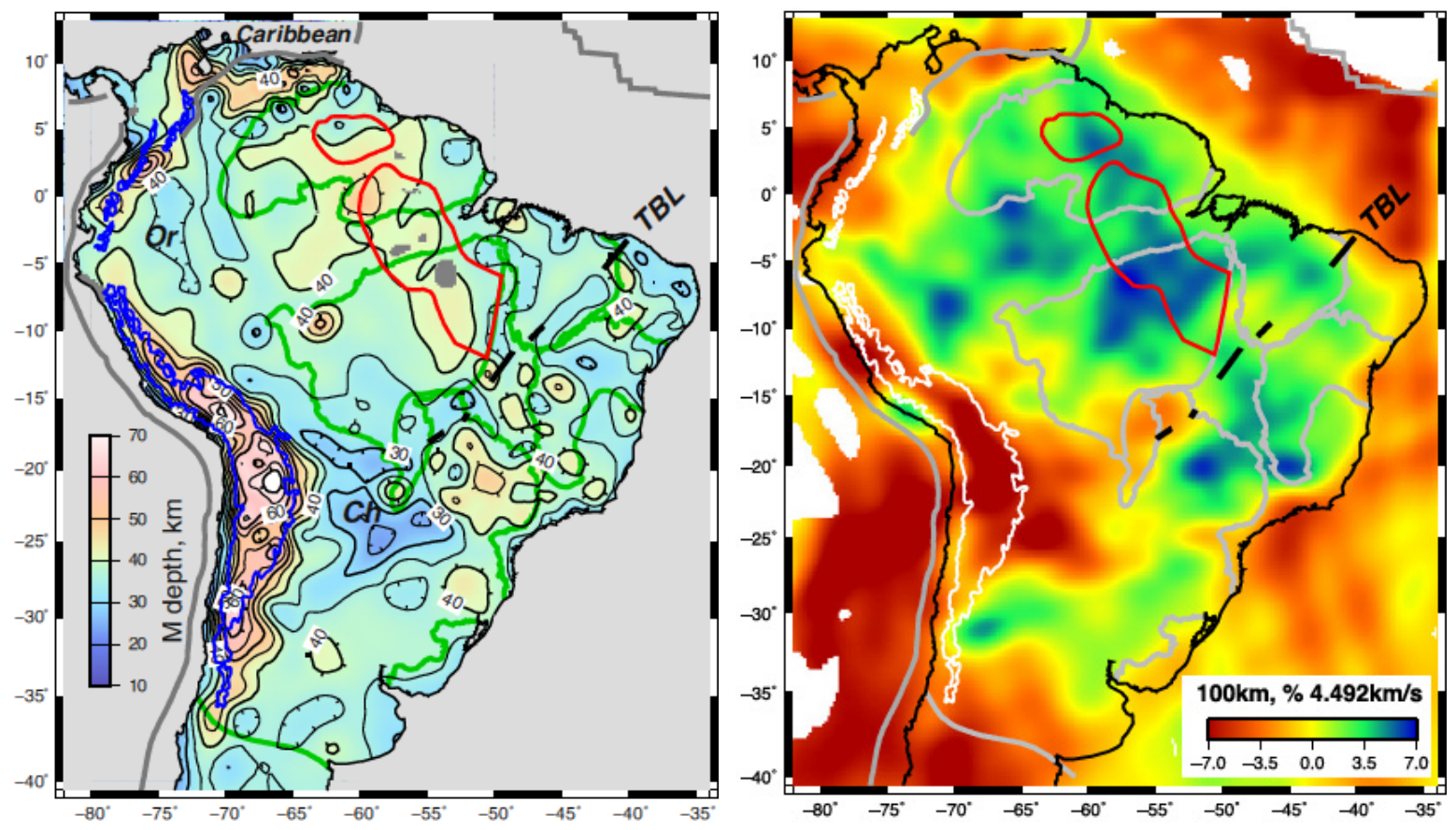

Figura 1.12: Modelo de profundidades de la Moho y modelo de velocidad de la onda $S$ relativo al modelo IASP para $100 \mathrm{~km}$ de profundidad, obtenido a partir de la compilación de Assumpção et al. (2013). Ch representa la región de la cuenca Chaco-Paraná. 
Los datos de gravedad han sido ampliamente utilizados para inferir el espesor cortical. A partir de modelos geopotenciales globales (EGM08, GOCE) diversos autores (e.g., Pavlis et al., 2008; Vitorello, 2011, Dragone, 2013) encontraron que la cuenca Chaco-Paraná se caracterizaba por una anomalía de Bouguer positiva en concordancia con las observaciones sismológicas de espesores corticales delgados.

Dragone (2013) encontró un gradiente de gravedad que separa las cuencas Chaco-Paraná y Paraná en dos provincias con características distintas, una con anomalías positivas y la otra con anomalías negativas, respectivamente. Van der Meijde et al. (2013) y Dragone et al. (2014) invirtieron anomalías de Bouguer obteniendo también una corteza delgada a lo largo de las cuencas subandinas. Sin embargo, las inversiones de gravedad a menudo asumen un contraste constante de densidad corteza-manto que no puede ser justificado. Las variaciones laterales de las densidades de la corteza o del manto superior pueden causar variaciones artificiales de espesores de la corteza cuando se asume una densidad constante.

\subsection{Objetivos}

El trabajo de Tesis que aquí se presenta tiene como propósito determinar un modelo de velocidades de la corteza y manto superior en la región de la cuenca Chaco-Paraná, mediante técnicas tomográficas y de inversión, a partir de las curvas de dispersión de velocidad de grupo de las ondas superficiales de sismos regionales de magnitudes moderadas a grandes, curvas de dispersión derivadas de la correlación de ruido ambiental entre estaciones y funciones receptoras, utilizando señales sismológicas obtenidas en estaciones de las redes globales GSN (Global Seismographic Network) y GEOSCOPE (French Global Network of Broad Band Seismic Stations); de las redes locales BRASIS (BRAzilian Seismographic Integrated Systems) e INPRES (Instituto Nacional de PREvención Sísmica) y en la estación LPA (La Plata) perteneciente a la Universidad Nacional de La Plata.

Los estudios de tomografía con ondas superficiales experimentan una distribución desigual de los datos, provocada por la concentración de fuentes sísmicas y por una distribución irregular de estaciones sismológicas (Pasyanos, 
2005). El creciente número de estaciones de banda ancha en América del Sur ha creado una oportunidad para evitar las limitaciones en la resolución lateral y en profundidad. El despliegue de redes sísmicas portátiles en la region central y oriental de América del Sur permite una mejor aproximación de la estructura sísmica del continente. El objetivo de este trabajo es mejorar la resolución de las imágenes de la corteza obtenidos a partir de mediciones tradicionales de dispersión de sismos de tamaño moderado a grande. Por lo tanto, se presentan los resultados de la tomografía $2 \mathrm{D}$ de la velocidad de grupo de las ondas superficiales mediante un conjunto más amplio de datos, que permite obtener una cobertura más densa de trayectorias con una distribución acimutal más uniforme, produciendo mejores imágenes tomográficas y mejorando la resolución en comparación con trabajos anteriores, especialmente en torno a la cuenca ChacoParaná.

Aprovechando la instalación, a principios del siglo XXI, de sensores banda ancha en estaciones sismológicas ubicadas en la provincia de Buenos Aires, se han analizado funciones receptoras, a efectos de contribuir al conocimiento de esta región del este de nuestro país, a través del uso de técnicas sismológicas. 


\section{Capítulo 2}

\section{Tomografía de Ondas Superficiales}

\subsection{Ondas superficiales}

La existencia de una superficie libre y otras superficies de discontinuidad de velocidad en el interior de la Tierra produce un acoplamiento de energía que da origen a dos tipos de ondas superficiales, las ondas Love y las ondas Rayleigh. Estas ondas se generan por superposición de ondas internas $\mathrm{P}$ y S y, se propagan a lo largo de la superficie terrestre a velocidades menores que aquellas de las internas. La propagación de estas ondas está determinada por los principios de la mecánica de los medios elásticos. El desarrollo teórico y matemático de las ondas superficiales puede consultarse más extensivamente en Takeuchi and Saito (1972), Aki and Richards (2002), Lay and Wallace (1995), Udías (1999), Shearer (2009), Stein and Wysession (2003). En esta Tesis sólo se describirán algunas propiedades de estas ondas.

Las ondas superficiales constituyen generalmente los arribos más intensos registrados a distancias telesísmicas debido a su gran energía y debido a la menor divergencia geométrica que experimentan comparada con aquella correspondiente a las ondas internas. Además, forman la parte más larga y de mayor energía de un registro sísmico generado por explosiones o terremotos superficiales.

Las ondas Love surgen por interferencia constructiva de ondas $\mathrm{SH}$ (componente horizontal de la onda $S$ ), que se reflejan en la superficie de separación entre una capa y un semiespacio. Presentan movimiento transversal en el plano horizontal, generando una vibración del suelo de lado a lado (Fig. 2.1). Poseen velocidades que varían entre 2.5 y $4.5 \mathrm{~km} / \mathrm{s}$ en zonas continentales.

Las ondas Rayleigh se generan por interferencia constructiva de ondas $P$ y SV (componente vertical de la onda S) en la superficie libre de la Tierra y viajan a lo largo de la superficie produciendo un desplazamiento en el plano de incidencia que genera una vibración del suelo de manera elíptica (Fig. 2.1), cambiando de 
retrógrada en la superficie a directa a una cierta profundidad. Viajan a velocidades que varían entre 2 y $4.5 \mathrm{~km} / \mathrm{s}$ en zonas continentales.

Las ondas Rayleigh pueden originarse en un semiespacio o en un medio de múltiples capas mientras que las ondas Love necesitan una guía de onda o capa para generarse.

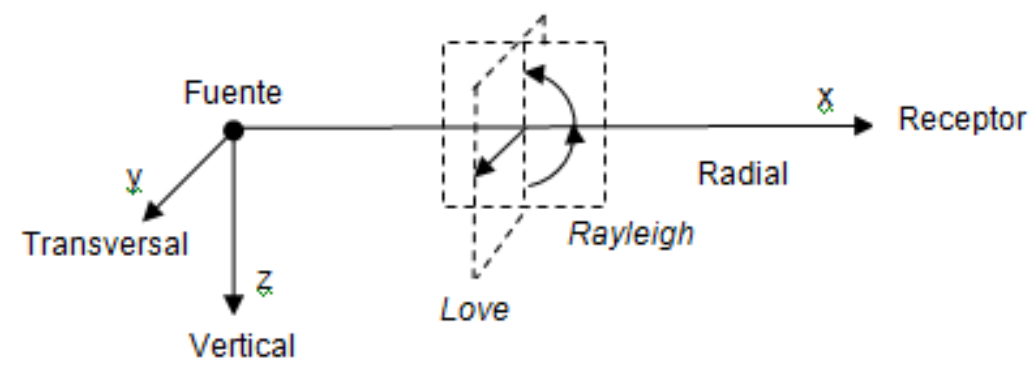

Figura 2.1: Geometría del movimiento de las ondas Love y Rayleigh (Stein and Wysession, 2003).

La amplitud del desplazamiento de las ondas superficiales decrece exponencialmente con la profundidad y la mayor parte de su energía se propaga en una región poco profunda, aproximadamente igual a una longitud de onda $\lambda$, en consecuencia su propagación está influenciada por las propiedades elásticas de esa región delimitada del subsuelo. Presentan un modo fundamental y un número finito de modos superiores, para los que la amplitud se hace cero en los nodos y se caracterizan por viajar más rápido que el modo fundamental.

La velocidad de las ondas superficiales a una frecuencia específica se denomina velocidad de fase $C(\omega)$, siendo $\omega$ la frecuencia angular, $\mathrm{k}$ el número de onda y T el período:

$$
\mathrm{C}(\omega)=\frac{\omega}{\mathrm{K}}=\frac{\lambda}{\mathrm{T}}
$$

Esta velocidad es la velocidad con la que se propaga la fase de cada componente armónico de las ondas superficiales y depende de los parámetros del medio (espesores y velocidades de las ondas $\mathrm{P}$ y $\mathrm{S}$ ) que varían con la profundidad. 
Por lo tanto las ondas superficiales son dispersivas es decir su velocidad de propagación depende de la frecuencia o período.

Debido a la dispersión cuando las ondas de frecuencias próximas viajan a velocidades ligeramente diferentes se mezclan en una tendencia modulada cuya frecuencia es la media de sus componentes y su envolvente varía lentamente en amplitud con el tiempo como se observa en la Fig. 2.2. En tal caso, la energía del movimiento se concentra en paquetes de ondas que viajan con una velocidad conocida como velocidad de grupo $U(\omega)$ o velocidad de transporte de la energía, que depende de la velocidad de fase de las ondas individuales (en consecuencia, de los parámetros del medio) y de cómo varía esa velocidad. Estos paquetes de energía tienden a separarse con la distancia (dispersión) a medida que viajan caminos más largos.

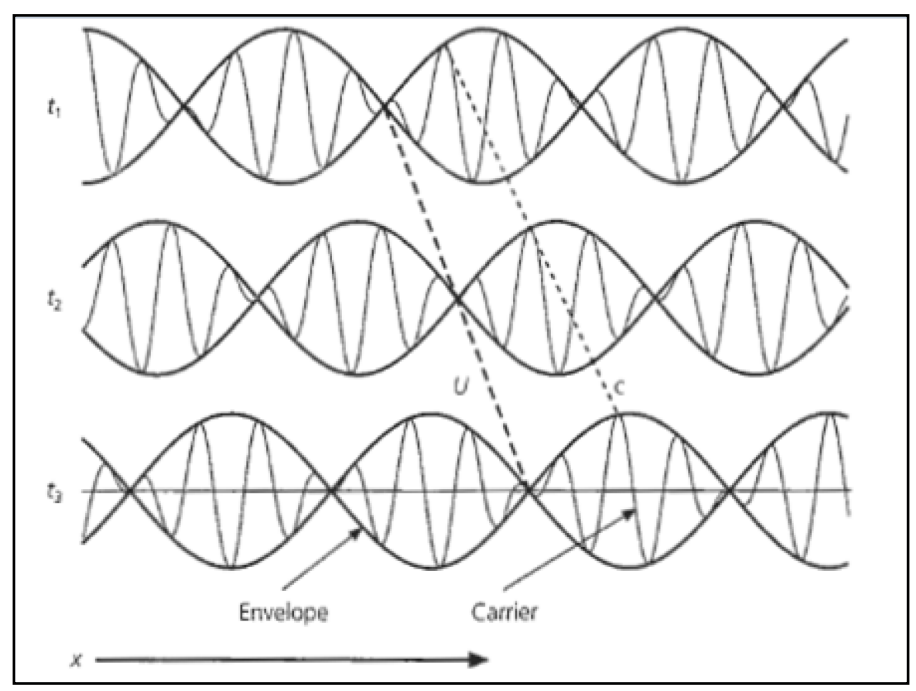

Figura 2.2: Suma de ondas superficiales viajando a distinta velocidad que generan una envolvente de largo período que se propaga con velocidad de grupo $U(\omega)$. La portadora (carrier), cuya amplitud está modulada por la envolvente (envelope), se propaga con velocidad de fase $\mathrm{C}(\omega)$ (Stein and Wysession, 2003).

La medición de la velocidad de fase, entre un epicentro y una estación implica la correcta identificación de una fase particular dentro de toda la señal y un buen conocimiento de la fase inicial en la fuente sísmica. Un valor que es mucho más fácil de medir corresponde al tiempo de llegada del paquete de energía cuya 
velocidad de propagación es la velocidad de grupo. Además de su obtención más simple, la velocidad de grupo es más sensible a los parámetros del medio (densidad y velocidad de ondas $P$ y $S$ ) que la velocidad de fase. Esto se debe a que los valores grandes de sensibilidad de la velocidad de grupo se encuentran a menores profundidades, que los de la velocidad de fase para la misma frecuencia según lo señalaron Ritzwoller and Levshin (1998). Esta característica presenta una ventaja en la estimación de la velocidad de onda S, mediante inversión (Mejia, 2001).

Se puede definir la velocidad de grupo en función de la frecuencia angular $\omega$ y el número de onda $\mathrm{K}$, como:

$$
U(\omega)=\frac{d \omega}{d k}=C(\omega)+k \frac{d C}{d x} .
$$

Sustituyendo $\mathrm{K}=\frac{\omega}{\mathrm{C}} \quad \mathrm{y}$

$$
\frac{\mathrm{dC}}{\mathrm{dK}}=\frac{\mathrm{dC}}{\mathrm{d} \omega} \frac{\mathrm{d} \omega}{\mathrm{dK}}=\frac{\mathrm{dC}}{\mathrm{d} \omega} \mathrm{U}
$$

la velocidad de grupo para una frecuencia en particular se puede expresar como:

$$
\mathrm{U}(\omega)=\frac{\mathrm{C}}{1-\left(\frac{\omega}{\mathrm{C}}\right)\left(\frac{\mathrm{dC}}{\mathrm{d} \omega}\right)} .
$$

Por lo tanto, si se conoce la distribución de velocidad de fase $\mathrm{C}(\omega)$ en función de la frecuencia para un rango de frecuencias, se puede calcular fácilmente la velocidad de grupo $U(\omega)$ para ese rango (Larson and Ekström, 2001). Cuando la velocidad de fase es constante $\left(\frac{\mathrm{d} C}{\mathrm{~d} \omega}=0\right)$, ambas velocidades coinciden.

La información de la estructura de la Tierra y de la fuente sísmica contenida en las ondas superficiales, dependiendo del rango de frecuencias y profundidad de 
penetración, es útil para resolver diversos problemas científicos y prácticos tales como:

- determinación de la estructura de la corteza, la litósfera y el manto superior.

- reconocimiento de cuencas sedimentarias tanto en tierra como en el mar.

- determinación de la estructura y propiedades elásticas del suelo en estudios de ingeniería civil, arqueología y de ambiente.

- caracterización de la fuente, incluyendo determinación de la magnitud, tensor momento, parámetros dinámicos de la fuente sísmica (tamaño de la zona de ruptura, dirección y velocidad de ruptura).

- discriminación entre pruebas nucleares subterráneas y eventos sísmicos (naturales o artificiales).

Las otras propiedades de estas ondas tales como polarización, contenido en frecuencia, atenuación y variación acimutal de su amplitud y fase también están controladas por el medio donde se propagan entre fuente sísmica y estación sismológica.

\subsection{Curvas de dispersión}

Como se mencionó en la sección anterior, las ondas superficiales a diferencia de las ondas de cuerpo $\mathrm{P}$ y $\mathrm{S}$, viajan a velocidades que se relacionan con sus longitudes de onda. Esta relación entre la frecuencia y la velocidad se denomina dispersión. La dispersión modifica la apariencia general de las ondas superficiales a medida que se propagan. Se puede visualizar a la onda superficial comenzando básicamente en la fuente sísmica como un pulso no dispersivo, donde cada componente armónica tiene una amplitud y una fase inicial determinada por la excitación de la fuente y el medio. A medida que la onda se propaga es modificada por la dispersión, diseminándose la energía a lo largo de un tren de ondas. Esta energía se propaga principalmente en paquetes de onda de interferencia constructiva que se mueven con velocidad de grupo (Stein and Wysession, 2003).

En un medio homogéneo, las ondas superficiales con distintas longitudes de onda penetran a diferentes profundidades del subsuelo pero dado que el material 
es uniforme, todas las ondas presentan la misma velocidad, como se observa en la Fig. 2.3 (gráfico A de la izquierda). Si el medio posee capas de distintas propiedades, el comportamiento de las ondas superficiales es diferente. Las ondas de distinta longitud de onda que atraviesan profundidades con distintas propiedades elásticas se propagan a una velocidad de fase que depende de las propiedades elásticas de las capas involucradas en la propagación. Como la velocidad normalmente aumenta con la profundidad, las ondas de mayor período y/o longitud de onda que atraviesan regiones más profundas del interior terrestre son más sensibles que las de menor período a las altas velocidades viajando entonces más rápidamente hacia la estación (Fig. 2.3, gráfico B de la derecha).
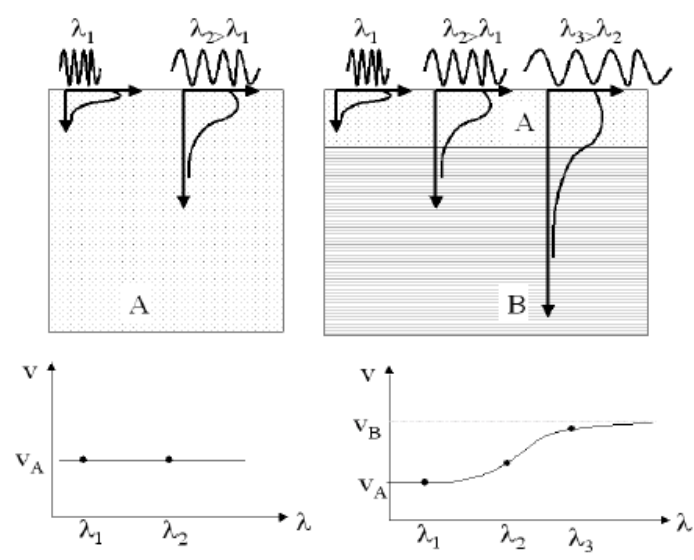

Figura 2.3: Las ondas Rayleigh con distinta longitud de onda $\lambda$ que penetran en un medio homogéneo (gráfico $A$ de la izquierda) presentan velocidad constante. Para un medio heterogéneo (gráfico B de la derecha) la velocidad depende de la longitud de onda.

En la Fig. 2.4 se muestra el fenómeno de dispersión para las ondas superficiales de dos sismos someros ocurridos en la dorsal del océano Pacífico y registrados en la estación LPA (La Plata). El primer ejemplo corresponde a un sismo que ocurrió el 17/11/2006 a una distancia de 5170 km con una magnitud Mw 5.2 y el segundo, el 14/6/2007 a una distancia de $3791 \mathrm{~km}$ con Mw 5.9. Se puede notar la variación en los períodos de las ondas y el efecto de batido provocado por la superposición de ondas superficiales de distinto período que viajan a una misma velocidad en un determinado instante. 

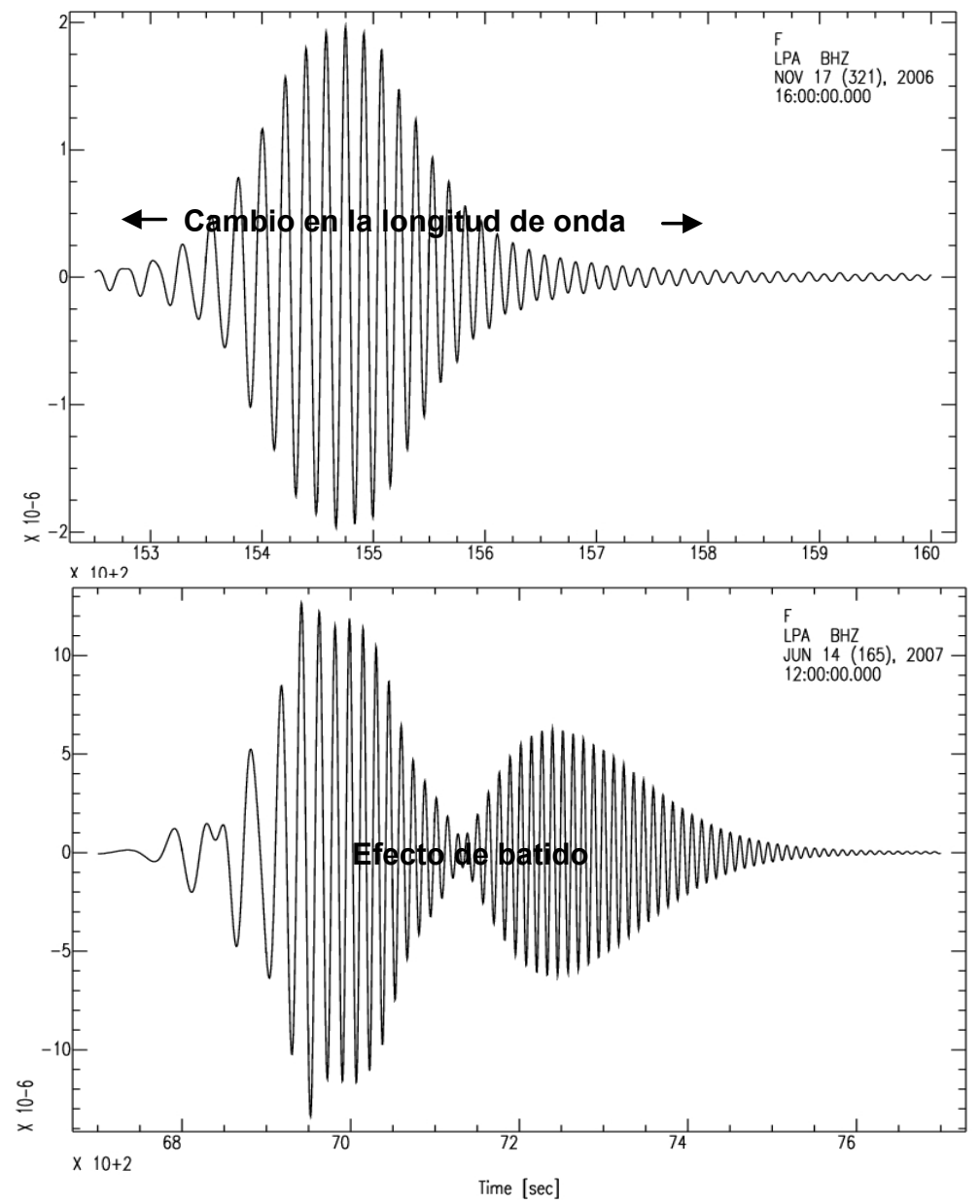

Figura 2.4: Efectos de la dispersión en dos registros sísmicos de componente vertical de la estación LPA correspondientes a dos sismos superficiales ocurridos en la dorsal del Pacífico, ubicados a una distancia de $5170 \mathrm{~km}$ (17/11/2006) y de $3791 \mathrm{~km}$ (14/06/2007). En el gráfico superior se observa que las longitudes de onda mayores que son más sensibles a mayores profundidades de la Tierra y por ello viajan más rápido que las ondas de corto período, arriban primero a la estación sismológica.

En el gráfico inferior se observa el efecto de batido provocado por la superposición de ondas de distinto período que viajan a una misma velocidad en un determinado instante.

Como la forma que presenta la curva de dispersión depende de los espesores, densidades y velocidades de las ondas $\mathrm{P}$ y $\mathrm{S}$, si se conoce la curva para una trayectoria determinada, es posible obtener, mediante procesos de inversión, la estructura de velocidad de la onda $S$ en dicha trayectoria. Esto hace que la determinación de las curvas de dispersión y su análisis sea una herramienta eficaz para estudiar la estructura del interior terrestre. Las observaciones más comunes están incluidas en el rango de períodos comprendido entre 15 y 300 segundos (Fig. 2.5). 
Entre 15 y 100 segundos las ondas reflejan la estructura de la corteza y manto superior, mientras que las de mayores períodos proporcionan información de la parte más profunda del manto. La velocidad de fase es generalmente mayor que la velocidad de grupo. Además la velocidad de grupo puede experimentar un aumento o disminución con el aumento del período, mientras que la velocidad de fase es monótonamente creciente (Stein and Wysession, 2003).
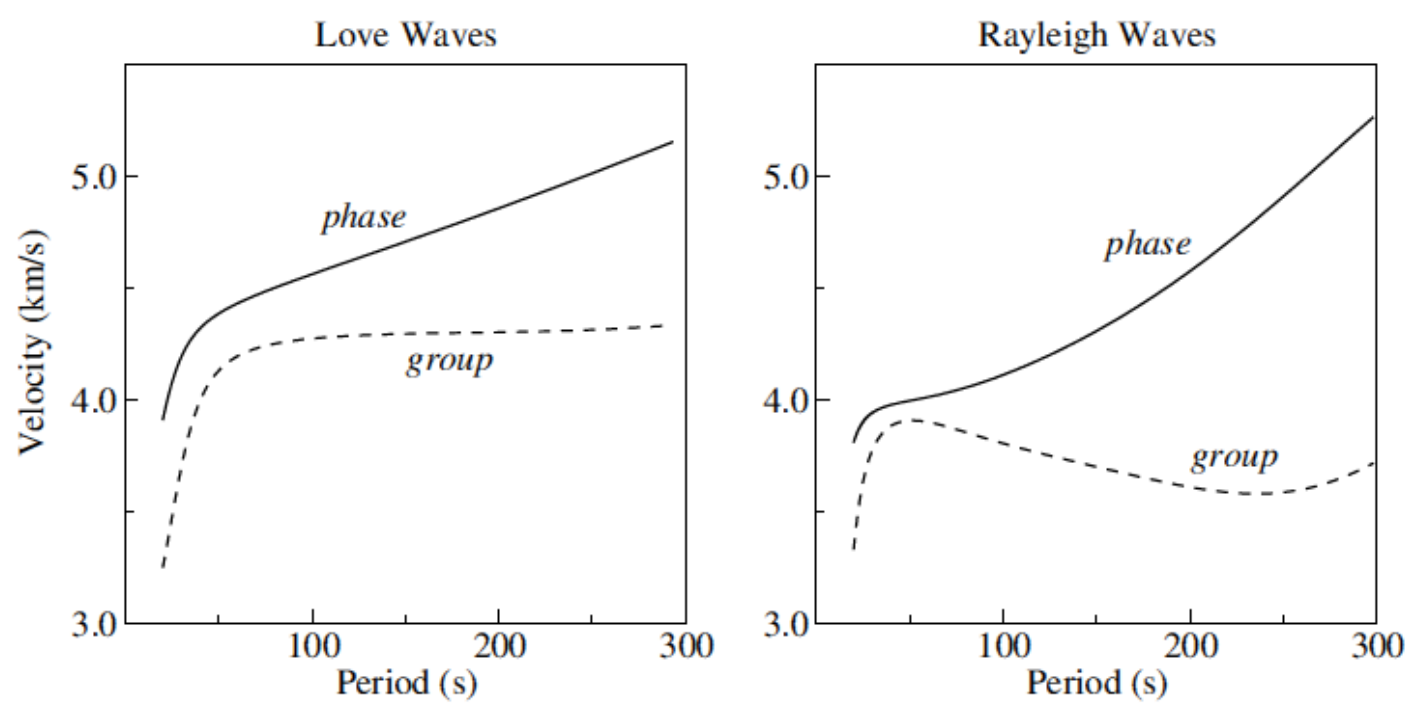

Figura 2.5: Curvas de dispersión para el modo fundamental de ondas Love y Rayleigh calculadas a partir del modelo isotrópico PREM (Preliminary Reference Earth Model) por G. Laske (Shearer, 2009).

Las diferencias en la composición y espesor de la corteza entre la región continental y la oceánica se traducen en diferencias significativas en las correspondientes curvas de dispersión, como se muestra en la Fig. 2.6. Mientras que las velocidades de las ondas Rayleigh varian entre 2.9 y $3.3 \mathrm{~km} / \mathrm{s}$ en el intervalo de periodos de 15 a 30 s para la región continental; para zonas oceánicas las variaciones son de aproximadamente 1.5 a $4.0 \mathrm{~km} / \mathrm{s}$ para el mismo rango de períodos. En consecuencia, en un sismograma se distingue que los trenes de ondas para trayectorias continentales son más cortos y dispersos, mientras que para trayectorias oceánicas son más largos con oscilaciones casi monocromáticas durante varios minutos. 


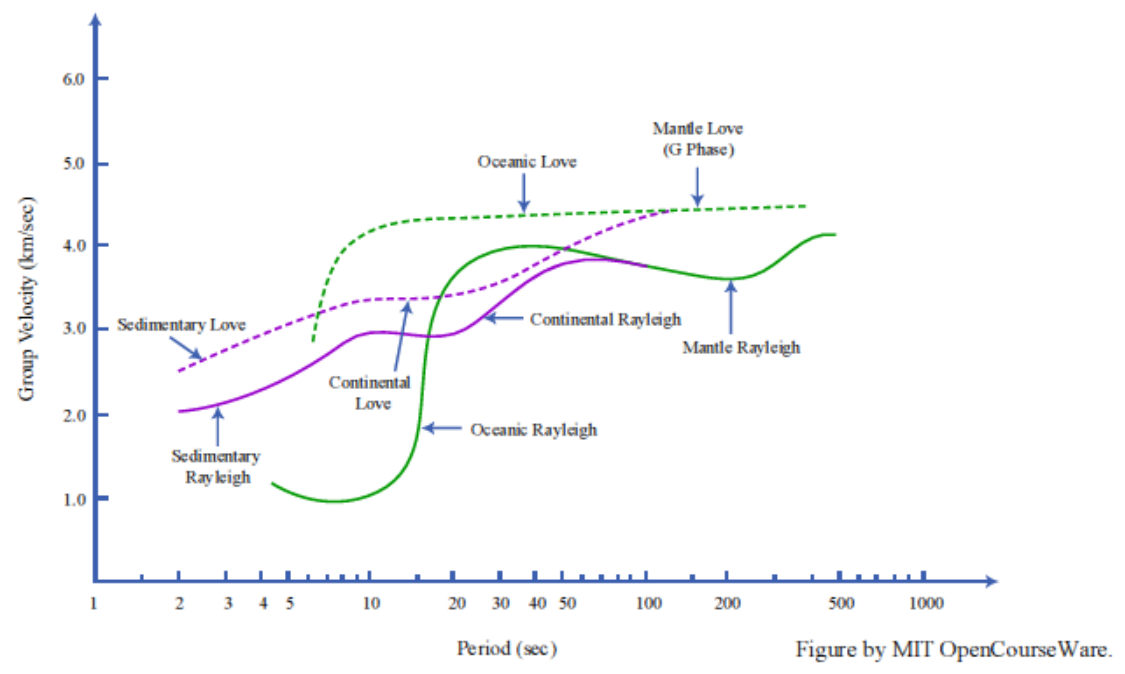

Figura 2.6: Curvas de dispersión de la velocidad de grupo para las ondas Love y Rayleigh con trayectorias oceánicas (líneas verde) y continentales (líneas violeta) extraída de MIT (Massachusetts Institute of Technology) Open Course Ware (2008).

Puede observarse en la Fig. 2.6 que las curvas de velocidad de grupo presentan un mínimo local aproximadamente a los $20 \mathrm{~s}$ para trayectorias continentales (curva violeta) y otro a los $200 \mathrm{~s}$ conocidos como la fase de Airy, que se generan a partir de una gran cantidad de energía arribando al mismo momento. Las observaciones de ondas de períodos menores que 15 segundos se ven afectadas por las capas sedimentarias más superficiales, de gran heterogeneidad y poseen propiedades que varían de una región a otra (Udías y Mezcua, 1997).

\subsection{Resolución}

Un aspecto importante a tener en cuenta en la inversión de las velocidades de las ondas superficiales es su resolución en profundidad, esto es la capacidad que poseen estas ondas para recuperar información sobre los parámetros del medio (densidad y velocidades de ondas $\mathrm{P}$ y $\mathrm{S}$ ) para diferentes profundidades. Por ello se analiza la sensibilidad de las velocidades a estos parámetros. Los llamados kernels o núcleos de sensibilidad que muestran la relación entre las velocidades de dispersión y la estructura de la Tierra (Mejia, 2001) se obtienen calculando la derivada parcial de la velocidad de dispersión respecto a los otros parámetros (velocidad de la onda S, densidad, profundidad). 
En general las mediciones de dispersión de la velocidad de las ondas superficiales son principalmente sensibles a los cambios en las velocidades de la onda $S$, siendo la velocidad de grupo más sensible que la velocidad de fase a estos cambios para las zonas más superficiales (Ritzwoller and Levshin, 1998). Además, estos autores también demostraron que los núcleos de sensibilidad de la velocidad de grupo se comprimen más cerca de la superficie respecto a los correspondientes a la velocidad de fase para un mismo período, lo que permitiría resolver de manera más eficiente las estructuras de la corteza con velocidades de grupo.

La Fig. 2.7 muestra los núcleos de sensibilidad relativos a la velocidad $\beta$ de la onda $S\left(\partial U_{T} / \partial \beta_{\mathrm{H}}\right)$, característicos de las ondas Rayleigh y Love para diferentes períodos, considerando una estructura típica de corteza continental de $30 \mathrm{~km}$ de espesor con un espesor de sedimentos de $5 \mathrm{~km}$ (Pasyanos, 2005).
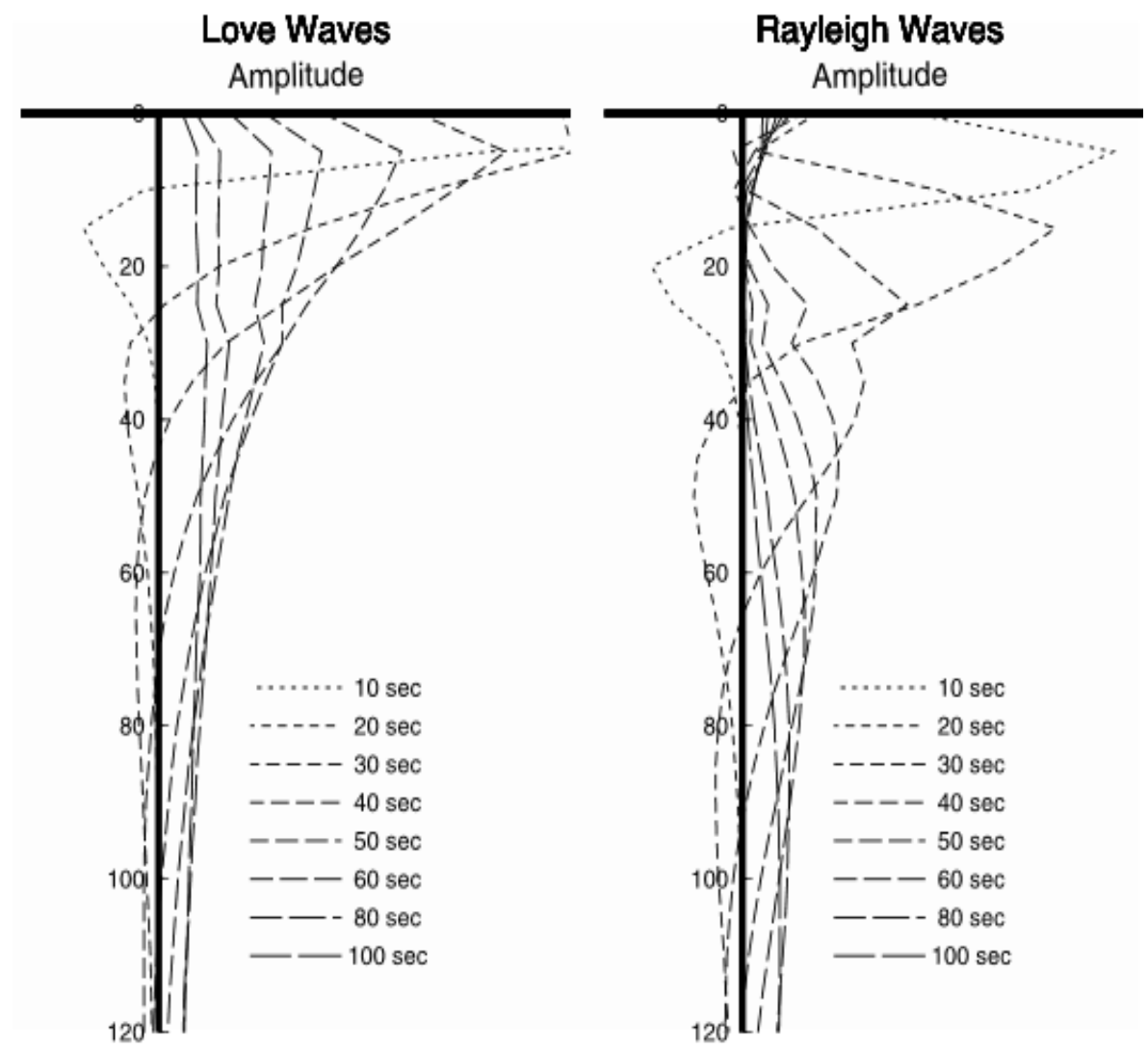

Figura 2.7: Núcleos de sensibilidad relativos a la velocidad de la onda $S\left(\partial U_{T} / \partial \beta_{H}\right)$ de las ondas Love y Rayleigh entre 10 y 100 s, a distintas profundidades, extraído de Pasyanos (2005). 
Se observa que las velocidades de grupo son sensibles a los cambios en los parámetros del medio a mayor profundidad a medida que el período aumenta. Además el valor máximo de los núcleos de sensibilidad se profundiza y su forma se ensancha.

Si se compara la sensibilidad de las ondas Rayleigh con la de las ondas Love para el mismo período, se observa que las ondas Love son más sensibles en la parte más superficial. Por ejemplo, las ondas Rayleigh de 30 s permiten resolver estructuras a $25 \mathrm{~km}$ de profundidad aproximadamente, mientras que las ondas Love para ese período permitirían resolver estructuras más someras del orden de $10 \mathrm{~km}$. Para períodos mayores, los núcleos de sensibilidad de las ondas Love continúan siendo sensibles a estructuras someras, siendo su forma más plana y sin picos. Contrariamente, los núcleos de las ondas Rayleigh presentan varios picos a mayores profundidades.

Si se compara la variación de los núcleos para ambas ondas considerando distintos períodos, es evidente que los núcleos de las ondas Rayleigh son más completos en el sentido de que las observaciones para diferentes períodos son más sensibles a los cambios en las propiedades sísmicas a diferentes profundidades. Por lo que las ondas Rayleigh son más sensibles a los parámetros del modelo que las ondas Love; sin embargo, ninguna de estas observaciones permitiría obtener un modelo único de la estructura.

\subsection{Determinación de las curvas de dispersión}

\subsubsection{Introducción}

Como se mencionó anteriormente, la medición de la velocidad de fase, entre un epicentro y una estación, no es una tarea sencilla. Contrariamente, la velocidad de grupo puede ser determinada sin necesidad de conocer el mecanismo focal del sismo y puede obtenerse para eventos de magnitudes menores (hasta magnitud de ondas internas $\left.m_{b}>4.5\right)$. Además como ya se ha mostrado, la velocidad de grupo permite resolver de manera más eficiente la estructura dentro de la corteza. En consecuencia, en este trabajo se considerarán solamente las mediciones e interpretaciones de las velocidades de grupo. 
Un método empleado en los primeros estudios para determinar las curvas de dispersión de la velocidad de grupo a partir de los sismogramas de ondas superficiales se basaba en el análisis de los tiempos de llegada de las crestas y valles de las ondas a una estación sismológica (Ewing and Press, 1952). Esta técnica tradicional proporciona en forma sencilla y rápida, valores aproximados de velocidad de grupo.

Landisman et al. (1969) introdujeron la técnica de ventana móvil en el dominio del tiempo para determinar la velocidad de grupo y también demostraron que era posible aplicar filtros pasa banda variables en frecuencia para mejorar el método. Posteriormente, Dziewonski et al. (1969) desarrollaron un método analítico para determinar la velocidad de grupo de ondas dispersivas, denominado técnica de filtrado múltiple MFT (Multiple Filter Technique). Esta técnica permite extraer el tren de ondas superficiales directas de la coda de ondas superficiales, modos superiores y ondas de volumen aplicando reiteradamente un filtro digital en el dominio de la frecuencia; de esta manera es posible obtener gran parte de la dispersión presente en los registros sísmicos comparado con el método clásico de Ewing and Press (1952). Herrmann (1973) mejoró la eficiencia de este método aplicando la transformada de Hilbert en el dominio de la frecuencia para determinar las envolventes en el dominio del tiempo.

Herrin and Goforth (1977) introdujeron un filtro de fase coincidente PMF (Phase Matched Filter) que, aplicado a las señales dispersivas optimiza la estimación de las velocidades de grupo, minimizando los efectos de trayectoria múltiple (multipathing) y mejorando la relación señal/ruido de los sismogramas. EI PMF es un filtro lineal en el cual la fase de Fourier del filtro coincide con la fase de Fourier de la señal. Este filtro permite aislar el modo fundamental, eliminando los modos superiores y efectos de ruido.

\subsubsection{Técnica de filtrado múltiple}

La técnica de filtrado múltiple (MFT) consiste en la aplicación de un conjunto de $\mathrm{N}$ filtros pasa-banda digitales de ancho de banda angosto, que aíslan el paquete de ondas correspondiente a la frecuencia central del filtro. La velocidad de grupo correspondiente a esa frecuencia se determina a partir del tiempo de arribo del pico 
o máximo de la amplitud instantánea, dividiendo la longitud de la trayectoria por ese tiempo de viaje. Para obtener las amplitudes instantáneas para cada traza filtrada, se define la señal analítica, que es una señal compleja cuya parte real definida por la traza y su parte imaginaria definida por la transformada de Hilbert de la misma. La amplitud instantánea es la envolvente de la traza y es igual al módulo de la traza compleja.

Estos filtros pasa-banda pueden resolver señales transitorias compuestas de varios períodos dominantes que arriban a una estación sismológica de manera casi simultánea. El resultado obtenido es un diagrama de velocidad de grupo versus período, para el cual la contaminación de señales espurias ha sido reducida. Considerando instrumentos de respuesta plana, el intervalo de períodos útiles para cada curva de dispersión depende de la magnitud del terremoto y de la longitud de la trayectoria sísmica, obteniéndose en terremotos de gran magnitud un mejor registro de los períodos grandes a mayores distancias (Feng et al., 2004).

La MFT se usa para estudiar las variaciones de amplitud (o energía) de una señal como función de la velocidad (tiempo) y período (frecuencia). Por lo tanto, es deseable que la señal filtrada tenga buena resolución en la vecindad de cada frecuencia central. Para ello se elige como filtro pasa-banda la función gaussiana que cumple esos requisitos:

$$
H_{n}(\omega)=e^{-\alpha\left(\frac{\omega-\omega_{n}}{\omega_{n}}\right)^{2}}
$$

donde $\omega_{\mathrm{n}}$ es la frecuencia central del filtro y $\alpha$ es el parámetro que controla el ancho de banda del mismo. La selección de un ancho de banda particular representa un compromiso entre la resolución en el dominio del tiempo y en el dominio de la frecuencia.

Para calcular las curvas de dispersión de la velocidad de grupo en este trabajo, se escogió el código de procesamiento de Herrmann (2013) que es un software de libre acceso que permite, entre otras aplicaciones, obtener curvas de velocidad de grupo y fase. Para cada traza, se eligen los rangos de variación permitidos para el período y para la velocidad de grupo, así como el ancho del filtro gaussiano. El ancho se selecciona en función de la distancia fuente receptor. La 
variación es proporcional a la distancia siendo más grande para distancias más largas.

Con el fin de calcular la curva de velocidad de grupo con más precisión, se aplica el filtro de fase coincidente (PMF). Usando una estimación inicial de la velocidad de grupo, el PMF comprime la señal en una ventana estrecha de tiempo centrada en el tiempo cero, permitiendo eliminar el ruido al considerar el espectro de esta ventana angosta en lugar de la ventana completa de tiempo de la señal. Sin embargo, la compresión depende de la coincidencia entre la fase del filtro y la fase de la señal. Luego se puede aplicar por segunda vez la técnica de filtrado múltiple y calcular con más exactitud la curva de dispersión de velocidad de grupo para el modo fundamental.

En las Figs. 2.8 (a) y 2.9 (a) se muestran los registros de las componentes vertical y transversal de un sismograma, obtenidos en la estación LPA, correspondientes a un sismo superficial (profundidad focal $h=23.8 \mathrm{~km}$ ) de magnitud 6.2 ocurrido en la región andina (latitud $\phi:-45^{\circ} .24$, longitud $\lambda:-72^{\circ} .67$ ) el día 21 de abril de 2007. En las Figs. 2.8 (b) y 2.9 (b) se presentan las correspondientes curvas de dispersión de la velocidad de grupo $U$ para las ondas Rayleigh y Love obtenidas para ese sismo mediante MFT. El gráfico de la izquierda muestra los valores de amplitud $A$ de la envolvente en función del período. Los puntos rojos representan las mayores amplitudes. El gráfico central muestra los valores de la envolvente filtrada o amplitud instantánea máxima, en función de la velocidad y el período, en distintos colores. El color rojo representa las mayores amplitudes. La línea de puntos blancos representa los valores de la velocidad de grupo inferida de los contornos. El gráfico de la derecha corresponde a la señal filtrada. 


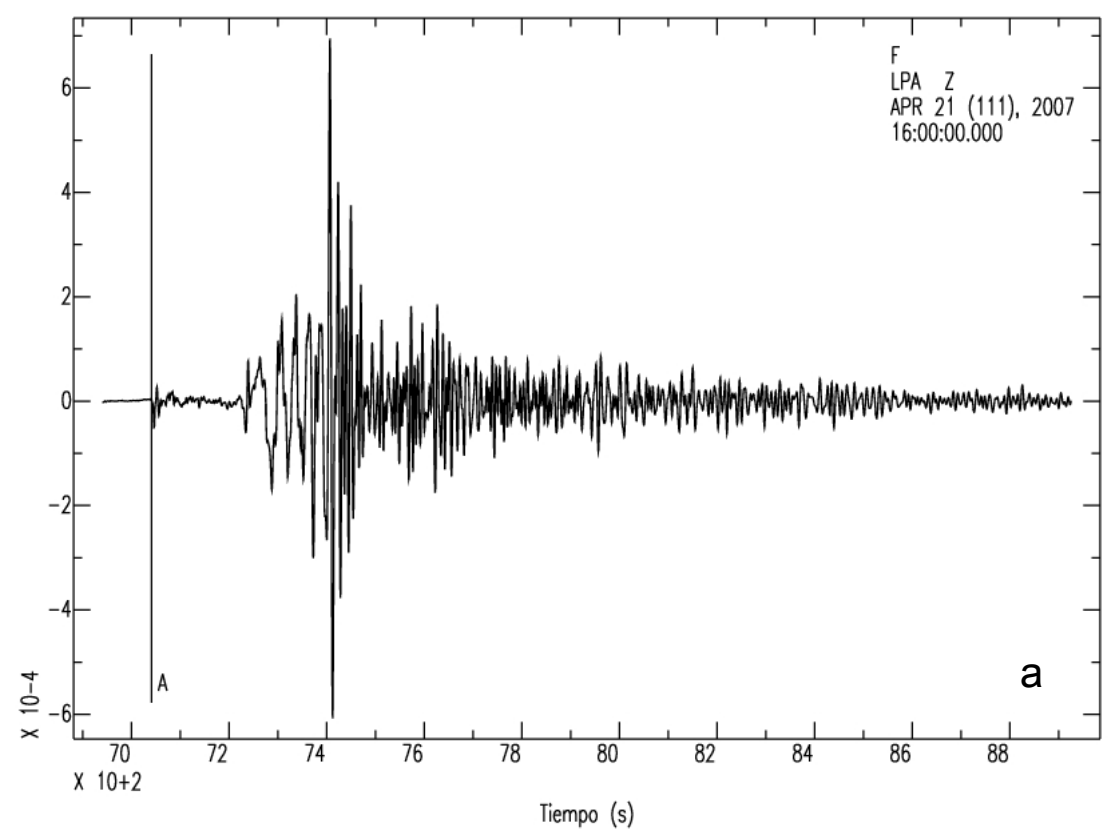

Figura 2.8: a) Registro vertical de un sismo andino $\left(\phi:-45^{\circ} .24, \lambda:-72^{\circ} .67\right)$ ocurrido a $4992 \mathrm{~km}$ de la estación LPA. A indica la hora de arribo de la onda $P$ relativa al tiempo de la primera muestra del registro.

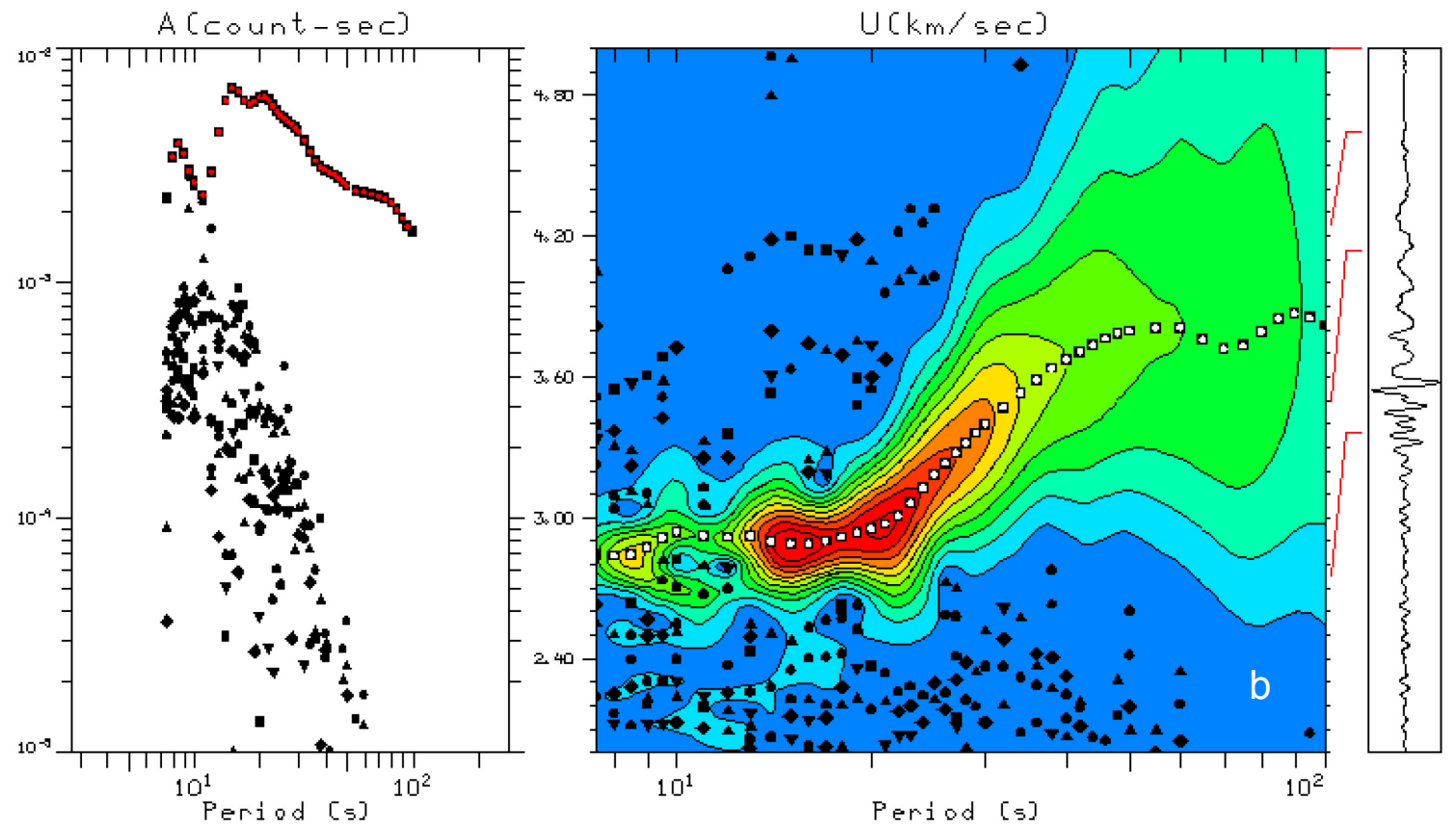

Figura 2.8: b) Gráfico de la velocidad de grupo de la onda Rayleigh en función del período. EI gráfico de la izquierda muestra los valores de amplitud A (cuentas/s) de la envolvente en función del período (s). Los puntos rojos representan las mayores amplitudes. El gráfico central muestra los valores de la envolvente filtrada en función de la velocidad y el período en distintos colores. El color rojo representa las mayores amplitudes. La línea de puntos blancos representa los valores de la velocidad de grupo inferida de los contornos. El gráfico de la derecha corresponde a la señal filtrada. 


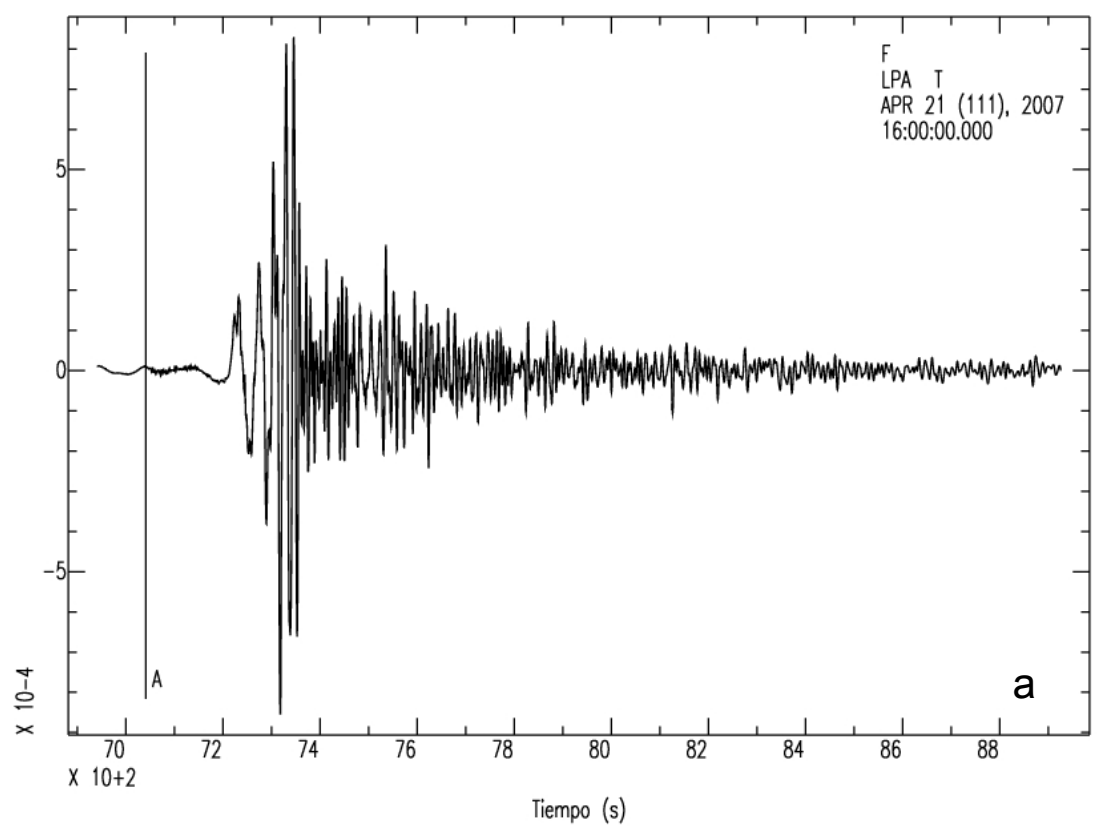

Figura 2.9: a) Registro transversal de un sismo andino $\left(\phi:-45^{\circ} .24, \lambda:-72^{\circ} .67\right)$ ocurrido a $4992 \mathrm{~km}$ de la estación LPA. A indica la hora de arribo de la onda $\mathrm{P}$ relativa al tiempo de la primera muestra del registro.

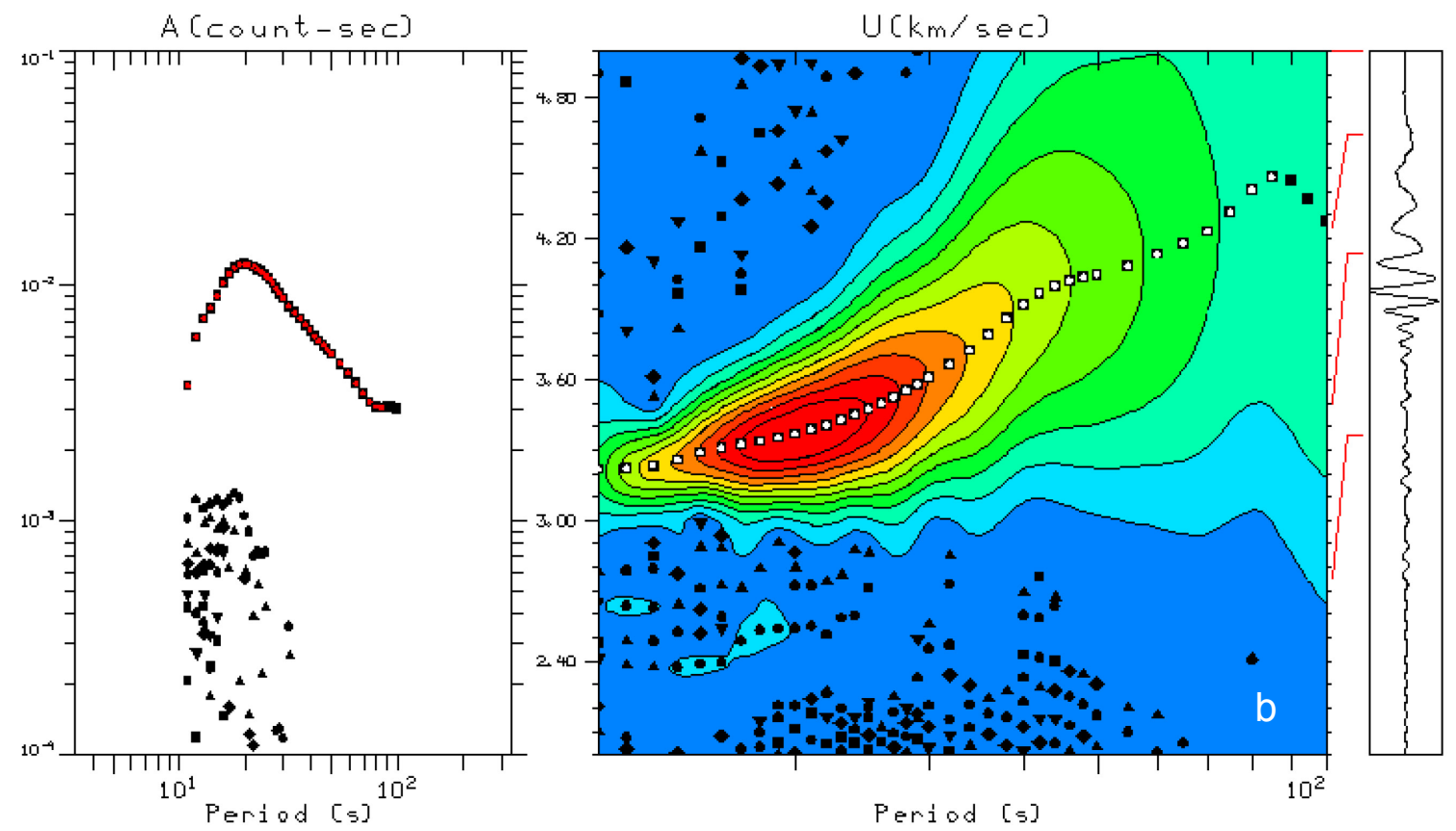

Figura 2.9: b) Gráfico de la velocidad de grupo de la onda Love en función del período. El gráfico de la izquierda muestra los valores de amplitud A (cuentas/s) de la envolvente en función del período (s). Los puntos rojos representan las mayores amplitudes. El gráfico central muestra los valores de la envolvente filtrada en función de la velocidad y el período en distintos colores. El color rojo representa las mayores amplitudes. La línea de puntos blancos representa los valores de la velocidad de grupo inferida de los contornos. El gráfico de la derecha corresponde a la señal filtrada. 


\subsection{Datos}

\subsubsection{Sismos}

\subsubsection{Selección de eventos sísmicos}

Se realizó la búsqueda de sismos superficiales localizados principalmente en y alrededor de Sudamérica, de magnitudes mayores que 6 con profundidades hasta los $100 \mathrm{~km}$ y de magnitudes entre 4.5 y 6 con profundidades hasta los $60 \mathrm{~km}$ en los catálogos internacionales de NEIC-USGS (National Earthquake Information Center, U.S. Geological Survey) y de IRIS (Incorporated Research Institutions for Seismology).

Se seleccionaron 2070 eventos sísmicos desde el año 2006 hasta el año 2012 para la estación LPA con trayectorias sísmicas menores que $7000 \mathrm{~km}$ de distancia (Fig. 2.10). La estación sismológica LPA se encuentra en la localidad de La Plata, a $11 \mathrm{~km}$ de la costa, en el noreste de la provincia de Buenos Aires. Esta

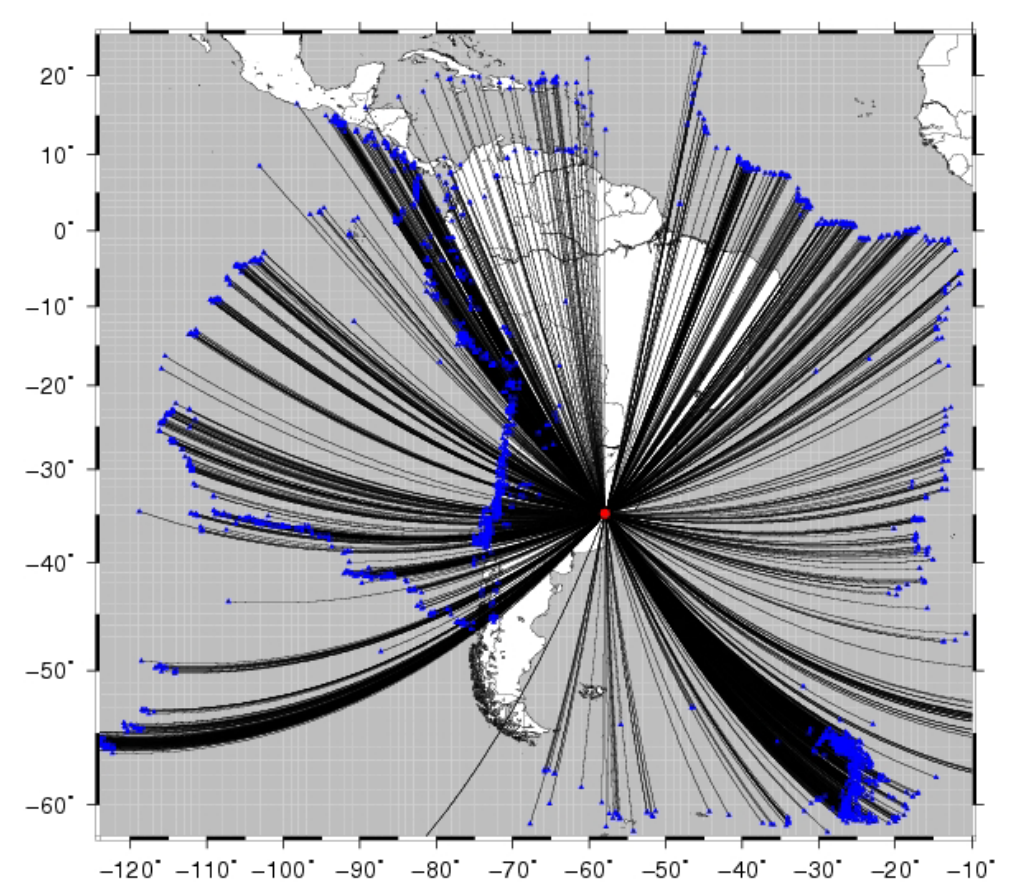

Figura 2.10: Sismos (puntos azules) registrados en la estación LPA (círculo rojo) en el período 2006-2012 con trayectorias (líneas negras) hasta 7000 km de distancia. 
localidad está emplazada en el cratón del Río de La Plata, próxima al borde norte de la cuenca del Salado (Cavallotto, 2002), en el extremo oriental de la denominada Pampa Ondulada, en la terraza alta pampeana comprendida entre las cotas de 15.75 y 18.35 m s.n.m (Bartel et al., 2005). La estación LPA pertenece a la Universidad Nacional de La Plata y está equipada con un sensor Guralp CMG 3ESPC con una banda de paso entre $60 \mathrm{seg}$ y $50 \mathrm{~Hz}$, que está funcionando de forma continua desde octubre de 2006.

También se seleccionaron 2940 eventos sísmicos con trayectorias de iguales características para la estación TRQA desde el año 2004 hasta el año 2012 (Fig. 2.11). La estación sismológica internacional TRQA se encuentra en la localidad de Tornquist, a unos $100 \mathrm{~km}$ de la costa, en el sudoeste de la provincia de Buenos Aires. Esta localidad está emplazada en las Sierras Australes de Buenos Aires o Sierras de la Ventana que conforman el afloramiento más importante de una extensa cuenca paleozoica desarrollada en el margen de Gondwana, dentro de la placa Sudamericana.

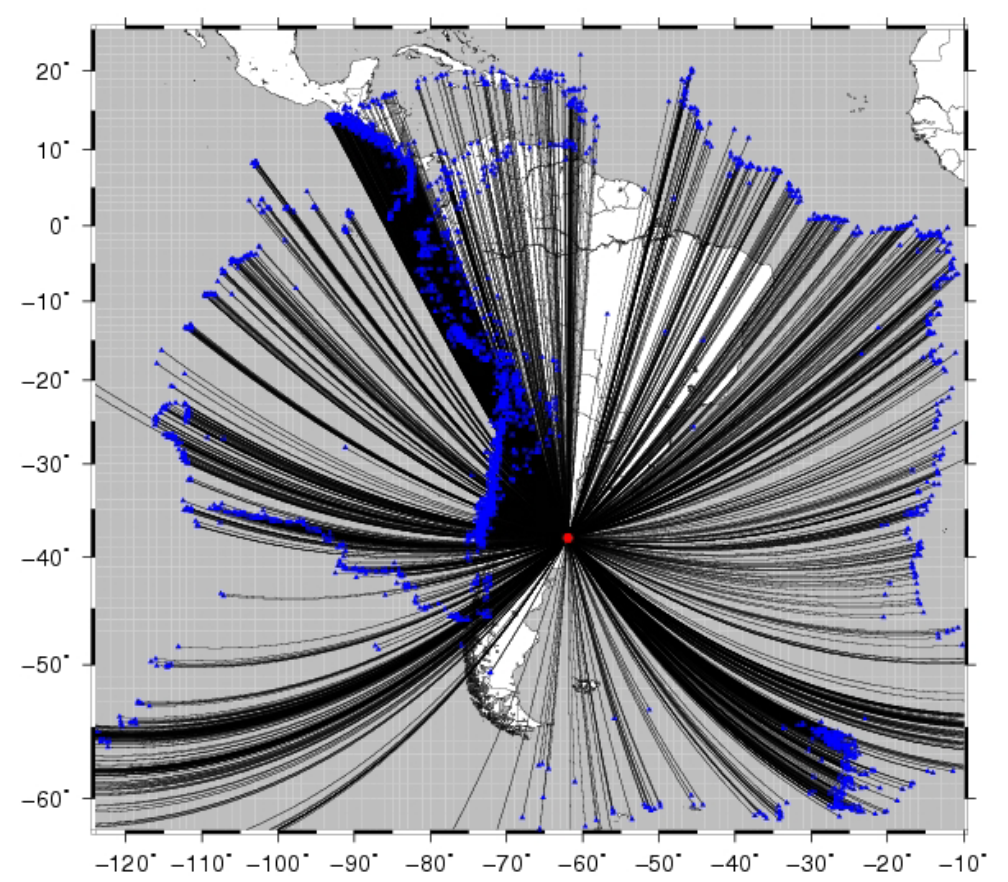

Figura 2.11: Sismos (puntos azules) registrados en la estación TRQA (círculo rojo) en el período 2004 - 2012 con trayectorias (líneas negras) hasta 7000 km de distancia. 
La estación TRQA funciona desde fines del 2000 y forma parte de la red IRIS/USGS-GSN (Global Seismographic Network). Está equipada con dos sensores de pozo banda ancha, un sensor Geotech KS54000 y un sensor Guralp CMG3T. Se solicitaron los datos registrados con el primer sensor.

\subsubsection{Procesamiento inicial}

Se adaptaron los programas de análisis existentes al formato de los datos y se elaboraron programas en Linux necesarios para poder leer y procesar los distintos formatos de los datos sismológicos. A partir de los sismos seleccionados para las estaciones LPA y TRQA, utilizando el programa de cálculo SAC (Seismic Analysis Code, Tapley and Tull, 2000) se decimaron los registros banda ancha de tres componentes (vertical y dos horizontales) a una menor cantidad de muestras; se completó la información en los encabezamientos (headers) de cada traza, se corrigieron los datos por valor medio e inclinación lineal para eliminar efectos de registración, se removió la respuesta de instrumento y se rotaron las componentes horizontales, a componentes radial y transversal. Mediante el programa TauP (Crotwell et al., 1999) se calcularon los tiempos de arribo de la fase P para cada evento sísmico.

La estimación de la dispersión de las ondas superficiales requiere asumir suposiciones importantes, por lo tanto se deben evaluar fuentes potenciales de incerteza para asegurar resultados significativos durante el proceso de inversión de la velocidad de corte. El ruido, la dispersión o el scattering y los errores en la hora de comienzo de los sismos pueden disminuir la precisión de la profundidad y la velocidad de corte halladas durante la inversión (Der et al, 1970). Para asegurarse una relación señal/ruido razonable, se controló la calidad de los datos de los sismos, filtrando las trazas con un filtro Butterworth $0.01 \mathrm{a} 0.1 \mathrm{~Hz}$ que enfatiza los períodos en los que la energía de las ondas superficiales está presente permitiendo así elegir los mejores sismos posibles a ser utilizados y en el caso en que el ruido fue un factor significativo en alguna serie de tiempos, la misma fue rechazada con el fin de utilizar sólo registros confiables. La aplicación del filtro fue transitoria, ya que para el análisis de dispersión se usaron las trazas sin filtrar. 


\subsubsection{Curvas de dispersión}

Para el análisis de la dispersión de velocidad de grupo de las ondas Rayleigh y Love se seleccionaron las componentes vertical y transversal de los registros y se utilizó un procesamiento de Herrmann (2013). Los criterios para la selección del intervalo de períodos en la curva de dispersión incluyeron: tratar de mantener la mayor cantidad de períodos posibles, pero sólo aquellos con una intensidad o energía de señal adecuada y elegir períodos que se encuentren en la parte más suave de la curva de amplitud espectral. El ancho del filtro pasa-banda gaussiano se seleccionó en función de la distancia epicentral siguiendo el criterio recomendado por Herrmann (2013) (Tabla 2.1). Este criterio se basa en Levshin et al. (1972), que recomienda, a partir de pruebas realizadas en distintos datos, utilizar valores del ancho del filtro gaussiano variables con la distancia.

\begin{tabular}{c|c}
$\begin{array}{c}\text { Ancho del filtro } \\
\alpha\end{array}$ & $\begin{array}{c}\text { Distancia } \\
\text { epicentral }(\mathrm{km})\end{array}$ \\
\hline 25 & 1000 \\
\hline 50 & 2000 \\
\hline 100 & 4000 \\
\hline 200 & 8000
\end{tabular}

Tabla 2.1: Ancho de filtro gaussiano en función de la distancia epicentral sugerido por Herrmann (2013).

Para el período de tiempo analizado, de aproximadamente 2070 sismos registrados por la estación LPA se obtuvieron cerca de 1000 curvas de dispersión de óptima calidad para ondas Rayleigh y 370 para ondas Love. El número de curvas para la onda Love es menor que la mitad de las correspondientes a la onda Rayleigh debido a la baja relación señal/ruido que presenta la estación LPA en las componentes horizontales de los registros. Sin embargo esta estación es de suma importancia para mejorar la cobertura de las trayectorias sísmicas en la región 
centro sur del continente. Para la estación TRQA, los 2940 sismos registrados permitieron generar 1990 curvas para ondas Rayleigh y 1670 para ondas Love.

Además se obtuvieron 314 curvas de dispersión para la onda Rayleigh de 163 sismos andinos registrados entre 2009 y 2011 en 18 estaciones del sur de Brasil, pertenecientes a la red BRASIS (BRAzilian Seismographic Integrated Systems).

El período máximo recuperable de cada curva de dispersión es diferente y depende de la magnitud del evento y de la distancia epicentral, como ya se ha mencionado. Para terremotos de gran magnitud por lo general las ondas de períodos mayores se registran mejor a distancias mayores. Pero para terremotos de magnitud moderada o con distancia epicentral menor, el período máximo recuperable es menor. En nuestro caso, el intervalo promedio de períodos recuperables para todas las trayectorias fue de 10 a 150 s para la onda Rayleigh y de 10 a 100 s para la onda Love.

Asimismo se incorporaron a los datos anteriores, con el fin de mejorar la cobertura de las trayectorias en la región norte y centro de Sudamérica, datos de dispersión de ondas Rayleigh y Love para sismos principalmente de la región andina, registrados entre 1990 y 2004 en estaciones internacionales permanentes GSN (Global Seismographic Network) y GEOSCOPE (French Global Network of Broad Band Seismic Stations), situadas en Sudamérica e islas circundantes y estaciones temporarias desplegadas en el sur de Brasil pertenecientes a los proyectos BLSP92 (James et al., 1993), BLSP95 (Assumpção et al., 2002) y BLSP02 (Feng et al., 2004) en operación entre 1992 y 2004, calculados por Feng et al. (2004; 2007) del Institute of Geomechanics, Chinese Academy of Geological Sciences, China, en estudios tomográficos previos y datos de dispersión de ondas Rayleigh y Love para sismos en y alrededor de Sudamérica registrados entre 2007 y 2013 en 22 estaciones ubicadas en el noreste de Brasil, obtenidos por Luz et al. (2014; 2015) de la Universidade Federal do Rio Grande do Norte, Brasil.

Como la mayoría de las trayectorias correspondientes a sismos andinos registrados en estaciones de Brasil son aproximadamente paralelas impidiendo una buena resolución espacial en la inversión tomográfica, se incluyeron curvas de dispersión inter-estación a partir de la correlación de ruido ambiental obtenidas por 
Collaço (2014) y Collaço et al. (2014¹) de la Universidade de São Paulo, Brasil en estudios previos. Este trabajo de colaboración se enmarca en el proyecto "Seismic Tomography in the Chaco and Paraná Basins".

\subsubsection{Ruido ambiental}

\subsubsection{Introducción}

El método conocido como tomografía de ruido ambiental ANT (Ambient Noise Tomography) es una técnica para estimar la velocidad de las ondas superficiales de períodos cortos (<20 s) y de períodos intermedios (20-50 s) a partir de la correlación del ruido ambiental (perturbaciones oceánicas y atmosféricas aleatorias debidas a la dispersión causada por las heterogeneidades de la Tierra sólida) entre pares de estaciones, y se utiliza tanto a escala regional como continental con el fin de mapear la estructura sísmica de la Tierra. Las curvas de dispersión inter-estación de ruido ambiental pueden ser combinadas con las curvas de dispersión pertenecientes a sismos ya que se aplica un procedimiento similar para su obtención, generando mapas tomográficos que presentan una analogía con las estructuras geológicas conocidas a partir de otros estudios geofísicos.

El concepto básico del método se basa en que la correlación cruzada de un campo de ondas aleatorias calculada entre pares de estaciones sismológicas resulta en una forma de onda que difiere apenas por un factor de amplitud de la función empírica de Green entre estas estaciones (Lobkis and Weaver, 2001; Wapenaar, 2004) siendo la función de Green la señal que arribaría a un receptor si la forma de onda de la fuente fuera una función delta o un impulso puntual, ubicado en el otro receptor. O sea que las funciones de Green inter-estación pueden ser extraídas de la correlación cruzada de registros largos y continuos de ruido sísmico ambiental (Shapiro and Campillo, 2004; Lin et al., 2008). Esto es particularmente útil, porque la forma y tiempo de viaje de la onda son función exclusiva de las propiedades del medio. La longitud de tiempo necesario para obtener funciones de Green fiables depende del periodo de la onda. En el análisis realizado por Collaço

\footnotetext{
${ }^{1}$ Se colaboró en el pre-proceso de los datos de ruido ambiental correspondientes a la estación LPA y se aportaron los datos de las curvas de dispersión de todos los eventos sísmicos analizados.
} 
et al. (2014) se utilizaron aproximadamente 30 meses de registro continuo, que proporcionan estimaciones robustas de las funciones de Green para las ondas Love y Rayleigh en la banda de períodos de 5 a $60 \mathrm{~s}$.

Esta metodología aplicada inicialmente por Shapiro et al. (2005) se emplea principalmente en regiones donde existe una gran densidad de estaciones sismológicas, permitiendo superar algunas limitaciones de los métodos convencionales basados en terremotos, como por ejemplo la distribución desigual de eventos y la incerteza en la localización de los epicentros. El proyecto BRASIS (Pirchiner et al., 2011) implementado recientemente, convierte a Brasil y en particular a la región de la cuenca Chaco-Paraná, en una región extremadamente favorable para el empleo de esta técnica por ser una zona de baja sismicidad (Moschetti et al., 2007).

\subsubsection{Correlación cruzada de ruido ambiental}

Para calcular las funciones de Green por correlación cruzada se sigue la metodología descrita en detalle por Bensen et al. (2007) que se resume brevemente a continuación.

Primero se separan los datos continuos en segmentos de un día, se eliminan la media y la tendencia y se remueve la respuesta del instrumento ya que las estaciones están equipadas con distintos tipos de sensores, obteniéndose registros de velocidad. Luego se deciman todos los datos a igual número muestras. En este caso se decimó a 2 muestras por segundo para facilitar su manejo, siendo este muestreo conveniente para analizar la dispersión. Se filtran con un filtro pasabanda con una banda de paso de $0.01 \mathrm{a} 0.33 \mathrm{~Hz}$. Se aplica un procedimiento de normalización de la señal en el dominio del tiempo llamado normalización temporal para eliminar terremotos y otras señales de gran amplitud.

Como el espectro de amplitud de la señal correspondiente al ruido ambiental no es plano en el dominio de la frecuencia, presentando picos correspondientes a $15 \mathrm{~s}$ (conocido como microsismo primario) y a $7.5 \mathrm{~s}$ (conocido como microsismo secundario) y aumentando a partir de $50 \mathrm{~s}$ para formar una señal conocida como Earth's Hum, se aplica una normalización espectral o blanqueamiento en el 
dominio de la frecuencia para aplanar el espectro de amplitud del ruido ambiental en la banda de períodos de interés.

Después de estas correcciones, se lleva a cabo la correlación cruzada entre todos los pares de estaciones. Las correlaciones cruzadas se obtienen en el dominio de la frecuencia y se suman (apilan) en el dominio del tiempo con otras del mismo par de estaciones, para mejorar la relación señal/ruido de la función de Green resultante (Wapenaar, 2004).

Las correlaciones cruzadas resultantes presentan una función temporal de dos lados, una con coordenadas de tiempo positivas llamada comúnmente señal causal y otra con coordenadas de tiempo negativas o señal acausal. Estas formas de onda juntas representan ondas viajando en direcciones opuestas entre las estaciones. Finalmente ambas señales, causal y acausal, se promedian y se unen en un único sismograma para realizar el análisis de dispersión. El sismograma resultante es una función de Green estimada y se lo denomina sismograma simétrico o correlación cruzada simétrica (Fig. 2.12).

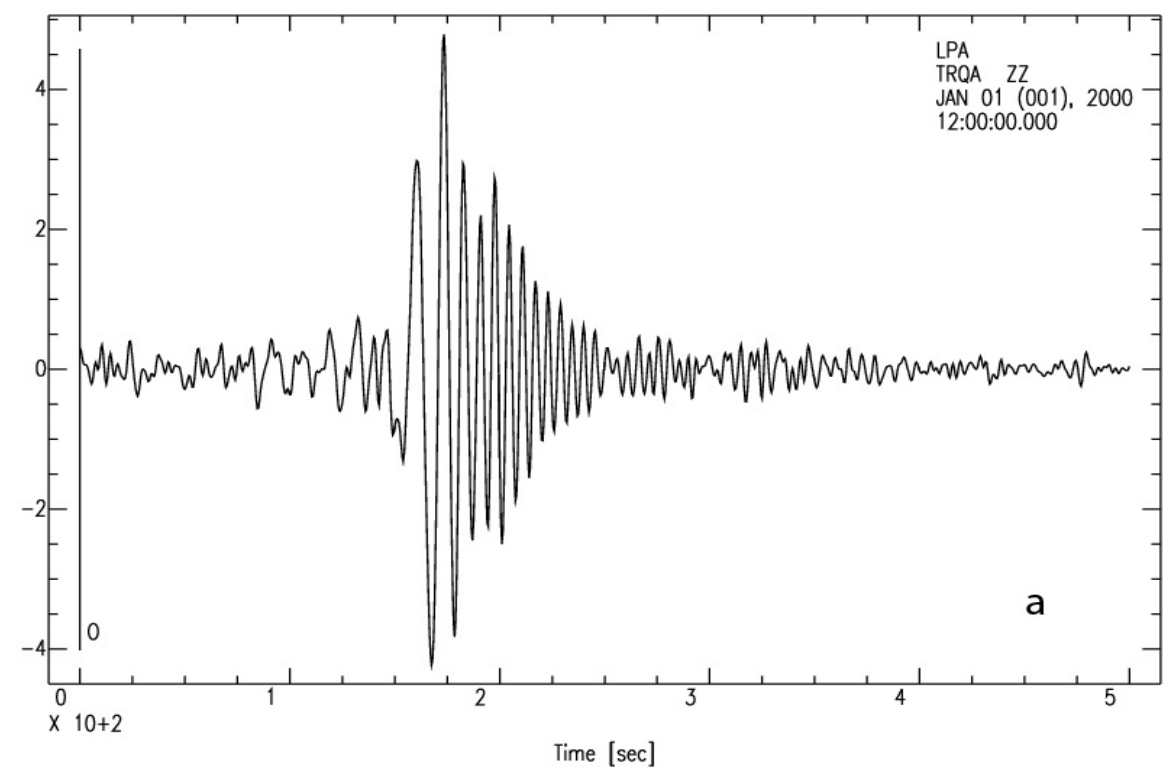

Figura 2.12: Ejemplo de la componente vertical de un sismograma simétrico, obtenido por correlación cruzada entre las estaciones LPA y TRQA. 


\subsubsection{Curvas de dispersión de ruido ambiental}

Para el cálculo de las curvas de dispersión inter-estación de ruido ambiental Collaço et al. (2014) procesaron sismogramas continuos de tres componentes de 57 estaciones de la red BRASIS (USP), de la red INPRES perteneciente al Instituto Nacional de Prevención Sísmica (San Juan, Argentina), la estación LPA y las estaciones CPUP (Villa Florida, Paraguay) y TRQA pertenecientes a la red internacional GSN. Todas las estaciones son de banda ancha y están situadas en América del Sur (Fig. 2.13), 41 de las cuales están en Brasil. Una vez obtenidas las funciones de Green por correlación cruzada para ambas ondas (1596 para Rayleigh y 1081 para Love) se calcularon las velocidades de grupo en función del período utilizando la técnica de filtrado múltiple (MFT), aplicando el software PGSWFMA (Surface Wave PGplot Multiple Filter Analysis) implementado en Pasyanos et al. (2001).

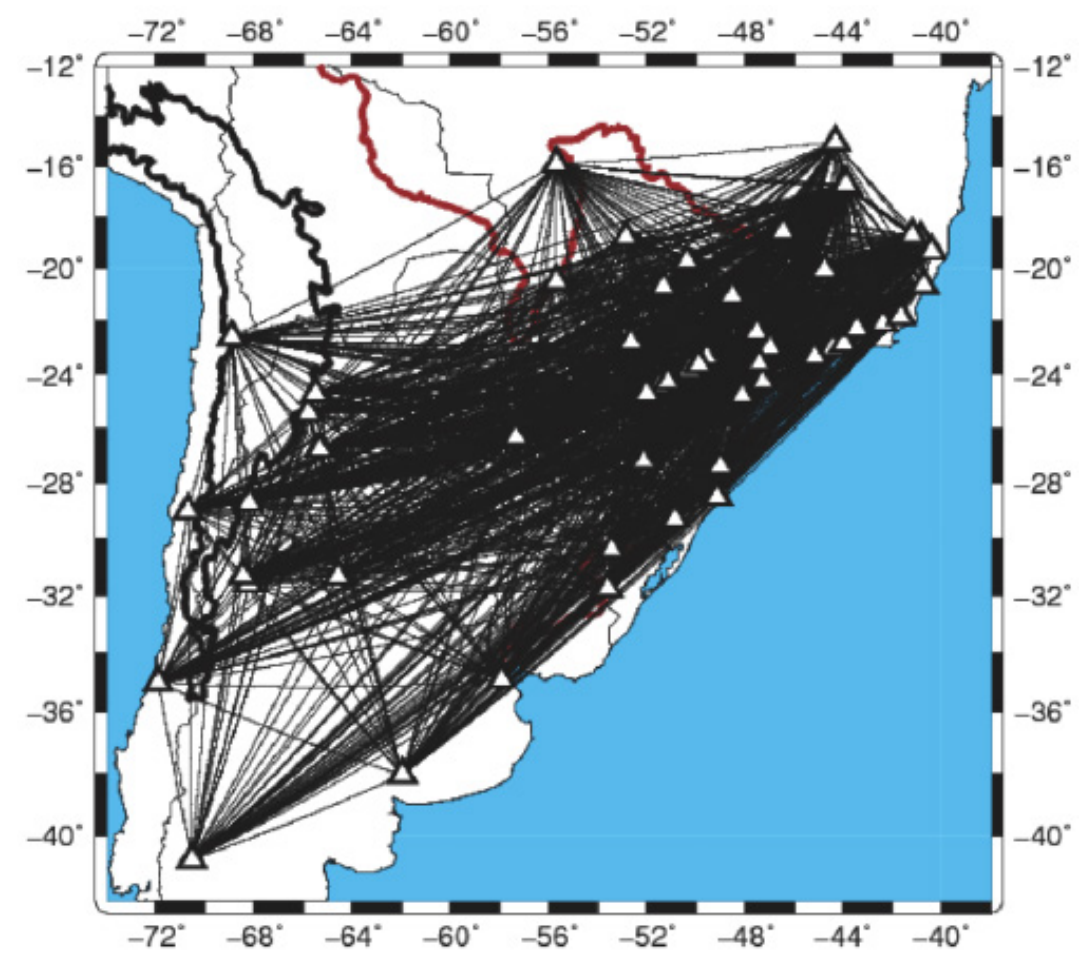

Figura 2.13: Trayectorias correspondientes a mediciones de dispersión obtenidas por correlación cruzada de ruido ambiental (extraído de Collaço et al., 2014) utilizadas en este trabajo. 
Previamente se realizó un control de calidad para garantizar que las curvas de dispersión son confiables, quedando 970 curvas de Rayleigh y 971 curvas de Love. La distancia entre pares de estaciones, los errores instrumentales y las imperfecciones en las trayectorias de las ondas, pueden dar lugar a curvas de dispersión muy irregulares. Sólo se utilizaron valores de velocidad de grupo obtenidos de curvas de dispersión continuas para eliminar esos errores potenciales. De todas las curvas analizadas se aprovecharon 865 curvas de Rayleigh y 718 de Love, de las cuales se muestran dos ejemplos en las Figs. 2.14 y 2.15. El gráfico de la izquierda muestra la curva de dispersión analizada con los contornos del espectro de velocidad y las incertezas asociadas. El gráfico central muestra el sismograma simétrico y el gráfico de la derecha, el espectro de amplitud en función del período.

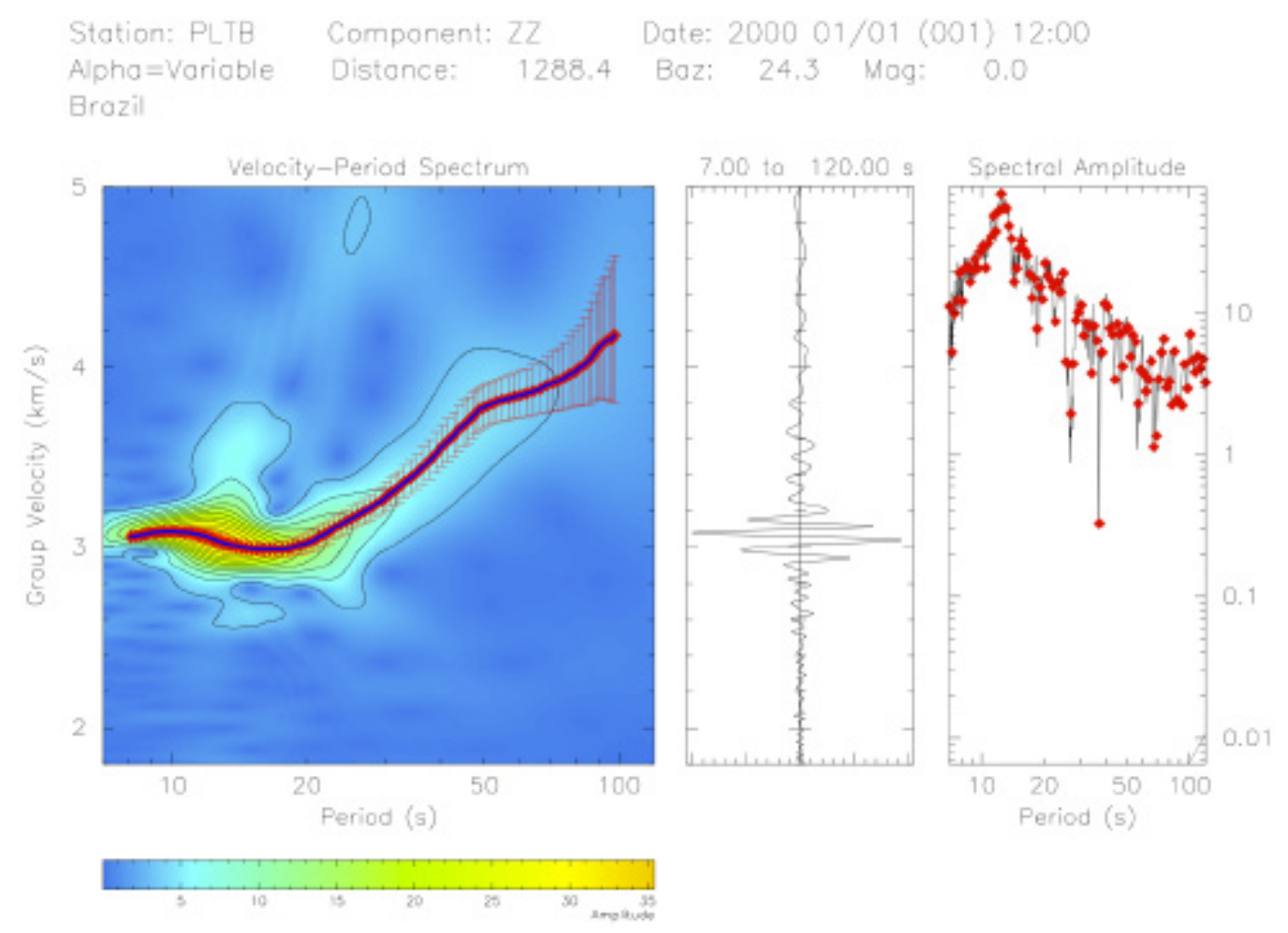

Figura 2.14: Curva de dispersión de la onda Rayleigh obtenida mediante PGSWMFA usando 2 años de datos de correlación entre las estaciones BB19B-PLTB en Brasil (izquierda). Onda Rayleigh (centro) y amplitud espectral en función del período (derecha), extraído de Collaço (2014). 


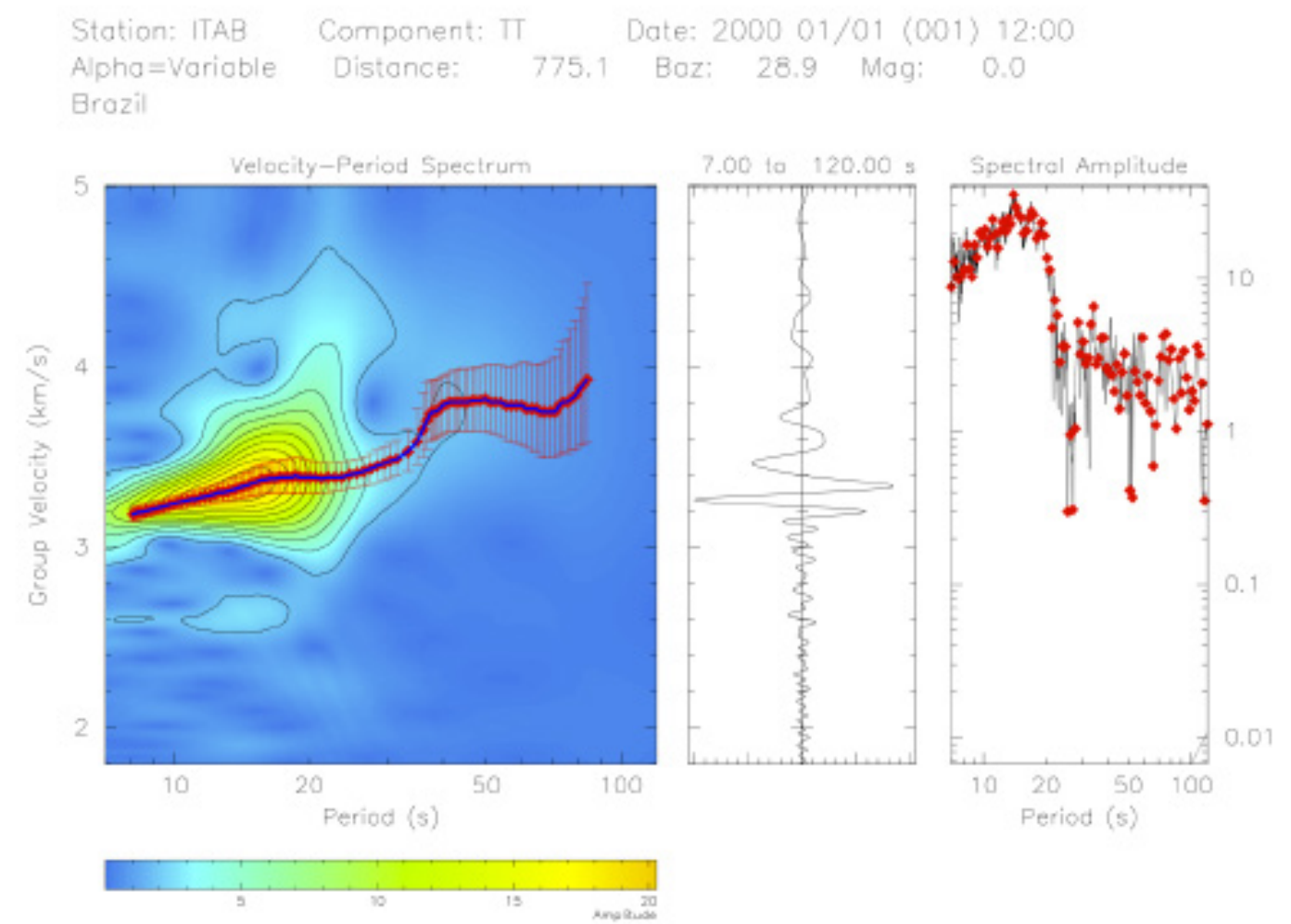

Figura 2.15: Curva de dispersión de la onda Love obtenida mediante PGSWMFA usando 2 años de datos de correlación entre las estaciones BB19B-ITAB en Brasil, extraído de Collaço (2014).

\subsection{Tomografía de ondas superficiales}

\subsubsection{Introducción}

La tomografía sísmica es una técnica que permite reconstruir la estructura del interior terrestre a partir de la información promedio medida en recorridos largos y por lo general requiere de la solución de un problema inverso para obtener un modelo sísmico heterogéneo que sea consistente con las observaciones. La tomografía de ondas superficiales se basa en las curvas de dispersión de la velocidad de las ondas superficiales para un amplio rango de periodos.

Una manera de realizar la tomografía de ondas superficiales es dividir el procesamiento en dos etapas. En la primera etapa, se usan datos para un periodo $\mathrm{T}$ fijo y se resuelve la tomografía para determinar la distribución 2D de las características de las ondas superficiales (velocidad de grupo o fase). En la siguiente etapa, una vez resuelto el problema para distintos periodos, se pueden obtener perfiles o secciones verticales de la velocidad en función de la profundidad 
para la corteza y el manto superior, en cada punto de una región a partir de las curvas de dispersión locales, resolviendo el problema inverso 1D. En otras palabras, el método inicial 3D se divide en dos etapas: método de tomografía 2D para la determinación de las variaciones laterales de la velocidad de las ondas superficiales, conocido como procedimiento de regionalización y método de inversión 1D para las curvas de dispersión. La regionalización que genera los mapas tomográficos es un resultado en sí mismo ya que permite extraer conclusiones acerca de las variaciones laterales de la estructura litosférica y resolver heterogeneidades de distinta dimensión a partir del análisis de los resultados para los distintos períodos considerados.

Los mapas tomográficos son un modelo sísmico que resumen grandes volúmenes de datos de una manera compacta. Aunque contienen sólo parte de la información de la estructura de la Tierra presente en los sismogramas, son producto también de la inversión y contienen incertezas debido a errores teóricos y observacionales.

Los datos iniciales utilizados para la regionalización son las curvas de dispersión de velocidad de las ondas superficiales obtenidas de observaciones a lo largo de trayectorias por diferentes estructuras tectónicas, de tal manera que los datos representan velocidades promedio sobre las trayectorias. Si se considera la variación lateral de velocidad suficientemente pequeña como ocurre para las ondas superficiales, las trayectorias pueden ser consideradas como líneas rectas (Rawlinson et al., 2010). Por consiguiente para estimar los valores locales de las velocidades se pueden utilizar las velocidades promedio a lo largo de las diferentes trayectorias que atraviesan la región analizada.

En la tomografía sísmica se ajustan los parámetros del modelo (velocidad en cada celda de la región) de manera de satisfacer las observaciones de tiempo de viaje de la onda sísmica, sujeto a cualquier restricción independiente (comúnmente conocida como regularización). Las principales dificultades que se plantean son el problema de la no linealidad (teniendo en cuenta que la trayectoria de la energía sísmica es función de la velocidad sísmica) y el problema de la no unicidad en la solución. Los estudios a escala cortical o litosférica son más propensos a presentar estas dificultades debido a la presencia de heterogeneidades verticales y laterales que se desvían significativamente de los modelos de referencia estándar de la 
Tierra, que son modelos globales. Por lo tanto, el "modelo de solución" será aquel que logre un equilibrio entre el ajuste de los datos en el tiempo de propagación (según criterios tales como el ajuste por residuo o error medio cuadrático) y la influencia de regularización (e.g., suavidad, desviación del modelo inicial), sin satisfacer estrictamente los datos (Rawlinson et al., 2010).

Los métodos de inversión más comunes son los métodos iterativos basados en gradientes que utilizan la derivada del modelo de predicción para generar una solución. Cuando el número de ecuaciones a resolver es muy grande, las técnicas iterativas como el método de gradiente conjugado (o sus variantes como el LSQR) resultan muy efectivas ya que poseen propiedades numéricas más favorables (Paige and Saunders, 1982a).

Una desventaja en la aplicación de los métodos iterativos es que es imposible calcular matrices de resolución y de covarianza para los modelos. Por ello, a menudo se realizan pruebas sobre datos sintéticos para analizar la robustez de la solución. Estos datos se generan asumiendo un modelo particular de las perturbaciones de velocidad y calculando las anomalías de tiempo de viaje, utilizando las mismas trayectorias que los datos reales. Estos datos sintéticos son invertidos para ver qué tan bien se recupera el modelo de prueba. Un método que se aplica a menudo es el llamado checkerboard test (test del tablero de damas), en el cual se examina un modelo que presenta un patrón regular de alternancia de anomalías de velocidad sísmicas lentas y rápidas con respecto a un valor determinado de velocidad. En este caso el grado de alternancia o manchas del patrón del tablero de ajedrez variará con la posición en el modelo, indicando la resolución relativa sobre las diferentes áreas que se consideren para la inversión.

\subsubsection{Mapas tomográficos}

Para obtener los mapas tomográficos 2D correspondientes a las variaciones laterales de la velocidad de grupo, a partir de las curvas de dispersión, se aplicaron dos procedimientos de inversión. Ambos procedimientos tratan de minimizar la diferencia entre el tiempo de viaje de las ondas superficiales observado y el predicho por el modelo a lo largo de las trayectorias, utilizando el método de gradiente conjugado el cual se aplica comúnmente en tomografía (e.g., Van der 
Lee and Nolet, 1997; Feng et al., 2004; 2007) y converge con bastante rapidez a soluciones cercanas a las reales. Pero la diferencia más importante entre ellos es el criterio de suavización que aplican, uno utiliza la derivada primera y el otro utiliza la derivada segunda.

Estos procedimientos se basan en la "teoría de rayo geométrico" o aproximación de rayos viajando por círculos máximos que supone que las ondas superficiales se propagan desde el epicentro a la estación sismológica a lo largo de un círculo máximo (sin refracción lateral) y sólo las estructuras debajo de la trayectoria de círculo máximo afectan el tiempo de viaje de la onda. Para evitar los efectos de las trayectorias refractadas fuera del círculo máximo, la mayoría de las trayectorias fueron elegidas dentro del área continental.

Para resolver el problema de la parametrización de los datos, o sea el problema de encontrar el camino desde la fuente a la estación se utilizaron en ambos casos, métodos basados en grillas, que son simples y fáciles de formular y resultan apropiados para recobrar estructuras de detalle (Rawlinson et al, 2010). Estos métodos son de utilidad cuando se supone una sola trayectoria de rayo (generalmente la primera) conectando ambos sitios (fuente-estación) y se considera que en cada celda de la grilla los segmentos de trayectoria son líneas rectas.

\subsubsection{Método de inversión (suavizado con $1^{\mathrm{er}}$ derivada)}

Primeramente se aplicó un método que utiliza la primer derivada espacial para la suavización, como el implementado por Feng et al. (2004). Para construir los mapas de velocidad de grupo, la región analizada fue dividida en una grilla con celdas de tamaño uniforme de $1^{\circ} \times 1^{\circ}$ con lentitud (inversa de la velocidad de grupo) constante en cada celda y se buscó el modelo de lentitud consistente con los tiempos de viaje observados, minimizando la función:

$$
\varphi=\|A s-t\|^{2}+\lambda\|\nabla s\|^{2}
$$


donde A es la matriz de longitud del segmento de trayectoria en cada celda, s es el vector lentitud y $\mathrm{t}$ es el vector tiempo de viaje observado. $\nabla \mathrm{s}$ representa la primer derivada espacial del modelo, utilizada para suavizar los mapas de velocidad de grupo y $\lambda$ es un factor de peso que controla el ajuste entre los tiempos de viaje y el suavizado del modelo. Si el grado de suavización es demasiado pequeño, la inversión ajusta por demás los datos y los mapas pueden presentar varios "artefactos" (artifacts) debido cambios bruscos en los valores de velocidad. Si es demasiado grande, el ajuste de los datos es pobre y sólo se pueden resolver las características de grandes longitudes de onda (baja resolución).

Se minimizó la ecuación (2.6) con el código de procesamiento Group Velocity Tomography Package desarrollado por Feng and An (2010) que utiliza el método de gradiente conjugado LSQR de Paige and Saunders (1982a, b).

\subsubsection{Método de inversión (suavizado con $2^{\text {da }}$ derivada)}

Este procedimiento utiliza la segunda derivada espacial para la suavización (Pasyanos et al., 2001 y Pasyanos, 2005). El área de estudio fue dividida según una grilla teselada con un espaciado de $1^{\circ}$ entre puntos y se utilizó la siguiente función para ajustar los tiempos de viaje:

$$
\varphi^{\prime}=\|A s-t\|^{2}+\lambda^{\prime}\|\Delta s\|^{2}
$$

donde $t$ es el vector de tiempos de viaje (distancia/velocidad de grupo) y A es la matriz de distancias recorridas en cada celda que relaciona el vector lentitud $\mathrm{s}$ con los tiempos de viaje. La restricción en suavización para la solución que se impone requiere que el Laplaciano de la lentitud $(\Delta s)$ sea cero. El factor de peso $\lambda^{\prime}$ controla el ajuste entre los tiempos de viaje y el suavizado del modelo. Al igual que en otros métodos de gradiente conjugado la convergencia se alcanza teóricamente cuando el número de iteraciones alcance al número de ecuaciones de restricción (Pasyanos, 2005). En la práctica, la convergencia depende de los residuos y de las distancias entre sucesivas iteraciones y para este conjunto de datos se alcanzó un resultado aceptable después de 30 iteraciones en promedio, para cada inversión. 
Para aplicar este método se utilizó un algoritmo de procesamiento desarrollado e implementado por Pasyanos et al. (2001).

\subsubsection{Resultados y discusión}

Se construyeron mapas de velocidad de grupo para períodos entre 10 y 150 s para onda Rayleigh y entre 10 y 100 s para onda Love, utilizando los métodos descriptos anteriormente (secciones 2.6.2.1 y 2.6.2.2).

Los tiempos de viaje observados generalmente muestran alguna diferencia en comparación con los tiempos predichos incluso por el mejor modelo de referencia 1D de la Tierra. Los residuos se obtienen de la diferencia entre el tiempo observado y el tiempo calculado para un modelo y se grafican en un histograma para mostrar su propagación. Los residuos negativos que resultan de arribos tempranos son indicativos de estructuras con velocidad mayor que la promedio mientras que los residuos positivos son arribos tardíos que sugieren estructuras lentas. Para una evaluación más cualitativa, primero se realizó una inversión tomográfica preliminar para ambas ondas y se calcularon los desajustes de los tiempos de viaje para distintos períodos con el fin de identificar y descartar las mediciones de velocidad de grupo con residuos muy grandes (y que posiblemente sean errores de medida). En la Fig. 2.16 se observan los resultados obtenidos para períodos bajos (20 s, $30 \mathrm{~s})$, medios (70 s) y altos (90 s).

Teniendo en cuenta que la dispersión en el histograma residual puede ser ocasionada por errores de picado de fases, las diferencias del tiempo de viaje sistemático debido a simplificaciones supuestas de la teoría de rayo y errores en la base de datos o a una mala relación señal/ruido, se analizó la variación de los residuos en función de la distancia epicentral para distintos períodos para ambas ondas (Fig. 2.17 y 2.18 ).

Analizados los resultados de las Figs. 2.16, 2.17 y 2.18, se descartaron las mediciones de velocidad de grupo con residuos de tiempo de viaje mayores que 50 s. El número de trayectorias resultantes para ambas ondas en función del período se muestra en la Fig. 2.19. Se observan un número menor de trayectorias para períodos cortos (<15 s) y períodos largos (>90 s), pero se cuenta con un número 
grande de trayectorias para períodos intermedios como por ejemplo $30 \mathrm{~s}$ de período, con 10423 trayectorias para la onda Rayleigh y 5945 trayectorias para la onda Love.
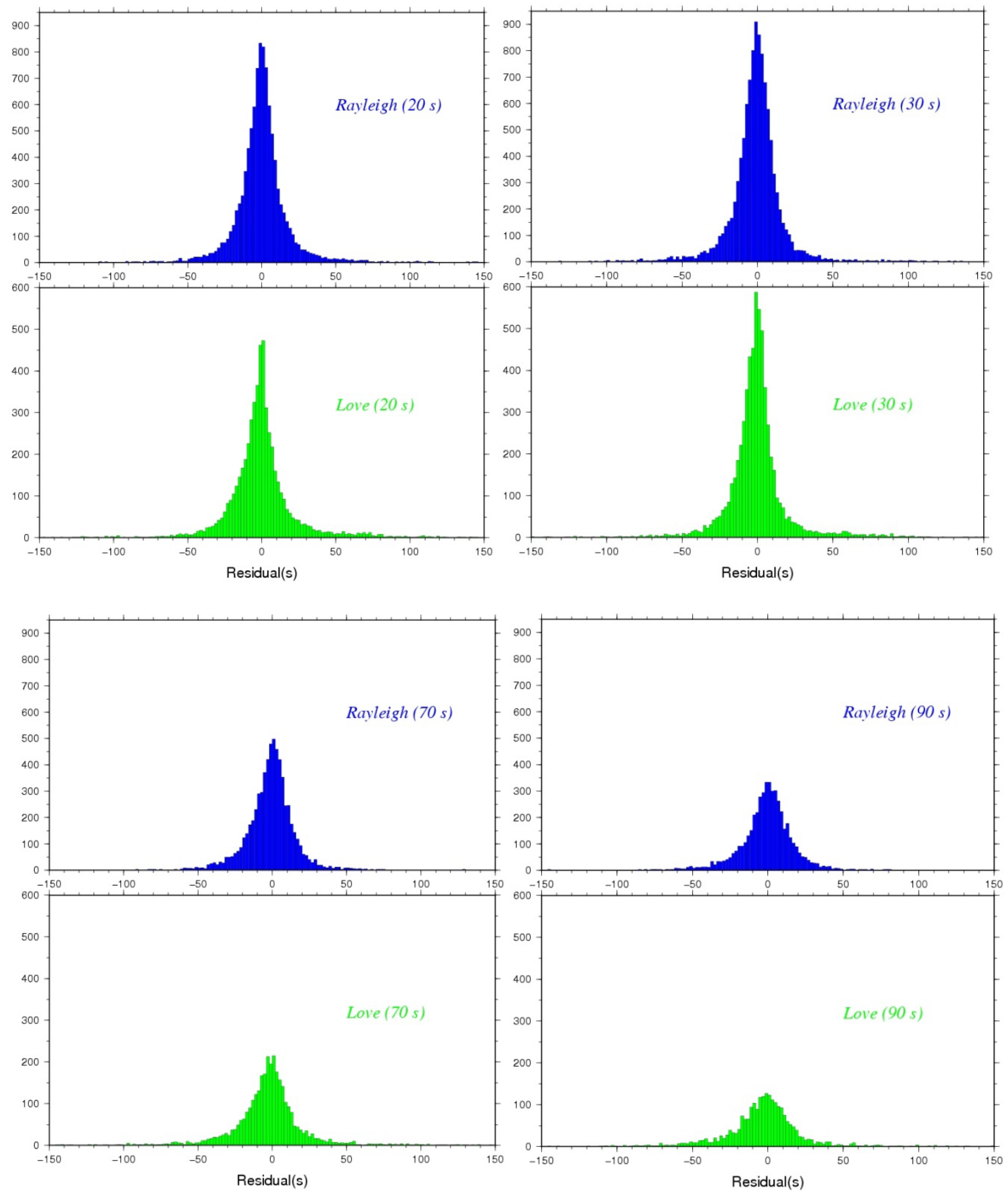

Figura 2.16: Residuos de los tiempos de viaje para 20, 30, 70 y 90 s para la onda Rayleigh (azul) y la onda Love (verde) para una inversión preliminar con todos los datos. 

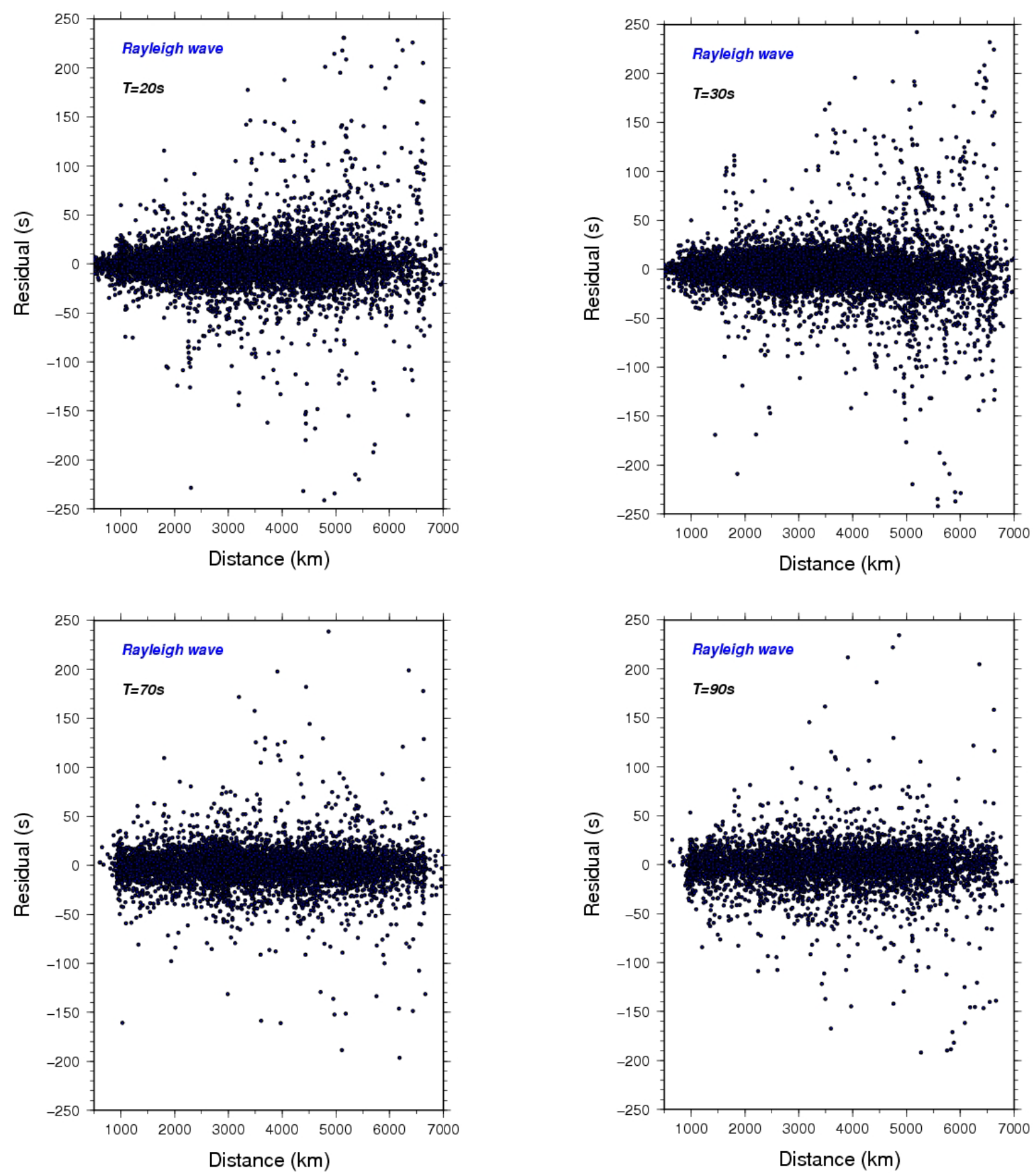

Figura 2.17: Variación de los residuos de los tiempos de viaje en función de la distancia epicentral para $20,30,70$ y 90 s para la onda Rayleigh. 

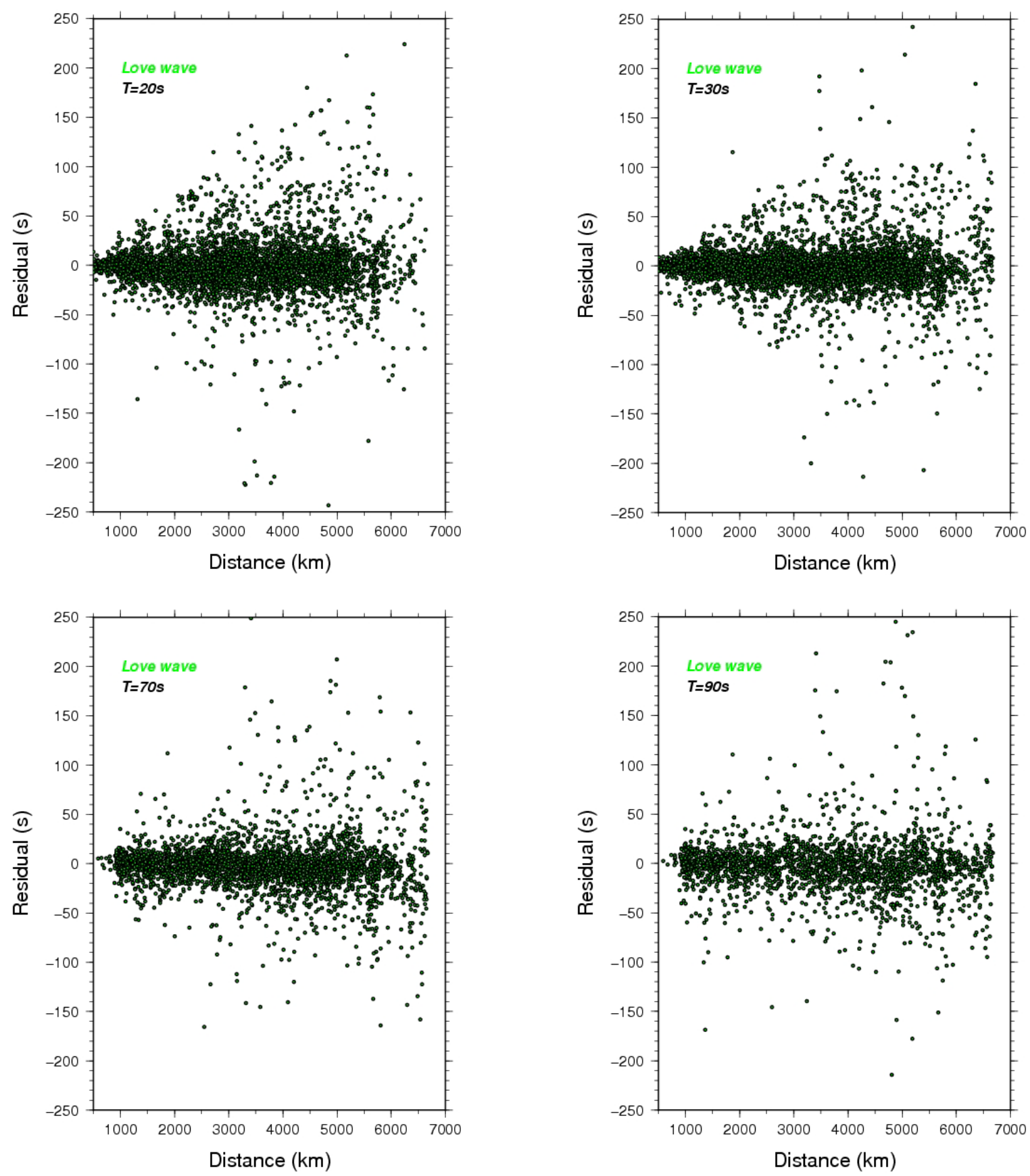

Figura 2.18: Variación de los residuos de los tiempos de viaje en función de la distancia epicentral para $20,30,70$ y 90 s para la onda Love. 


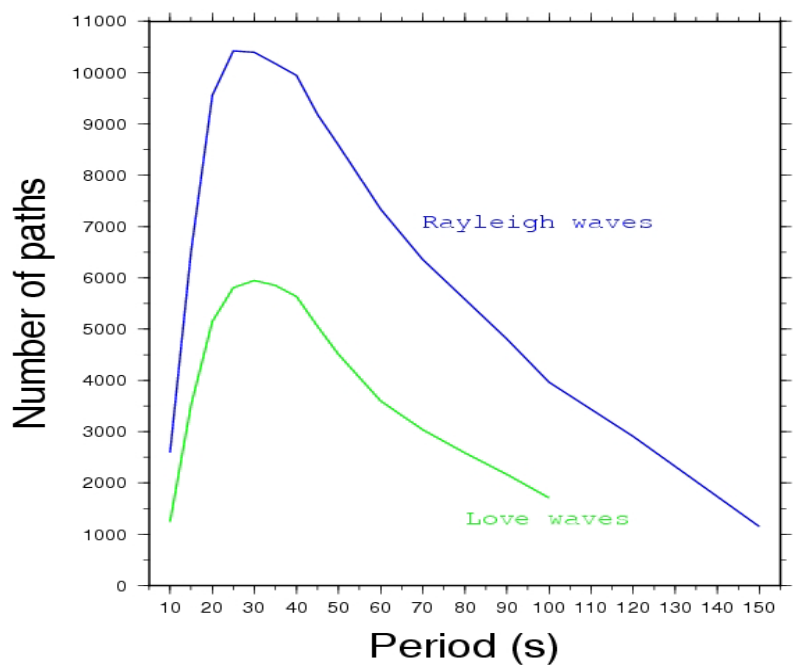

Figura 2.19: Número de trayectorias para la onda Rayleigh (línea azul) y para la onda Love (línea verde) en función del período de las ondas.

La distribución de las distancias epicentrales de las trayectorias de las ondas Rayleigh y Love de $30 \mathrm{~s}$ de período se muestra en la Fig. 2.20. La mayoría de las trayectorias tienen una longitud promedio de $2778 \mathrm{~km}\left(25^{\circ}\right)$. Las trayectorias correspondientes a los datos de ruido ambiental poseen longitudes más cortas (como se observa en la Fig. 2.13), siendo la mayoría menores que $2222 \mathrm{~km}\left(20^{\circ}\right)$.

Figura 2.20: Distribución de las distancias epicentrales de las trayectorias en grados para $30 \mathrm{~s}$ de período. Los datos de terremotos se muestran en azul (onda Rayleigh) y verde (onda Love) y los datos de ruido ambiental en negro.

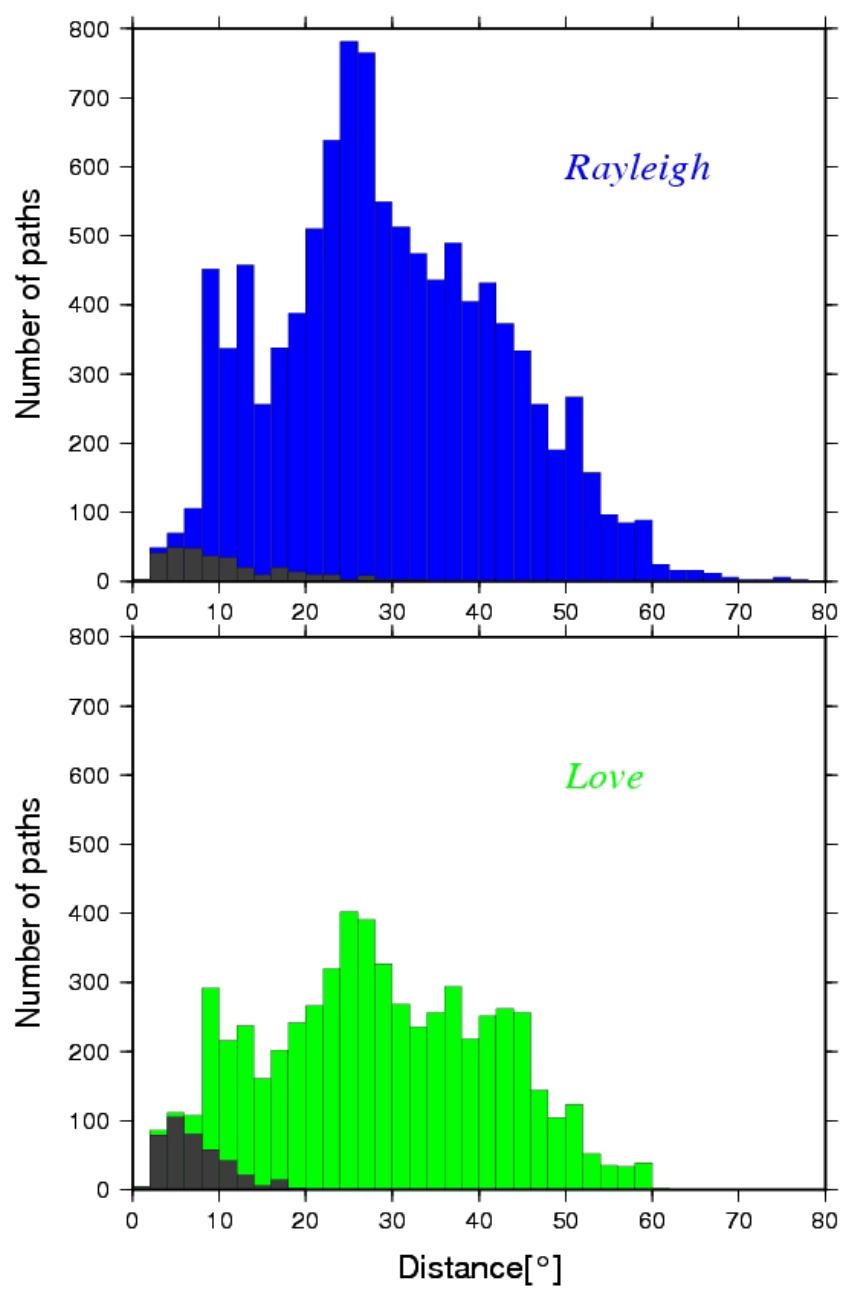

Con la nueva base de datos se determinaron nuevamente las curvas de dispersión regionalizadas. Se calculó el residuo o error medio cuadrático (rmse) 
entre los tiempos de viaje observados y calculados, con el fin de evaluar el modelo de inversión tomográfico

$$
\text { rmse }=\sqrt{\frac{1}{n} \sum_{i=1}^{n}\left(t_{i}^{\text {obs }}-t_{i}^{\text {modelo }}\right)^{2}}
$$

donde tobs y tmodelo son los tiempos de viaje observados y modelados para la trayectoria iésima, su diferencia es el residuo y $\mathrm{n}$ es el número de trayectorias considerando una onda y un período en particular.

Las incertezas en la estimación de los mapas de velocidad de grupo surgen de distintas fuentes como la anisotropía acimutal, la ubicación incorrecta del sismo, trayectorias fuera de círculo máximo, multipathing (parte de la energía del tren principal que se divide y se propaga por su propio camino conducido por alguna zona de baja velocidad), corrimientos SGT (Source Group Time) que son efectos de fuente y errores de medición (Ritzwoller and Levshin, 1998; Levshin et al., 1999; Ritzwoller, 2000) además de los efectos por frecuencia finita. El efecto SGT es despreciable para períodos menores que $75 \mathrm{~s}$ y para sismos con profundidades menores que $25 \mathrm{~km}$. Para períodos mayores o eventos más profundos puede generar perturbaciones en la velocidad de grupo del orden del 1-2\% en áreas donde existe una cobertura de trayectorias muy pobre, para zonas continentales. Sin embargo estas correcciones son prácticamente innecesarias para los estudios actuales de tomografía (Levshin et al., 1999).

Teniendo en cuenta las incertezas en la localización de los telesismos (errores en el epicentro del orden de 10 a $20 \mathrm{~km}$ y errores en la hora de origen de alrededor de $1 \mathrm{~s}$ ) el error mínimo en las mediciones del tiempo de viaje es de alrededor de $5 \mathrm{~s}$. Las estimaciones de la velocidad de grupo mediante la técnica de filtrado múltiple depende en parte del ancho del filtro gaussiano elegido. Para una distancia media de $30^{\circ}$, la incerteza en la estimación de las velocidades de grupo es de cerca de $0.01 \mathrm{~km} / \mathrm{s}$, que se corresponde con una incerteza en el tiempo de viaje de aproximadamente $3 \mathrm{~s}$. Combinando la variación de estas dos fuentes principales de error, en promedio, los errores en los tiempos de viaje son de 
aproximadamente $6 \mathrm{~s}$ para la dispersión calculada a partir de sismos. Para la dispersión calculada a partir del ruido ambiental, los errores en los tiempos de viaje son menores, de alrededor de $3 \mathrm{~s}$, para una distancia típica de $12^{\circ}$, ya que no existe error en la localización del epicentro (el número de trayectorias de ruido representa solo el $5 \%$ de los datos). El parámetro de suavizado $\lambda$ se elige generalmente como el menor valor que evita inestabilidades en los mapas tomográficos (como posibles secuencias alternantes de baja y alta velocidad). El mejor parámetro de suavizado puede elegirse de un gráfico de residuo rms vs rugosidad (roughness) del modelo (que incluyen las inestabilidades del modelo), conocido como curva L. El roughness o Laplaciano del modelo se obtiene como:

$$
\|\Delta s\|=\left|\frac{\partial^{2} \mathrm{U}}{\partial \mathrm{x}^{2}}+\frac{\partial^{2} \mathrm{U}}{\partial \mathrm{y}^{2}}\right|
$$

La Fig. 2.21 muestra un ejemplo de la curva $L$ para las ondas Rayleigh de 20 $\mathrm{s}$ y de $30 \mathrm{~s}$, donde el mejor valor de $\lambda$, cercano al origen, es 4 . Este valor produce un modelo con un residuo rms de $5.4 \mathrm{~s}$ para la onda de $20 \mathrm{~s}$ y de $5 \mathrm{~s}$ para la onda de $30 \mathrm{~s}$, compatible con el error promedio del tiempo de viaje. Por lo tanto se seleccionó un parámetro de suavizado $\lambda$ variable entre 2 y 8 , en donde los mayores valores se aplicaron para períodos menores (10 s) y períodos mayores (>90s).

Los resultados de la tomografía de las ondas Rayleigh y Love para todos los períodos calculados se encuentran disponibles en el Apéndice A. En este capítulo se analizan los resultados para algunos períodos significativos. Sin embargo para realizar la siguiente etapa de inversión 1D se tuvieron en cuenta todos los resultados, así como para las conclusiones del trabajo.

Se analizaron los mapas de 15,50 y 100 s de la onda Rayleigh y 15,50 y 90 $s$ de la onda Love que presentan variaciones laterales significativas atribuyendo las mismas a las características geológicas y tectónicas. A pesar de los distintos métodos de suavización utilizados, los mapas de velocidad de grupo para un mismo período se asemejan y muestrean las mismas estructuras (Rosa et al., 2016). Las ondas superficiales son más sensibles a las estructuras más profundas 
a medida que se incrementan sus períodos, siendo particularmente útiles ya que permiten comparar estructuras a distintas profundidades. Para períodos de hasta 25 s se pueden muestrear los sedimentos y la corteza superior, mientras que para períodos mayores, entre 30 y 70 s se pueden obtener detalles de la corteza inferior y el manto superior (Pasyanos, 2005). La estructura vertical de velocidad en cualquier punto de la región se interpreta a partir de la dependencia en frecuencia de la velocidad de grupo y de acuerdo con el rango de períodos considerado, se pueden resolver heterogeneidades de diferentes tamaños.

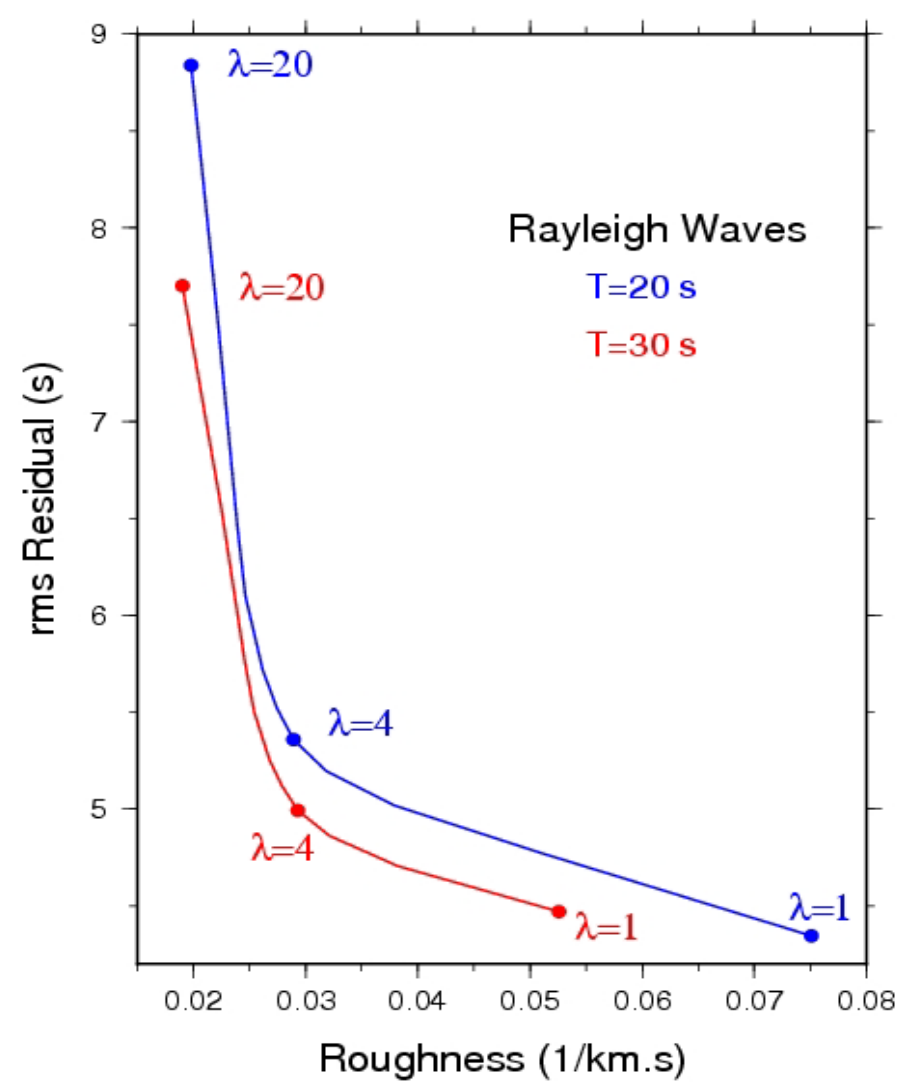

Figura 2.21: Gráfico de residuo rms vs rugosidad (roughness) del modelo conocido como curva L para las ondas Rayleigh de $20 \mathrm{~s}$ (trazo azul) y $30 \mathrm{~s}$ (trazo rojo).

Las anomalías de velocidad presentes en períodos de hasta $20 \mathrm{~s}$ se correlacionan principalmente con estructuras geológicas someras como por ejemplo las cuencas sedimentarias. Los mapas de $15 \mathrm{~s}$ de período de las ondas Rayleigh (Fig. $2.22 a$ y 2.22 b) y Love (Fig. 2.23a y 2.23 b), calculados utilizando los dos criterios de suavización, representan el mejor indicador de la ubicación y profundidad de las cuencas sedimentarias en Sudamérica. 

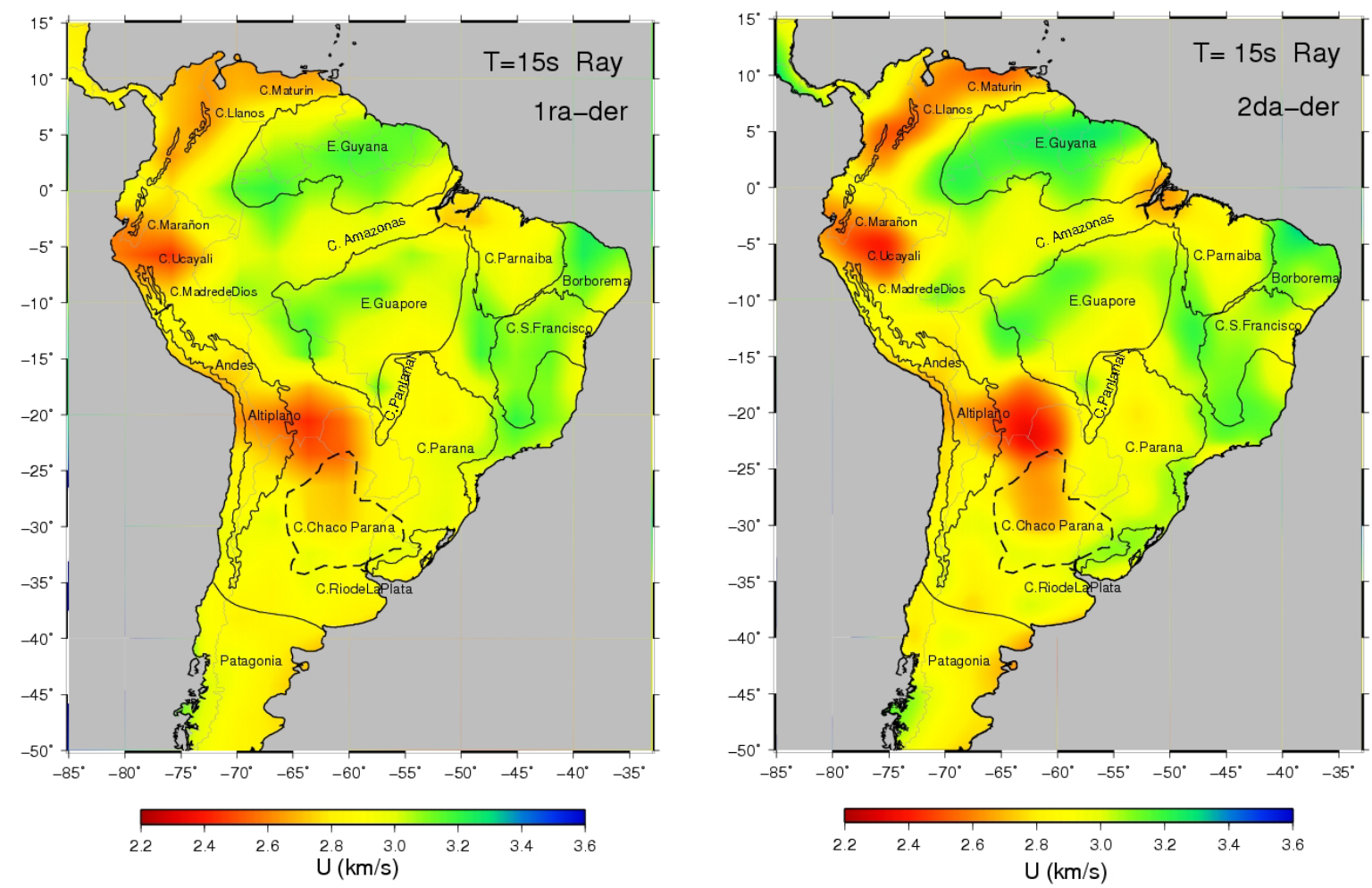

Figura 2.22: Mapa de velocidad de grupo de ondas Rayleigh para $15 \mathrm{~s}$ de período con suavizado de $1^{\text {er }}$ derivada y de $2^{\text {da }}$ derivada.
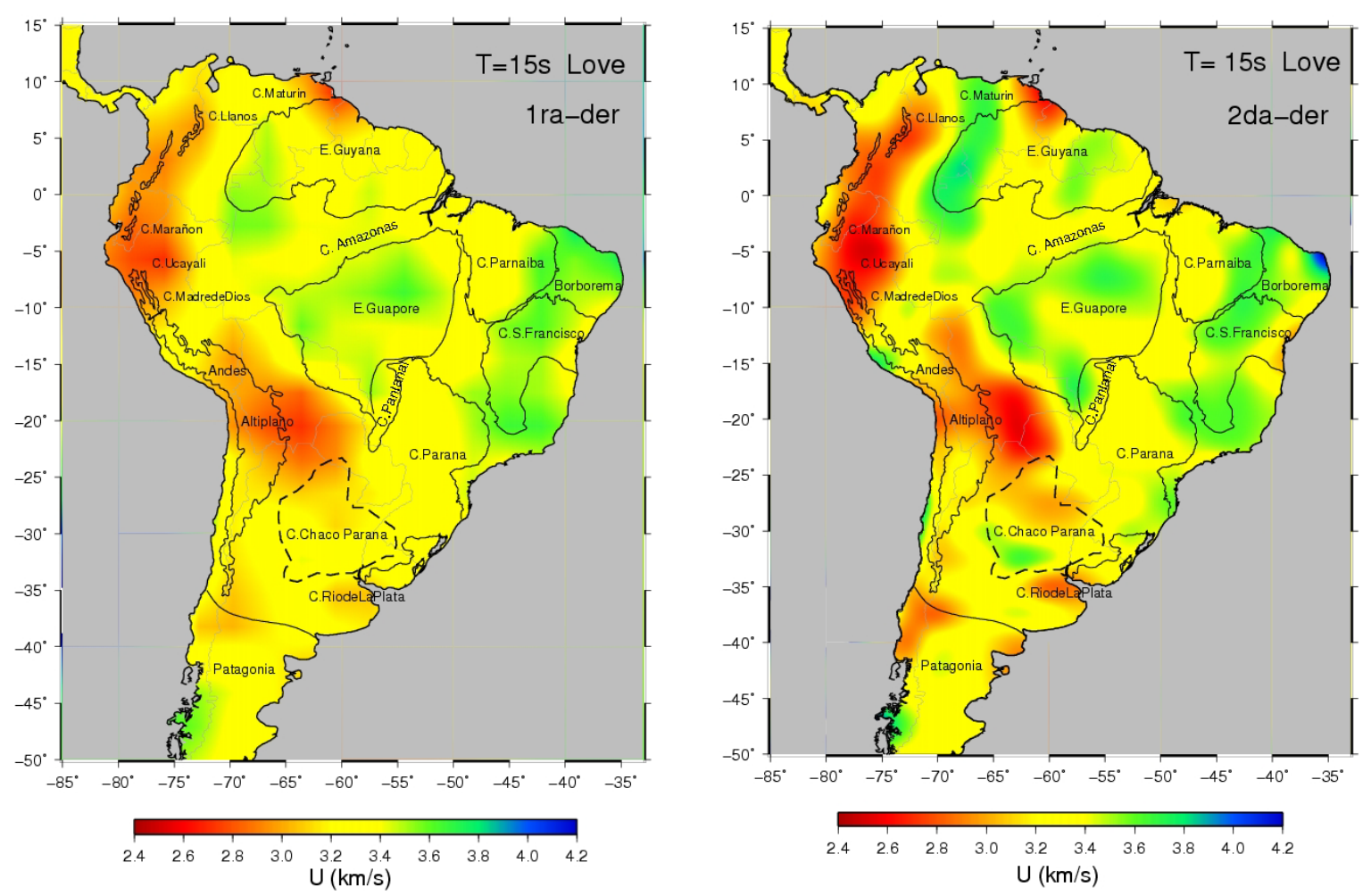

Figura 2.23: Mapa de velocidad de grupo de ondas Love para $15 \mathrm{~s}$ de período con suavizado de $1^{\text {er }}$ derivada y de $2^{\text {da }}$ derivada. 
Las anomalías de muy baja velocidad observadas en (1) el noreste de Colombia y el oeste de Venezuela, (2) el noroeste de Perú y Ecuador, (3) el este de Bolivia y (4) el oeste de Paraguay y noreste de Argentina se relacionan, respectivamente, con (1) las cuencas subandinas de Llanos y Maturín, (2) el complejo de cuencas subandinas de Marañon-Ucayali-Madre de Dios, (3) el Altiplano subandino y (4) la cuenca intracratónica de Chaco-Paraná. Otras anomalías destacadas de baja velocidad son atribuibles a las grandes cuencas intracratónicas de Amazonas, Parnaíba y Paraná. Por otro lado, se observan anomalías de alta velocidad, especialmente para los mapas de ondas Rayleigh, en las regiones de los escudos de Guyana, Guaporé y del Atlántico, este último formado por cuatro provincias estructurales: el cratón de São Francisco y las provincias plegadas de Borborema, Tocantins y Mantiqueira. La cuenca de Solimões ubicada en la parte occidental de la región del Amazonas, presenta velocidades ligeramente más altas comparada con su contraparte, la cuenca Amazónica ubicada en la parte oriental, posiblemente atribuible al menor espesor sedimentario de aproximadamente $4 \mathrm{~km}$ respecto a los $6 \mathrm{~km}$ de la cuenca este (Milani and Zalán, 1999). Lo mismo ocurre en la cuenca de Pantanal ya que presenta velocidades levemente superiores comparadas con las cuencas circundantes de Chaco-Paraná y Paraná, debido a su pequeño espesor sedimentario (cerca de $0.5 \mathrm{~km}$ ).

Los mapas de las ondas Love son más inestables comparado con los mapas de las ondas Rayleigh debido a la influencia de rasgos someros de pequeña escala y a la menor cobertura de las trayectorias (Fig. 2.24b) comparada con aquellas de las ondas Rayleigh (Fig. 2.24a).

Para analizar la robustez de los mapas se calcularon varios tests de resolución espacial de ambas ondas, para distintos períodos usando el método conocido como checkerboard test que se aplicó utilizando celdas de $5^{\circ}$. Las Figs. $2.25 a$ y $2.25 b$ muestran los resultados obtenidos para las dos ondas, respectivamente. Se observó una buena resolución en la parte central del continente, en particular para las cuencas de Paraná y Chaco-Paraná, mientras que en las regiones norte y sur del continente la resolución es mucho menor. 

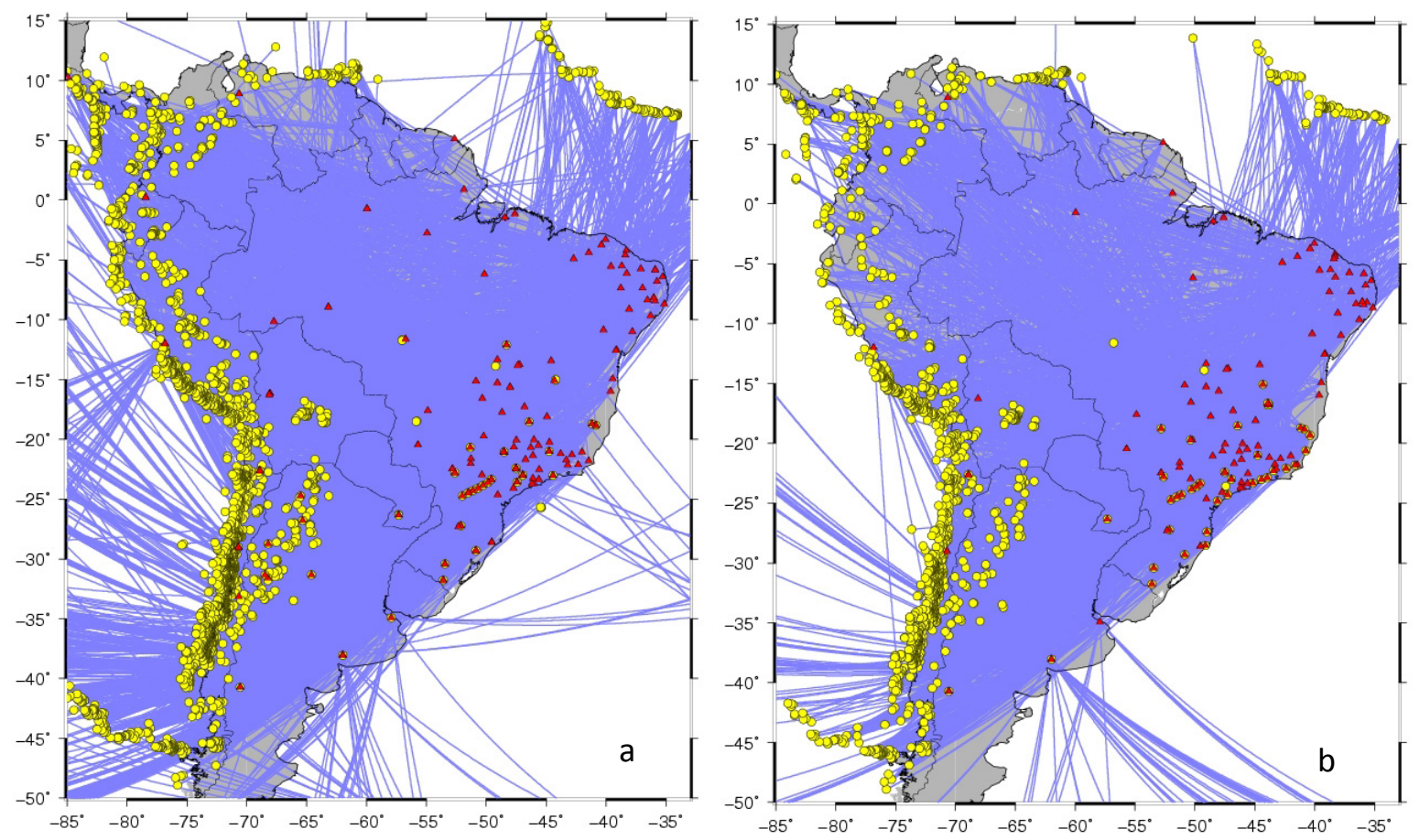

Figura 2.24: Mapa de trayectorias (líneas azules), sismos (círculos amarillos) y estaciones sismológicas (triángulos rojos) para a) ondas Rayleigh, b) ondas Love de $15 \mathrm{~s}$ de período.
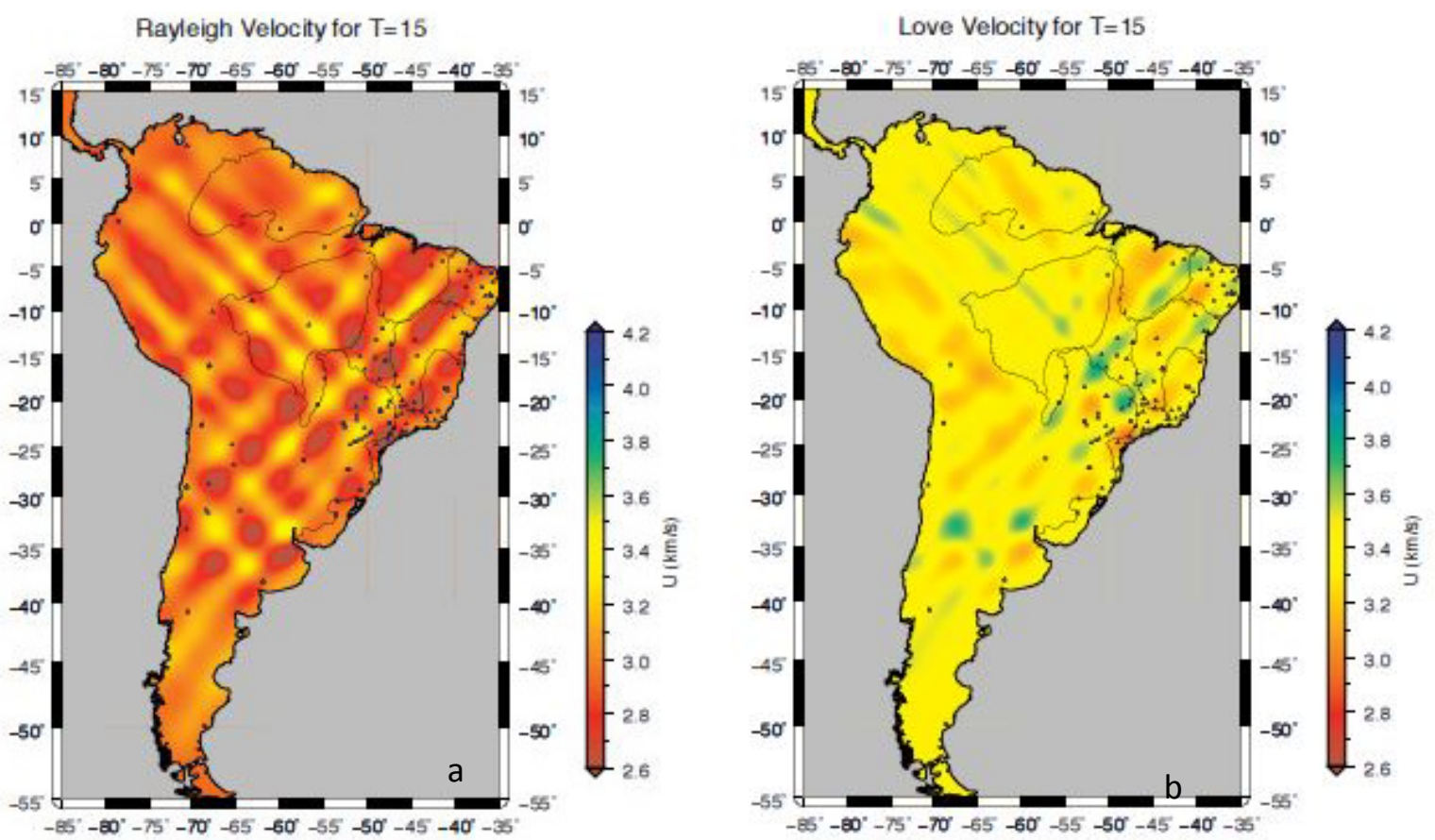

Figura 2.25: Resultados de los tests de resolución usando celdas de $5^{\circ}$ para a) ondas Rayleigh, b) ondas Love de $15 \mathrm{~s}$ de período. 
Para períodos intermedios, entre 30 y $60 \mathrm{~s}$, la velocidad de grupo es más sensible a la velocidad media cortical y al cambio de espesor no sólo entre corteza oceánica y continental, sino también entre distintos tipos de corteza continental.

En la zona continental, los mapas de las ondas Rayleigh (Fig. 2.26a y 2.26b) y de las ondas Love (Fig. 2.27a y 2.27b) para $50 \mathrm{~s}$, obtenidos a partir de los dos criterios de suavizado, muestran los efectos de la profundidad de la Moho (Vdovin et al., 1999). En zonas correspondientes a corteza engrosada, se observa que las ondas superficiales son más lentas porque las altas velocidades en el manto no se muestran adecuadamente para este período. Esta característica se destaca con marcadas anomalías de baja velocidad en la cadena montañosa de los Andes (donde la profundidad de la Moho alcanza los $70 \mathrm{~km}$ ) y con velocidades aumentando a medida que el espesor de la corteza disminuye hacia el este del continente.
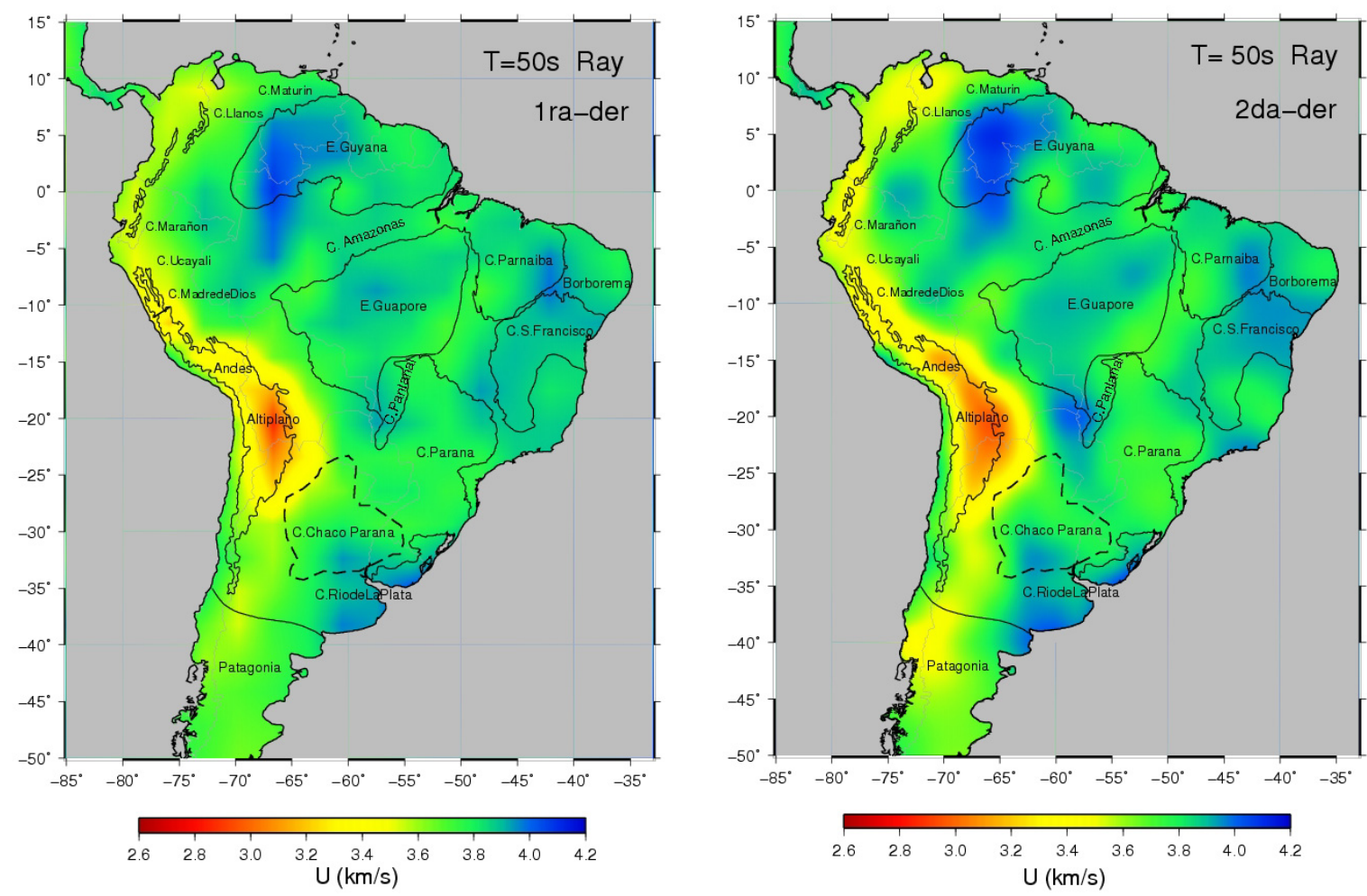

Figura 2.26: Mapa de velocidad de grupo de ondas Rayleigh para $50 \mathrm{~s}$ de período con suavizado de $1^{\text {er }}$ derivada y de $2^{\text {da }}$ derivada. 

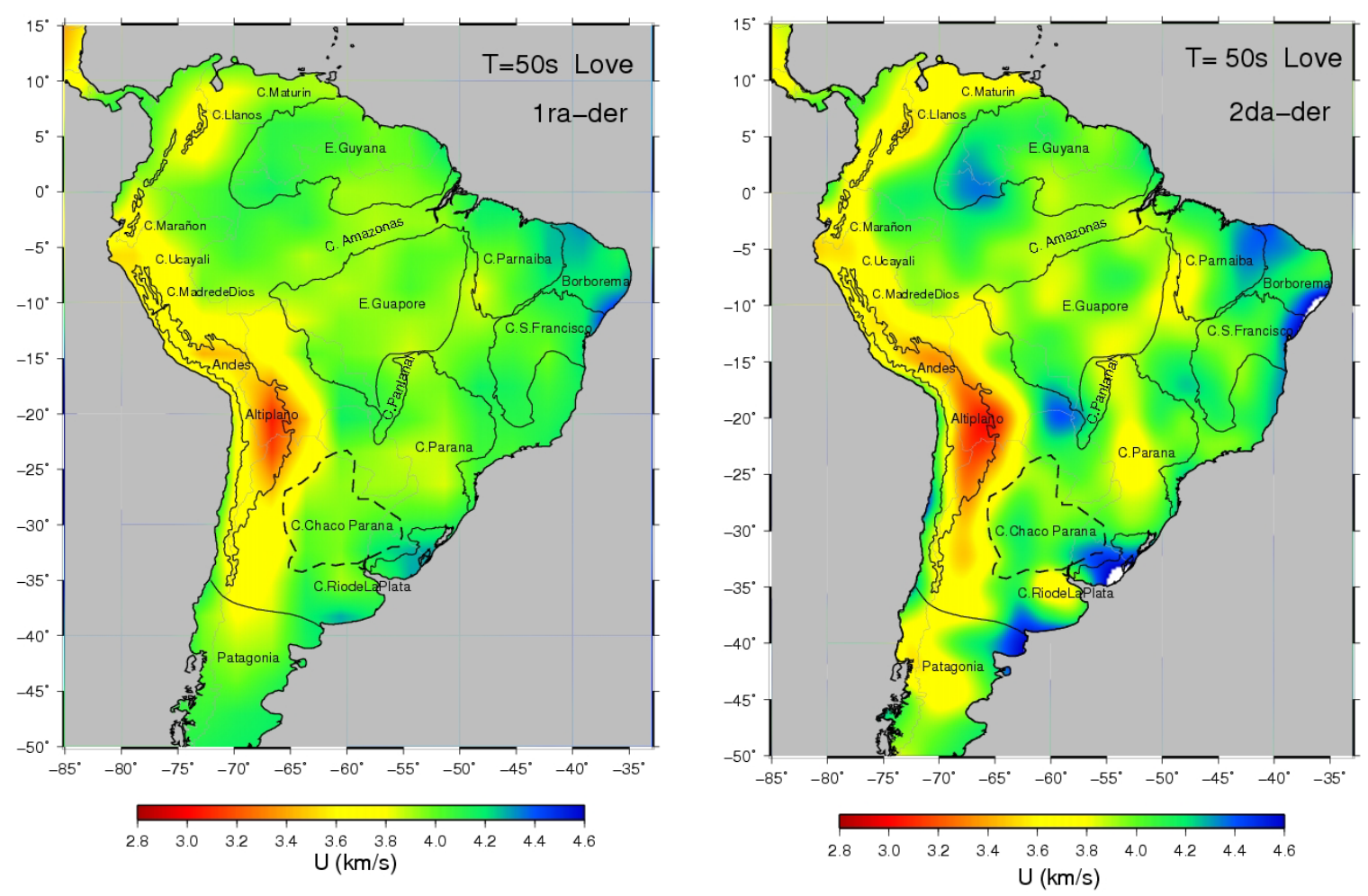

Figura 2.27: Mapa de velocidad de grupo de ondas Love para $50 \mathrm{~s}$ de período con suavizado de $1^{\text {er }}$ derivada y de $2^{\text {da }}$ derivada.

Las anomalías de baja velocidad más destacadas se encuentran por debajo de la región del Altiplano, en los Andes centrales (cerca de $20^{\circ} \mathrm{S} 68^{\circ} \mathrm{W}$ ). Esto también fue observado por Feng et al. (2004), Schmitz et al. (1999) y Yuan et al. (2000). Las velocidades sísmicas aumentan en los Andes del Norte y del Sur, donde el espesor de la corteza se reduce a $45 \mathrm{~km}$ (Van der Meijde et al., 2013).

La cuenca de Paraná presenta velocidades relativamente bajas $(\sim 3.8 \mathrm{~km} / \mathrm{s})$ comparada con la cuenca de Chaco-Paraná ( 4.0 km/s) (Fig. 2.27a y $2.27 \mathrm{~b})$, en concordancia con las velocidades bajas encontradas mediante inversión de velocidad de fase por An and Assumpção (2004), que pueden atribuirse a la corteza engrosada de aproximadamente $45 \mathrm{~km}$ (Assumpção et al., 2013). Se observan altas velocidades $(\sim 4.2-4.4 \mathrm{~km} / \mathrm{s})$ en las regiones más estables del continente: cratones de Amazonía, São Francisco y Río de la Plata. Una anomalía de velocidad levemente superior $(\sim 4.1 \mathrm{~km} / \mathrm{s})$ se observa cerca de la cuenca de Pantanal en comparación con las cuencas circundantes de Paraná y ChacoParaná que puede ser causada por una mayor densidad de corteza inferior (Feng et al., 2004) o por una corteza más delgada (Assumpção et al., 2013). 
Las trayectorias correspondientes a las ondas de $50 \mathrm{~s}$ se muestran en las Figs. 2.28 a y 2.28 b. Los tests de resolución (Fig. 2.29 a y $2.29 b$ ) presentan una buena respuesta excepto para la zona de la plataforma patagónica y la región noreste del continente donde disminuye la densidad de trayectorias.
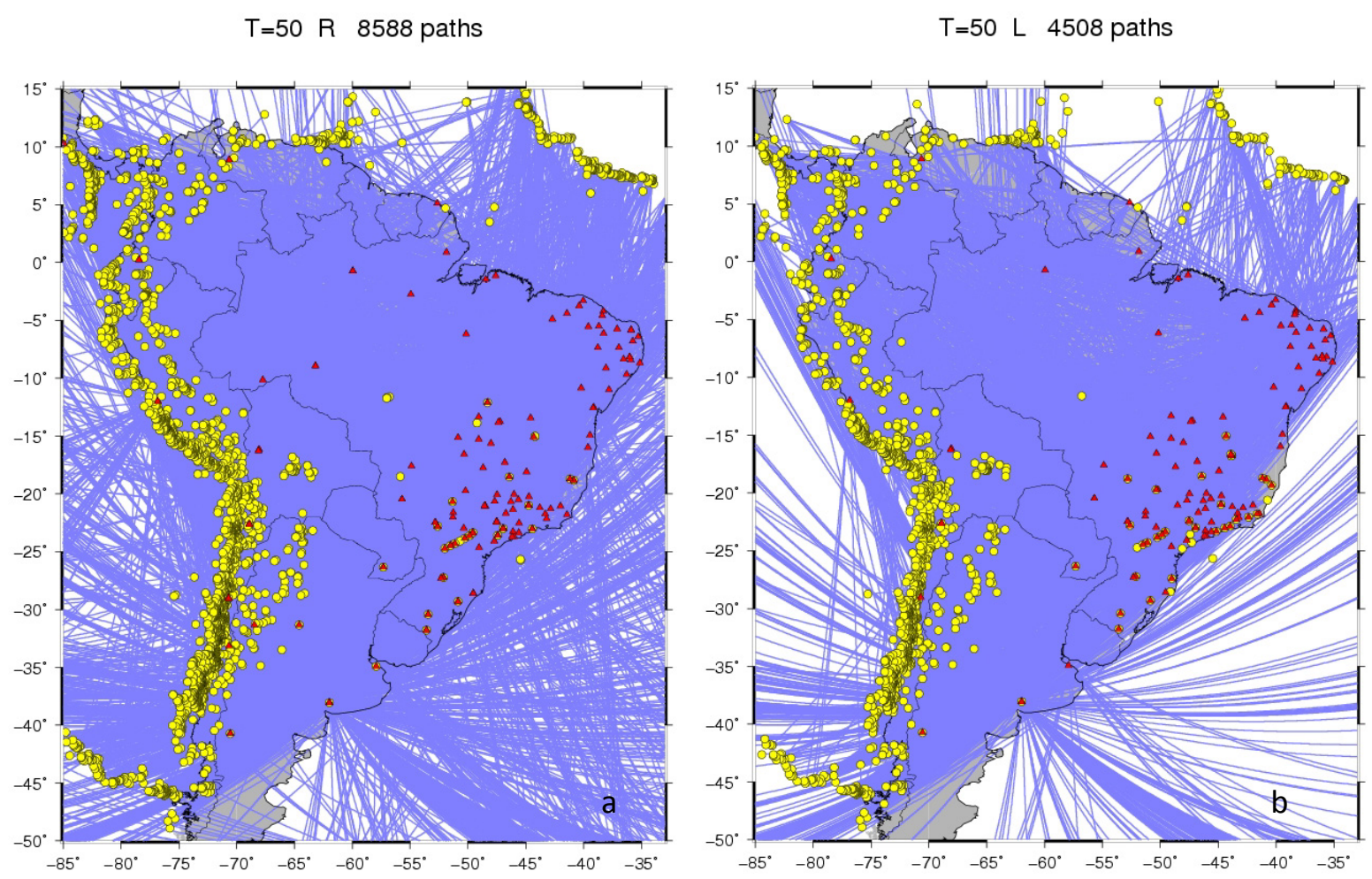

Figura 2.28: Mapa de trayectorias (líneas azules), sismos (círculos amarillos) y estaciones sismológicas (triángulos rojos) para a) ondas Rayleigh, b) ondas Love de $50 \mathrm{~s}$ de período.

Los factores más importantes que afectan a las ondas de períodos mayores que $70 \mathrm{~s}$ en las zonas continentales son la velocidad de las ondas sísmicas y el espesor de la región de la litósfera en el manto superior. En regiones donde la velocidad del manto superior es baja, las velocidades de grupo de las ondas superficiales son bajas y viceversa (Pasyanos, 2005). Los mapas de $100 \mathrm{~s}$ para la onda Rayleigh (Fig. 2.30a y 2.30b) y de 90 s para la onda Love (Fig. 2.31a y 2.31b) calculados usando los dos criterios de suavizado (secciones 2.6.2.1 y 2.6.2.2), presentan anomalías de baja velocidad bajo la cuenca Chaco-Paraná, confirmando análisis previos (e.g., Feng et al., 2004; Heintz et al., 2005). Esta baja velocidad parece extenderse hacia la cuenca de Pantanal y puede sugerir la existencia de 

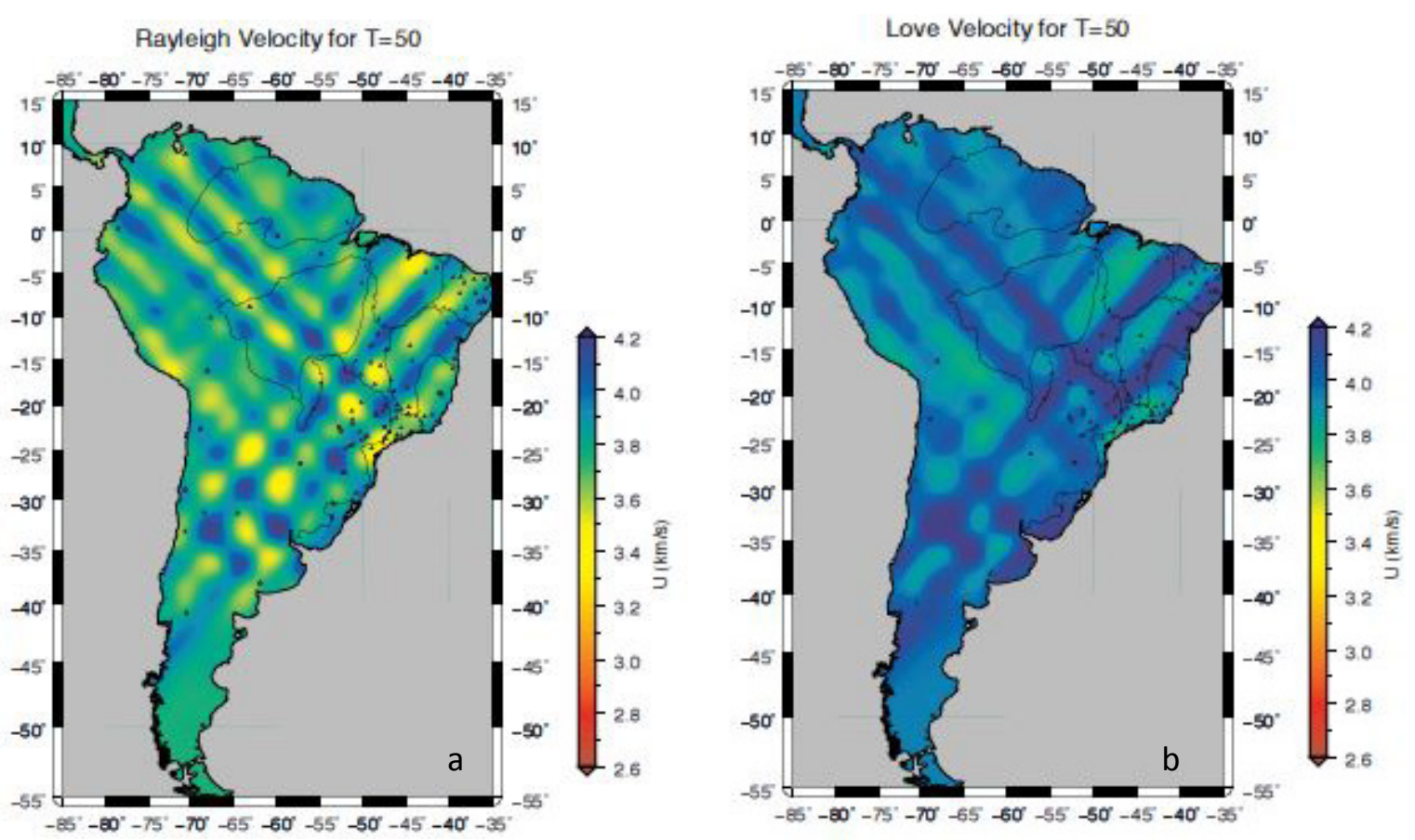

Figura 2.29: Resultados de los tests de resolución usando celdas de $5^{\circ}$ para a) ondas Rayleigh, b) ondas Love de $50 \mathrm{~s}$ de período.

astenósfera superficial (Van der Lee et al., 2001). La cuenca de Paraná presenta velocidades de grupo más altas $(\sim 4 \mathrm{~km} / \mathrm{s})$ y por lo tanto mayores velocidades de onda S, comparada con las cuencas circundantes, en concordancia con las velocidades halladas por Snoke and James (1997), que han sido atribuidas a un bloque cratónico debajo de la cuenca (Heintz et al., 2005).

Otra característica interesante es la anomalía de alta velocidad en todo el cratón amazónico, al noreste del continente y alrededor del cratón de São Francisco, concentrándose en pequeñas áreas en el NE del escudo de Guaporé y en el SE del cratón de São Francisco, que puede ser atribuido probablemente a litosfera de mayor espesor comparada con otras regiones de los escudos precámbricos. El escudo de Guaporé presenta velocidades ligeramente más altas en comparación con el escudo de Guyana donde la litosfera es presumiblemente de menor espesor (Heintz et al., 2005; Feng et al., 2007). En la provincia de Borborema se observan bajas velocidades compatibles con una litósfera de menor espesor. 

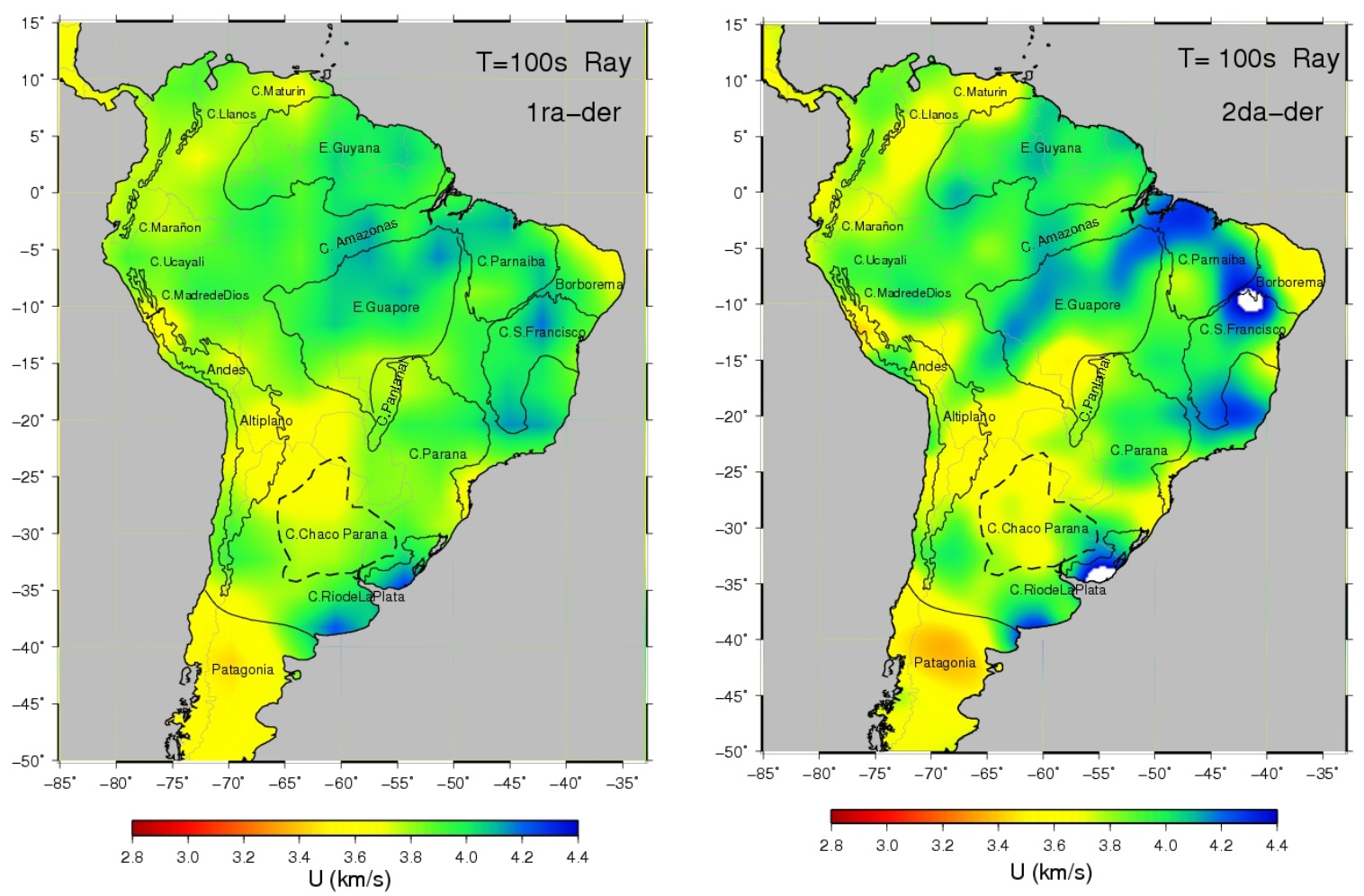

Figura 2.30: Mapa de velocidad de grupo de ondas Rayleigh para $100 \mathrm{~s}$ de período con suavizado de $1^{\text {er }}$ derivada y de $2^{\text {da }}$ derivada.
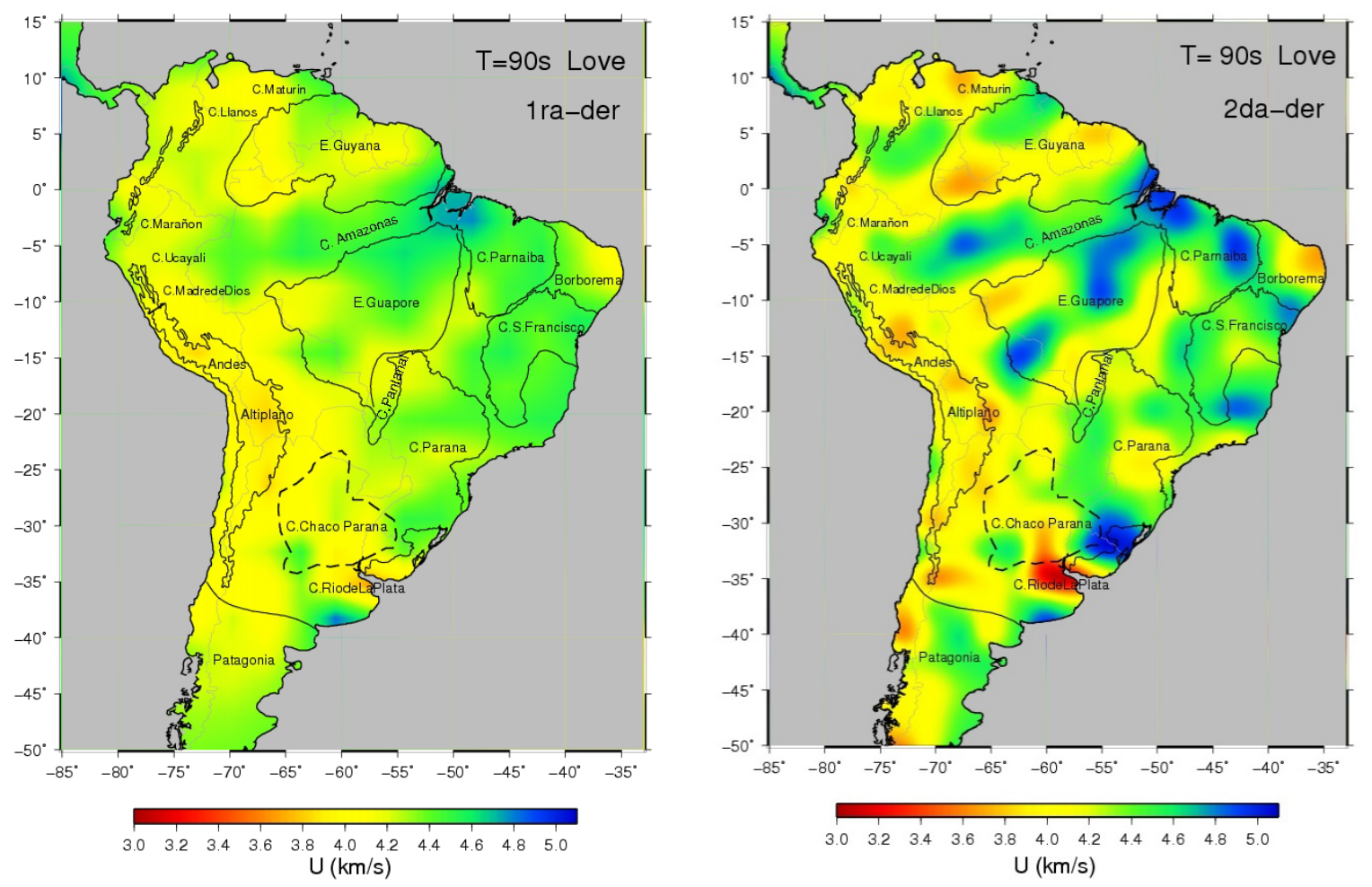

Figura 2.31: Mapa de velocidad de grupo de ondas Love para $90 \mathrm{~s}$ de período con suavizado de $1^{\mathrm{er}}$ derivada y de $2^{\text {da }}$ derivada. 
Para largos períodos, la región andina presenta en general velocidades de grupo bajas, particularmente para ondas Love (Fig. 2.31a y 2.31b), en comparación con la parte más estable del continente probablemente debida a la presencia de una cuña astenosférica de menor velocidad cerca de la zona de subducción. La región del Altiplano presenta velocidades bajas mientras que se observan velocidades relativamente altas en las zonas de subducción horizontal de Perú $\left(5^{\circ}\right.$ a $10^{\circ} \mathrm{S}$ ) y San Juan, Argentina ( $\left.\sim 32^{\circ} \mathrm{S}\right)$, mejor muestreada por las ondas Rayleigh (Fig. 2.30a y 2.30b), esto también fue observado por Feng et al. (2007). El test de resolución para ondas Rayleigh (Fig. 2.33a) muestra que los mapas de ondas superficiales están bien resueltos en la región central donde existen muchas trayectorias entrecruzadas (Fig. 2.32a), no así en la región norte de Sudamérica. Para la onda Love de $90 \mathrm{~s}$ no se obtuvo un buen resultado en el test de resolución (Fig. 2.33b), quizás debido a la menor cantidad de trayectorias existentes (Fig. $2.32 b)$.
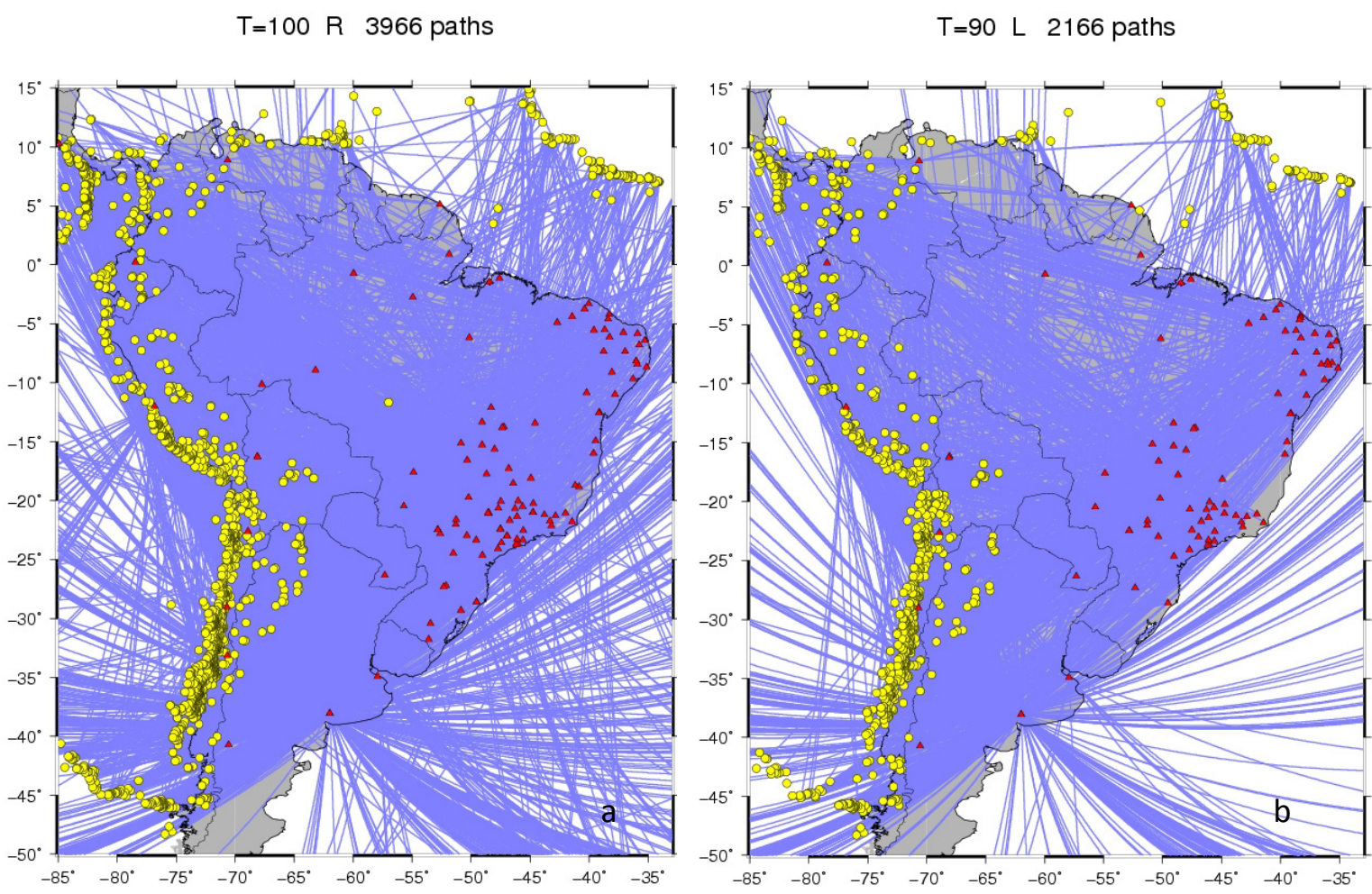

Figura 2.32: Mapa de trayectorias (líneas azules), sismos (círculos amarillos) y estaciones sismológicas (triángulos rojos) para a) ondas Rayleigh de $100 \mathrm{~s}$ de período, b) ondas Love de $90 \mathrm{~s}$ de período. 
En todos los mapas analizados, la mayor resolución se obtuvo en la región central de Sudamérica (en particular en el área de las cuencas de Paraná y ChacoParaná), donde se cuenta con una gran cantidad de trayectorias y la distribución acimutal de las mismas es óptima, dada la configuración de datos disponibles. Mientras que en los bordes del continente, donde la distribución acimutal disminuye, la resolución es menor. También es importante mencionar que la resolución obtenida para las ondas Rayleigh es superior, teniendo en cuenta que las trayectorias usadas duplican en número a las correspondientes para las ondas Love.
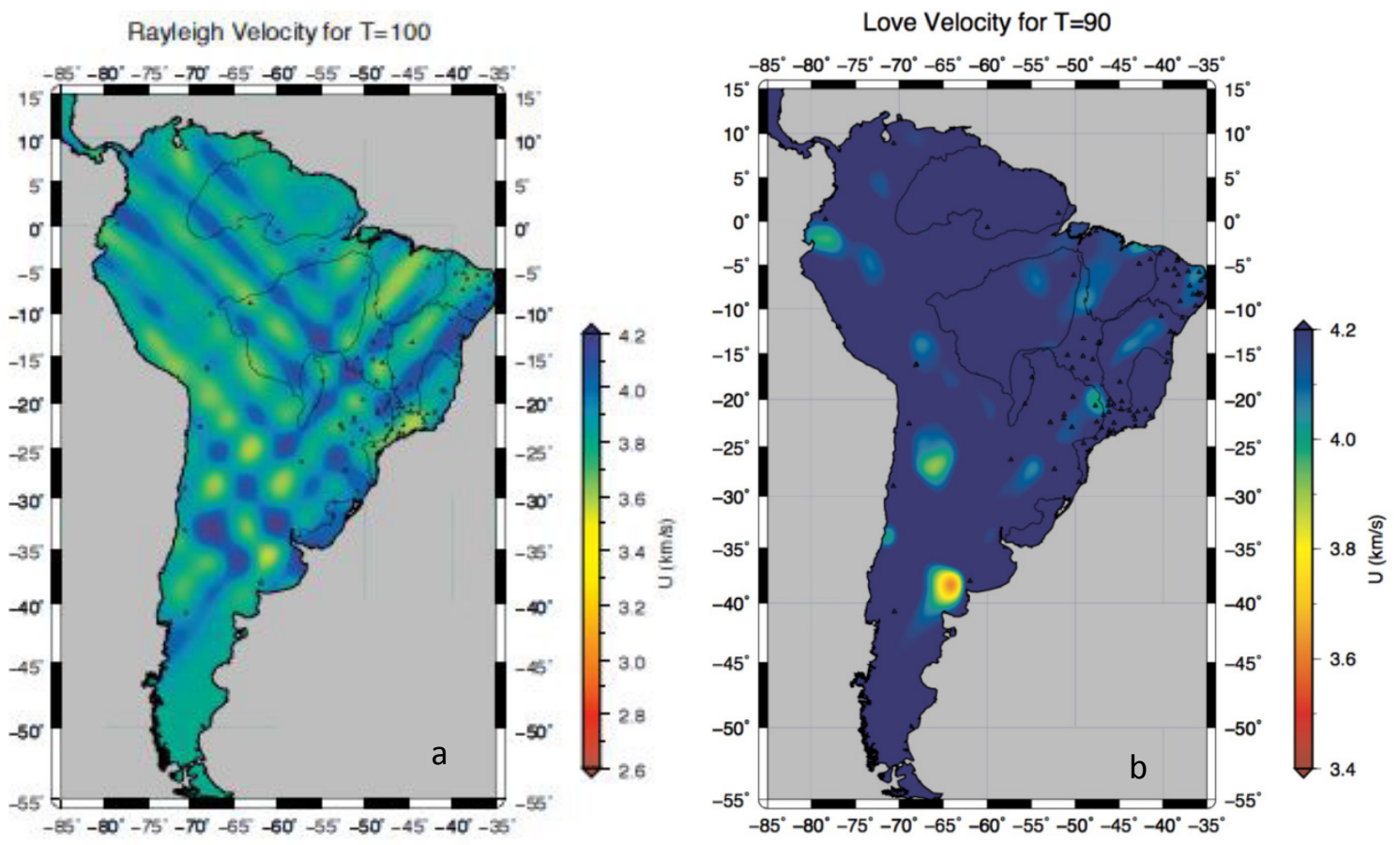

Figura 2.33: Resultados de los tests de resolución usando celdas de $5^{\circ}$ para a) ondas Rayleigh de $100 \mathrm{~s}$ de período, b) ondas Love de $90 \mathrm{~s}$ de período. 


\section{Capítulo 3}

\section{Funciones Receptoras}

\subsection{Introducción}

La sismología ha aportado durante mucho tiempo herramientas valiosas para inferir la composición de nuestro planeta. En 1979, Charles Langston publicó un trabajo acerca de la información contenida en los sismogramas de tres componentes de sismos lejanos y profundos. Él observó que la componente vertical de estos registros estaba levemente afectada por la estructura superficial aledaña a la estación sismológica y mediante la deconvolución entre las componentes vertical y radial, pudo extraer información de los efectos de esta estructura. Este descubrimiento dio inicio a una nueva era de estudios dirigidos a conocer la estructura de la litósfera, ya que esta metodología proporciona una forma de aislar la señal conocida como función del receptor o función receptora para una sola estación sismológica a partir de varios sismos ocurridos en distintas regiones del planeta. Durante los años posteriores al trabajo de Langston, la técnica de funciones receptoras se ha utilizado para analizar la distribución vertical de velocidades de la onda $S$ debajo de estaciones sísmicas permanentes y temporales en todo el mundo.

Las funciones receptoras (FRs) son series de tiempo calculadas a partir de los registros de 3 componentes de ondas $P$ telesísmicas, sensibles a la estructura cercana a la estación. Las trazas obtenidas mediante la deconvolución pueden ser consideradas como una combinación lineal de picos y valles que representan la energía secundaria generada después de la interacción del frente de onda $\mathrm{P}$ con las discontinuidades presentes debajo del receptor. Esta interacción generalmente resulta en una serie de tiempo que está constituida por la fase $\mathrm{P}$ directa, la fase Ps convertida y sus reverberaciones múltiples, PpPs y PpSs+PsPs, generadas en la estructura debajo de la estación que arriban a la superficie como una onda $\mathrm{S}$. Modelando la amplitud y el tiempo de estas ondas reverberantes se pueden obtener restricciones de la geología del lugar. Las características más importantes 
de la estructura pueden ser aproximadas generalmente por una secuencia de capas casi horizontales. En este caso los arribos generados por cada discontinuidad se asemejan a los de la Fig. 3.1. En una FR, la amplitud de estos arribos dependen del ángulo de incidencia de la onda $\mathrm{P}$ y del contraste de velocidad que genera la conversión Ps y las múltiples. La Ps presenta normalmente una amplitud del orden del $15 \%-20 \%$ de la fase P directa.

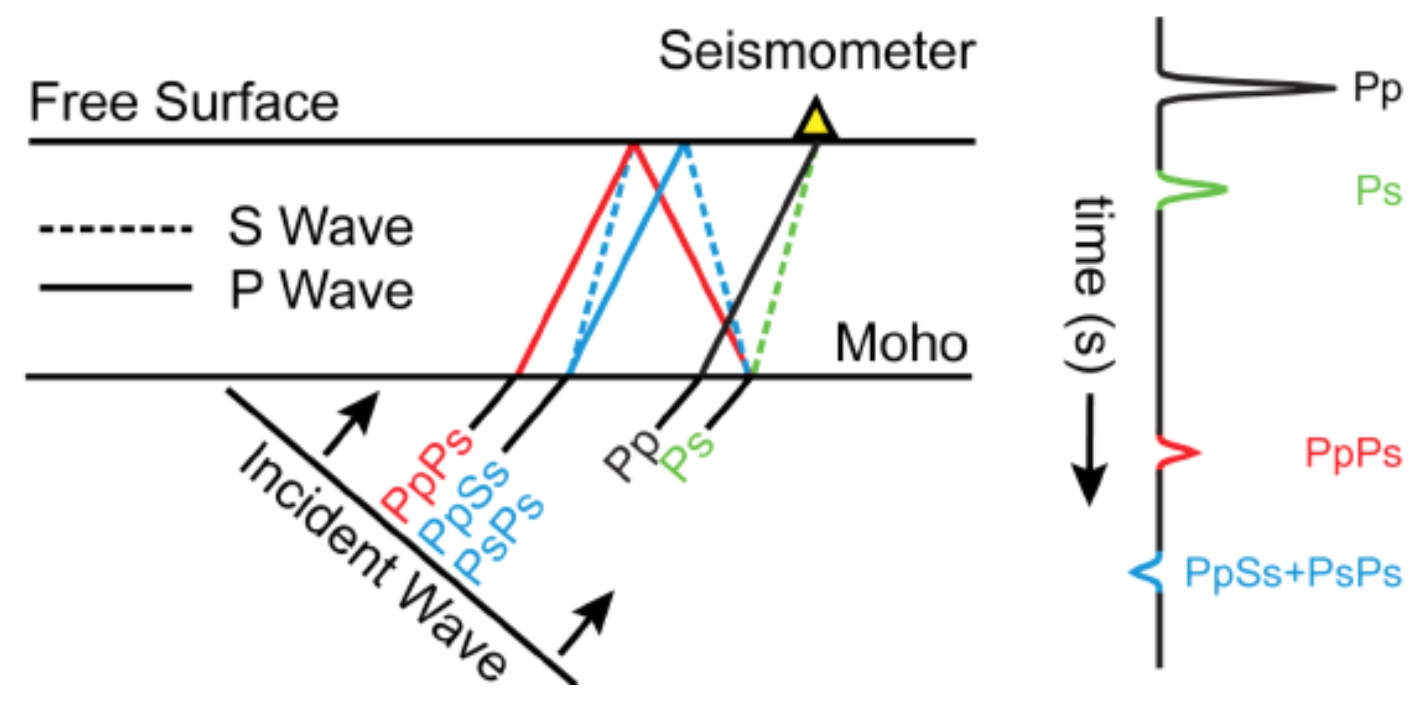

Figura 3.1: Función receptora. Cada pico de la función receptora se corresponde con una trayectoria en la estructura local.

Las ondas $\mathrm{P}$ contienen información relacionada con la fuente, la estructura cercana a la fuente, los efectos de propagación y la estructura local aledaña al receptor. La técnica de FRs elimina los efectos de la fuente y de la propagación, pudiéndose utilizar para determinar la naturaleza de la discontinuidad cortezamanto (Owens et al., 1984), la distribución de la velocidad de corte en la corteza (Ammon et al., 1990; Ammon and Zandt, 1993), la geometría de los reflectores sísmicos (Langston, 1979) y el valor de la relación de Poisson en corteza (Zandt and Ammon, 1995; Zhu and Kanamori, 2000). Las amplitudes de las FRs se pueden utilizar para estimar con precisión los contrastes de densidad y velocidad de las ondas $S$ en la discontinuidad corteza-manto teniendo en cuenta que la amplitud de la onda $\mathrm{P}$ directa es sensible a la estructura cercana a la superficie, la 
amplitud de la fase Ps convertida es sensible al contraste de velocidad de S y las fases múltiples son sensibles a ambos contrastes (Julià, 2007).

Debido a la gran diferencia de velocidad en el límite corteza-manto, la fase Ps convertida en la Moho es a menudo la señal más grande que se reconoce después de la fase $\mathrm{P}$ directa. La diferencia de tiempo entre estas dos fases, función de la relación $\mathrm{V}_{\mathrm{P}} / \mathrm{V}_{\mathrm{S}}$ cortical, se utiliza para estimar el espesor de la corteza que también depende de esta relación $\mathrm{V}_{\mathrm{P}} / \mathrm{V}_{\mathrm{S}}$. Esta ambigüedad puede ser reducida significativamente incorporando las fases múltiples ya que la diferencia de tiempo entre la Ps y las múltiples es función de la relación $V_{P} / V_{S}$ (Zandt and Ammon, 1995).

La onda $\mathrm{P}$ telesísmica que llega a una estación, en el dominio del tiempo, es una composición de la función fuente sísmica efectiva, la respuesta de instrumento y la estructura local aledaña a la estación, como ya se mencionó. Con el fin de integrar la información contenida en numerosos eventos provenientes de distintas fuentes sísmicas, se necesita aislar de manera efectiva el efecto de la fuente en los sismogramas observados. Para ello se aplica la técnica propuesta y discutida por Langston (1979), que resulta eficaz para separar los efectos de la estructura local mediante ecualización de la fuente. Es recomendable analizar eventos lejanos y profundos con formas de onda impulsivas en la componente vertical porque se pueden analizar directamente las conversiones $\mathrm{P}$ a $\mathrm{S}$ en las componentes horizontales.

La respuesta sísmica $\mathrm{D}(\mathrm{t})$ en una estación puede representarse teóricamente en el dominio del tiempo mediante:

$$
\mathrm{D}(\mathrm{t})=\mathrm{I}(\mathrm{t}) * \mathrm{~S}(\mathrm{t}) * \mathrm{E}(\mathrm{t}),
$$

donde $\mathrm{I}(\mathrm{t})$ es la respuesta impulsiva del instrumento, $\mathrm{E}(\mathrm{t})$ es la respuesta impulsiva de la estructura terrestre local, $\mathrm{S}(\mathrm{t})$ es la función fuente sísmica efectiva o señal que incide en la base de la estructura local y $*$ es el operador convolución. Dado que la estructura por debajo de la estación produce una conversión $\mathrm{P}$ a $\mathrm{S}$, las componentes horizontales serán en general distintas a la vertical, quedando expresado como: 


$$
\begin{aligned}
& \mathrm{D}_{\mathrm{v}}(\mathrm{t})=\mathrm{I}(\mathrm{t}) * \mathrm{~S}(\mathrm{t}) * \mathrm{E}_{\mathrm{v}}(\mathrm{t}), \\
& \mathrm{D}_{\mathrm{r}}(\mathrm{t})=\mathrm{I}(\mathrm{t}) * \mathrm{~S}(\mathrm{t}) * \mathrm{E}_{\mathrm{r}}(\mathrm{t}), \\
& \mathrm{D}_{\mathrm{t}}(\mathrm{t})=\mathrm{I}(\mathrm{t}) * \mathrm{~S}(\mathrm{t}) * \mathrm{E}_{\mathrm{t}}(\mathrm{t}),
\end{aligned}
$$

donde $\mathrm{v}, \mathrm{r}$ y $\mathrm{t}$ representan las componentes vertical, radial y tangencial respectivamente. Langston (1979) señaló que la componente vertical del movimiento del suelo para una onda $\mathrm{P}$ con incidencia casi normal consiste de una fase $P$ directa muy grande seguida de una fase convertida $P$ a $S$ pequeña $y$ reverberaciones en la corteza y demostró utilizando un modelo de una capa sobre un semiespacio, que el método de ecualización propuesto supone que la componente vertical de la respuesta impulsiva de la estructura local, $E_{v}(t)$, se comporta como una función delta de Dirac $\left[\mathrm{E}_{\mathrm{v}}(\mathrm{t}) \approx \delta(\mathrm{t})\right]$, luego

$$
\mathrm{D}_{\mathrm{v}}(\mathrm{t})=\mathrm{I}(\mathrm{t}) * \mathrm{~S}(\mathrm{t})
$$

contiene los factores que se desean remover del sismograma (fuente y receptor). Así $\mathrm{D}_{\mathrm{r}}(\mathrm{t})$ y $\mathrm{D}_{\mathrm{t}}(\mathrm{t})$ pueden estimarse a partir de la deconvolución entre la componente vertical y las componentes radial y tangencial, respectivamente, de manera de ecualizar la fuente. Así se tiene:

$$
\begin{aligned}
& H_{r}(t)=\frac{D_{r}(t)}{D_{v}(t)}=\frac{I(t) * S(t) * E_{r}(t)}{I(t) * S(t) * E_{v}(t)} \\
& H_{t}(t)=\frac{D_{t}(t)}{D_{v}(t)}=\frac{I(t) * S(t) * E_{t}(t)}{I(t) * S(t) * E_{v}(t)}
\end{aligned}
$$

con $\mathrm{H}_{\mathrm{r}}(\mathrm{t})$ y $\mathrm{H}_{\mathrm{t}}(\mathrm{t})$ FRs radial y tangencial, respectivamente. Las funciones obtenidas $E_{r}(t)$ y $E_{t}(t)$ representan las características de la estructura local directamente por debajo del receptor. En el dominio de la frecuencia se tiene: 


$$
\begin{aligned}
& H_{r}(w)=\frac{D_{r}(w)}{D_{v}(w)}=\frac{E_{r}(w)}{E_{v}(w)} \approx E_{r}(w) \\
& H_{t}(w)=\frac{D_{t}(w)}{D_{v}(w)}=\frac{E_{t}(w)}{E_{v}(w)} \approx E_{t}(w)
\end{aligned}
$$

donde $\mathrm{D}(\mathrm{w}), \mathrm{E}(\mathrm{w})$ y $\mathrm{H}(\mathrm{w})$ son las transformadas de Fourier de $\mathrm{D}(\mathrm{t}), \mathrm{E}(\mathrm{t})$ y $H(t)$, respectivamente.

\subsection{Estimación de las funciones receptoras}

Para estimar las FRs se pueden utilizar dos técnicas de deconvolución, una se aplica en el dominio de la frecuencia y otra en el dominio del tiempo. Ambas técnicas funcionan bien si la relación señal/ruido es alta. En general, la técnica de deconvolución óptima depende del problema a resolver y de los datos con que se trabaja. Si bien la deconvolución en el dominio frecuencial (water-level) es más eficiente, la deconvolución en el dominio temporal presenta mayor estabilidad en períodos largos para datos contaminados con ruido (Julià, 2007). Considerando los datos que serán analizados en este trabajo, se decide aplicar la técnica en el dominio del tiempo.

El método de deconvolución iterativa en el dominio del tiempo fue introducido por Kikuchi and Kanamori (1982) con el objetivo de obtener la función fuente de ondas de cuerpo complejas mediante la deconvolución de sismogramas sintéticos a partir de las ondas observadas. Ligorria and Ammon (1999) aplicaron esta técnica a sismogramas de tres componentes para calcular las FRs en una estación sismológica. Ellos encontraron que para señales ruidosas, esta técnica funcionaba mejor ya que las FRs resultantes no exhibían la inestabilidad de largo período que se observa generalmente en la aproximación frecuencial. Asimismo la deconvolución iterativa no requiere de la elección de un parámetro de estabilización óptima comparado con el otro método. Otra ventaja de este método es la imposición de causalidad a la solución, que habitualmente se pierde en la 
deconvolución en el dominio de la frecuencia. El éxito del procedimiento consiste en minimizar la diferencia entre la componente radial del sismograma observado, filtrado mediante un filtro gaussiano, y la señal sintética generada por la convolución de la componente vertical del sismograma con un tren de spikes, actualizado en cada iteración (Ammon, 2006a). En la Fig. 3.2, se muestra un ejemplo de una FR radial para la estación TRQA (Bs. As.) obtenida con 1, 2, 10, 50 y 500 iteraciones respectivamente, para un sismo de magnitud 6.2 ocurrido a 4050 $\mathrm{km}$ de la estación. Para arribar a un buen resultado, como se observa en la figura, generalmente 500 iteraciones son suficientes.

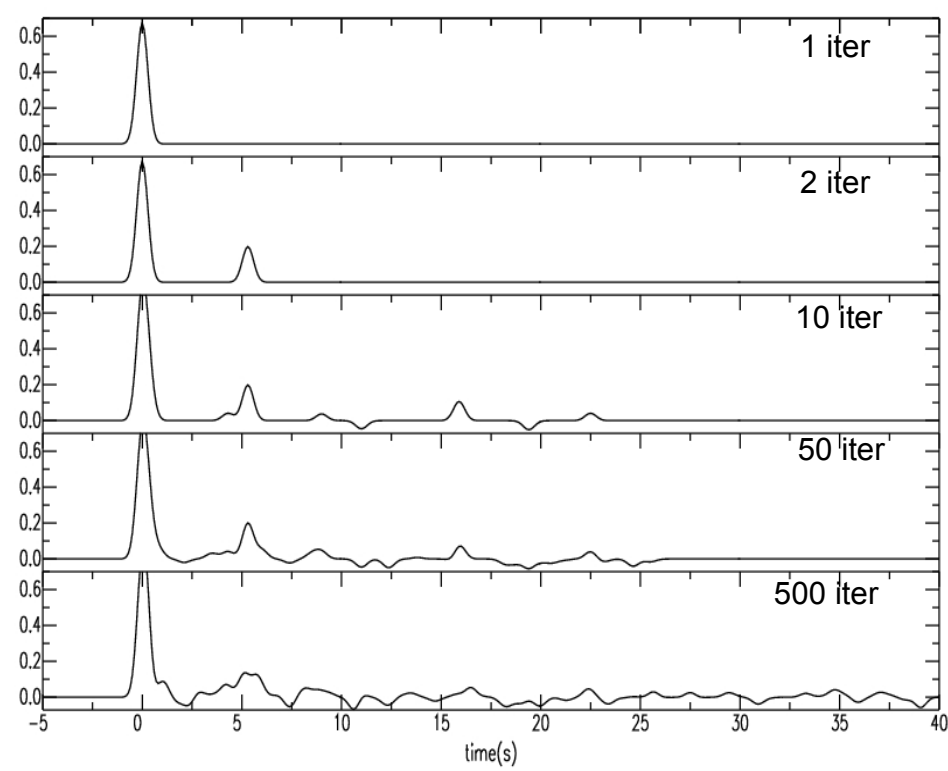

Figura 3.2: Funciones receptoras radiales para la estación TRQA, obtenidas con 1, 2, 10, 50 y 500 iteraciones correspondientes a un sismo de magnitud 6.2 ocurrido a $4050 \mathrm{~km}$ de la estación.

Para simplificar la forma de la ondícula y remover la energía dispersada de alta frecuencia o ruido de alta frecuencia se utiliza un filtro gaussiano pasa-bajos $\mathrm{e}^{-\left(\frac{\omega^{2}}{4 \alpha^{2}}\right)}$, con un ancho de banda $\alpha$ determinado, que controla el contenido frecuencial. Valores probables de $\alpha$ con sus correspondientes frecuencias de corte se detallan en Ammon (2006b). Las FRs calculadas con un parámetro a mayor incluyen componentes de altas frecuencia del dato que permiten una mayor 
resolución. De esta manera se pueden mapear estructuras más detalladas, sin embargo se incluye más ruido en el proceso, que puede desestabilizar la deconvolución. Para valores bajos de $\alpha$ se excluye la mayor parte de la energía de alta frecuencia y solo se examinan las componentes de baja frecuencia que permiten obtener características más simples y generales de la región, (Cassidy, 1992). Por lo general el valor $\alpha=2.5$ resulta ser la mejor selección para compensar entre calidad y resolución.

La FR radial se obtiene de la deconvolución entre la componente vertical y la radial, removiendo los efectos de la fuente sísmica efectiva y la respuesta de instrumento; dejando solamente el efecto de la estructura local bajo la estación de observación (Fig. 3.3). La FR transversal se obtiene de una deconvolución similar entre la componente vertical y la transversal. Generalmente sólo la FR radial se utiliza para interpretar la estructura, ya que la energía transversal debería ser nula para medios isotrópicos y lateralmente homogéneos. Sin embargo, las amplitudes de las FRs transversales observadas en la práctica, servirán como una medida de la validez de esa suposición (Julià and Mejia, 2004).

Las FRs se calcularon mediante un software desarrollado por Ammon (2006a) basado en el algoritmo de deconvolución iterativa de Kikuchi and Kanamori (1982).

Para que resulte efectiva la separación de la respuesta local mediante el proceso de deconvolución, las ondas $\mathrm{P}$ deben penetrar la estructura debajo de la estación, con ángulos de incidencia muy pequeños. De este modo el movimiento de partículas se polariza de manera que las ondas $\mathrm{P}$ dominan la componente vertical del registro y las ondas de corte se registran preferentemente en las componentes horizontales (Ammon, 1991). Estos ángulos se obtienen para sismos provenientes de fuentes ubicadas a distancias epicentrales entre $30^{\circ}$ y $90^{\circ}$ de los receptores. Esta condición podría limitar la cobertura acimutal de los datos. 


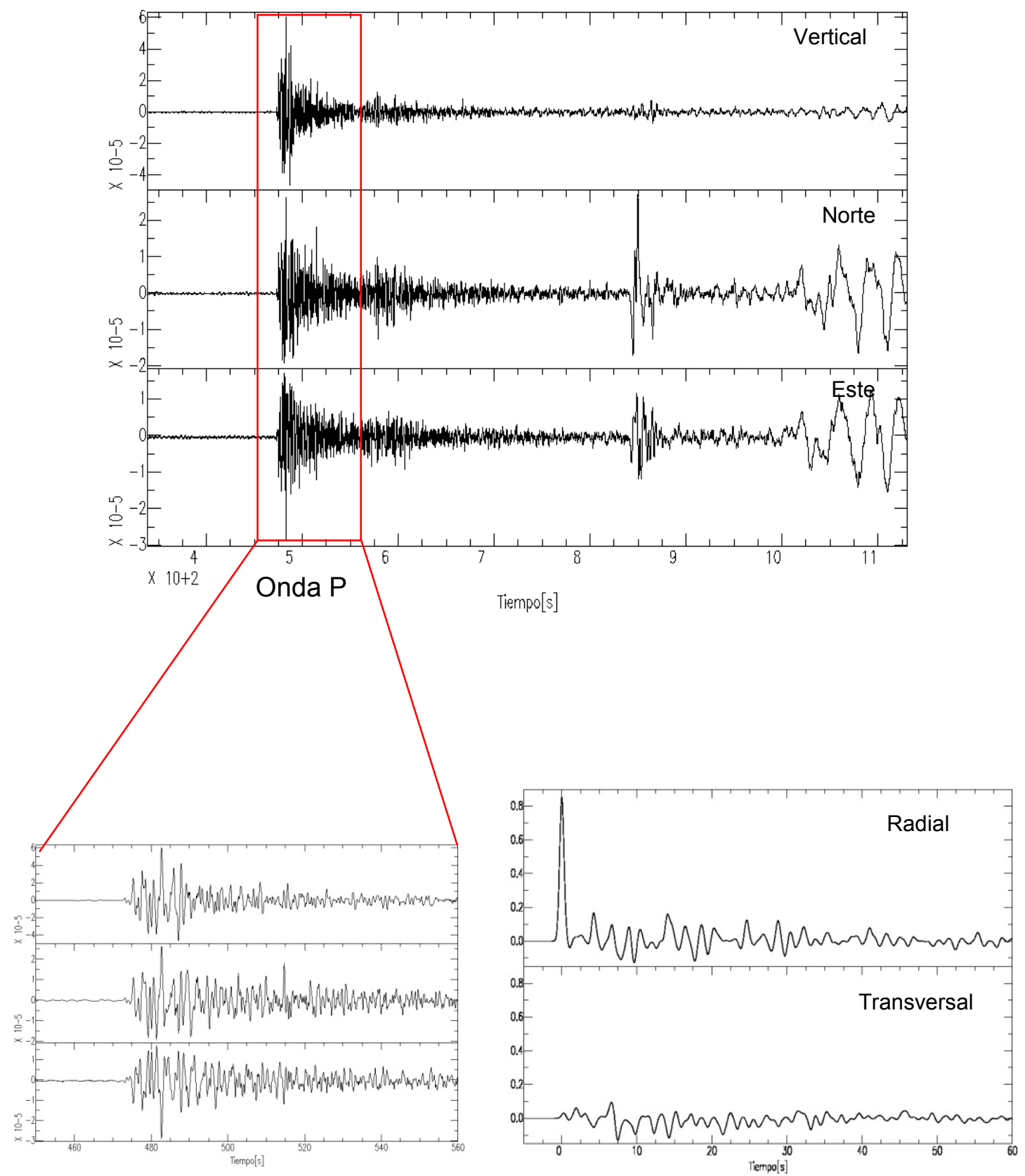

Figura 3.3: Registro de un sismo de magnitud 6.6 en la estación CPUP distante 4490 km (gráfico superior). Registro de la forma de onda P (gráfico inferior, panel izquierdo) y funciones receptoras radial y transversal (gráfico inferior, panel derecho). 


\subsection{Datos}

Se realizó un análisis de funciones receptoras en tres estaciones sismológicas ubicadas en el Sudamérica (Fig. 3.4). Las estaciones LPA y TRQA se ubican en la provincia de Buenos Aires, Argentina y fueron presentadas en el capítulo 2, inciso 2.5.1.1. La estación CPUP se encuentra en la localidad de Villa Florida, Paraguay.

En Paraguay se manifiestan dos núcleos precámbricos que se localizan al oeste de la cuenca de Paraná, el cratón del Río Apa que representa la continuación más austral del cratón del Amazonas, en Brasil y el cratón del Río Tebicuary que representa la manifestación más septentrional del cratón del Río de La Plata.

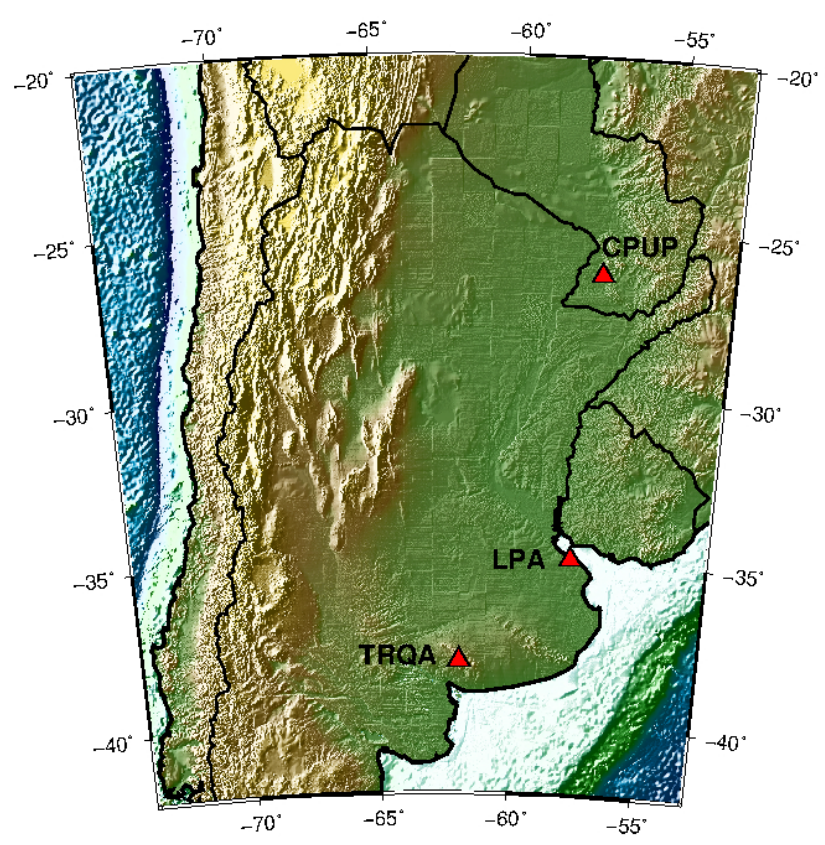

Figura 3.4: Estaciones sismológicas CPUP (Paraguay), LPA y TRQA (Argentina) utilizadas en el análisis de funciones receptoras.

La estación sismológica internacional CPUP se sitúa en el centro del Precámbrico Sur de Paraguay, en el Complejo del Río Tebicuary, que está compuesto de rocas cristalinas afectadas por un metamorfismo de alto grado. La estación funciona desde el año 1994 y forma parte de la red GTSN (Global Telemetered Seismograph Network). Está equipada con un sensor de pozo banda ancha de tres componentes Geotech/Teledyne modelo KS54000 y con un adquisidor Quanterra QX80.

\subsubsection{Selección de eventos}

Para obtener las FRs se utilizaron registros de ondas $\mathrm{P}$ de eventos telesísmicos $\left(30^{\circ}-90^{\circ}\right)$ localizados en los catálogos internacionales de NEIC-USGS 
(National Earthquake Information Center, U.S. Geological Survey, EEUU) y de IRIS (Incorporated Research Institutions for Seismology, EEUU). Se seleccionaron sismos con magnitudes mayores que 5.5 para el caso de las estaciones TRQA y CPUP; y mayores que 5.8 para la estación LPA, teniendo en cuenta la relación señal/ruido de esta última. Los 340 sismos registrados en la estación LPA corresponden a un período comprendido entre octubre de 2006 y noviembre de 2013. Para la estación TRQA se obtuvieron 1697 sismos correspondientes a un período comprendido entre octubre de 2000 y septiembre de 2013. Finalmente para la estación CPUP se emplearon 1302 sismos en un período comprendido entre septiembre de 1994 y septiembre de 2013. Las fuentes telesísmicas utilizadas se ubican principalmente a lo largo de los bordes de la placa de Nazca, placa Antártica; en la dorsal Atlántica; en las placas de Scotia, del Caribe y en el sur de la placa Norteamericana.

\subsubsection{Procesamiento inicial}

Se adaptaron los programas de análisis existentes al formato de los datos y se elaboraron programas en Linux necesarios para poder leer y procesar los distintos formatos de los datos sismológicos. Para los sismos registrados en la estación LPA, se completaron los encabezamientos (headers) de los datos con la información de cada sismo mediante el programa de cálculo SAC. Se calculó el tiempo de arribo de la fase P para cada sismo, similar a lo detallado en la sección 2.5.1.2, que sirvió de guía para realizar el picado manual de la fase en cada traza mediante el programa SAC. Las formas de onda fueron decimadas a $10 \mathrm{~Hz}$ y se corrigieron por inclinación lineal para eliminar efectos de registración. Se realizó un filtrado pasa-altos por encima de $0.05 \mathrm{~Hz}$ para remover el ruido instrumental de baja frecuencia. La etapa final en la preparación de los datos consistió en considerar longitudes de ventana de distinta duración de la forma de onda y luego compararlas durante el proceso de ecualización de la fuente. En este caso las trazas se cortaron en ventanas cuya duración variaba entre $5 \mathrm{~s}$ antes y $40,60,80$, $100,120,140$ y $160 \mathrm{~s}$ después del arribo de la fase principal, respectivamente. Finalmente se rotaron las componentes horizontales, a componentes radial y transversal. 


\subsection{Resultados}

Se aplicó el método iterativo de deconvolución en el dominio del tiempo a las trazas rotadas mediante una rutina desarrollada por Ammon (2006a). Se usaron distintos anchos de banda $\alpha$ del filtro gaussiano, dependiendo de cada estación, con el fin de optimizar la información contenida en los datos. Para ello se analizaron distintos valores de $\alpha$ y se seleccionaron aquellos que exhibían mejores resultados, basados en la calidad, ruido y contenido de frecuencias de las FRs obtenidas. Los datos de las estaciones CPUP y TRQA se analizaron con dos anchos de banda (1.3 y 2.5) y se seleccionaron las FRs calculadas con un parámetro de 2.5. Las FRs para la estación LPA se estimaron con cinco valores de $\alpha(1,1.3,2.5,5.0$ y 10.0) debido al carácter oscilante que presentan y a la relación señal/ruido de la misma, escogiendo finalmente un parámetro de 1.3.

En general las FRs obtenidas presentaron una combinación de picos y valles generados por la interacción del frente de ondas $\mathrm{P}$ con la discontinuidad de Mohorovicic y otras discontinuidades debajo del receptor. El porcentaje de recuperación de la forma de onda radial fue evaluado mediante el desajuste por RMS (Root Mean Square) entre la forma de onda radial original y la convolución de la FR radial con la componente vertical original. Aquellos eventos que recuperaron menos del $80 \%$ de la forma de onda fueron descartados. Por último, las FRs seleccionadas $(\geq 80 \%)$ se inspeccionaron visualmente controlando la coherencia de la forma de onda y la estabilidad.

Una de las maneras más apropiadas para organizar la información de las FRs es clasificarlas en grupos que posean las mismas propiedades. Considerando que la respuesta del receptor puede variar de acuerdo a la dirección desde donde la onda $\mathrm{P}$ telesísmica se aproxima a la estación, resulta conveniente realizar un análisis de los distintos grupos de FRs de acuerdo a la dirección de procedencia, en vez de analizar todas las trazas en conjunto. Por tal motivo, las componentes radial y transversal para cada estación fueron calculadas y graficadas en función del back-azimuth. Esta representación resulta útil para identificar variaciones laterales en la estructura subyacente y para examinar una posible estructura 3-D compleja debajo de la estación. En escenarios homogéneos y planos, la amplitud de los arribos de la componente transversal debería ser muy pequeña comparada 
con la componente radial. Diversos trabajos han utilizado FRs transversales para detectar capas buzantes o anisotropía local (e.g., Zhang and Langston, 1995).

Las FRs también fueron agrupadas por la distancia recorrida o por el parámetro de rayo o lentitud horizontal. Estas representaciones permiten distinguir de manera más sencilla las distintas fases presentes en las FRs. La amplitud de la fase Ps siempre disminuye para distancias mayores o disminución del parámetro $P$. Mientras que las amplitudes de las fases múltiples permanecen constantes o aumentan a distancias mayores. Esto es útil para discernir entre las fases Ps y múltiples (Cassidy, 1992).

\subsubsection{Estación sismológica CPUP}

De acuerdo a los criterios mencionados anteriormente se seleccionaron 321 FRs para esta estación, que corresponden a sismos cuyos epicentros se presentan en la Fig. 3.5.

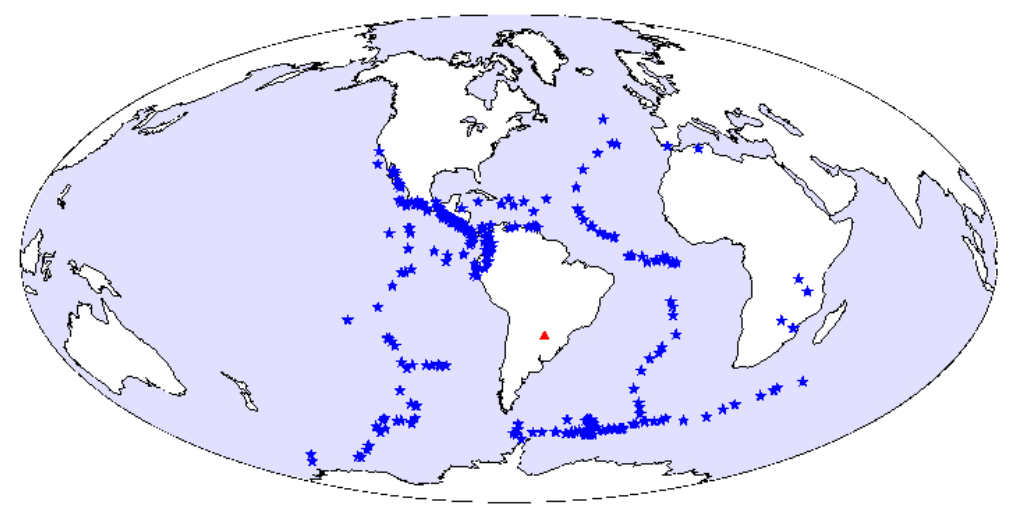

Figura 3.5: Eventos telesísmicos (azul) correspondientes a las FRs seleccionadas en la estación CPUP (rojo) para el período comprendido entre septiembre de 1994 y septiembre de 2013.

Los datos analizados se ordenaron en grupos afines por distancia epicentral, por parámetro de rayo y por back-azimuth. El gráfico de FRs en función de la distancia epicentral (Fig. 3.6) permitió reconocer las distintas fases que fueron señaladas en la figura. La fase P directa se marcó en azul, la fase Ps convertida en rojo y la múltiple PpPs en verde.

Se observa en la Fig. 3.6 que la diferencia de tiempo entre la fases directa y convertida disminuye para distancias epicentrales mayores, siendo éste, a 
menudo, un recurso utilizado para distinguir ambas fases. Una situación similar se observa en el gráfico de las FRs en función del parámetro del rayo (Fig. 3.7), en donde esta diferencia de tiempo aumenta con el aumento del parámetro del rayo.

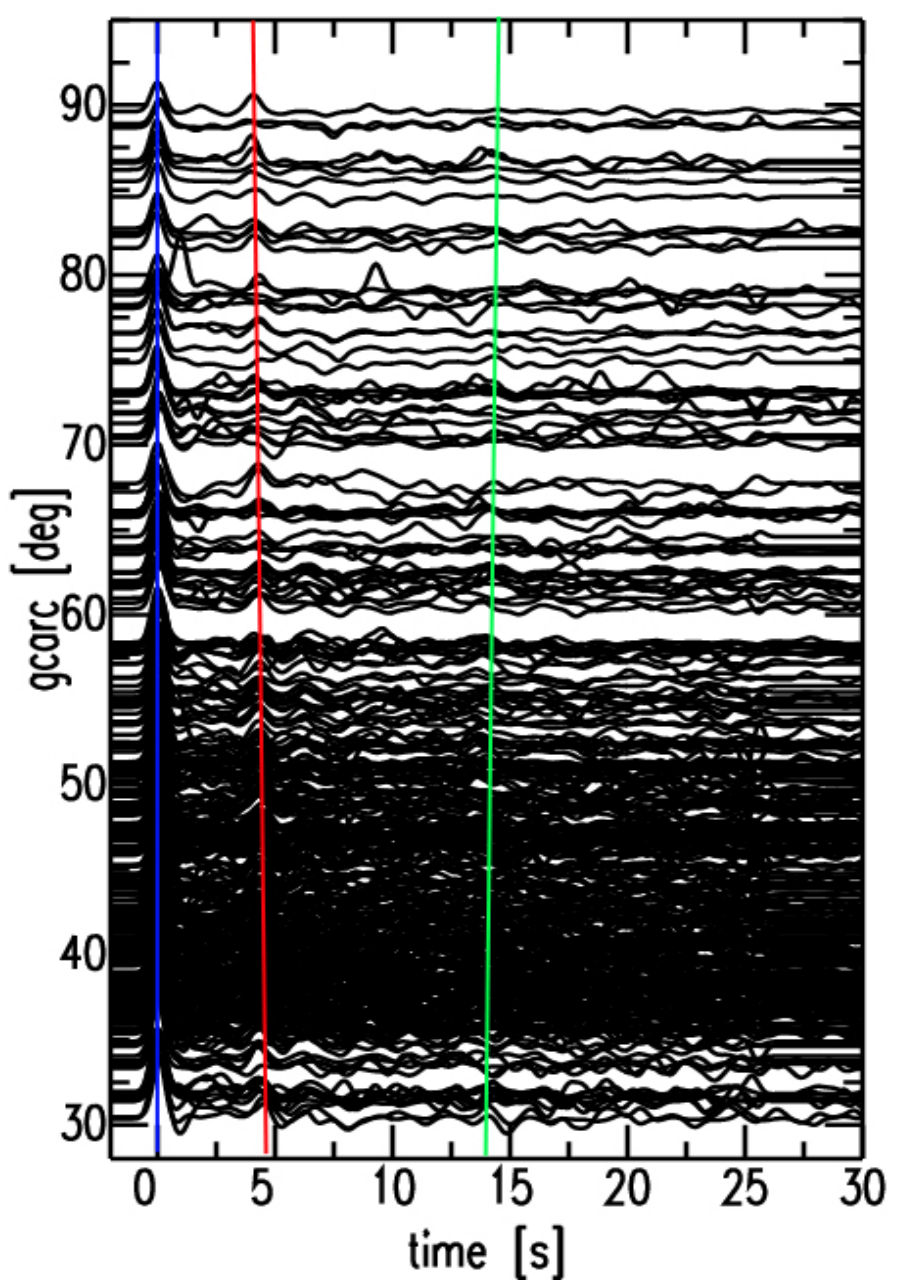

Figura 3.6: Funciones receptoras para la estación CPUP (calculadas con un ancho de banda $\alpha$ de 2.5) en función de la distancia epicentral. Se indican las distintas fases supuestas: fase $P$ en azul, fase Ps en rojo y fase PpPs en verde.

La Fig. 3.8 muestra las FRs radiales seleccionadas. Se puede observar la fase $\mathrm{P}$ directa centrada en el cero, la fase positiva distante aproximadamente $4 \mathrm{~s}$. correspondiente a la Ps convertida en la Moho y poca energía reverberante entre 0 y $4 \mathrm{seg}$, características típicas de estaciones con poco sedimento (Clitherol et al., 2000). Esta diferencia de tiempo entre la $P$ y la Ps es esperable en cortezas de aproximadamente $35 \mathrm{~km}$ espesor. 


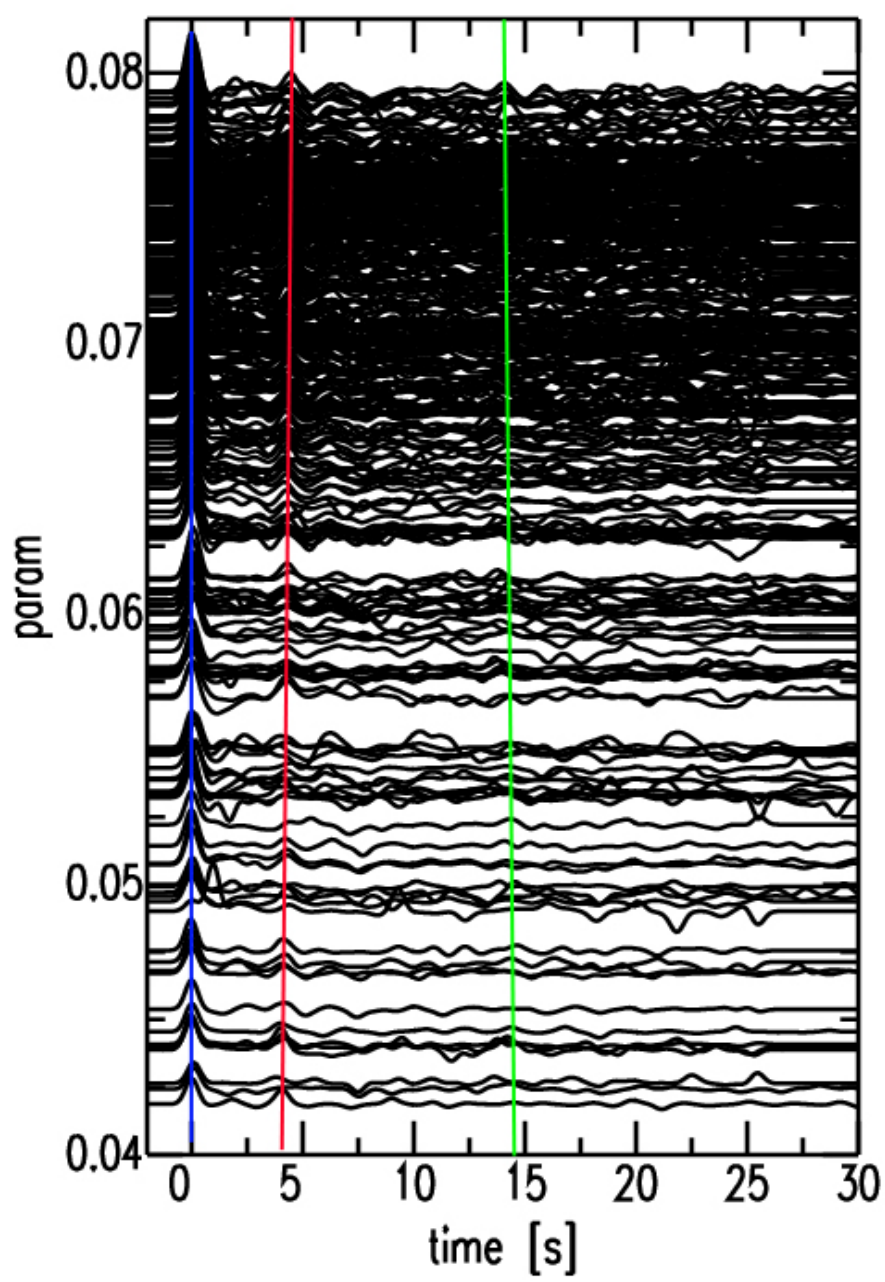

Figura 3.7: Funciones receptoras para la estación CPUP (calculadas con $\alpha$ de 2.5) en función del parámetro del rayo o lentitud horizontal. Se indican las distintas fases supuestas: fase P en azul, fase Ps en rojo y fase PpPs en verde.

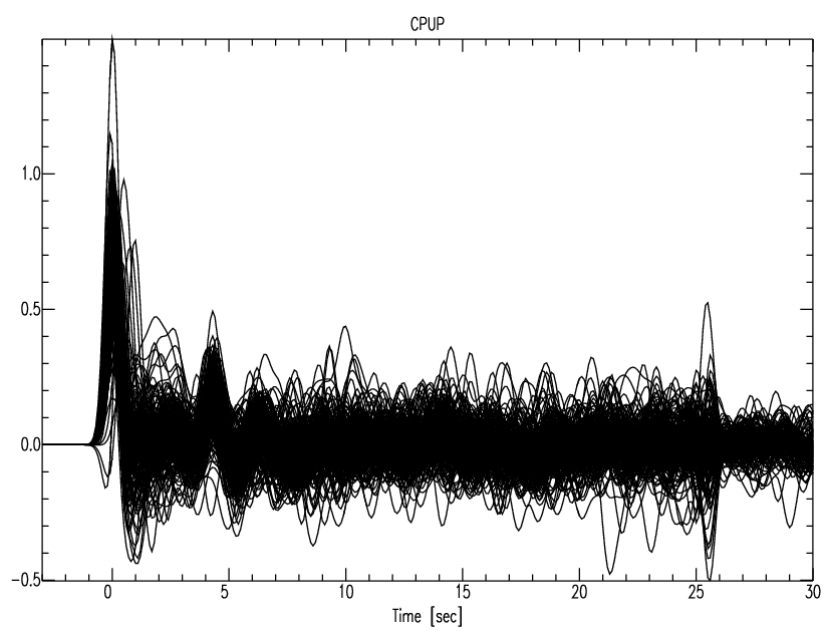

Figura 3.8: Funciones receptoras radiales seleccionadas para la estación CPUP. Se observan las fases $\mathrm{P}$ y $\mathrm{Ps}$ distantes $4 \mathrm{~s}$ aproximadamente. 
Se realizó el promedio o stack robusto de FRs para los distintos backazimuths de manera de reducir el ruido y resaltar los arribos más fuertes y consistentes (Fig. 3.9). El criterio implementado para formar los grupos consistió en dividir los back-azimuths de las FRS en 8 conjuntos NE [22.5 $5^{\circ}-67.5^{\circ}$ ], E [67.5

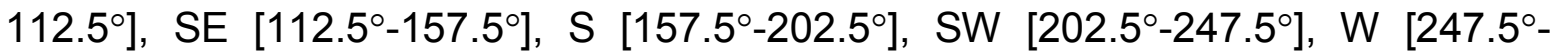
$292.5^{\circ}$ ], NW [292.5 $\left.-337.5^{\circ}\right]$, y $\mathrm{N}\left[337.5^{\circ}-22.5^{\circ}\right]$. Los resultados se muestran en pares de gráficos que presentan características muy similares.
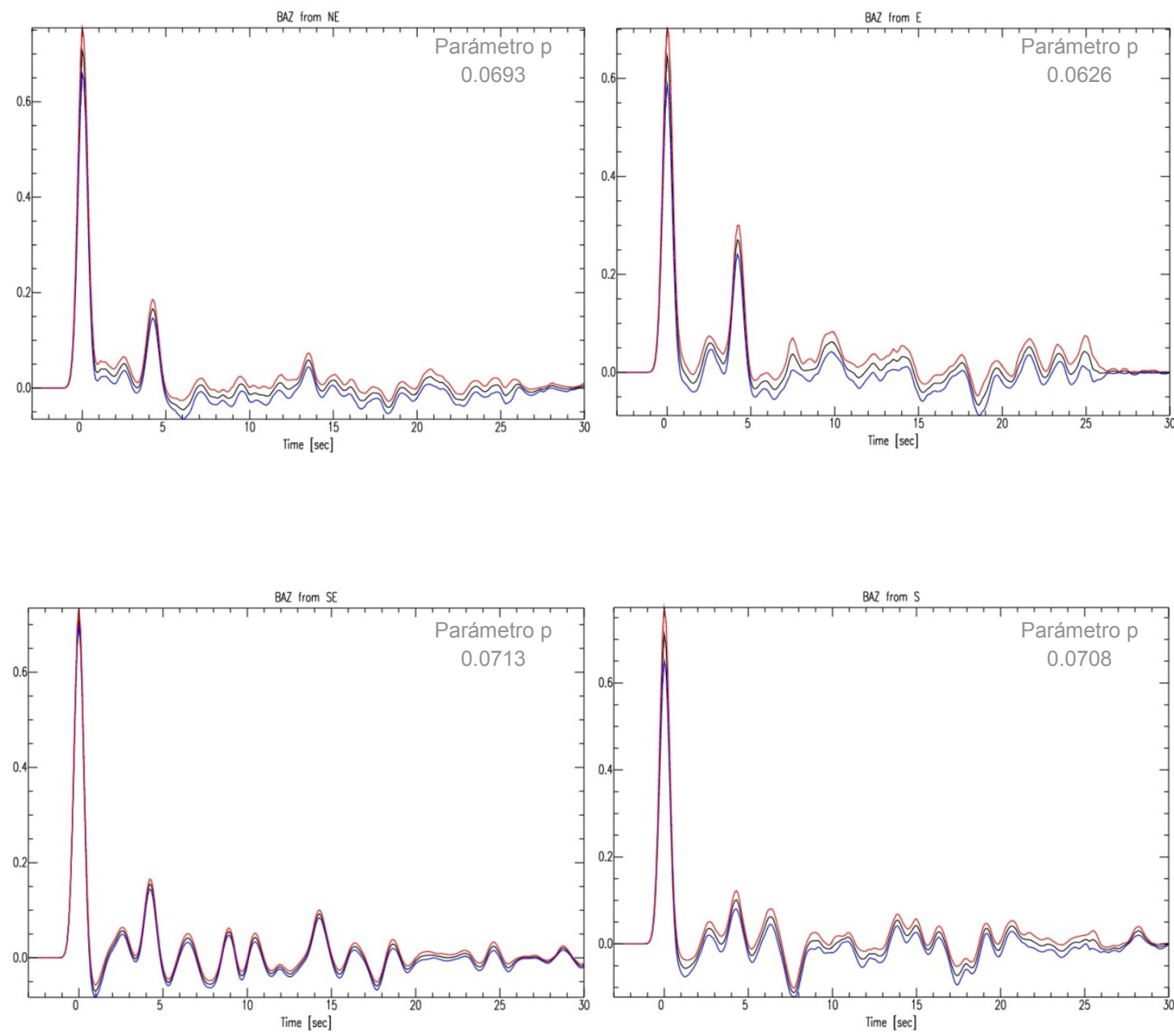

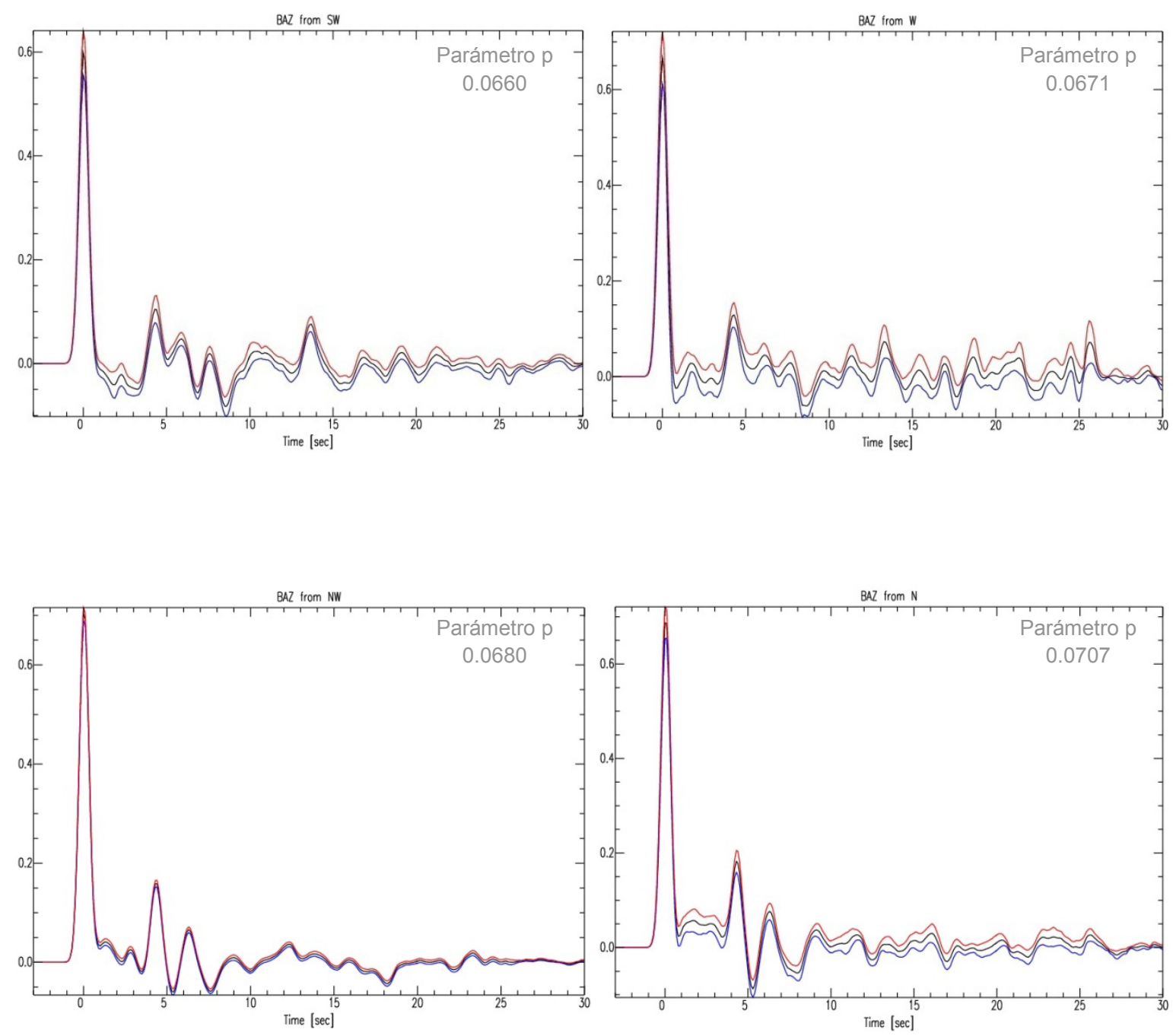

Figura 3.9: Stack de funciones receptoras por back-azimuth, agrupados en 8 direcciones, para CPUP.

Analizando los gráficos de las FRs radiales y transversales en función del back-azimuth (Fig. 3.10) se observa que las amplitudes de los arribos de las componentes transversales son en general pequeñas en relación con las radiales.

Con el fin de poder efectuar una mejor comparación, se realizaron los promedios de las FRs transversales para los distintos back-azimuths según el criterio mencionado anteriormente, y se graficaron junto a los promedios correspondientes de las FRs radiales (Fig. 3.11). Se observa que las ondas que llegan a la estación desde el S (back-azimuth $\sim 180^{\circ}$ ), SW (back-azimuth $\sim 225^{\circ}$ ) y 
NW (back-azimuth $\sim 315^{\circ}$ ) presentan mayor energía para la componente transversal, indicando posibles variaciones laterales en la estructura subyacente.
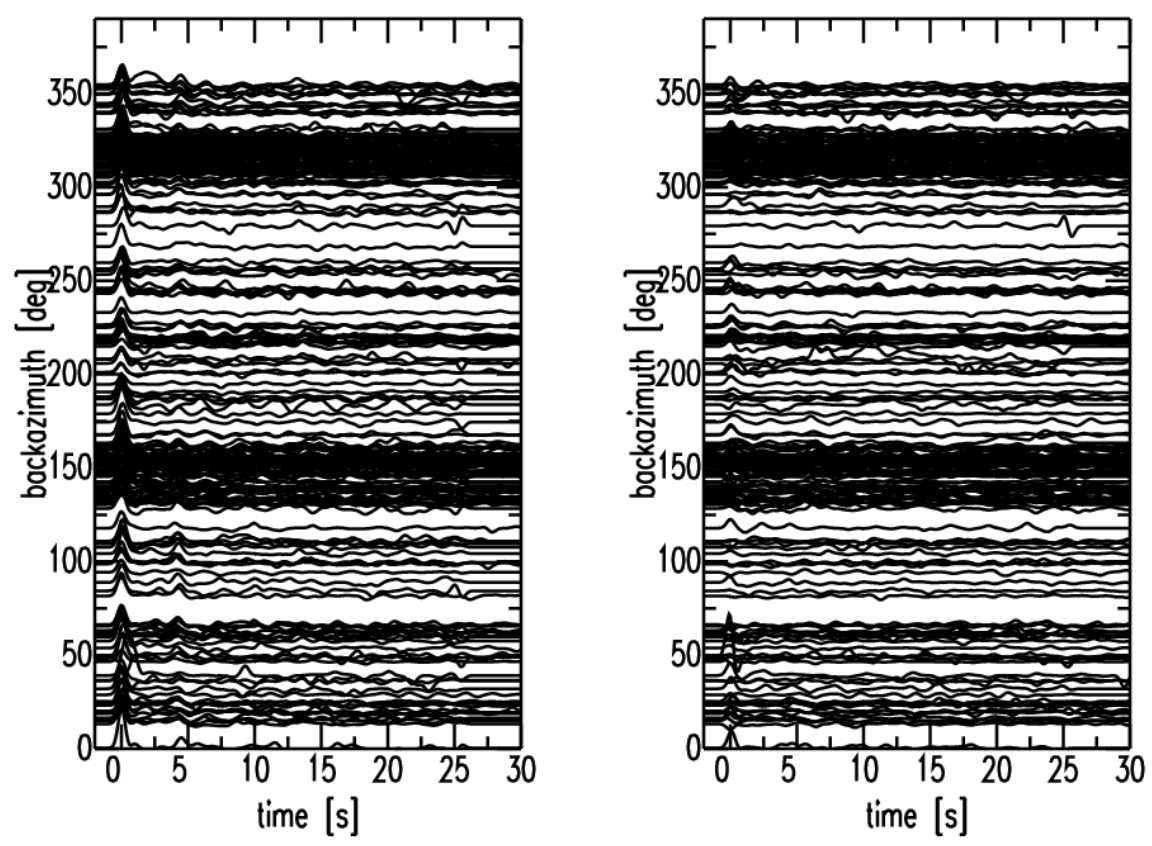

Figura 3.10: Funciones receptoras radiales (izquierda) y transversales (derecha) en función del back-azimuth para CPUP. Las amplitudes de los arribos de las componentes transversales son en general pequeñas en relación con las radiales.
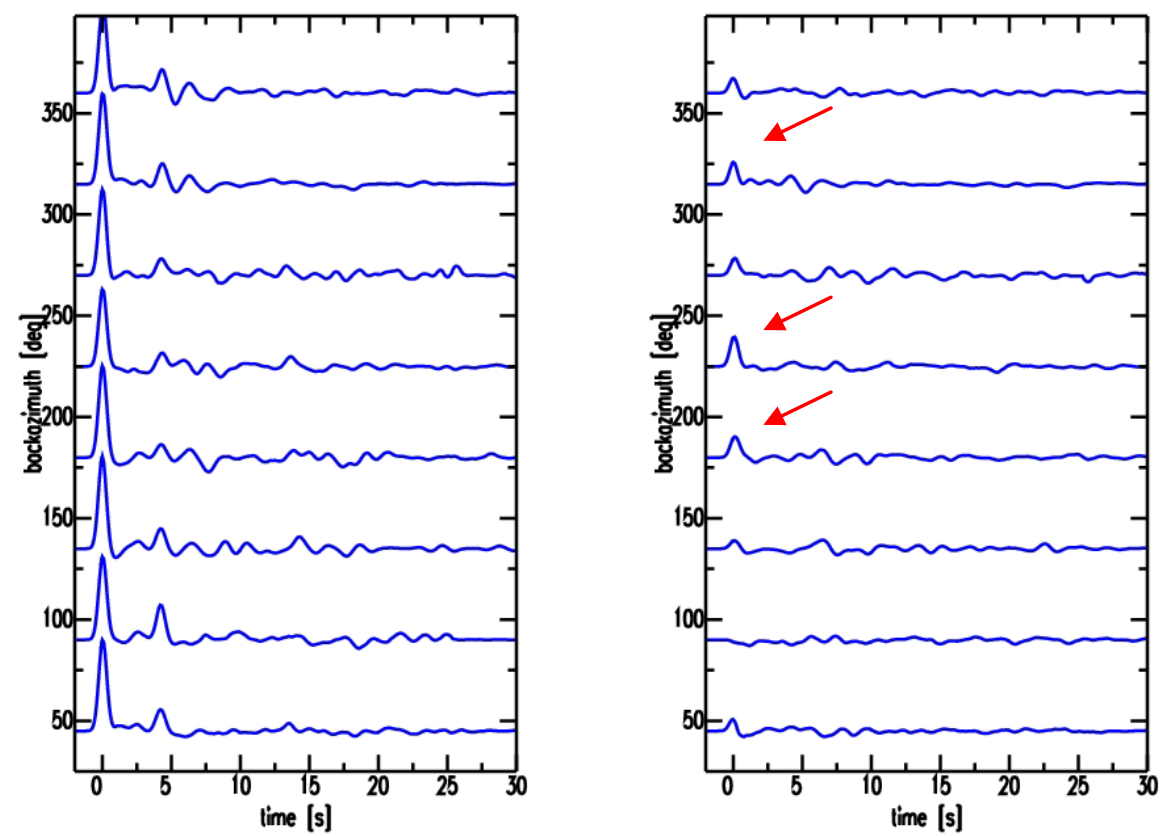

Figura 3.11: Funciones receptoras radiales y transversales promediadas para back-azimuths similares para CPUP. Se indican con flechas las FRs transversales que presentan mayor amplitud que pueden indicar posibles variaciones laterales en la estructura subyacente. 


\subsubsection{Estación sismológica TRQA}

En la Fig. 3.12 se muestran los epicentros de los sismos correspondientes a las 270 FRs que cumplen con los criterios de selección, para la estación TRQA.

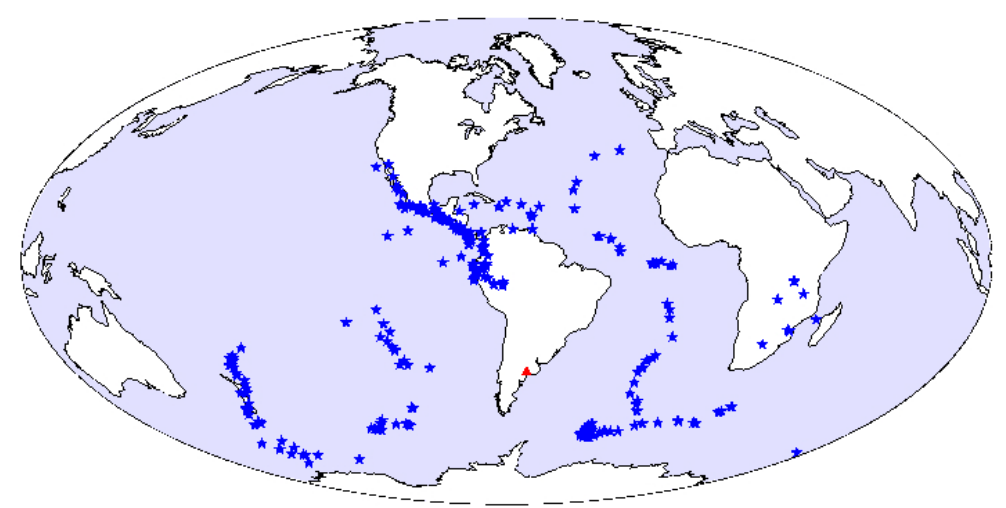

Figura 3.12: Telesismos (azul) correspondientes a las FRs seleccionadas en la estación TRQA (rojo) para el período comprendido entre octubre de 2000 y septiembre de 2013.

Las FRs fueron agrupadas de acuerdo a la distancia recorrida, al parámetro de rayo y al back-azimuth en la estación. En los gráficos de las FRs en función de la distancia epicentral (Fig. 3.13) y en función del parámetro del rayo (Fig. 3.14) se puede observar claramente la fase $\mathrm{P}$ directa marcada en azul. La Ps convertida marcada en rojo, no se distingue claramente. Una situación similar ocurre para las fases múltiples que no han sido destacadas en los gráficos. Esto podría deberse a una transición corteza-manto gradual que hace que la energía de las fases que interactúan en el borde se disperse en tiempo, de modo que los pulsos correspondientes disminuyen en amplitud y aumentan su ancho. Este efecto es mayor en las múltiples debido a que siguen trayectorias más largas por el medio, y las fases reverberantes se vuelven más propensas a estar contaminadas o incluso enmascaradas por un scattering de fondo (background scattering) (Julià and Mejia, 2004). Esto no afecta la interpretación porque se puede prescindir de la información de las amplitudes de una de las múltiples, pero no de la información de la fase Ps (Julià, 2007).

Con el propósito de identificar las distintas fases, se realizaron los promedios para distancias epicentrales entre $30^{\circ}$ y $90^{\circ}$ (Fig. 3.15), de manera de 
reducir el ruido y resaltar los arribos más enérgicos y consistentes. El criterio utilizado fue agrupar las FRs cada $10^{\circ}$. Esto permitió poder distinguir la fase directa (azul), la convertida en la Moho (rojo), la múltiple positiva (verde) y la múltiple negativa (amarillo). La diferencia de tiempo observada entre las distintas fases es esperable en una corteza de aproximadamente $40 \mathrm{~km}$ espesor.

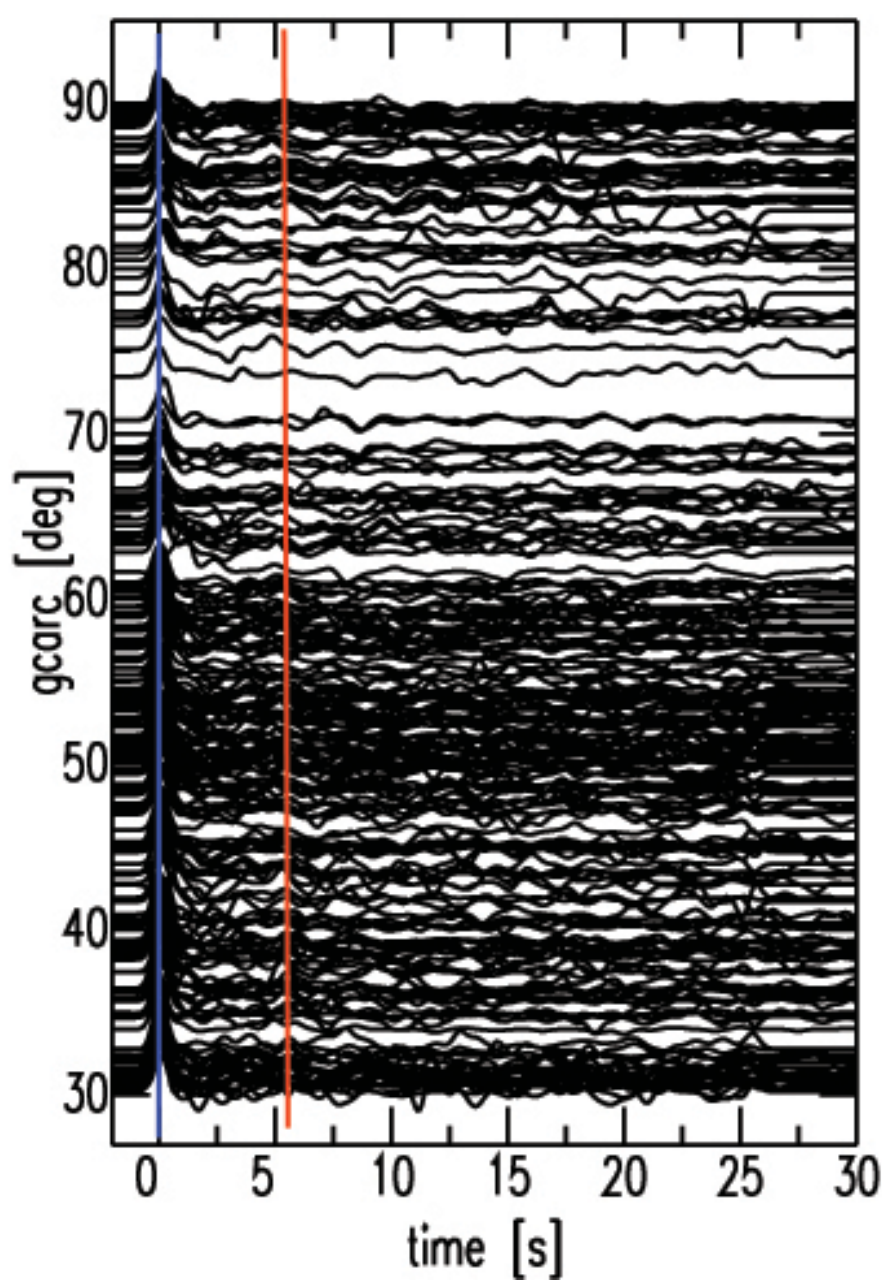

Figura 3.13: Funciones receptoras para la estación TRQA (calculadas con un ancho de banda $\alpha$ de 2.5) en función de la distancia epicentral. Se señaló la fase $P$ en azul y la fase Ps en rojo que ha sido identificada a partir de los promedios realizados.

De igual manera que lo realizado para la estación anterior, en la Fig. 3.16 se muestran todas las FRs seleccionadas para TRQA. La Ps convertida en la Moho se observa aproximadamente a los $5 \mathrm{~s}$, la múltiple positiva cercana a los $16 \mathrm{~s}$ y múltiple negativa a los $20 \mathrm{~s}$. 


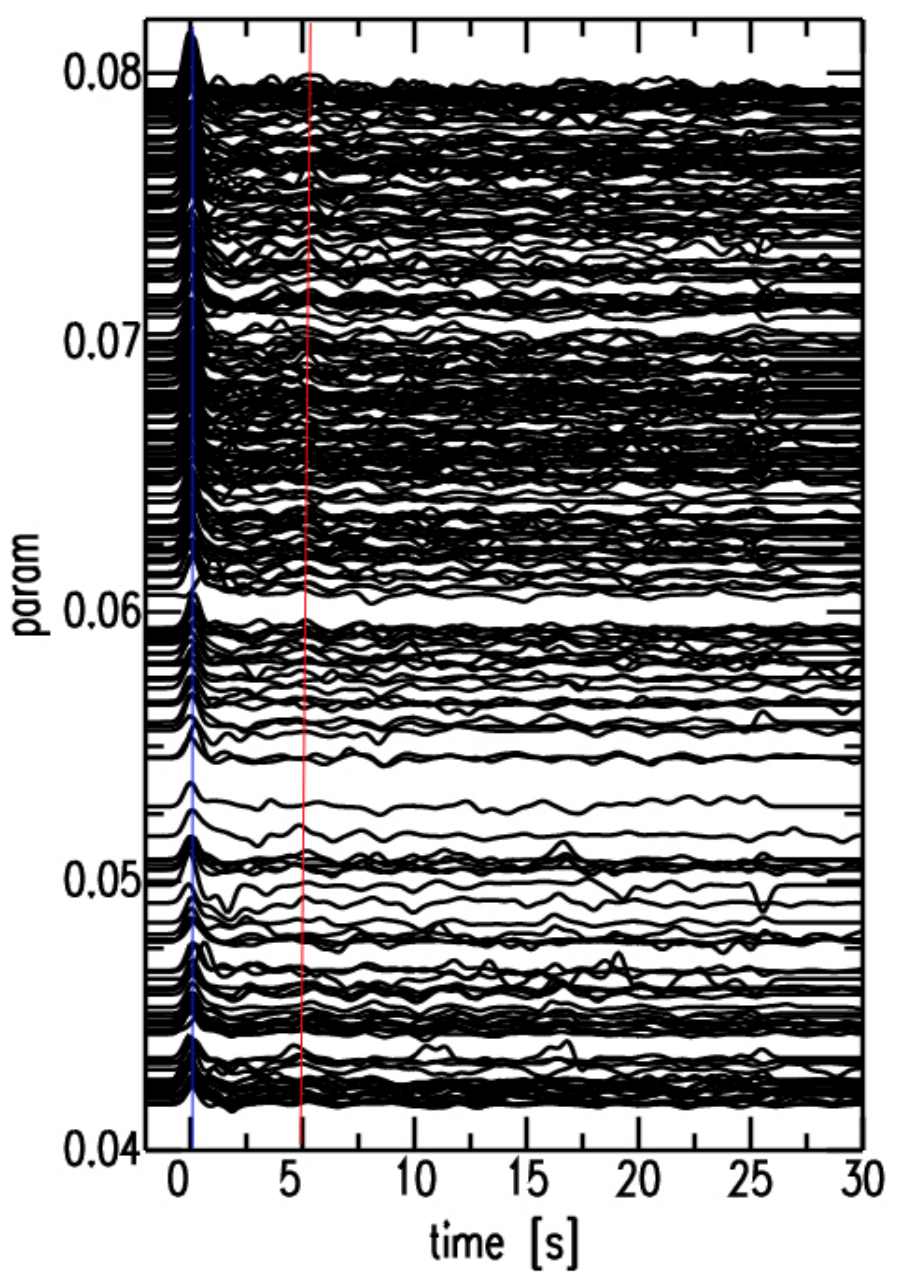

Figura 3.14: Funciones receptoras para la estación TRQA (calculadas con $\alpha 2.5$ ) en función del parámetro del rayo o lentitud horizontal. Se señaló la fase $\mathrm{P}$ en azul y la fase Ps en rojo que ha sido identificada a partir de los promedios realizados.

El análisis de las FRs en función del back-azimuth (Fig. 3.17) se realizó siguiendo los mismos criterios empleados para la estación CPUP. En todos los gráficos se observa claramente la fase directa. En los gráficos correspondientes a los BAZ del S, SW y W, se observa una fase negativa cercana a los $2 \mathrm{~s}$, más evidente que en el resto de los grupos. 


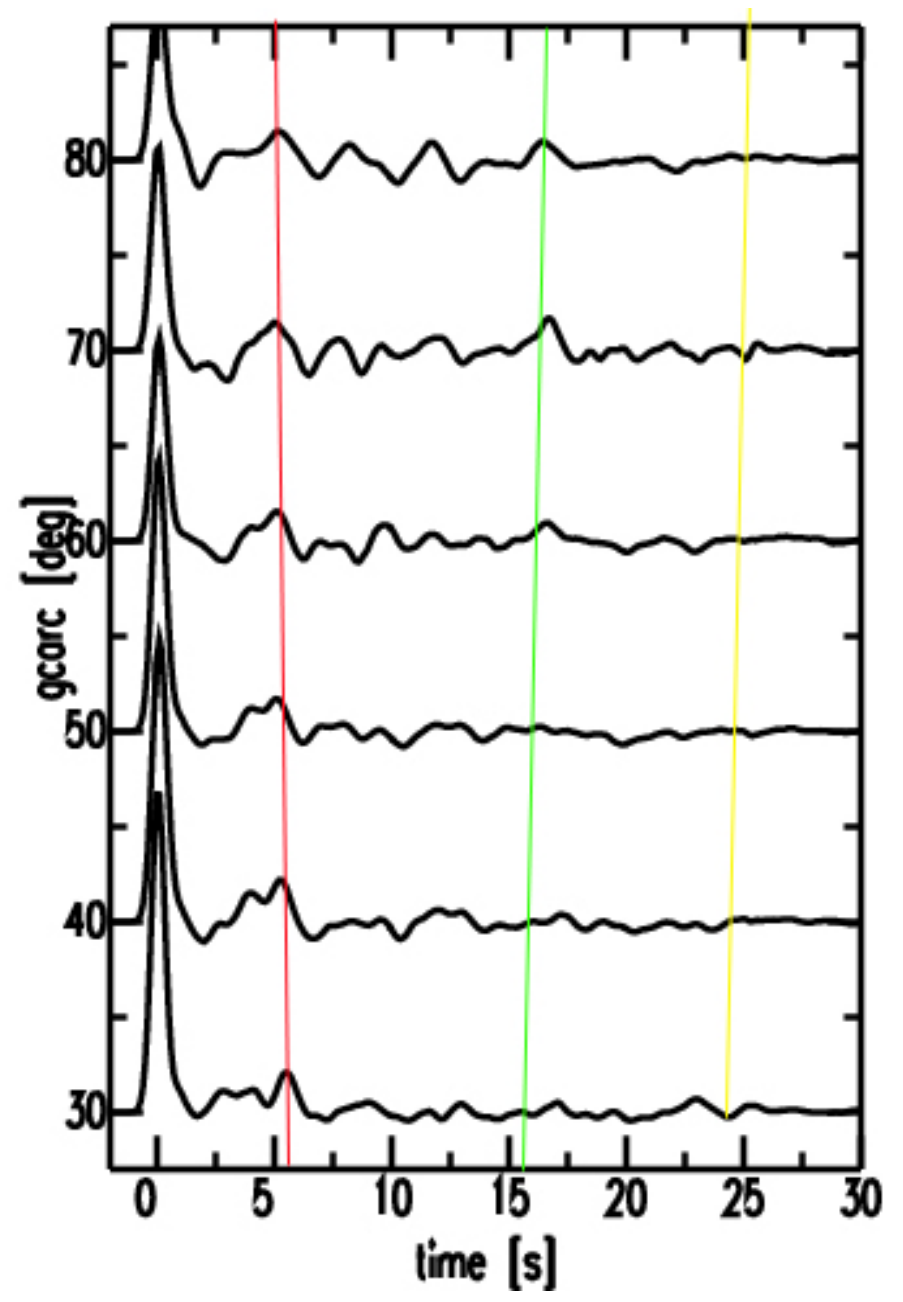

Figura 3.15: Funciones receptoras para TRQA promediadas por grupos de distancia epicentral. Se señaló la fase P en azul, la fase Ps en rojo, la fase PpPs en verde y la fase PpPs+PpSs en amarillo.

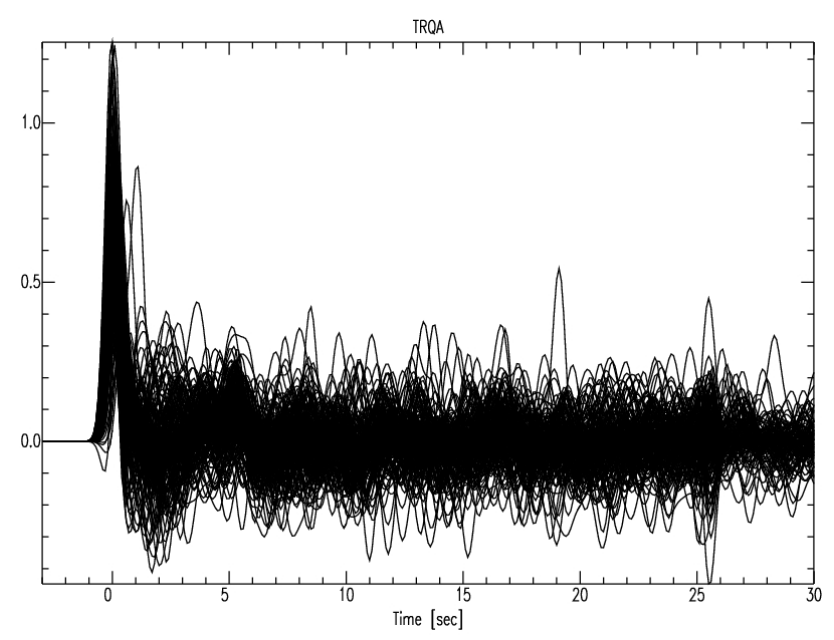

Figura 3.16: Funciones receptoras para la estación TRQA. 

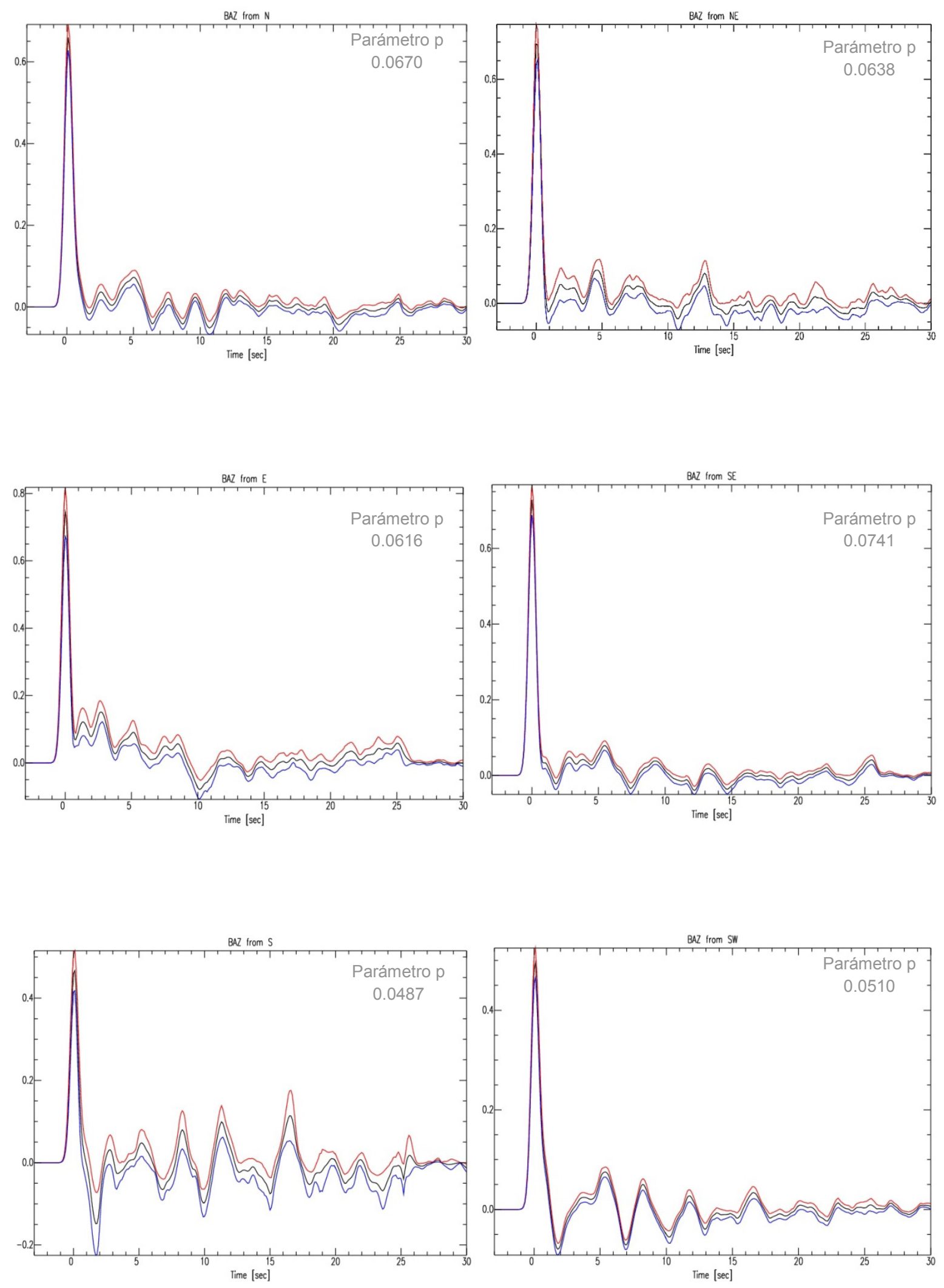

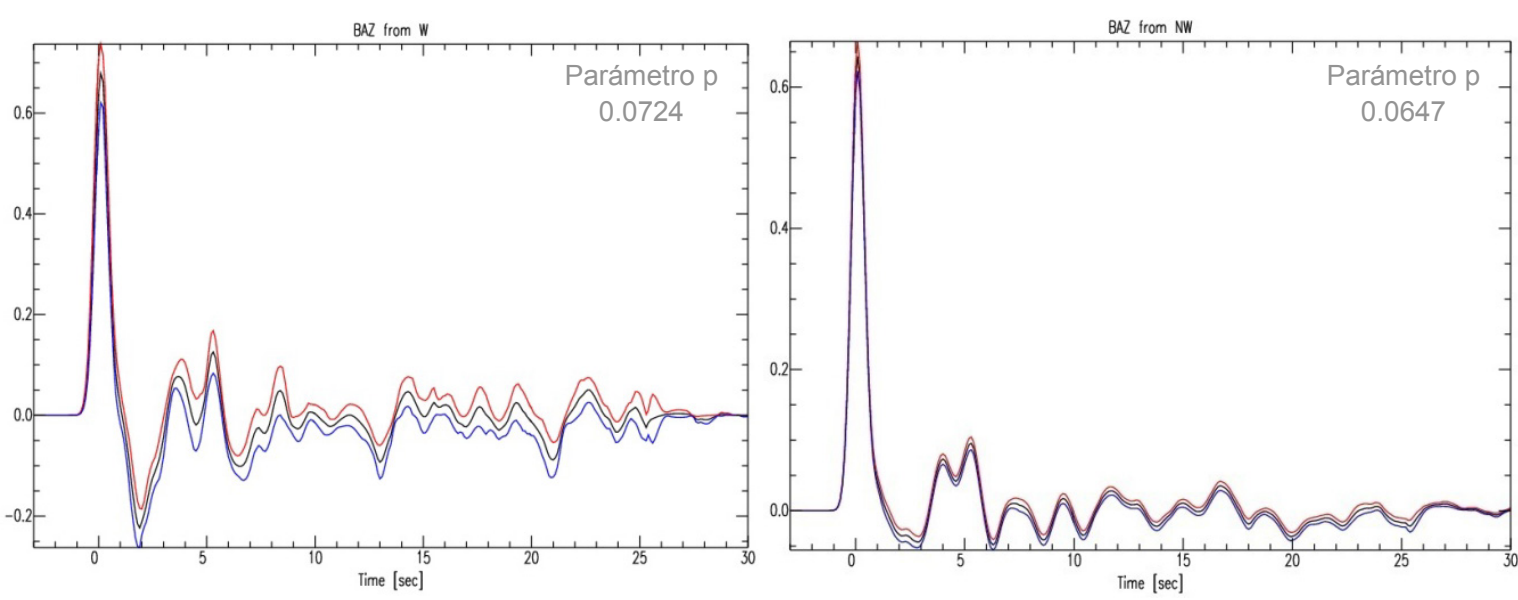

Figura 3.17: Stack de funciones receptoras por back-azimuth agrupadas en 8 direcciones para TRQA.

Analizando las FRs radiales y transversales en función del back-azimuth (Fig. 3.18) se observa que los arribos de las componentes transversales presentan en general amplitudes pequeñas comparadas con las radiales. La FR transversal correspondiente al NE (back-azimuth de $45^{\circ}$ ) presenta mayor energía, siendo esto
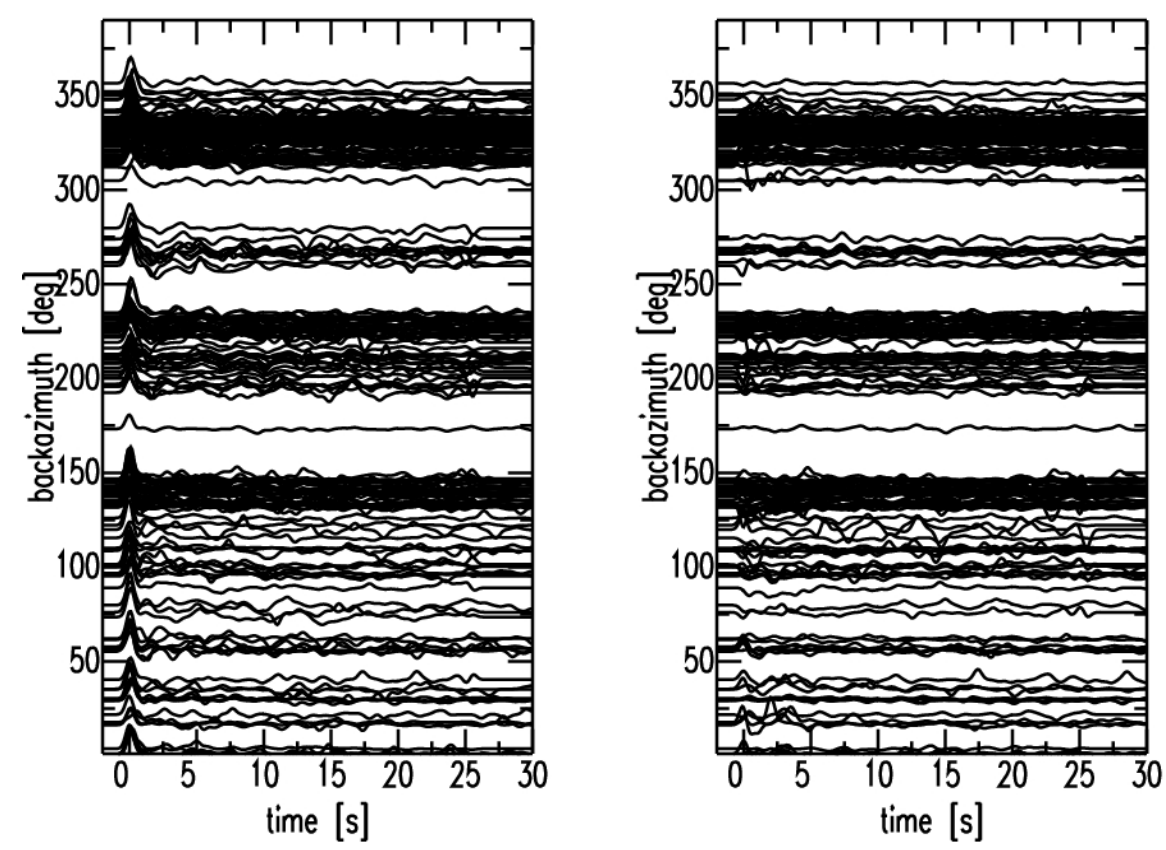

Figura 3.18: Funciones receptoras radiales (izquierda) y transversales (derecha) en función del back-azimuth para TRQA. Las amplitudes de los arribos de las componentes transversales son en general pequeñas en relación con las radiales. 
más claramente observable en los gráficos de los promedios de FRs para backazimuths similares (Fig. 3.19).
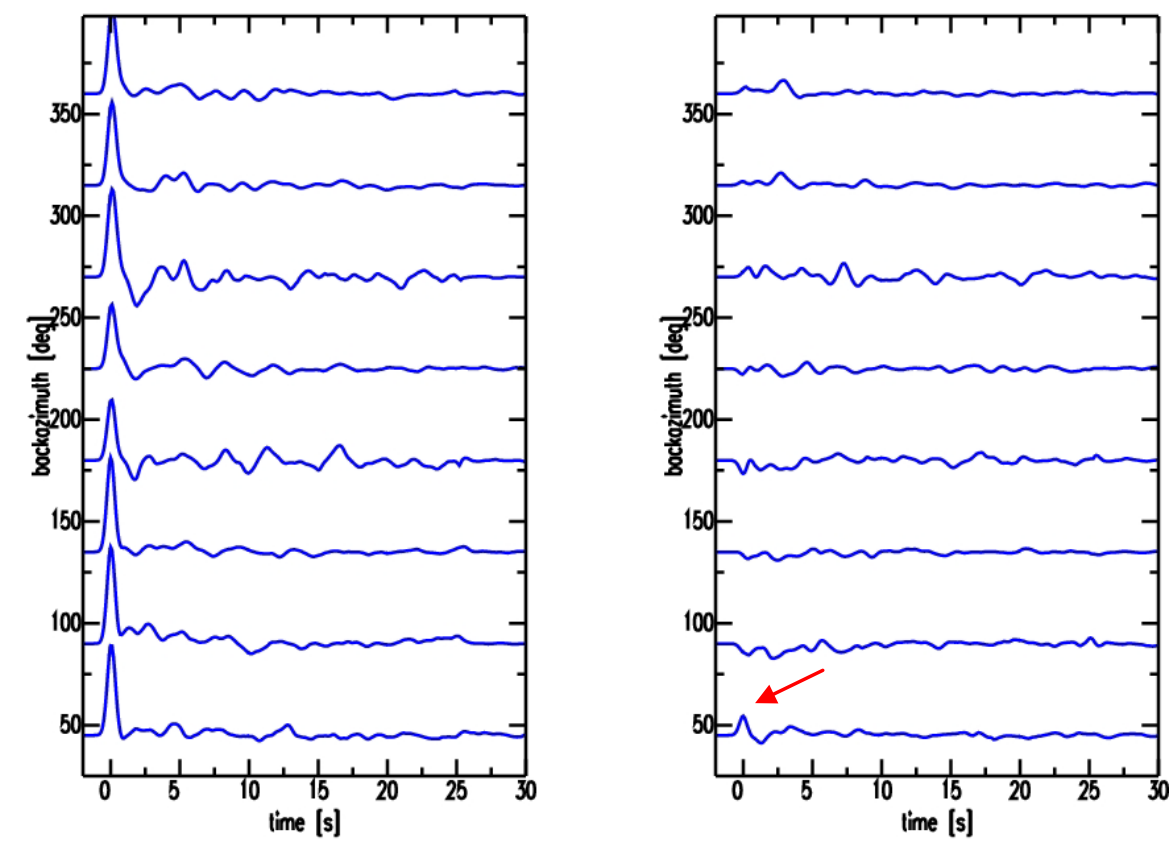

Figura 3.19: Funciones receptoras radiales y transversales promediadas para back-azimuths similares para TRQA. La flecha señala la FR transversal con mayor amplitud que puede indicar una posible variación lateral en la estructura subyacente.

\subsubsection{Estación sismológica LPA}

En esta estación se eligieron 171 FRs, correspondientes a sismos cuyos epicentros se presentan en la Fig. 3.20, que cumplen con los criterios de selección (sección 3.3.1).

Las FRs obtenidas (Fig. 3.21) presentan muchas oscilaciones. Este comportamiento es típico en estaciones ubicadas en regiones donde el cratón está cubierto por una gruesa capa de sedimentos con un alto contraste de velocidad respecto a las rocas del basamento, generando grandes reverberaciones que pueden enmascarar las conversiones en la discontinuidad de Mohorovicic (Zhu and Kanamori, 2000). 


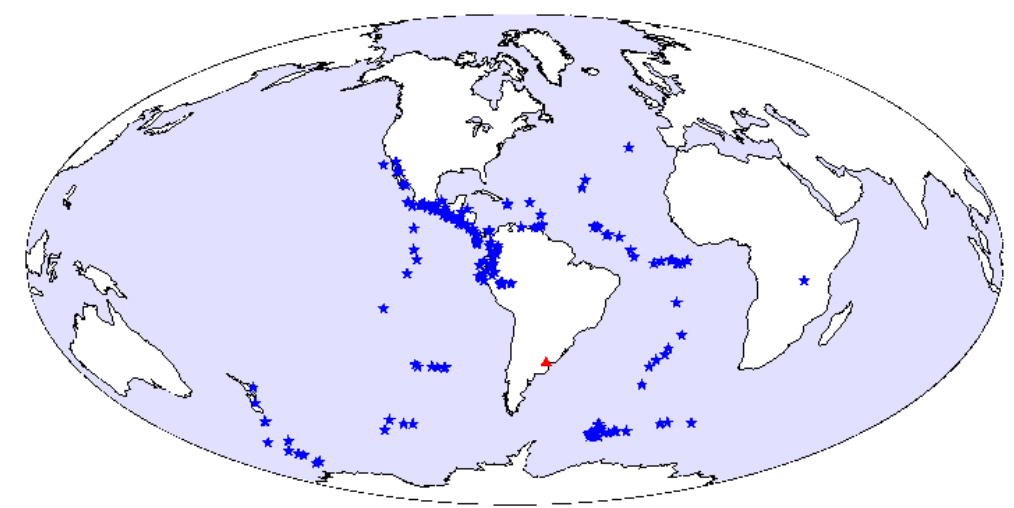

Figura 3.20: Telesismos (azul) utilizados en el análisis de las funciones receptoras en la estación LPA (rojo) para el período comprendido entre octubre de 2006 y noviembre de 2013.

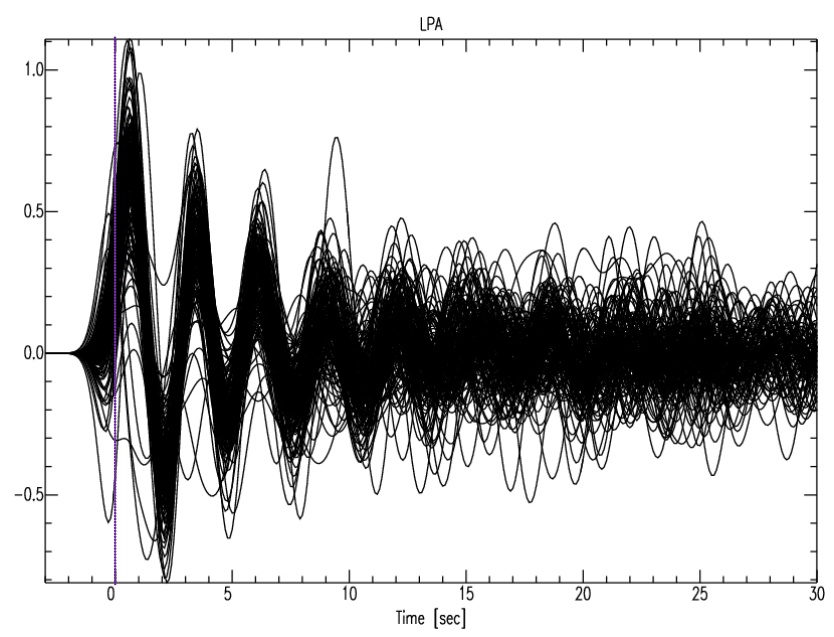

Figura 3.21: Funciones receptoras para la estación LPA calculadas con un ancho de banda $\alpha$ de 1.3. Se observa el carácter oscilante que presentan las mismas y el retraso en la fase $P$ directa.

No resulta fácil obtener funciones receptoras en estaciones ubicadas sobre sedimentos. Las capas con gran espesor sedimentario o con bajas velocidades asociadas a sedimentos no consolidados pueden interferir seriamente con las señales generadas en la Moho siendo difícil y hasta a veces imposible superar esas dificultades, incluso valiéndose de las bajas frecuencias. La energía atrapada puede reverberar por un largo tiempo en las estructuras cercanas a la superficie, interfiriendo con la Ps y con otras múltiples, enmascarando la información proveniente de la discontinuidad corteza-manto (Julià et al., 2004).

El retraso en el pico de la fase $P$ directa (Fig. 3.21) marca la presencia de esta interface de sedimentos bajo la estación. Esta pronunciada discontinuidad 
sedimento-basamento desvía los rayos, que entonces llegan a la superficie con pequeños ángulos de incidencia, aumentando su contribución en las FRs, generando al mismo tiempo una conversión Ps mayor que se registra apenas después de la $\mathrm{P}$ directa. El filtro gaussiano no puede separar ambos arribos, obteniéndose como resultado un pico de gran amplitud desplazado respecto del cero, supuesto como la $\mathrm{P}$ directa, en la FR. Esta amplitud está dominada por la fase convertida y no debe confundírsela con la onda P directa. La observación del desfasaje en el primer arribo es, por lo tanto, un diagnóstico de la fuerte influencia de los sedimentos (Julià, 2007).

A modo de ejemplo, en la Fig. 3.22 obtenida de Yeck et al. (2013) se muestran FRs sintéticas calculadas para un conjunto de espesores de cuencas sedimentarias, generadas utilizando una lentitud de 0.04 grado/s. Si la fase Ps de la Moho es contemporánea con las múltiples generadas en el sedimento, la situación se complica ya que arriban juntas a la estación, como se observa en el ejemplo de la figura correspondiente a los espesores sedimentarios de 5, 6 y $7 \mathrm{~km}$.
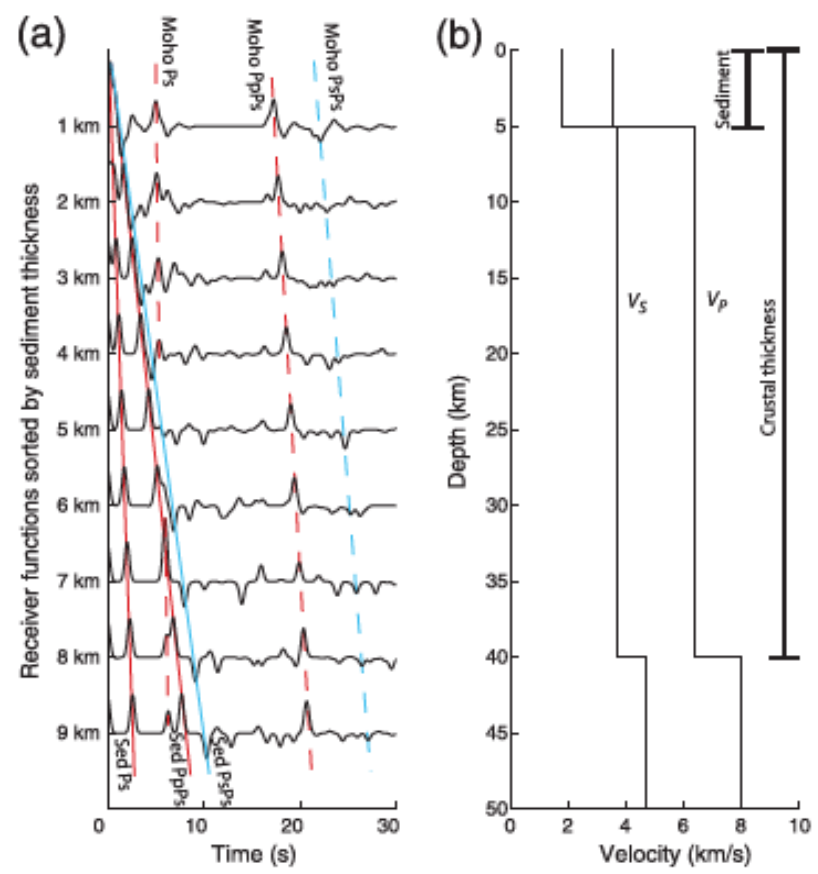

Figura 3.22: a) FR sintéticas calculadas para distintos espesores de cuencas sedimentarias. Las fases generadas en sedimentos están indicadas con línea sólida, las de la Moho con línea punteada. Algunas fases pequeñas son "artefactos" (artifacts) generados por la deconvolución. b) Modelo de velocidad utilizado para crear los sintéticos, donde se varió el espesor de la cuenca y se mantuvo constante el espesor cortical (extraido de Yeck et al., 2013). 
Se graficaron las FRs en función de la distancia recorrida (Fig. 3.23) y del parámetro de rayo (Fig. 3.24). Analizando los gráficos se puede interpretar que efectivamente existe una capa de sedimentos debajo de la estación, con velocidades pequeñas de $\mathrm{P}$ y $\mathrm{S}$, generando un alto contraste de velocidades en la discontinuidad sedimento-basamento. Debido a la gran diferencia de velocidad, los rayos de $\mathrm{P}$ y $\mathrm{Ps}$ se acentúan. La $\mathrm{P}$ directa se encuentra principalmente en la componente vertical y no en la radial (como se vio en las otras estaciones). El primer pulso positivo cerca de los 0.5 segundos (Fig. 3.21) corresponde a la conversión Ps en la discontinuidad sedimento-basamento. La energía de la onda S queda atrapada en la capa sedimentaria debido al gran contraste de velocidades, generando varias múltiples a los 2 segundos (PsSs negativa), a los 3 segundos (PsSsSs positiva), a los 4.5 segundos (PsSsSsSs negativa) y así continuando. Por

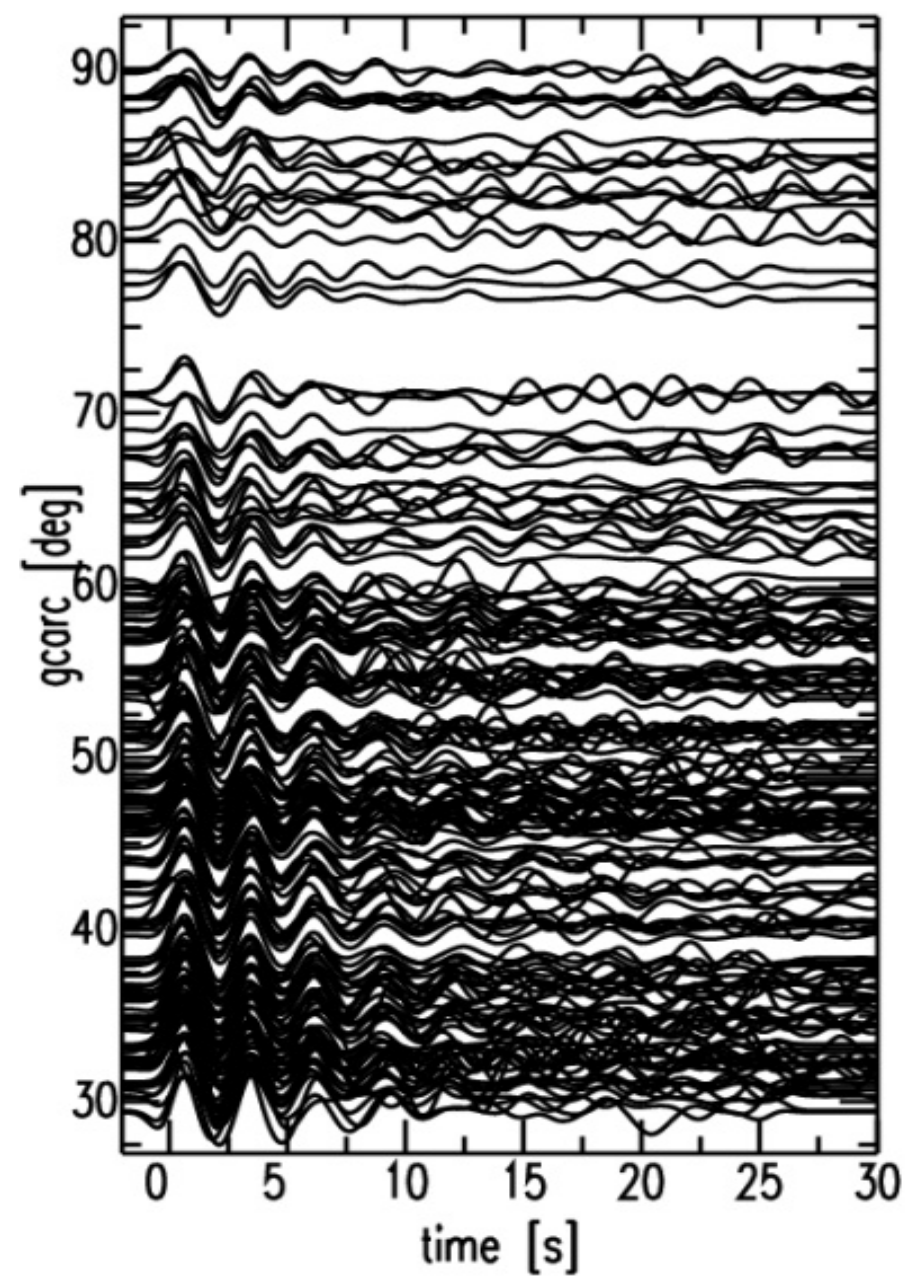

Figura 3.23: Funciones receptoras para la estación LPA en función de la distancia recorrida. Se observa en los primeros 20 segundos la reverberación de la energía de la onda S convertida. 
lo tanto, en los primeros 20 segundos se observa la reverberación de la energía de la onda S convertida, enmascarando las conversiones en la Moho. A partir de allí, las amplitudes comienzan a decaer.

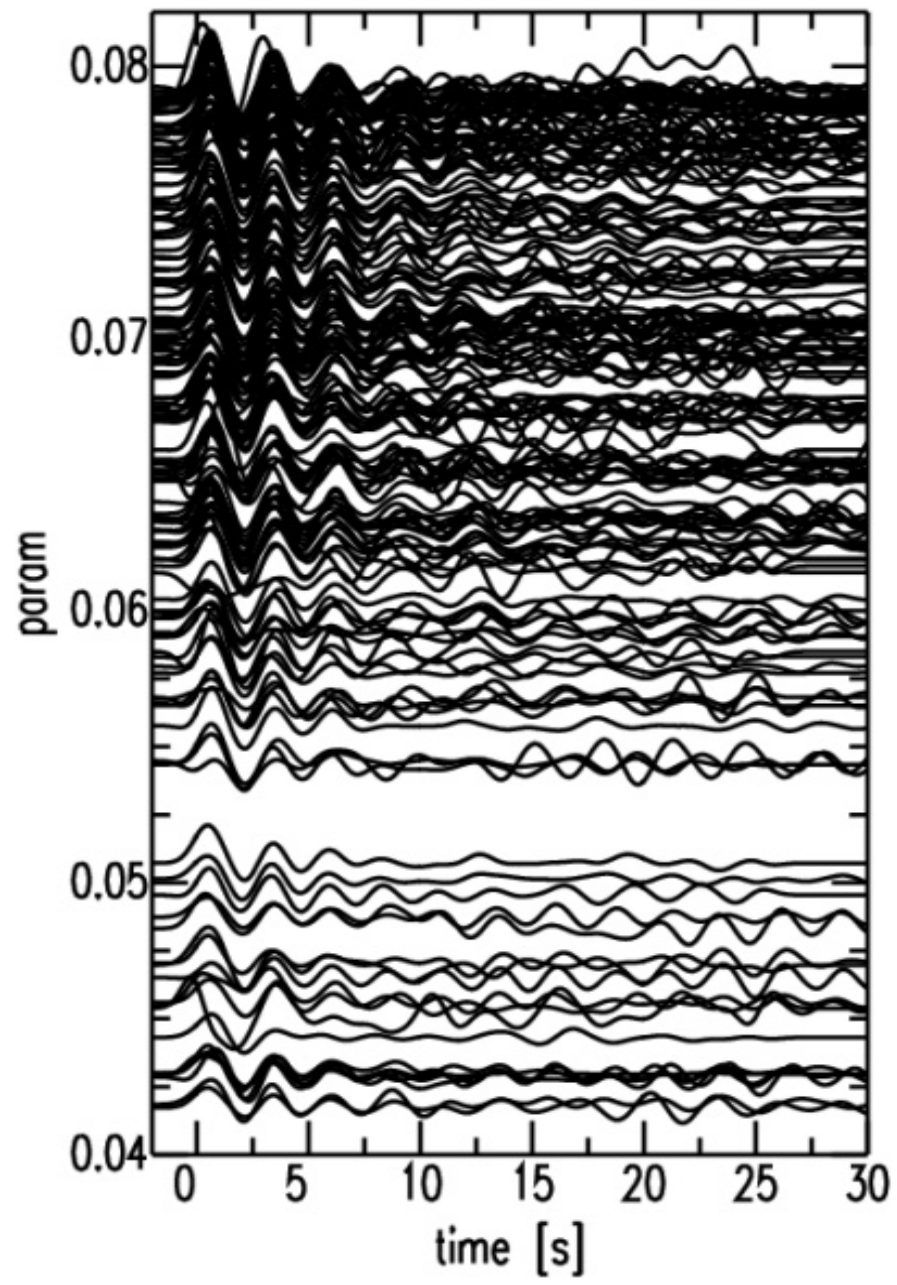

Figura 3.24: Funciones receptoras para la estación LPA en función del parámetro del rayo o lentitud horizontal.

El análisis de las FRs radiales en función del back-azimuth se realizó siguiendo los mismos criterios empleados para las otras estaciones (Fig. 3.25). En todos los gráficos se observa claramente el carácter oscilante y el desfasaje del primer arribo. Las FRs correspondientes a los BAZ del S y SW que son generadas por ondas con incidencia casi normal en la estación, presentan una amplitud menor, probablemente debido a anisotropía en la capa sedimentaria. 
Debido al carácter oscilante que también presentan las FRs transversales (Fig. 3.26), se realizaron los promedios de las componentes transversales para los distintos back-azimuths según el criterio mencionado anteriormente, y se graficaron junto a los de las radiales (Fig. 3.27).
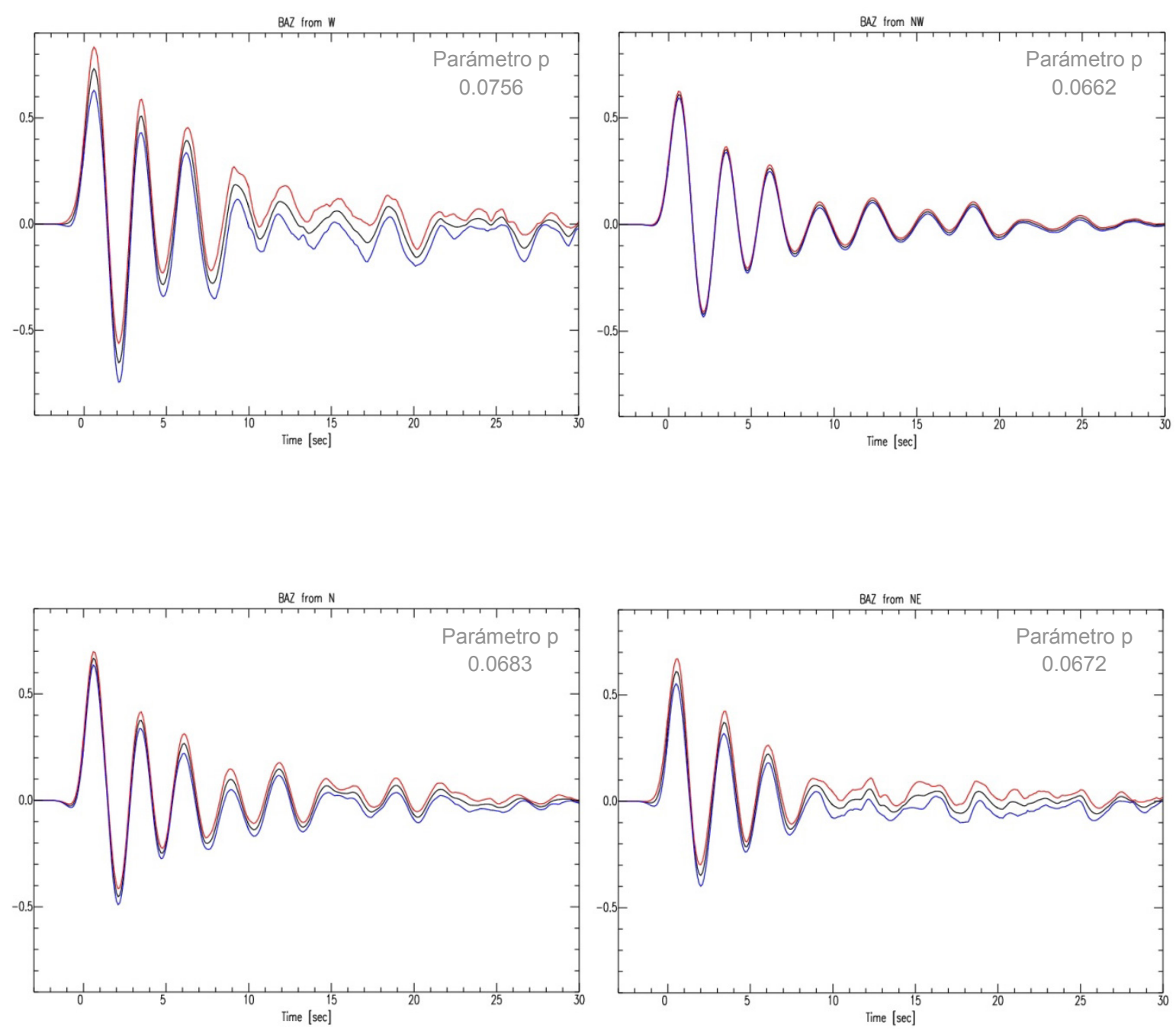

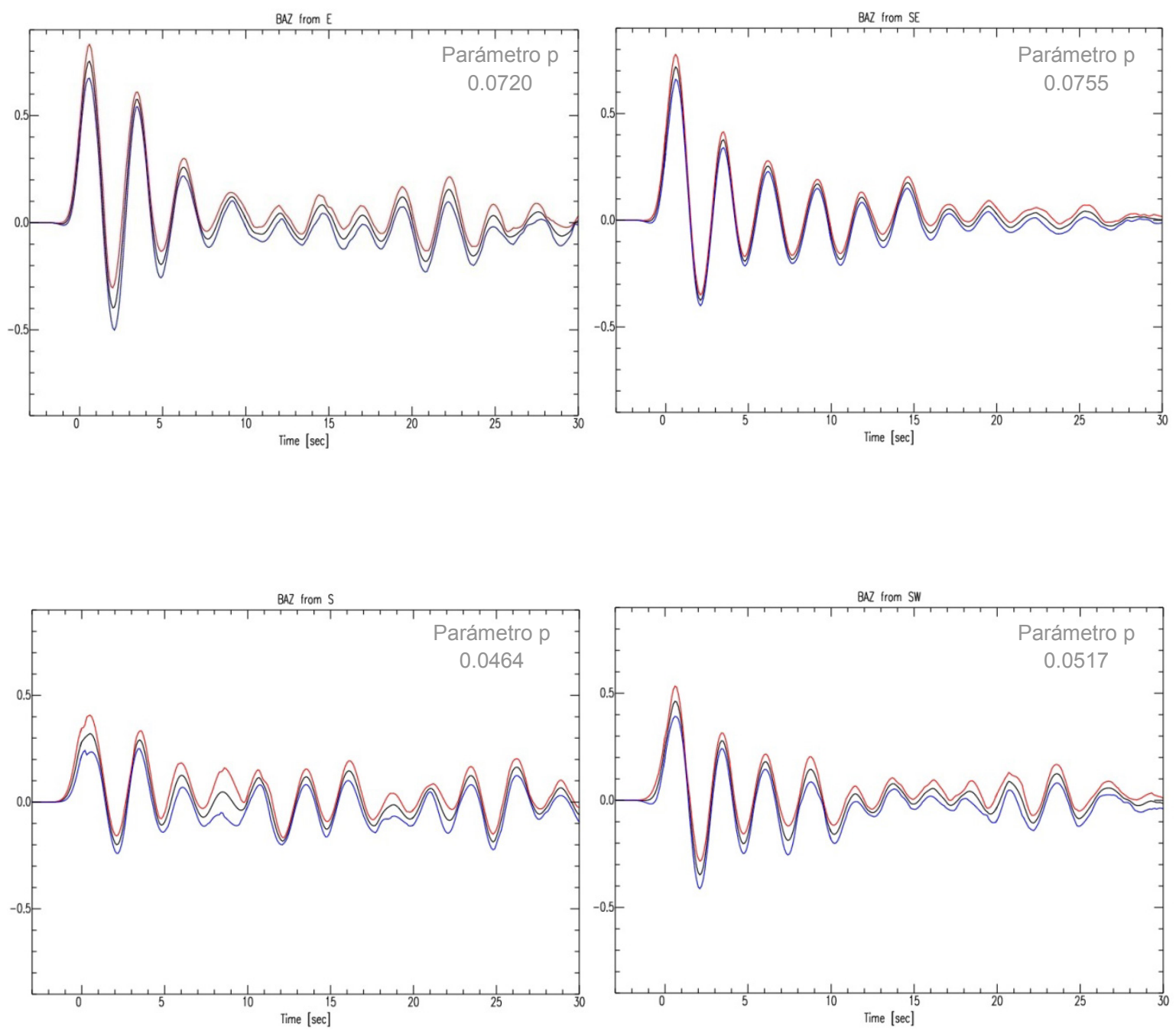

Figura 3.25: Stack de funciones receptoras por back-azimuth agrupadas en 8 direcciones para LPA.

Las componentes radiales exhiben coherencia y mayores amplitudes comparadas con las transversales en los primeros 8 segundos, para todas las direcciones. Para las ondas $\mathrm{P}$ aproximándose a la estación por el $\mathrm{E}$ (back-azimuth $\sim 90^{\circ}$ ), y SE (back-azimuth $\sim 135^{\circ}$ ) se observan componentes transversales de mayor amplitud y mucho más oscilantes comparadas con el resto de las transversales. 

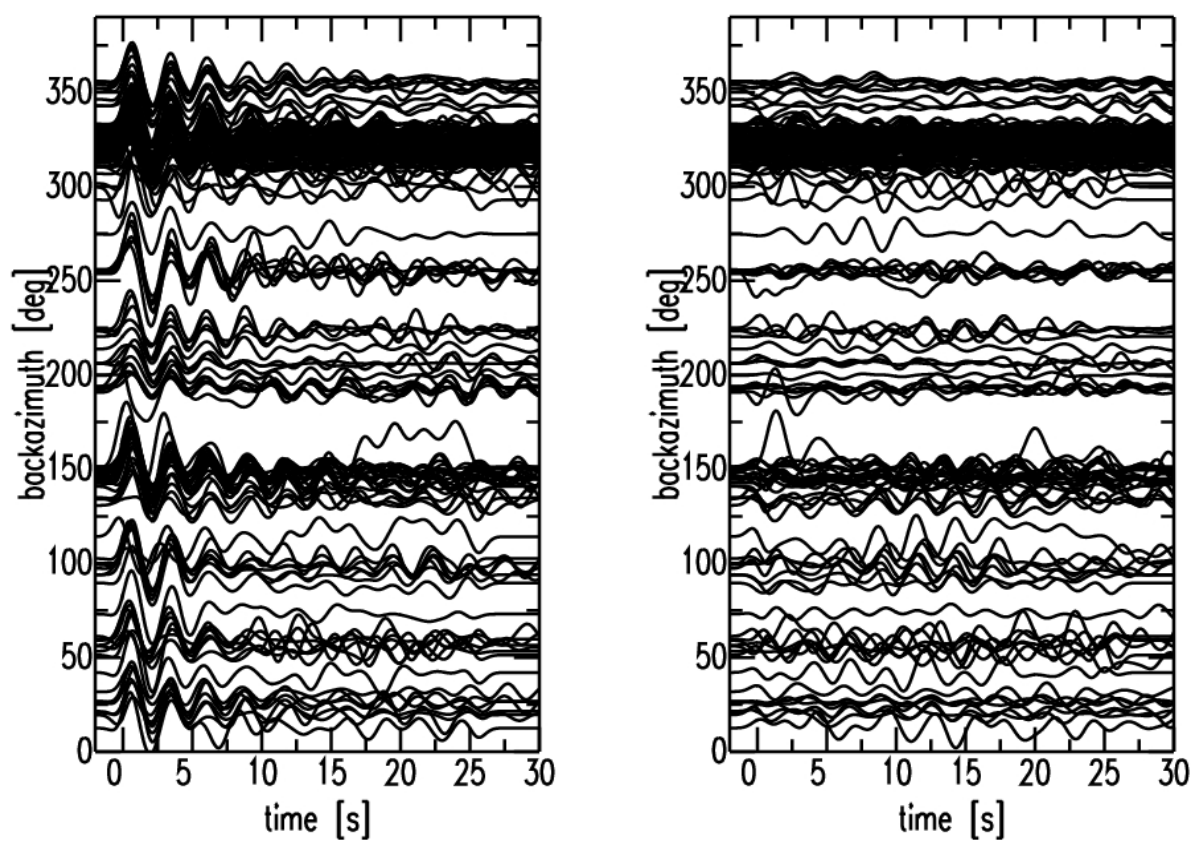

Figura 3.26: Funciones receptoras radiales (izquierda) y transversales (derecha) en función del back-azimuth para LPA. Se observa el carácter oscilante que presentan ambas componentes.
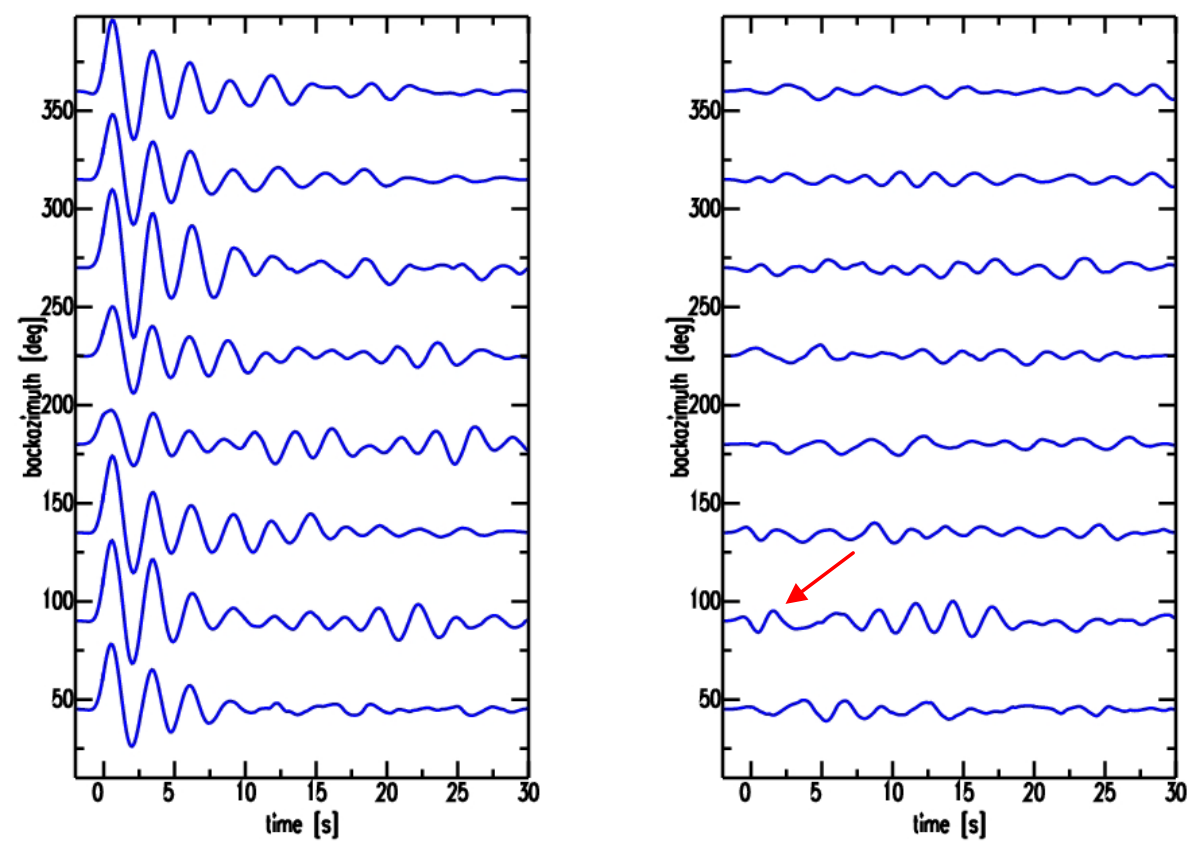

Figura 3.27: Funciones receptoras radiales y transversales promediadas para back-azimuths similares para LPA presentando un carácter oscilante. La flecha señala la FR transversal con mayor amplitud. 


\subsection{Método de Stacking}

Una FR puede dar una medida del espesor cortical bajo una estación sismológica. Comparando la diferencia de tiempos de arribo de la fase convertida Ps y la fase directa $P$ se puede determinar el tiempo que emplea la onda en atravesar el espesor cortical $(\mathrm{H})$. Así, la velocidad y la distancia recorrida pueden ser determinadas utilizando una relación lineal. El espesor estimado se relaciona fuertemente con la relación cortical entre las velocidades sísmicas $V_{P} / V_{S}(K)$, ya que el tiempo de arribo de la onda Ps es sensible al producto profundidadvelocidad, mientras que su amplitud depende del contraste de velocidad de la onda S en la discontinuidad (Cassidy, 1992) como ya fue mencionado. Para reducir esta ambigüedad se incorporan las fases múltiples convertidas PpPs y PpSs+PsPs (Fig. 3.1), cuyas diferencias de tiempo con la Ps son función de la relación $\mathrm{K}$.

El espesor $\mathrm{H}$ y la relación $\mathrm{K}$ pueden ser estimados a través de las ecuaciones (3.10) en función de $\mathrm{p}$ (parámetro del rayo) y de los tiempos de la fase Ps y otras múltiples.

$$
\begin{aligned}
& \mathrm{H}=\frac{\mathrm{t}_{\mathrm{Ps}}}{\sqrt{\frac{1}{\mathrm{~V}_{\mathrm{S}}^{2}}-\mathrm{p}^{2}}-\sqrt{\frac{1}{\mathrm{VP}_{\mathrm{P}}^{2}}-\mathrm{p}^{2}}} \\
& \mathrm{H}=\frac{\mathrm{t}_{\mathrm{PpPs}}}{\sqrt{\frac{1}{\mathrm{~V}_{\mathrm{s}}^{2}}-\mathrm{p}^{2}}+\sqrt{\frac{1}{\mathrm{~V}_{\mathrm{P}}^{2}}-\mathrm{p}^{2}}} \\
& \mathrm{H}=\frac{\mathrm{t}_{\mathrm{PpSs}+\mathrm{PsPs}}}{2 \sqrt{\frac{1}{\mathrm{~V}_{\mathrm{s}}^{2}}-\mathrm{p}^{2}}}
\end{aligned}
$$

Si se cuenta con un número adecuado de FRs, se puede realizar un stacking (apilamiento) para aumentar la relación señal/ruido, evitando las dispersiones por heterogeneidades corticales, las conversiones $\mathrm{P}$ a $\mathrm{S}$ en otras discontinuidades de velocidad y el ruido ambiental. La técnica de stacking de Zhu y Kanamori (2000), que utiliza un algoritmo basado en el método de búsqueda de grilla sobre un rango de posibles $\mathrm{H}$ y $\mathrm{K}$ para realizar la estimación, suma las 
amplitudes de las FRs para los tiempos de arribo de las fases convertidas calculados para diferentes $\mathrm{H}$ y K.

Este método consiste en una transformación de las amplitudes de las FRs en el dominio del tiempo a un nuevo dominio que es función de $\mathrm{H}$ y $\mathrm{K}$, usando los tiempos calculados de las tres fases múltiples principales $\sin$ necesidad de identificar las fases y de picar sus tiempos de arribo. Estos tiempos dependen de la velocidad $V_{P}$ supuesta antes del stacking aunque los resultados son relativamente insensibles a ella. Una vez hecha la transformación al sistema $\mathrm{H}-\mathrm{K}$, las amplitudes de las FRs no dependen más del tiempo, eliminándose el parámetro de rayo como variable. De esta manera los sismos se pueden agrupar para diferentes azimuths y diferentes distancias, con sus correspondientes parámetros de rayo. Cada par $(\mathrm{H}$, $\mathrm{K}$ ) junto con la $\mathrm{V}_{\mathrm{P}}$ asumida corresponde a un modelo cortical para el cual los tiempos predichos pueden ser calculados para cada una de las tres fases múltiples principales. Las amplitudes para cada tiempo se extraen de la FR y se realiza la suma sobre todas las FRs en esa estación, notando que la polaridad de la PsPs+PpSs (Fig. 3.1) es inversa. Una vez realizados los stacks, los parámetros óptimos de $\mathrm{H}$ y de $\mathrm{K}$ son aquellos que maximizan la suma ponderada de las amplitudes de las FRs en el tiempo de la Ps y de las múltiples; y son considerados la mejor estimación de las propiedades de la corteza.

En sistemas automáticos como el anterior, es importante la estimación del error para separar los resultados válidos y definir los errores verdaderos. Para dar significado a la representación del error se hace uso de la técnica de bootstrap (Efron and Tibshirani, 1991) para estimar las incertezas en los parámetros de $\mathrm{H}$ y K. Esto implica la creación mediante muestreo al azar de un nuevo grupo de FRs, que tiene el mismo tamaño que el original pero puede tener duplicados de algunas FRs. Luego se realiza el mismo análisis por búsqueda de grilla (Ramesh et al., 2005). O sea para ese grupo se aplica un nuevo procedimiento de stacking y se escogen los valores de $\mathrm{H}$ y $\mathrm{K}$ correspondientes al máximo. El procedimiento de remuestreo se repite un número $\mathrm{n}$ de veces para producir un conjunto de valores de $\mathrm{H}$ y $\mathrm{K}$, a los que se les calcula la desviación estándar que tiene un significado diferente para el caso de un solo máximo global bien definido respecto a muchos máximos locales. En el primer caso, la estimación del error indica una incerteza real en los valores. En el segundo caso, el máximo global de cada bootstrap 
individual puede corresponder a un máximo local diferente del stacking original, siendo el error una indicación de que hay diversas interpretaciones posibles y que el sistema no es capaz de diferenciar entre ellas. Generalmente, los valores pequeños de desviación estándar indican un único máximo y los valores grandes indican múltiples máximos locales similares, teniéndose que controlar, en este caso las estaciones. Debido a la gran dificultad en observar la PpSs+PsPs comparada con la Ps, se suele utilizar al momento del stacking, un peso menor en las fases más tardías comparadas con la Ps de acuerdo a la relación señal/ruido (Zhu and Kanamori, 2000).

Es importante la elección del rango de variación de los valores iniciales de $\mathrm{H}$ y $\mathrm{K}$, ya que si ese intervalo es pequeño, puede quedar afuera un máximo que tal vez sea el indicado para esos datos. En estaciones con pocos datos, con presencia de ruido o con estructuras locales complejas se pueden obtener múltiples máximos locales y puede no ser una opción sabia elegir entre ellos basándose en la amplitud. Es aconsejable tener un rango amplio de valores iniciales (por ejemplo $\mathrm{H}$ entre 5 y $70 \mathrm{~km}$ y K entre 1.5 y 2.4) y luego acotar esos valores usando información de la región circundante a la estación (por ejemplo geología, modelos de velocidad, etc.), sin poner demasiadas restricciones de manera que los resultados sólo reflejen lo que uno ya sabe a priori y no aporten nueva información.

\subsubsection{Estación sismológica CPUP}

Con el objetivo de obtener una aproximación de la estructura cortical bajo la estación CPUP se realizó un procedimiento de stacking para todas las FRs analizadas, de manera de lograr una estimación de la relación $V_{\mathrm{P}} / \mathrm{V}_{\mathrm{S}}(\mathrm{K})$ y el espesor cortical $(H)$. Se utilizaron distintas velocidades promedio de onda $P$ en corteza (6.1 a $6.7 \mathrm{~km} / \mathrm{s})$, de acuerdo a los valores sugeridos por Christensen and Mooney (1995) y los valores sugeridos para el $85 \%$ de la corteza continental por Artemieva (2002). Dicha velocidad es un factor que influye en el espesor pero tiene poco efecto en la relación $V_{P} / V_{S}$. Si bien no se puede obtener el mejor valor de $V_{P}$ con este método, se probaron distintos valores de $V_{P}$ y se encontraron mejores correlaciones en los stacks utilizando una $V_{P}$ de $6.5 \mathrm{~km} / \mathrm{s}$. La fase $P s$ y las múltiples fueron ponderadas de igual manera al momento de realizar el 
procedimiento. Una vez calculados los stacks, se consideraron los valores máximos de $\mathrm{H}$ y de $\mathrm{K}$. Los errores en ambos parámetros se estimaron usando la técnica de bootstrap. El procedimiento de remuestreo se repitió 200 veces.

Se obtuvieron valores de $\mathrm{H}$ de $34.4 \mathrm{~km} \pm 0.4$ y de $\mathrm{K}$ de $1.76 \pm 0.01$ (Fig. 3.28), definiendo un módulo de Poisson $(\sigma)$ de 0.261 .

El módulo de Poisson es más sensible a la composición de las rocas de la corteza que a las velocidades $\mathrm{P}$ o S. Para las rocas más típicas, $\sigma$ varía entre 0.20 y 0.35 , aumentando para rocas con contenido más máfico o menos cuarcítico. Debido a que el contenido de sílice en la corteza continental disminuye con la profundidad, $\sigma$ aumenta generalmente con la profundidad. El módulo de Poisson de 0.26 es un valor típico de plataformas y orógenos paleozoicos $(\sigma=0.27 \pm 0.03)$ y es indicativo de la existencia de rocas corticales profundas, intermedias a máficas (pobres en cuarzo). Este valor obtenido indica la existencia de dos capas corticales de diferente composición, con $\sigma \leq 0.26$ en la corteza superior y $\sigma \sim 0.30$ en la corteza inferior (Artemieva, 2002).

Se sabe que una limitación importante en los estudios con datos de una sola estación es la suposición de una estructura de velocidad horizontal, lateralmente homogénea o con un buzamiento moderado. La validez de suponer interfaces horizontales o ligeramente buzantes depende del contenido de frecuencia de la señal y de la extensión lateral de la estructura muestreada. La extensión del área muestreada por ondas $\mathrm{P}$ es aproximadamente igual a la profundidad de la interface de reflexión más profunda (Ammon et al., 1990). Se realizó un análisis para distintos back-azimuths para comparar la estructura bajo la estación. Para ello, se obtuvieron stacks de FRs agrupadas por back-azimuth según el criterio adoptado en la sección 3.4.1. En las Fig. 3.29 y 3.30 se observan los resultados del método de HK stacking.

En la Tabla 3.1 se muestran los valores $\mathrm{H}-\mathrm{K}$ obtenidos para cada backazimuth. Se calcularon, además, los correspondientes valores del módulo de Poisson.

Analizando los resultados se observa que el espesor cortical bajo la estación presenta valores similares en todas las direcciones, considerando las incertidumbres. A partir del análisis de todas las FRs juntas (Fig. 3.28) se 
obtuvieron valores de $\mathrm{H}$ de $34.4 \mathrm{~km}$ y de $\mathrm{K}$ de 1.76 . Los valores promedios obtenidos a partir del análisis por back-azimuth son $\mathrm{H}$ de $34.6 \mathrm{~km}$ y $\mathrm{K}$ de 1.76. Se asumen entonces como representativos para la corteza bajo la estación CPUP, un espesor cortical aproximado de $34.4 \mathrm{~km}$ y una relación $V_{\mathrm{P}} / \mathrm{V}_{\mathrm{S}}$ de 1.76.

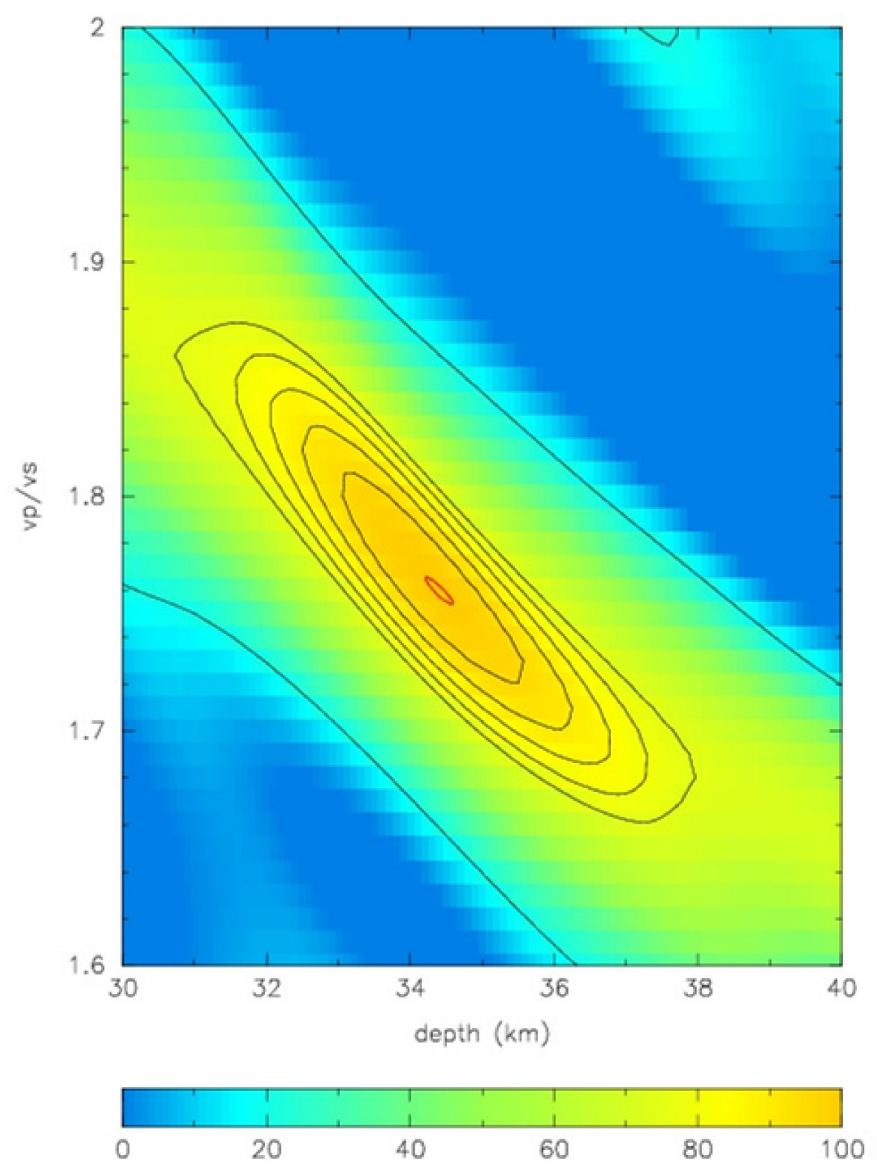

Figura 3.28: HK stacking para CPUP a partir de las FRs de la Fig. 3.8, como función de la profundidad de la Moho y de la relación $\mathrm{V}_{\mathrm{P}} / \mathrm{V}_{\mathrm{S}}$. La zona con colores más amarillos muestra las mayores amplitudes del stack. La elipse roja indica el rango de incerteza estimado con el bootstrap.

Los valores obtenidos en este trabajo son comparables con los valores de $\mathrm{H}=35 \pm 0.3 \mathrm{~km}$ y $\mathrm{K}=1.74 \pm 0.1$, para de $\mathrm{V}_{\mathrm{P}}$ de $6.498 \mathrm{~km} / \mathrm{s}$, estimados en octubre de 2015, por EARS (EarthScope Automated Receiver Survey) que es un servicio automático desarrollado por Crotwell and Owens (2005) de la Universidad de Carolina del Sur e implementado por IRIS, se observa que son muy similares. Se hace notar que los valores de EARS se obtuvieron a partir de $93 \mathrm{FRs}$, mientras que los valores presentados aquí son más robustos ya que son el resultado de analizar 
321 FRs, considerándolas para el procedimiento de stacking no sólo como un único grupo sino también realizando un análisis por back-azimuth.
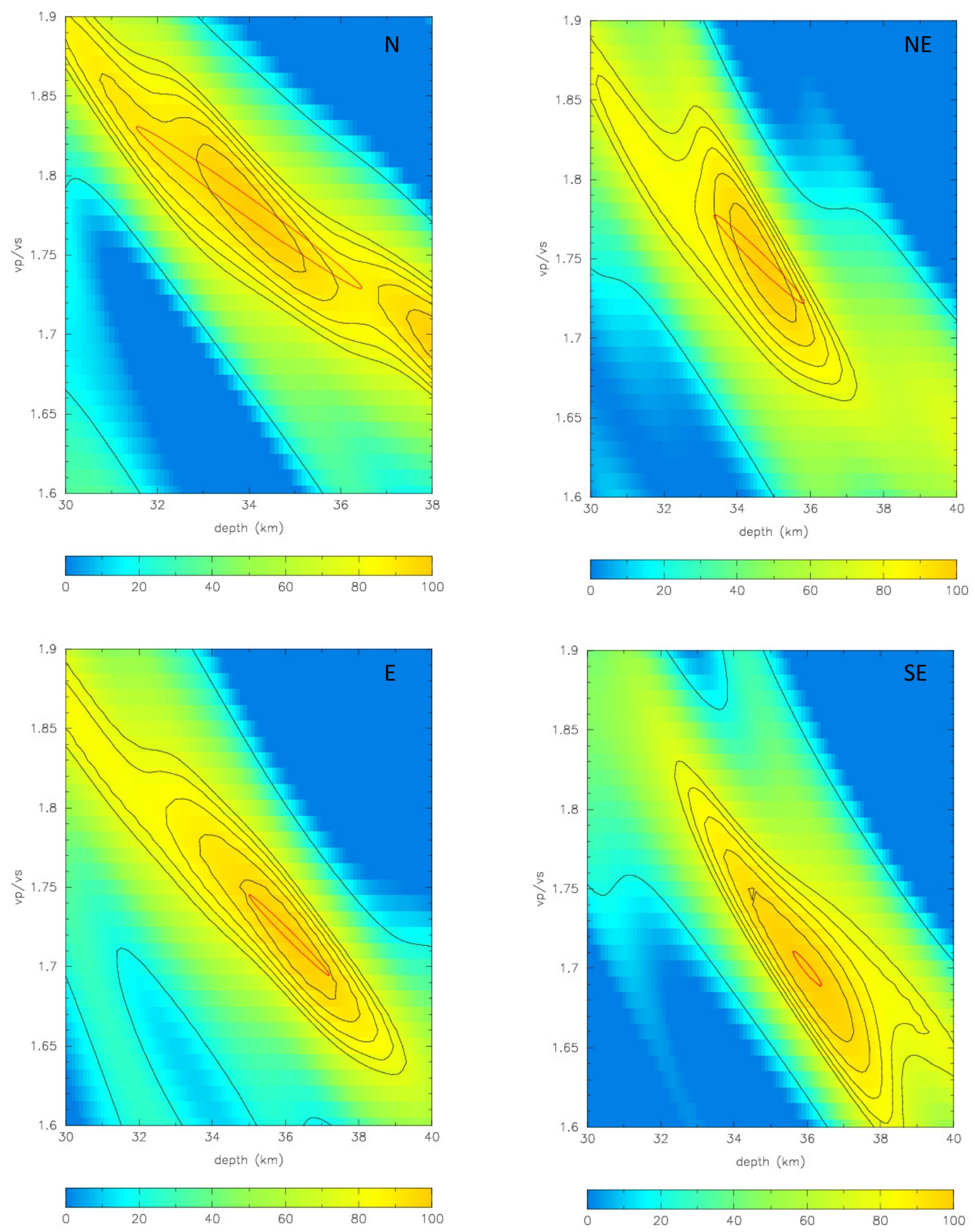

Figura 3.29: HK stacking para FRs agrupadas por back-azimuth (N, NE, E, SE) para CPUP, como función de la profundidad de la Moho y de la relación $V_{\mathrm{P}} / \mathrm{V}_{\mathrm{S}}$. La zona con colores más amarillos muestra las mayores amplitudes del stack. La elipse roja indica el rango de incerteza estimado con el bootstrap. 

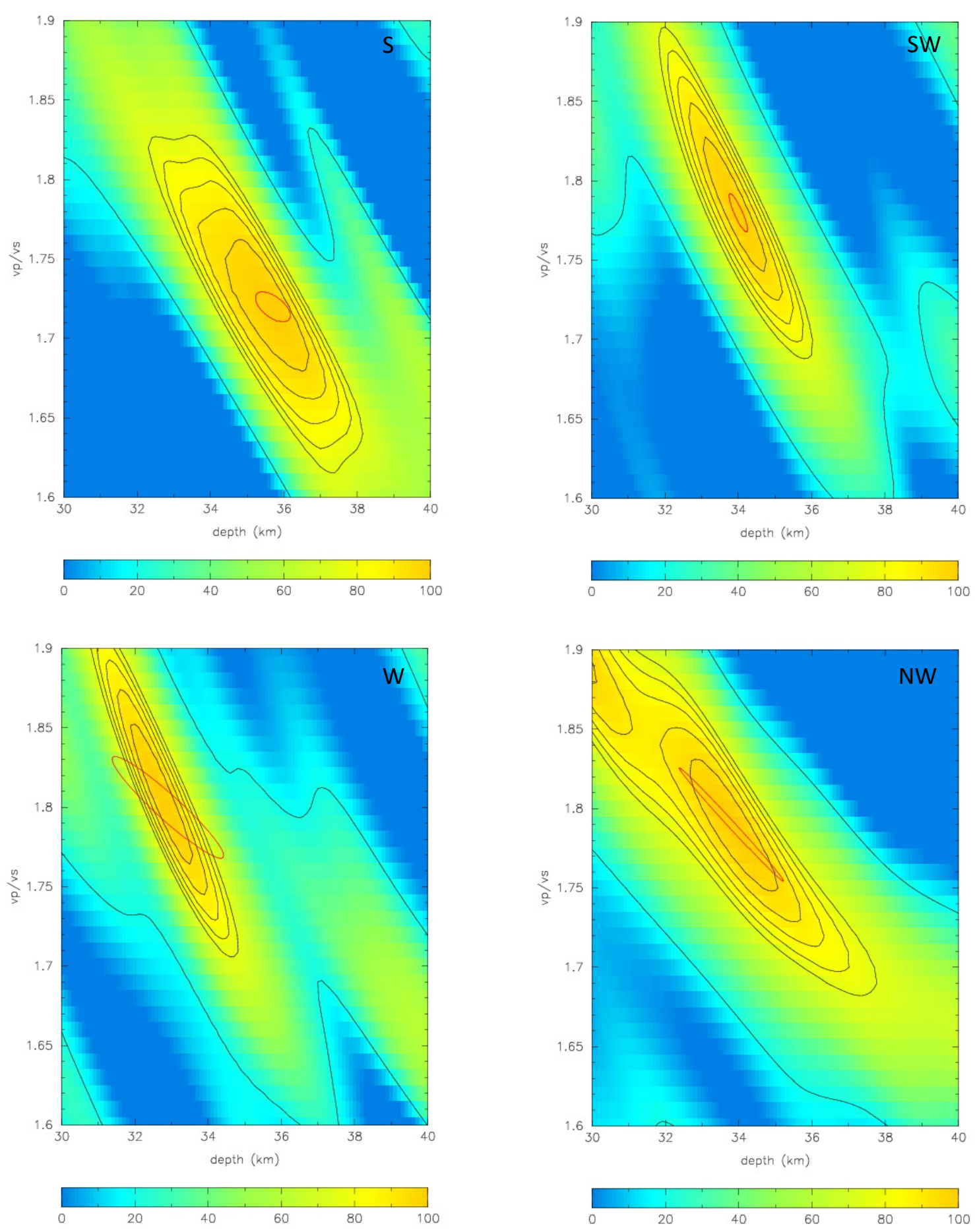

Figura 3.30: HK stacking para FRs agrupadas por back-azimuth (S, SW, W, NW) para CPUP, como función de la profundidad de la Moho y de la relación $V_{\mathrm{P}} V_{\mathrm{S}}$. La zona con colores más amarillos muestra las mayores amplitudes del stack. La elipse roja indica el rango de incerteza estimado con el bootstrap. 


\begin{tabular}{|c|c|c|c|}
\hline BAZ & $\mathrm{H}(\mathrm{km})$ & $\mathrm{K}$ & Mod. Poisson \\
\hline $\mathrm{N}(22 \mathrm{FR})$ & $34.0 \pm 4.9$ & $1.78 \pm 0.10$ & 0.269 \\
\hline $\mathrm{NE}(24 \mathrm{FR})$ & $34.6 \pm 2.5$ & $1.75 \pm 0.06$ & 0.257 \\
\hline $\mathrm{E}(12 \mathrm{FR})$ & $36.1 \pm 2.2$ & $1.72 \pm 0.05$ & 0.244 \\
\hline $\mathrm{SE}(77 \mathrm{FR})$ & $36.0 \pm 0.8$ & $1.70 \pm 0.02$ & 0.235 \\
\hline $\mathrm{S}(19 \mathrm{FR})$ & $35.7 \pm 1.0$ & $1.72 \pm 0.02$ & 0.244 \\
\hline $\mathrm{SW}(24 \mathrm{FR})$ & $34.0 \pm 0.5$ & $1.78 \pm 0.02$ & 0.269 \\
\hline W (10 FR) & $32.9 \pm 3.0$ & $1.80 \pm 0.06$ & 0.277 \\
\hline NW (133 FR) & $33.8 \pm 2.8$ & $1.79 \pm 0.07$ & 0.273 \\
\hline Todas (321 FR) & $34.4 \pm 0.4$ & $1.76 \pm 0.01$ & 0.261 \\
\hline
\end{tabular}

Tabla 3.1: Valores de $\mathrm{H}, \mathrm{K}$ y relación de Poisson para la corteza bajo la estación CPUP correspondientes a los gráficos de las Figs. 3.29 y 3.30 .

\subsubsection{Estación sismológica TRQA}

Se realizó el procedimiento de stacking de las FRs para esta estación, utilizando velocidades promedio de onda $P$ en corteza entre 6.0 y $6.7 \mathrm{~km} / \mathrm{s}$. Se asignaron distintos pesos a las fases convertidas, teniendo en cuenta que las múltiples son más propensas a estar contaminadas e incluso enmascaradas por ruido y no pudieron ser distinguidas claramente en todas las FRs. Las mejores correlaciones se encontraron para una $V_{P}$ de $6.5 \mathrm{~km} / \mathrm{s}$, usando pesos de 0.5 para la Ps, 0.4 para la múltiple positiva y 0.1 para la negativa. Para el cálculo de los errores se repitió el procedimiento de remuestreo 200 veces. Los valores obtenidos para $\mathrm{H}$ y K son $39.4 \mathrm{~km} \pm 1.4$ y $1.82 \pm 0.03$ respectivamente (Fig. 3.31), definiendo un módulo de Poisson $(\sigma)$ de 0.283 , indicativo de la presencia de rocas corticales profundas intermedias a máficas (Artemieva, 2002). Estos valores están dentro del 
rango de valores esperados para plataformas y escudos precámbricos según Christensen and Mooney (1995).

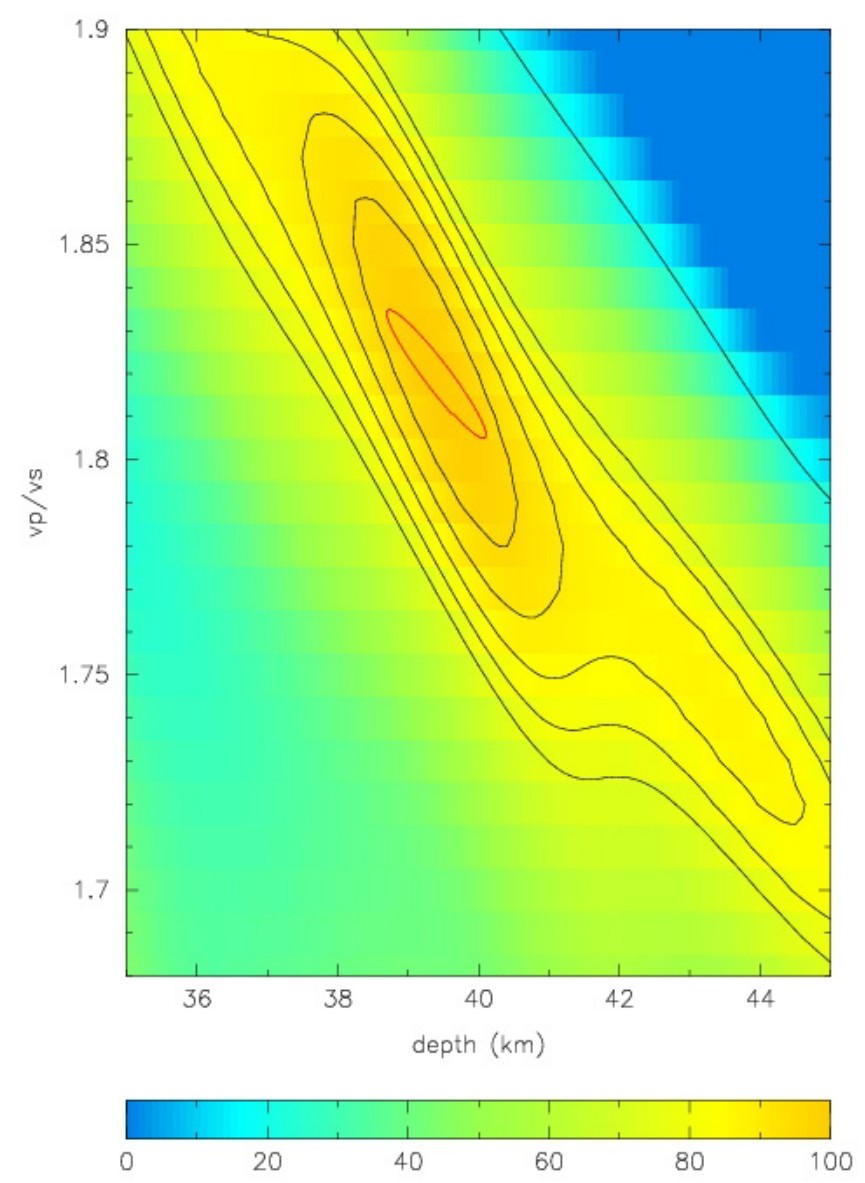

Figura 3.31: HK stacking para TRQA a partir de las FRs de la Fig. 3.16, como función de la profundidad de la Moho y de la relación $V_{\mathrm{P}} / \mathrm{V}_{\mathrm{S}}$. La zona con colores más amarillos muestra las mayores amplitudes del stack. La elipse roja indica el rango de incerteza estimado con el bootstrap.

Al realizar los stacks para los distintos back-azimuths (Figs. 3.32 y 3.33 ), los valores obtenidos del espesor cortical y de la relación $V_{P} / V_{S}$ resultaron no ser homogéneos en todas las direcciones (Tabla 3.2), pero debido a que las incertidumbres de cada valor son grandes, los valores para todos los azimuths se asemejan al valor promedio de $39-40 \mathrm{~km}$. Por consiguiente se asumen como valores representativos para la corteza bajo TRQA, un espesor cortical aproximado de $39.4 \mathrm{~km}$ y una relación $V_{\mathrm{P}} / \mathrm{V}_{\mathrm{S}}$ de 1.82 . 

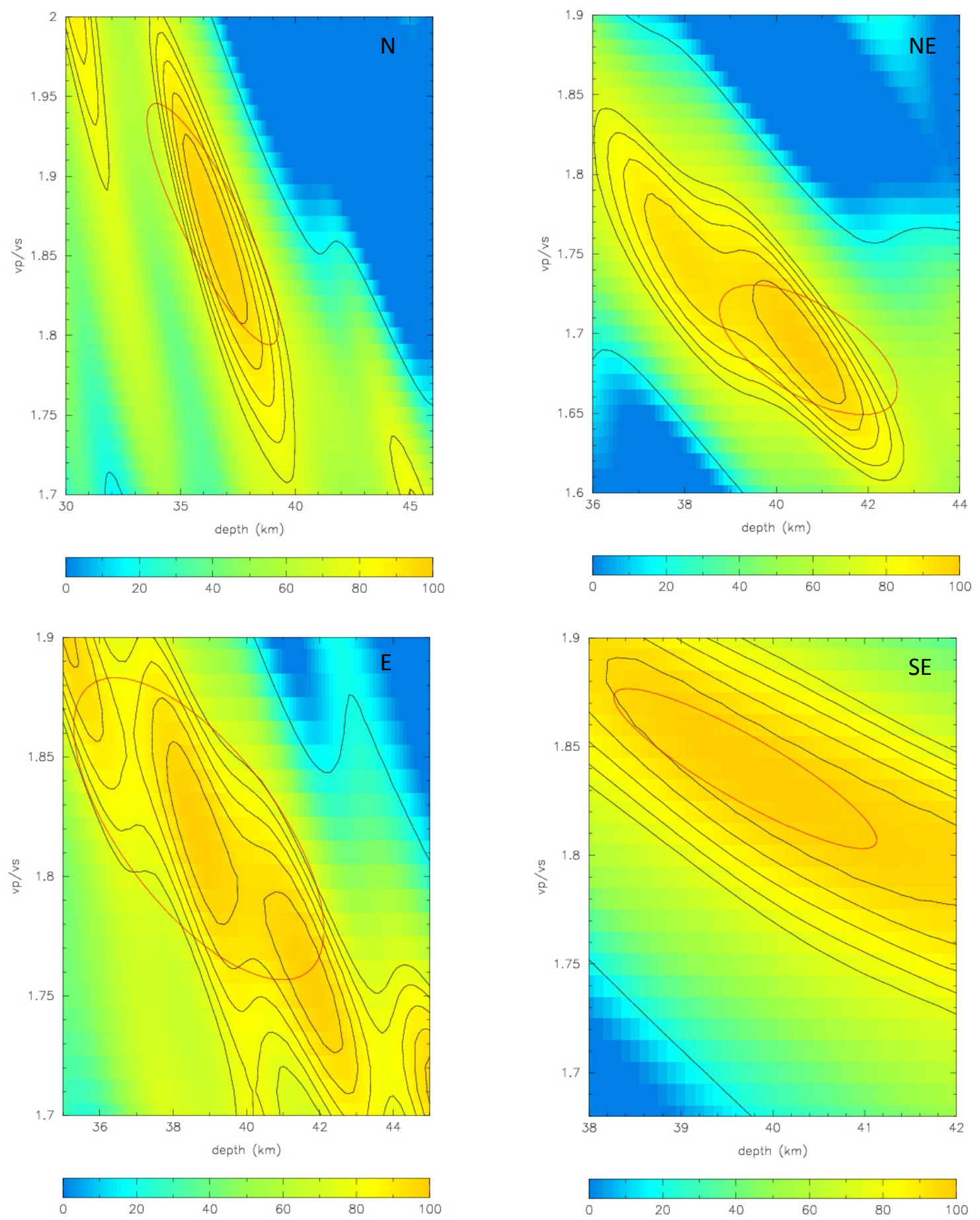

Figura 3.32: HK stacking para FRs agrupadas por back-azimuth (N, NE, E, SE) para TRQA, como función de la profundidad de la Moho y de la relación $V_{\mathrm{P}} / \mathrm{V}_{\mathrm{S}}$. La zona con colores más amarillos muestra las mayores amplitudes del stack. La elipse roja indica el rango de incerteza estimado con el bootstrap. 

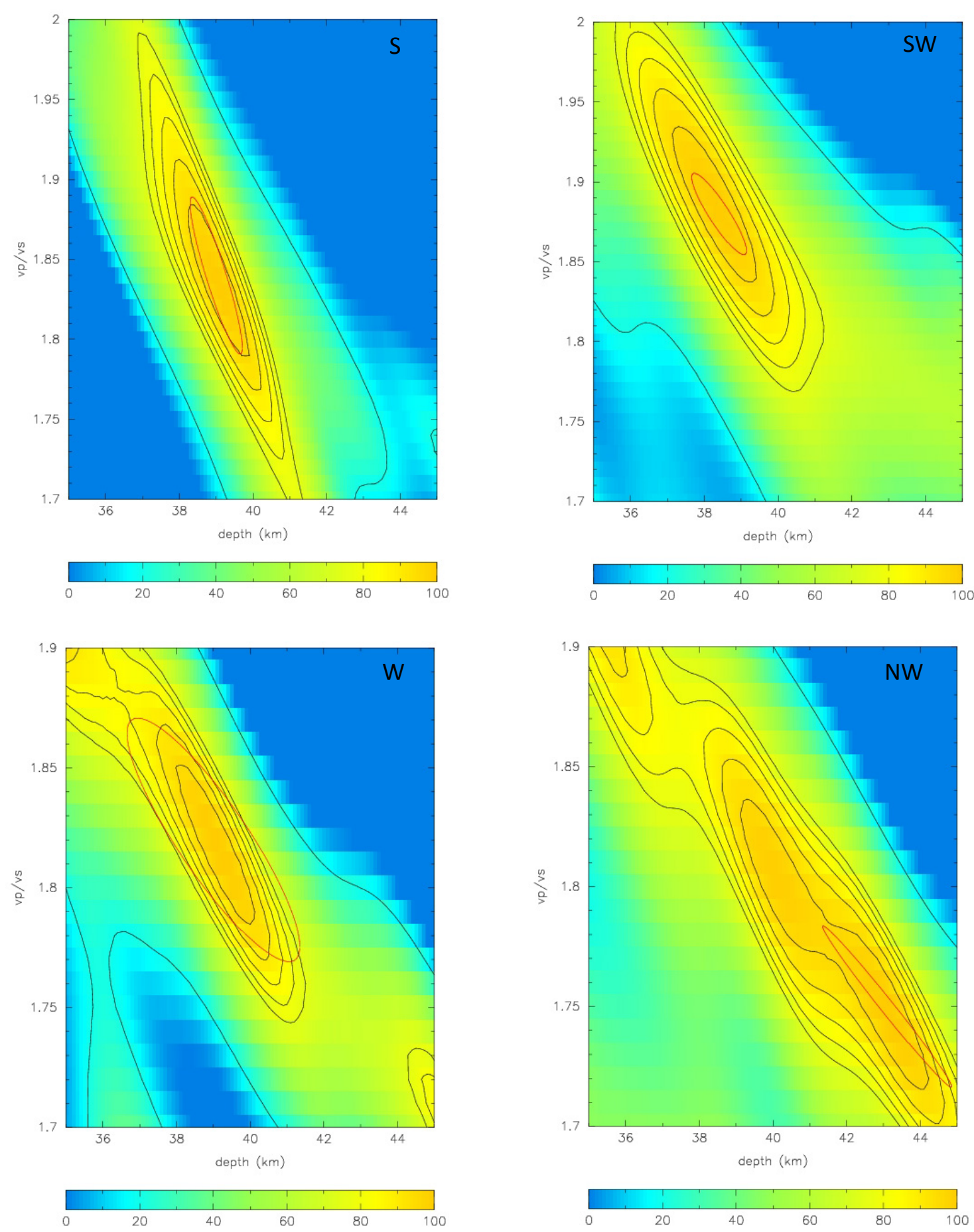

Figura 3.33: HK stacking para FRs agrupadas por back-azimuth (S, SW, W, NW) para TRQA, como función de la profundidad de la Moho y de la relación $V_{\mathrm{P}} / \mathrm{V}_{\mathrm{S}}$. La zona con colores más amarillos muestra las mayores amplitudes del stack. La elipse roja pequeña indica el rango de incerteza estimado con el bootstrap. 


\begin{tabular}{|c|c|c|c|}
\hline BAZ & $\mathrm{H}(\mathrm{km})$ & $\mathrm{K}$ & Mod. Poisson \\
\hline $\mathrm{N}(29 \mathrm{FR})$ & $36.4 \pm 5.7$ & $1.87 \pm 0.15$ & 0.299 \\
\hline $\mathrm{NE}(15 \mathrm{FR})$ & $40.7 \pm 3.9$ & $1.69 \pm 0.08$ & 0.231 \\
\hline $\mathrm{E}(14 \mathrm{FR})$ & $38.7 \pm 6.8$ & $1.82 \pm 0.13$ & 0.283 \\
\hline $\mathrm{SE}(46 \mathrm{FR})$ & $39.7 \pm 2.9$ & $1.84 \pm 0.07$ & 0.290 \\
\hline $\mathrm{S}(9 \mathrm{FR})$ & $39.0 \pm 1.4$ & $1.84 \pm 0.10$ & 0.290 \\
\hline $\mathrm{SW}(48 \mathrm{FR})$ & $38.4 \pm 1.5$ & $1.88 \pm 0.05$ & 0.302 \\
\hline W (13 FR) & $39.0 \pm 4.7$ & $1.82 \pm 0.10$ & 0.283 \\
\hline NW (96 FR) & $43.1 \pm 3.5$ & $1.75 \pm 0.07$ & 0.257 \\
\hline Todas (270 FR) & $39.4 \pm 1.4$ & $1.82 \pm 0.03$ & 0.283 \\
\hline
\end{tabular}

Tabla 3.2: Valores de H, K y relación de Poisson para la corteza bajo la estación TRQA de los gráficos de las Figs. 3.32 y 3.33 .

Comparando los valores obtenidos en este trabajo con los estimados en octubre de 2015 por EARS, $\mathrm{H}=43 \pm 2.6 \mathrm{~km}$ y $\mathrm{K}=1.76 \pm 0.05$ para $V_{\mathrm{P}}$ de $6.472 \mathrm{~km} / \mathrm{s}$, correspondientes a $102 \mathrm{FRs}$, y con los publicados por Sabbione et al. (2009), se observa que estos valores difieren, aunque están dentro de los límites de la desviación estándar. Sin embargo, los datos de EARS provienen de sismos cuya distribución acimutal no es equitativa en todas las direcciones. En la Tabla 3.3 se compara la cantidad de FRs analizadas en cada dirección por este estudio y por EARS. Aproximadamente el $40 \%$ de los datos de EARS provienen de la misma dirección (NW) y se obtuvieron utilizando la misma ponderación para las fases convertidas. Mientras que los valores presentados aquí son más robustos ya que son el resultado de analizar más del doble de FRs (270), usando distintos pesos para las fases convertidas que no pudieron ser distinguidas claramente (Fig. 3.13 y 3.14), considerando los stacks de las FRs juntas y de las FRs agrupadas por backazimuth. 


\begin{tabular}{|c|c|c|}
\hline BAZ & FRs (este estudio) & FRs (EARS) \\
\hline NE & 15 & 3 \\
\hline E & 14 & 3 \\
\hline SE & 46 & 16 \\
\hline SE & 9 & 3 \\
\hline SW & 48 & 23 \\
\hline W & 13 & 2 \\
\hline NW & 96 & 40 \\
\hline N & 29 & 12 \\
\hline
\end{tabular}

Tabla 3.3: FRs analizadas por este estudio y por EARS en cada dirección para TRQA.

\subsubsection{Estación sismológica LPA}

Las FRs para la estación LPA presentan muchas oscilaciones (Fig. 3.21). Por tal motivo sólo se aplicó el método de stacking para obtener una medida del espesor y la relación $V_{\mathrm{P}} / \mathrm{V}_{\mathrm{S}}$ en la capa de sedimentos que se encuentra por encima del cratón. Dicha capa asociada a sedimentos no consolidados, presentaría un alto contraste de velocidades respecto de las rocas metamórficas y plutónicas del basamento precámbrico e interferiría con las señales generadas en la Moho. Estos suelos que amplifican en mayor grado el movimiento sísmico corresponden en su mayoría a suelos de edad cuaternaria.

Para poder modelar esta capa, se le dio mayor peso a la fase múltiple negativa y se utilizaron distintos valores de la velocidad promedio $V_{P}$ para los sedimentos. Los mejores ajustes se obtuvieron para $V_{P}$ entre 1.0 y $1.7 \mathrm{~km} / \mathrm{s}$ (Fig. 3.34). Los resultados de estos ajusten se muestran en la Tabla 3.4.

La fase múltiple negativa cercana a los 2 segundos pudo ser modelada en todos los casos. Un ejemplo de ese ajuste se observa la Fig. 3.35. 

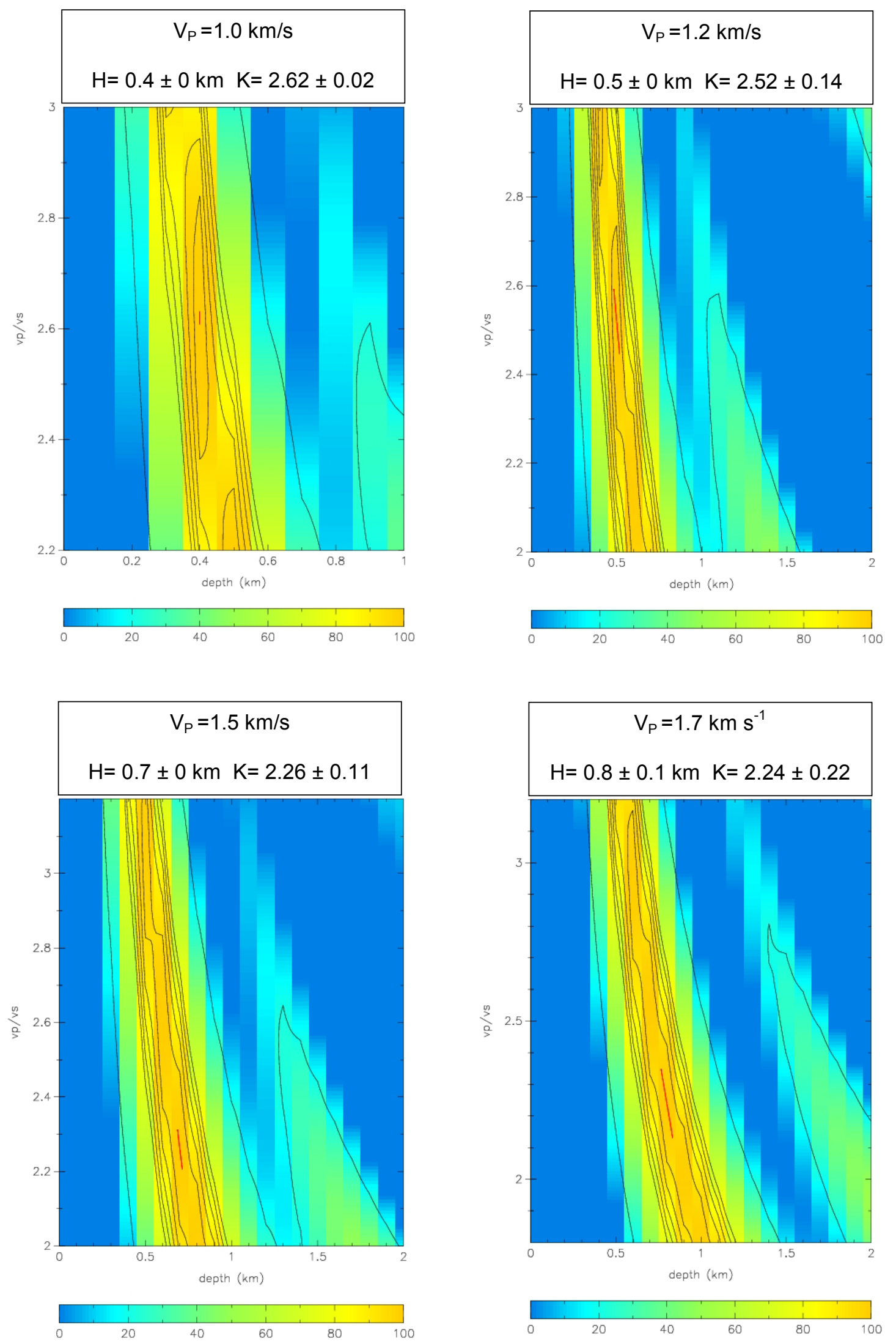

Figura 3.34: HK stacking para FRs de LPA como función de la profundidad y de la relación $V_{P} / V_{S}$. La zona con colores más amarillos muestra las mayores amplitudes del stack. La elipse roja indica el rango de incerteza estimado con el bootstrap. 


\begin{tabular}{|c|c|c|}
\hline $\mathrm{V}_{\mathrm{P}}(\mathrm{km} / \mathrm{s})$ & $\mathrm{H}(\mathrm{km})$ & $\mathrm{K}$ \\
\hline 1.0 & 0.4 & $2.62 \pm 0.02$ \\
\hline 1.2 & 0.5 & $2.52 \pm 0.14$ \\
\hline 1.5 & 0.7 & $2.26 \pm 0.11$ \\
\hline 1.7 & $0.8 \pm 0.1$ & $2.24 \pm 0.22$ \\
\hline
\end{tabular}

Tabla 3.4: Valores de H y K para la corteza bajo la estación LPA correspondientes a los gráficos de la Fig. 3.34.

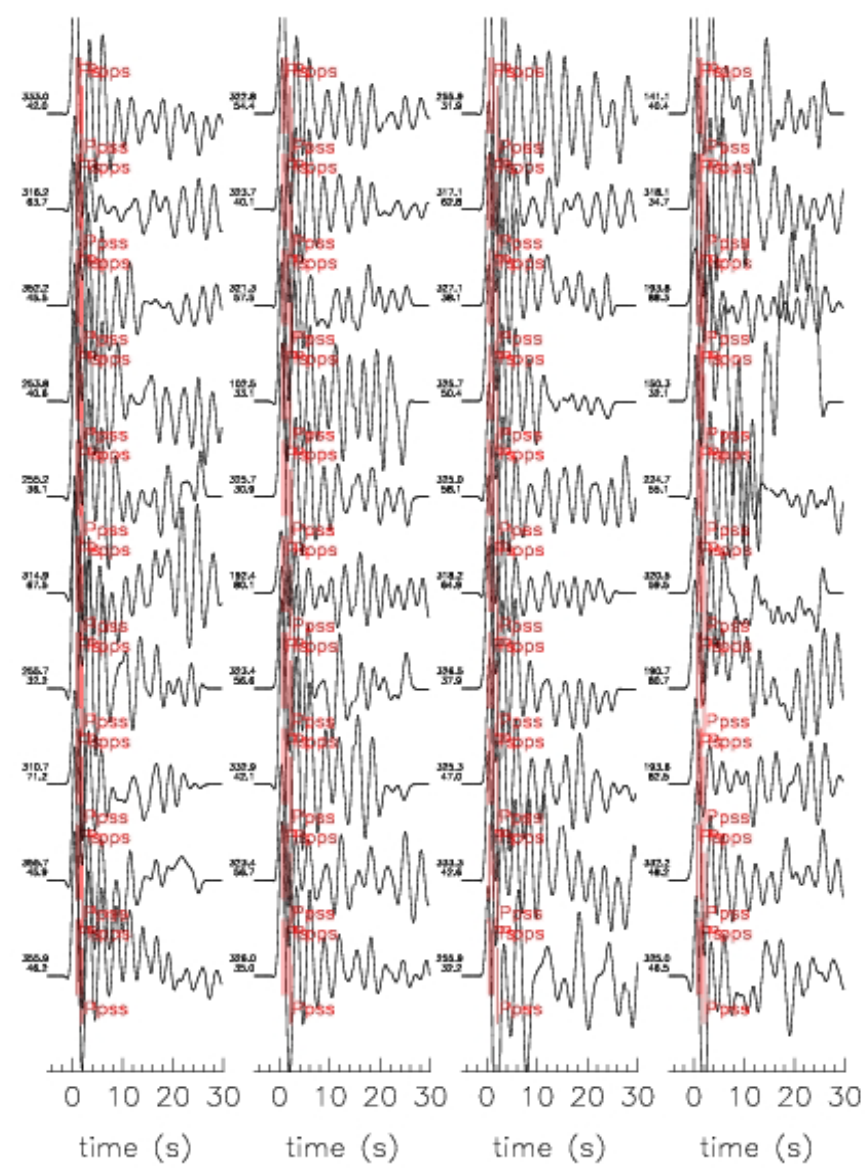

Figura 3.35: FRs de LPA indicando las fases convertidas calculadas a partir del HK stacking.

Considerando la información geológica que se tiene de la región a partir de la perforación Plaza de Armas (Fig. 3.36) realizada en cercanías de la estación, que señala que el basamento se encuentra a aproximadamente $486 \mathrm{~m}$ de 
profundidad (Auge et al., 2004; Laurencena et al., 2010) y considerando los resultados obtenidos aquí, se asumen como valores representativos para la capa de sedimentos bajo la estación LPA, un espesor aproximado de $0.5 \mathrm{~km}$ y una relación $V_{\mathrm{P}} / \mathrm{V}_{\mathrm{S}}$ de 2.52 , con un módulo de Poisson de 0.406 , que indica la presencia de arcillas y arenas en el lugar.

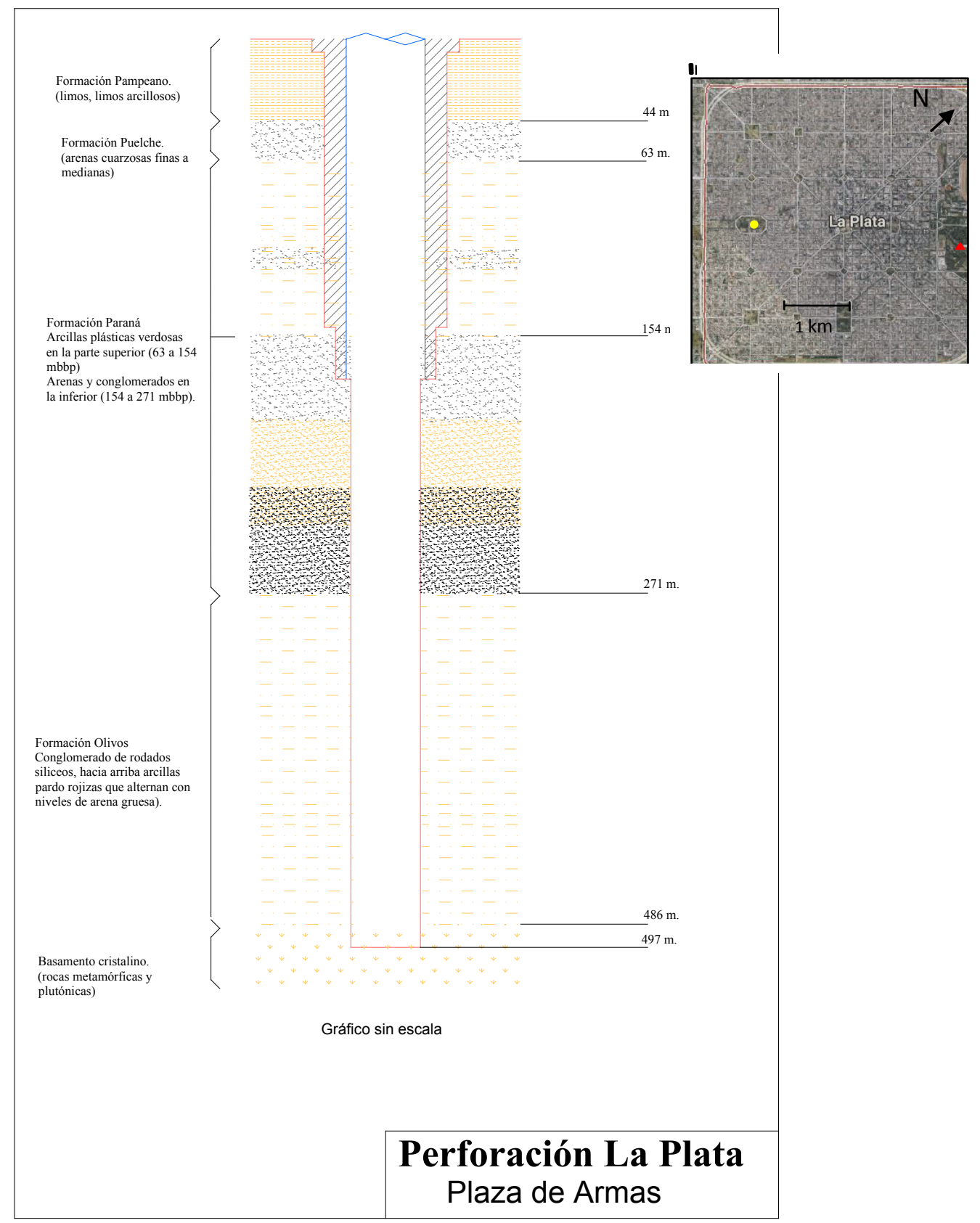

Figura 3.36: Gráfico de la perforación Plaza de Armas realizada en cercanías de la estación LPA.

Se indica en el mapa adjunto de la ciudad de La Plata la ubicación de la perforación (círculo amarillo) y de la estación LPA (triángulo rojo). 


\section{Capítulo 4}

\section{Inversión en Profundidad: Estimación de \\ la Estructura Cortical en la}

\section{Cuenca Chaco-Paraná}

\subsection{Introducción}

La relación entre los datos observados y los modelos de velocidad puede ser determinada mediante métodos directos e inversos. En el método directo se asume a priori un modelo teórico aproximado de velocidad y se determina el sismograma sintético, que luego es comparado con los sismogramas observados. Se utiliza una inversión automática iterativa con el criterio de mínimos cuadrados amortiguados usando distintos factores de suavización y criterios de actualización. El éxito se alcanza al ir implementando cambios al modelo propuesto, por prueba y error, hasta que los modelos observados y calculados no produzcan variaciones significativas en los sismogramas calculados y observados. Esto fue implementado en el capítulo 2, sección 6 , donde el ajuste se realizó sobre los tiempos observados en los sismogramas. El método inverso que permite determinar los modelos de velocidad a partir de los datos observados, presenta más dificultades de resolución que el método directo.

\subsection{Inversión conjunta de funciones receptoras y curvas de dispersión}

Con el fin de estimar con precisión la estructura en detalle y las características geológicas del subsuelo, se suelen combinar distintas técnicas geofísicas. Si bien el análisis de las funciones receptoras es un recurso valioso 
para obtener las características de la corteza por debajo de las estaciones, la inversión para la velocidad de corte no es única.

Ammon et al. (1990) mostraron la no unicidad del problema de inversión de funciones receptoras (FRs). Mediante pruebas con datos sintéticos, los autores demostraron que la inversión era sensible principalmente a los contrastes de velocidad de corte y tiempos de viaje relativos y no a la velocidad absoluta del medio. Ellos probaron que una inversión simultánea de FRs a diferentes velocidades no bastaría para remover la ambigüedad entre velocidad y profundidad. Se debe considerar que la amplitud de la conversión P a S es función principalmente del contraste de velocidad en la discontinuidad, pero no es sensible a la velocidad absoluta o a las variaciones suaves de velocidad en profundidad (Langston, 1994). Por lo tanto, sólo se podría reducir la no unicidad con el agregado de información a priori.

La combinación de observaciones de dispersión de ondas superficiales, sensibles a los valores de velocidad absoluta del medio y no a los contrastes de velocidad, y de funciones receptoras de onda $P$, puede dar una estimación más consistente de la velocidad de corte del medio por el cual se propagan, que mejora las estimaciones proporcionadas por cualquiera de los conjuntos de datos considerados separadamente, y ayuda a evitar la mala interpretación derivada de la utilización individual de cada grupo. Su inversión conjunta produce modelos de Tierra donde los detalles ajustados por las FRs son superpuestos a un modelo de fondo restringido por las mediciones de dispersión, generando estrechos ajustes a la variación de la velocidad de corte con la profundidad, reduciendo la falta de singularidad de cada dato individual, estabilizando la inversión y minimizando la dependencia del modelo final con el modelo inicial (Julià et al., 2003). El éxito de esta inversión simultánea se debe al hecho de que ambas mediciones son consistentes y complementarias (Julià et al., 2000). El costo de esta combinación implica la pérdida del muestreo local generado por la técnica de FRs y la obtención de un promedio lateral mayor, determinado por las ondas superficiales.

La inversión conjunta no remueve los efectos del ruido en los datos, pero puede reducir la sobreinterpretación de los datos contaminados (Julià et al., 2000). Aunque se necesita información a priori para distinguir entre diferentes modelos que ajustan razonablemente ambos conjuntos de datos, esto no desvirtúa la 
técnica de inversión conjunta que reduce en gran medida la no unicidad en las inversiones.

En resumen, las curvas de dispersión restringen la velocidad de corte absoluta del medio y las FRs, los contraste de velocidad de corte. Integrando lo anterior en un algoritmo de inversión simultánea simple se obtendrán mejores restricciones de los valores de velocidad de la onda $S$, ya que la información dada por un grupo de datos cubriría las falencias del otro. Sin embargo, para combinar los datos de FRs y mediciones de dispersión, el alcance lateral del área contemplada por ambos conjuntos de datos debe ser similar, de otro modo se estaría agrupando información dependiente de diferentes estructuras. Cuando se aplica el método de una única estación para la obtención de las curvas de dispersión, las mismas dependen de la trayectoria desde la fuente hasta la estación de registro. Afortunadamente es posible obtener curvas locales mediante inversión tomográfica de las velocidades de dispersión medidas (Julià et al., 2000).

\subsubsection{Metodología}

La metodología de inversión conjunta detallada a continuación se aplicó inicialmente en la estación TRQA, ubicada en la provincia de Buenos Aires (Fig. 3.4 ), con el fin de ilustrar los pasos del procedimiento a través de datos reales. En la siguiente sección se mostrarán los resultados obtenidos para la estación CPUP ubicada en Villa Florida, Paraguay (Fig. 3.4), que se encuentra en la región de interés de este capítulo.

Como en toda inversión, se definen los datos que serán las curvas de dispersión de la velocidad de grupo y las FRs radiales, y los parámetros del modelo que serán las velocidades del medio. Se asume que la distribución de la velocidad de corte con la profundidad puede ser representada por un número discreto de capas cuyos espesores (elegidos a priori) dependen de las observaciones.

Para realizar la inversión de la velocidad de corte se aplica una aproximación lineal iterativa que se resuelve mediante mínimos cuadrados amortiguados, que incorporan a priori ajustes en la suavización para las velocidades en capas adyacentes. En general, se requiere aplicar estos ajustes a los perfiles resultantes para evitar variaciones repentinas, quizás físicamente 
insostenibles, de la velocidad con la profundidad, buscando un balance óptimo entre resolución y estabilidad (Julià et al., 2000; 2003). El software que se utiliza fue desarrollado por Julià (2001) y modificado por Ammon (2004), haciendo variable la suavización en cada capa.

Existen dos parámetros a considerar en la inversión, los parámetros de influencia (p) y de suavización (n). El parámetro p controla la contribución relativa de cada grupo de datos (FRs y curvas de dispersión) a la solución. Su valor varía entre 0 y 1 , de manera que $p=0$ significa invertir datos de FRs solamente y $p=1$ significa invertir datos de dispersión solamente. El factor $\mathrm{n}$ regula el balance entre estabilidad y resolución, controlando los contrastes de velocidad entre las distintas capas (Julià et al., 2003). Los valores de estos parámetros se determinan empíricamente realizando conjuntos de inversiones y eliminando las observaciones cuestionables. Si bien esto no representa un análisis estadístico de los errores, es una práctica estándar en este procedimiento.

Se parte de un modelo sencillo, generalmente derivado del PREM (Preliminary Referente Earth Model, Dziewonski and Anderson, 1981) al que se le adiciona información geológica de la región. Dado que la corteza continental es altamente heterogénea en las tres dimensiones, es útil dividirla en varias discontinuidades que difieran en velocidad sísmica (composición). Los modelos clásicos constan de tres capas, superior, intermedia e inferior con rangos de $V_{P}$ de $\sim 5.7-6.4 \mathrm{~km} / \mathrm{s}, 6.4-6.8 \mathrm{~km} / \mathrm{s}$ y $6.8-7.6 \mathrm{~km} / \mathrm{s}$, respectivamente (Christensen and Mooney, 1995; Artemieva, 2002). Sin embargo el método utilizado no varía los espesores sino las velocidades. Por tal motivo es conveniente considerar una variación gradual de velocidad a pequeños intervalos de profundidad, utilizando capas con espesores de aproximadamente 2 a $2.5 \mathrm{~km}$ para la corteza y de 5 a 10 $\mathrm{km}$ para el manto superior. Si se utiliza un número grande de capas con espesores muy pequeños $(<1 \mathrm{~km})$ pueden producirse inestabilidades que no permiten que el proceso iterativo converja (Julià et al., 2008). El valor inicial de $V_{S}$ en cada capa es ponderado mediante un factor. Esto permite introducir al modelo información de velocidades obtenidas a priori por algún otro método. También se incluyen ajustes en la suavización mediante un factor que modifica este parámetro $\mathrm{n}$ en cada capa. 
La relación de Poisson se mantiene constante en cada capa. Se puede utilizar para este coeficiente, el valor estimado a partir de método de HK stacking.

Para la inversión se utilizan FRs promedio obtenidas a partir del stack para los distintos back-azimuths, según el criterio que se describió en el capítulo 3. Antes de aplicar los códigos de inversión se ajustan las amplitudes de las FRs que fueron calculadas con el método iterativo, normalizando por el área de la función promedio (que surge de la deconvolución de la función consigo misma). El valor de normalización depende del ancho $\alpha$ del filtro gaussiano aplicado (Tabla 4.1).

\begin{tabular}{c|c} 
Ancho $\alpha$ & $\begin{array}{c}\text { Factor } \\
\text { Normalización }\end{array}$ \\
\hline 0.5 & 0.29 \\
\hline 1.0 & 0.57 \\
\hline 1.5 & 0.85 \\
\hline 2.5 & 1.42 \\
\hline 3.0 & 1.7 \\
\hline 5.0 & 2.83
\end{tabular}

Tabla 4.1: Factor de normalización para distintos anchos $\alpha$ del filtro gaussiano.

Para asegurarse que ambos conjuntos de datos muestrean regiones similares de la Tierra, se identifica la celda tomográfica que contiene a la estación y se extrae la curva local de velocidad de grupo para las ondas Rayleigh y Love para el modo fundamental, a partir de la regionalización tomográfica de $1^{\circ} \times 1^{\circ}$, obtenida en el capítulo 2 .

Las FRs y las curvas de dispersión se invierten minimizando la diferencia entre los valores observados y los sintéticos, calculados a partir del modelo de entrada, mientras que se ajusta simultáneamente la suavización del modelo (parámetro n). La inversión produce modelos simples con un número mínimo de 
contrastes abruptos de velocidad. Los mejores modelos se seleccionan mediante inspección visual del ajuste de los datos.

El problema a resolver consiste en invertir simultáneamente dos conjuntos de datos para un único conjunto de parámetros. La solución no es tan simple como minimizar la suma de las funciones objetivo. Primero hay que normalizar para ecualizar las unidades y el número de puntos. El sistema de ecuaciones a resolver es:

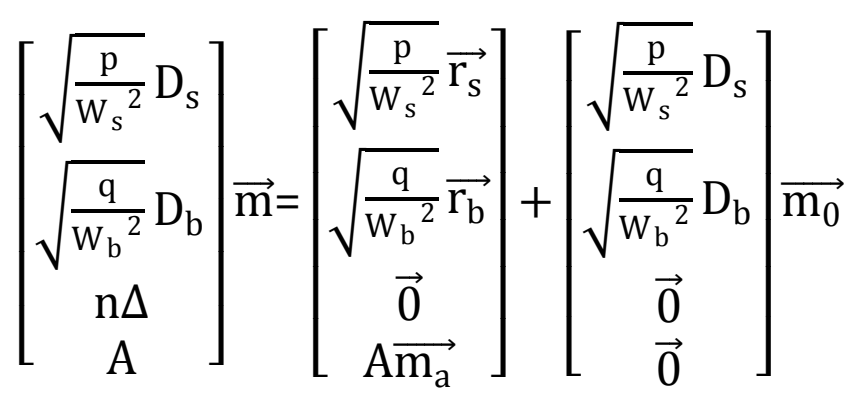

donde $\mathrm{p}$ es el parámetro de influencia, $\mathrm{q}=1-\mathrm{p} ; \mathrm{D}_{\mathrm{s}}$ y $\mathrm{D}_{\mathrm{b}}$ son las matrices de las derivadas parciales para la estimación de la dispersión y las FRs, respectivamente. $\overrightarrow{\mathrm{r}_{\mathrm{s}}}$ y $\overrightarrow{\mathrm{r}_{\mathrm{b}}}$ son los correspondientes vectores residuos; $\mathrm{W}_{\mathrm{s}}{ }^{2}$ y $\mathrm{W}_{\mathrm{b}}{ }^{2}$ son los pesos que ecualizan el set de datos y son iguales al producto entre el número de puntos en la curva de dispersión y en las FRs y la varianza de las observaciones. El vector $\overrightarrow{\mathrm{m}}$ contiene el modelo de velocidad, el vector $\overrightarrow{\mathrm{m}_{0}}$ contiene el modelo inicial, la matriz $\Delta$ impone las condiciones de suavización con $\mathrm{n}$ parámetro de suavización y $\mathrm{A}$ es una matriz de pesos para el modelo de velocidades a priori, contenido en el vector $\overrightarrow{\mathrm{m}_{\mathrm{a}}}$. La ecuación (4.1) se resuelve mediante mínimos cuadrados para un modelo $\mathrm{m}$ comenzando con un modelo inicial $\mathrm{m}_{0}$.

A modo de ejemplo, la Fig. 4.1 muestra los resultados para TRQA, partiendo de un modelo compuesto de varias capas con velocidades crecientes hasta los 60 $\mathrm{km}$, un aumento gradual de velocidad en el manto superior y una marcada discontinuidad de velocidad a los $224 \mathrm{~km}$ aproximadamente. La figura consta de 4 imágenes: los gráficos de la izquierda muestran los resultados de la inversión para las FRs (gráfico superior) y para las curvas de dispersión (gráfico inferior). Los gráficos de la derecha muestran el modelo inicial y el modelo final, en detalle para 
los primeros $80 \mathrm{~km}$ (gráfico superior) y para los $300 \mathrm{~km}$ de profundidad (gráfico inferior).

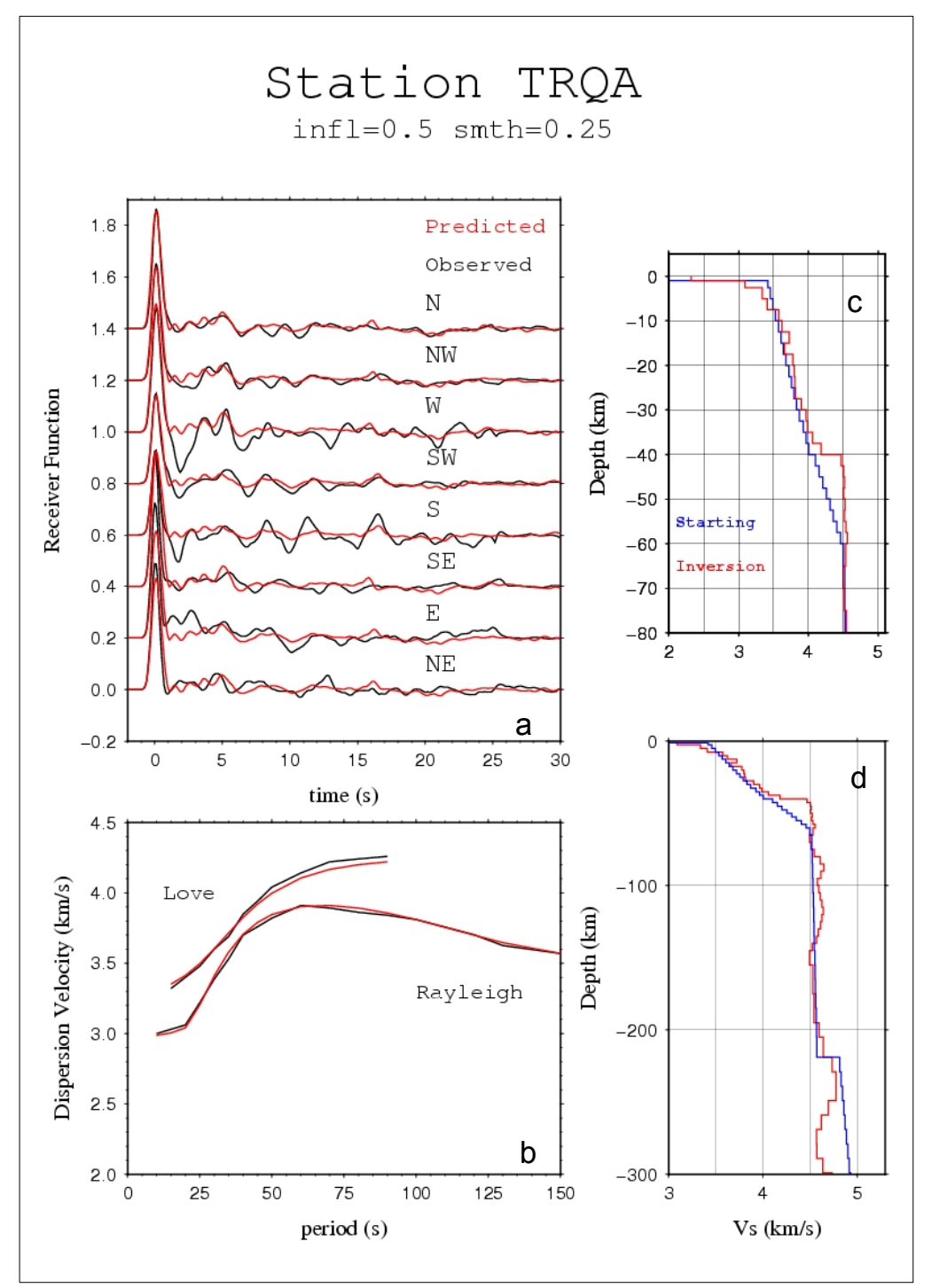

Figura 4.1: Resultados de la inversión conjunta para la estación TRQA utilizando $\mathrm{p}$ (infl) de 0.5 y $\mathrm{n}$

(smth) de 0.25 , partiendo de un modelo de varias capas con velocidad creciente, un aumento gradual de velocidad en el manto superior y una discontinuidad de velocidad a los $224 \mathrm{~km}$. a) FRs observadas (trazo negro) y sintéticas (trazo rojo). b) Curvas de dispersión observadas (trazo negro) y modeladas (trazo rojo). c) y d) Modelo final de velocidad para corteza y manto superior (trazo rojo) correspondiente al mejor ajuste comparado con el modelo inicial (trazo azul).

Se observa que a pesar de la sencillez del modelo de entrada, el método de inversión produce resultados aceptables con un ajuste razonable entre datos observados y sintéticos, permitiendo ser aplicado en regiones que no cuenten con 
ninguna información a priori. El modelo final presenta un aumento de velocidad a los $40 \mathrm{~km}$ de profundidad atribuible al límite corteza - manto que coincide con el obtenido para espesor cortical en la estación TRQA en la sección 3.5.2.

En la siguiente inversión (Fig. 4.2) se parte de un modelo con una única capa cortical de $40 \mathrm{~km}$ de espesor y una $V_{S}=3.8 \mathrm{~km} / \mathrm{s}$, manteniendo las mismas características del modelo anterior para la región del manto.

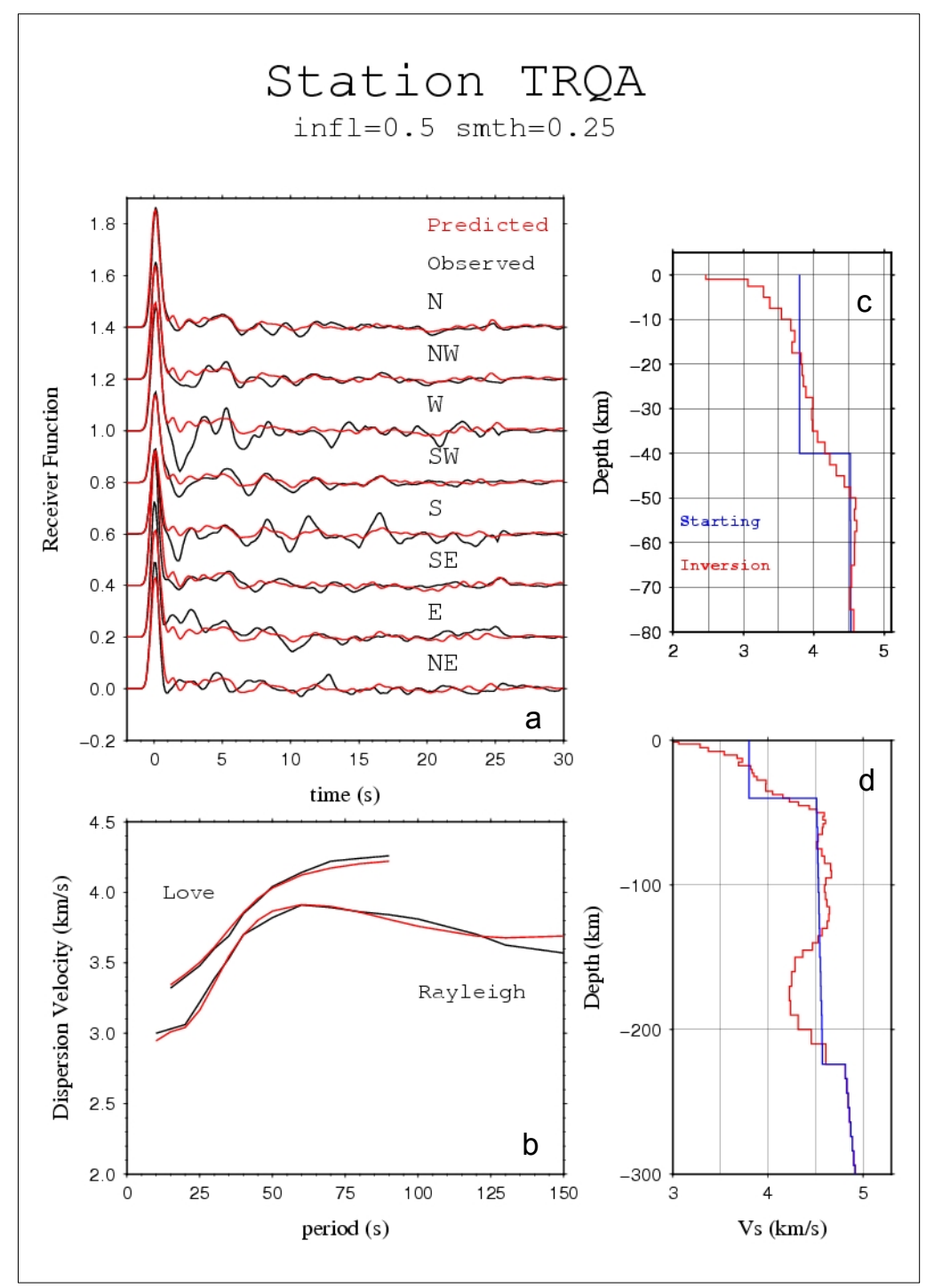

Figura 4.2: Resultados de la inversión conjunta para TRQA utilizando $\mathrm{p}$ (infl) de $0.5 \mathrm{y} \mathrm{n}$ (smth) de 0.25 , partiendo de un modelo con una capa cortical de $40 \mathrm{~km}$ de espesor. a) FRs observadas (trazo negro) y sintéticas obtenidas por modelado directo (trazo rojo). b) Curvas de dispersión observadas (trazo negro) y modeladas (trazo rojo). c) y d) Modelo final de velocidad para corteza y manto superior (trazo rojo) correspondiente al mejor ajuste comparado con el modelo inicial (trazo azul). 
La inversión muestra que el modelo final "percibe" las velocidades promedio a partir de las curvas de dispersión, ya que oscila hacia el modelo real siendo importante el ajuste con los valores observados de dispersión. Esto sucede porque las observaciones de dispersión restringen la velocidad promedio en el modelo y las FRs, la estructura fina, superponiéndose a las velocidades de fondo.

La Fig. 4.3 muestra los resultados de la inversión para un modelo inicial con 4 capas en la región cortical.

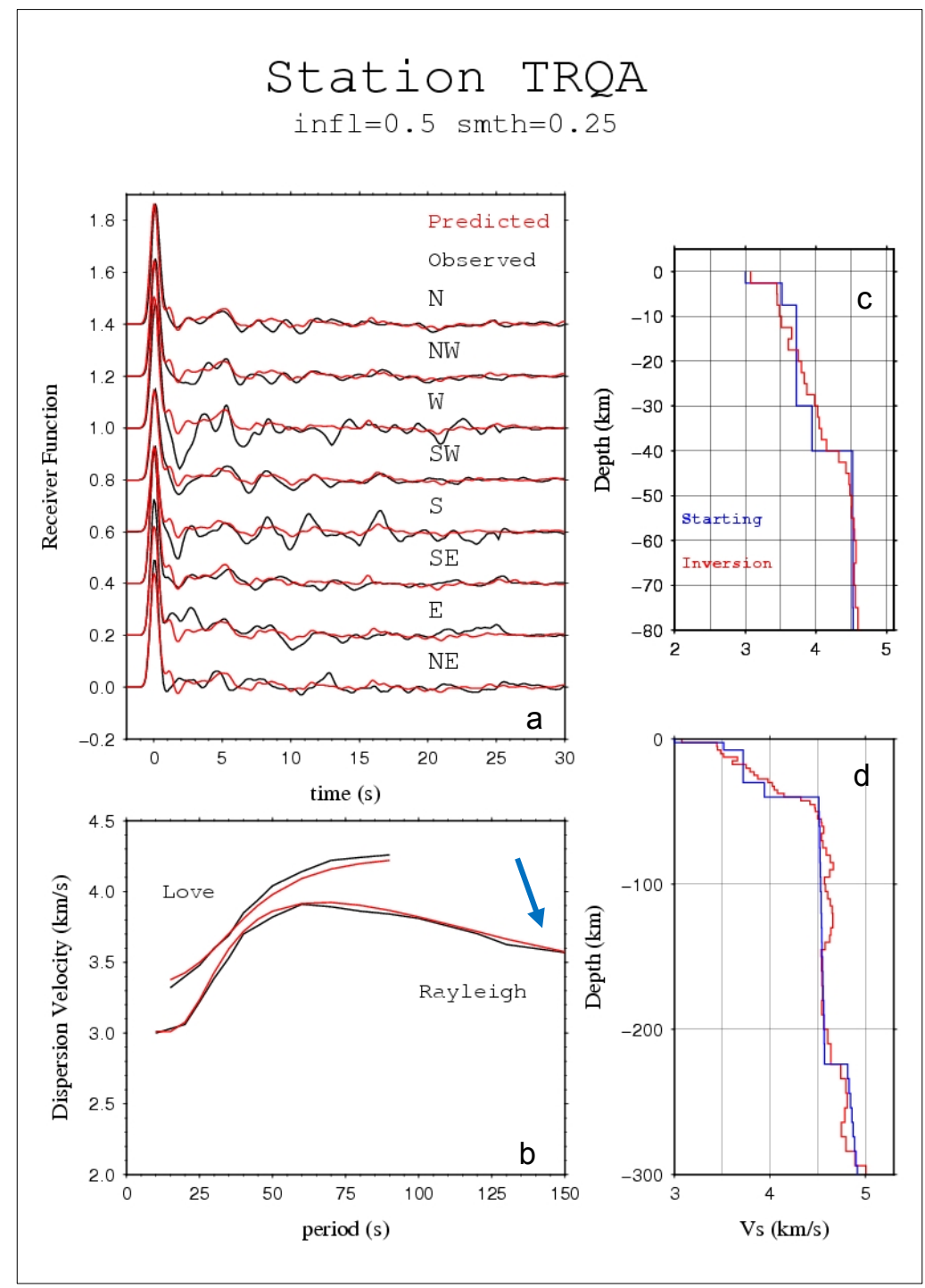

Figura 4.3: Resultados de la inversión conjunta para TRQA utilizando p (infl) de 0.5 y $n$ (smth) de 0.25, partiendo de un modelo con 4 capas en la región cortical. a) FRs observadas (trazo negro) y sintéticas (trazo rojo). b) Curvas de dispersión observadas (trazo negro) y modeladas (trazo rojo). c) y d) Modelo final de velocidad (trazo rojo) comparado con el modelo inicial (trazo azul). La flecha indica un mejor ajuste en esa región de la curva comparada con la Fig. 4.2. 
Se distingue una mejor correlación entre las FRs observadas y sintéticas para la fase Ps convertida y entre las curvas de dispersión, en particular para la onda Rayleigh.

En la última inversión presentada se obtienen mejores ajustes a las observaciones (Fig. 4.4), partiendo de un nuevo modelo que incluye un aumento gradual de velocidad en la corteza (15 capas) y discontinuidades de velocidad más marcadas para profundidades mayores a los $220 \mathrm{~km}$. Las curvas de dispersión modeladas para la onda Rayleigh para todos los períodos y para la onda Love para los períodos menores a $45 \mathrm{~s}$ claramente coinciden con las observadas.

Los modelos presentados, a modo de ejemplo, ajustan satisfactoriamente las FRs y los valores de dispersión para un parámetro de influencia de 0.5 y de suavización de 0.25 . Las incertidumbres del perfil velocidad-profundidad pueden estimarse de manera aproximada mediante la comparación de los resultados entre las diferentes iteraciones en la inversión. Generalmente 4 iteraciones resultan suficientes para que converja la solución. Por lo general, las variaciones observadas en la velocidad de corte para cada capa son menores que $\sim 0.1 \mathrm{~km} / \mathrm{s}$, para este tipo de inversión. Las incertezas en la profundidad para la región cortical pueden ser $\leq 1 \mathrm{~km}$ ya que los espesores son del orden de $2 \mathrm{~km}$.

Aunque se necesita información a priori para distinguir entre diferentes modelos que ajustan razonablemente ambos grupos de datos, esto no desvirtúa la técnica de inversión conjunta que reduce en gran medida la no unicidad en las inversiones (Julià, 2007).

Mediante este ejemplo del proceso de inversión, utilizando el coeficiente de Poisson estimado a partir de método de HK stacking en el capítulo 3, se determinó que la estación TRQA presenta un espesor cortical de $\sim 40 \mathrm{~km}$, típico de regiones continentales estables (Christensen and Mooney, 1995) y un perfil de velocidadprofundidad compatible con un basamento metamórfico ígneo debajo de rocas sedimentarias altamente deformadas, no consolidadas con $V_{S}<3.5 \mathrm{~km} / \mathrm{s}$ (Artemieva, 2002). 


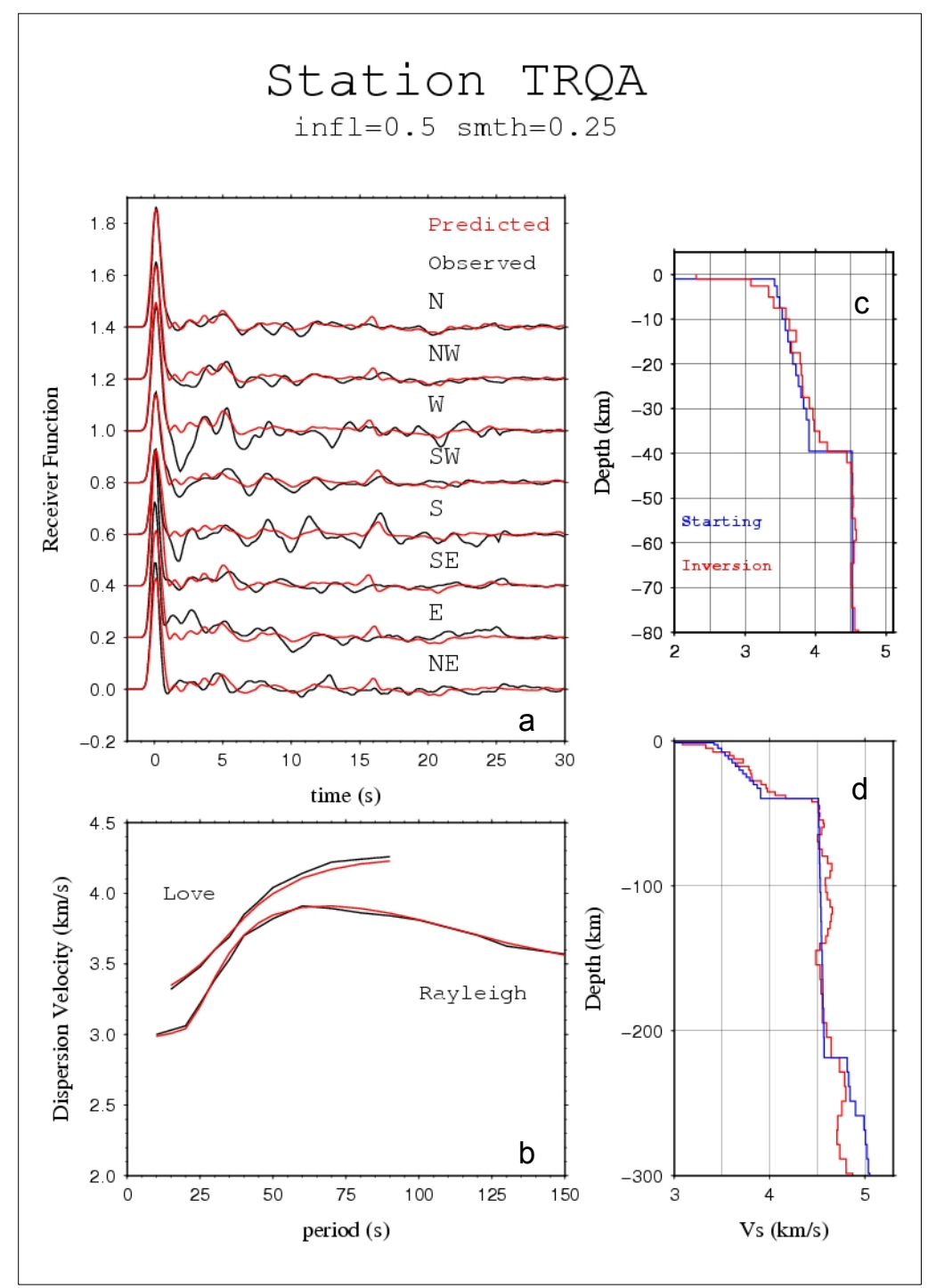

Figura 4.4: Resultados de la inversión conjunta para TRQA utilizando $\mathrm{p}$ (infl) de 0.5 y $\mathrm{n}$ (smth) de 0.25 , partiendo de un modelo con 15 capas en la corteza y discontinuidades de velocidad más marcadas para profundidades mayores a los $220 \mathrm{~km}$. a) FRs observadas (trazo negro) y sintéticas (trazo rojo). b) Curvas de dispersión observadas (trazo negro) y modeladas (trazo rojo). c) y d) Modelo final de velocidad (trazo rojo) comparado con el modelo inicial (trazo azul).

La utilización de la inversión conjunta de FRs y datos de dispersión de ondas superficiales ha mostrado ser una herramienta eficaz para determinar la velocidad absoluta de ondas de corte. Esto ha sido demostrado en trabajos previos por Julià et al. (2000; 2003), Lawrence and Wiens (2004) y Yoo et al. (2007). 


\subsubsection{Resultados y discusión}

Se determinó la estructura de velocidad de la onda de corte en profundidad bajo la estación sismológica CPUP mediante la inversión conjunta de FRs y velocidades de grupo de ondas superficiales. Para la inversión, se utilizaron FRs promedios para los distintos back-azimuths y curvas de dispersión de onda Rayleigh y Love obtenidas de la regionalización tomográfica. Se partió de un modelo sencillo derivado del PREM, en el cual se consideró la corteza compuesta de tres capas, una capa superior de $1 \mathrm{~km}$ de espesor con una $V_{\mathrm{S}}=2.34 \mathrm{~km} / \mathrm{s}$, una capa intermedia de $5 \mathrm{~km}$ con una $\mathrm{V}_{\mathrm{S}}=3.31 \mathrm{~km} / \mathrm{s}$ y una capa más profunda de 25 $\mathrm{km}$ con una $\mathrm{V}_{\mathrm{S}}=3.8 \mathrm{~km} / \mathrm{s}$; y para el manto, un aumento gradual de la velocidad hasta aproximadamente los $220 \mathrm{~km}$, donde se consideró un incremento en la velocidad de 4.57 a $4.81 \mathrm{~km} / \mathrm{s}$. En la región cortical se utilizó 1.76 para la relación $\mathrm{V}_{\mathrm{P}} / \mathrm{V}_{\mathrm{S}}$, estimada a partir de método de HK stacking.

Se realizaron varias iteraciones. En la Fig. 4.5 se muestran los resultados para 4, 6 y 8 iteraciones. Comparando los distintos modelos obtenidos y sus ajustes, se estableció que un número de 4 iteraciones resulta suficiente para que el modelo converja a una solución aceptable.

Esta primera inversión produjo un modelo simple que presenta una variación gradual de las velocidades a pequeños intervalos de profundidad tanto en la región cortical como en el manto, con buenos ajustes para ambos grupos de datos observados.

En la siguiente inversión (Fig.4.6) se modificó el modelo de entrada de acuerdo a los resultados obtenidos en la etapa anterior y se realizaron sólo 4 iteraciones. Los datos calculados ajustaron mejor a los observados, como por ejemplo las curvas de dispersión de onda Rayleigh para períodos largos (> 120s). Se realizaron nuevas inversiones modificando sutilmente el modelo de entrada hasta obtener un resultado satisfactorio. 

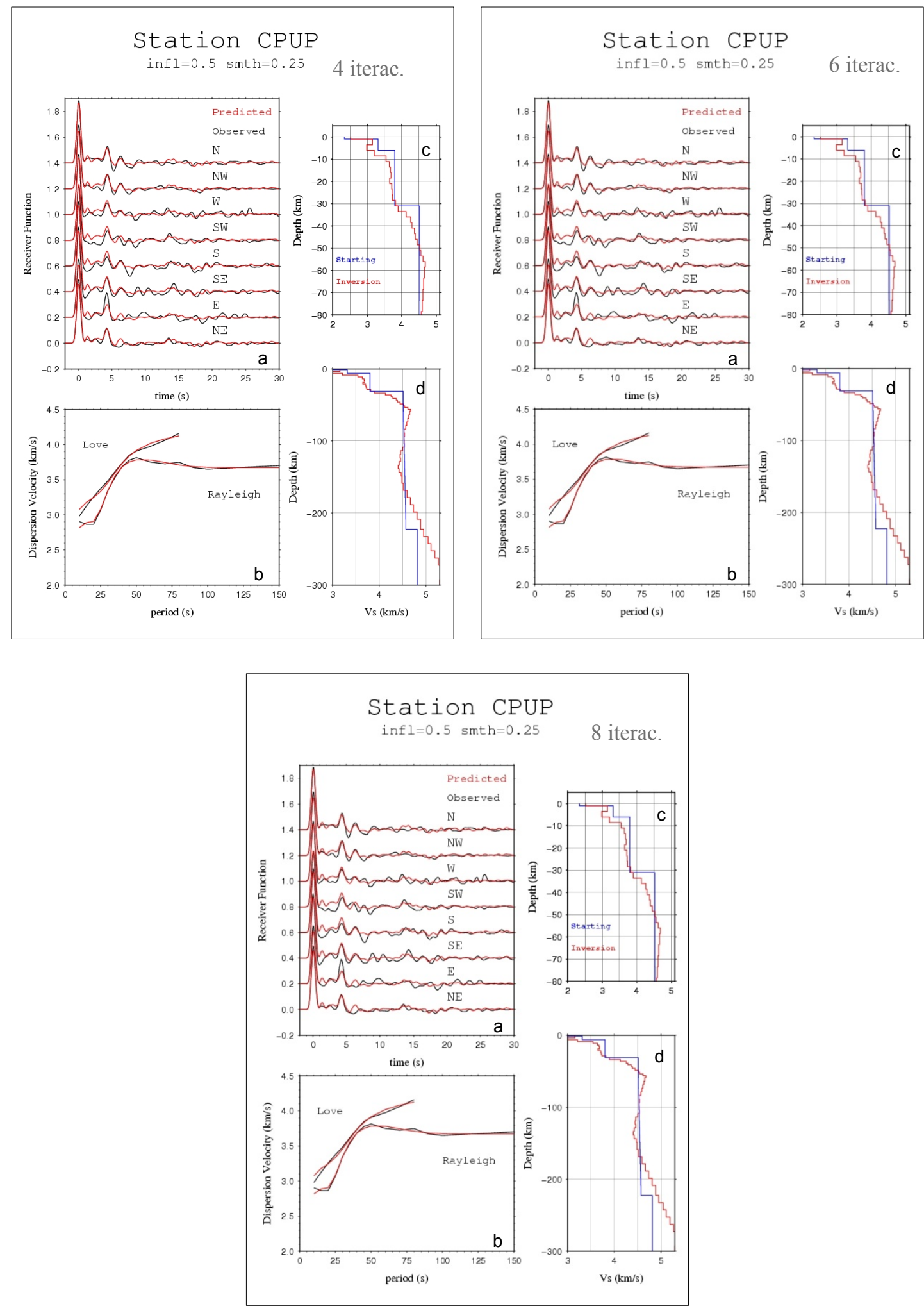

Figura 4.5: Resultados de la inversión conjunta para 4, 6 y 8 iteraciones para CPUP utilizando p

(infl) de 0.5 y n (smth) de 0.25 , partiendo de un modelo con 3 capas en la corteza. a) FRs observadas (trazo negro) y sintéticas (trazo rojo). b) Curvas de dispersión observadas (trazo negro) y modeladas (trazo rojo). c) y d) Modelo final de velocidad para corteza y manto superior (trazo rojo) correspondiente al mejor ajuste en comparación al modelo inicial (trazo azul). 


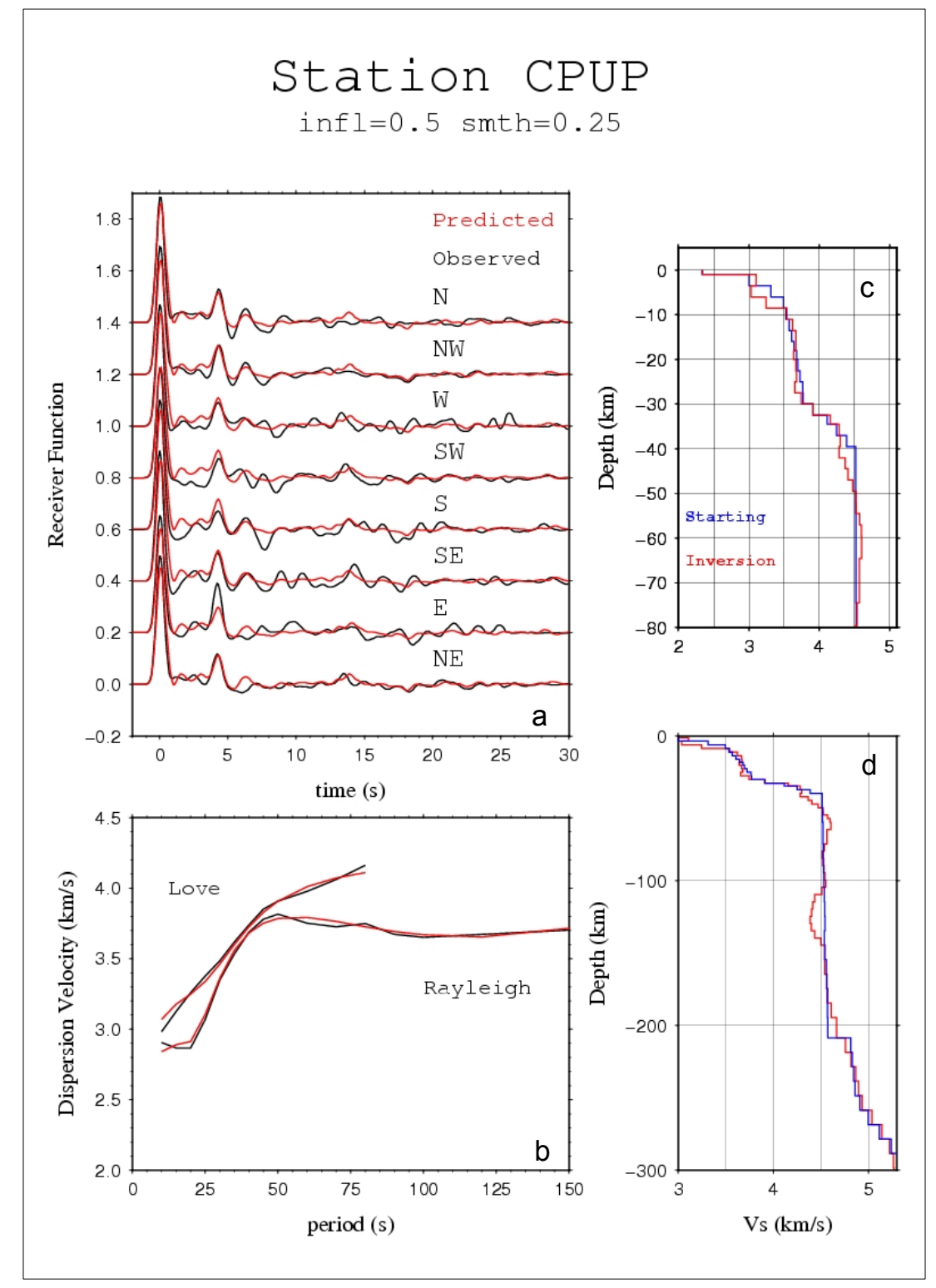

Figura 4.6: Resultados de la inversión conjunta para CPUP utilizando $\mathrm{p}$ (infl) de $0.5 \mathrm{y} \mathrm{n}$ (smth) de 0.25. a) FRs observadas (trazo negro) y sintéticas (trazo rojo). b) Curvas de dispersión observadas (trazo negro) y modeladas (trazo rojo). c) y d) Modelo final de velocidad (trazo rojo) en comparación al modelo inicial (trazo azul).

Para elegir el parámetro de suavización que brinda el mejor balance entre estabilidad y resolución, y analizar la influencia relativa de los dos grupos de datos, se realizaron varias inversiones para distintos valores de $\mathrm{n}$ y de $\mathrm{p}$. El parámetro de suavización $n$ se varió para $0.10,0.20,0.25,0.30,0.40,0.50$ y 0.75 y el parámetro de influencia p entre 0.1 y 0.9 con un paso de 0.2 . En todos los casos analizados, se produjo un ajuste razonable entre los datos observados y los calculados. Los 
modelos obtenidos son análogos entre sí, ya que todos muestran características similares: un contraste de velocidad en la discontinuidad corteza-manto ( $\sim 35 \mathrm{~km})$, una disminución de velocidad a los $\sim 125 \mathrm{~km}$ de profundidad y un gradiente positivo de velocidad a partir de los $250 \mathrm{~km}$ de profundidad que presenta las diferencias más notorias entre cada uno.

En la Fig. 4.7 se muestran los resultados obtenidos variando $n$, con $p=0.5$. Las diferencias en los resultados son muy sutiles según se observa en la figura. Se compararon todas las inversiones por separado, analizando los cambios que se producían a medida que $\mathrm{n}$ variaba. Se observó que a valores bajos de $\mathrm{n}$ se produjo un mejor ajuste entre las curvas observada y calculada para la onda Rayleigh, mientras que el ajuste en las FRs para más de $25 \mathrm{~s}$ mejoraba cuando $\mathrm{n}$ aumentaba.

Al analizar la influencia de cada grupo de datos en la inversión, para $\mathrm{n}$ fijo (Fig. 4.8), se encontró que los ajustes en las curvas de dispersión en particular para la onda Love de bajo período, mejoran notablemente para p altos. Cuando los p disminuyeron, se obtuvieron mejores ajustes en las amplitudes de las FRs para la P directa y mejores ajustes de las fases múltiples.

Si se analizan los modelos finales de velocidad correspondientes a los valores extremos de $\mathrm{p}$ (0.1 y 0.9$)$ con $\mathrm{n}$ fijo (Fig. 4.9), se observa que ambos modelos presentan variaciones de velocidad en la corteza y en el manto del orden de los $\sim 0.12-0.14 \mathrm{~km} / \mathrm{s}$. Por consiguiente, es conveniente utilizar la misma influencia de ambos conjuntos de datos en la inversión (o sea $\mathrm{p}=0.5$ ), reduciendo la falta de singularidad de cada conjunto individual, de manera de estabilizar la inversión, minimizando la dependencia del modelo final con el modelo inicial y así obtener buenos ajustes.

Si se realiza el mismo análisis para los resultados de inversión con p fijo y $\mathrm{n}$ variable, los modelos finales (Fig. 4.10) calculados a partir de los extremos de $n$ (0.1 y 0.7), presentan una gran similitud en la región de la corteza y del manto hasta los $\sim 250 \mathrm{~km}$ de profundidad donde las variaciones de velocidad entre ambos modelos son del orden de $\sim 0.3 \mathrm{~km} / \mathrm{s}$. Sin embargo a esas profundidades, el alcance de los resultados es menor debido a los datos con los que se cuenta. Por 
tal motivo la inversión de estos datos permite utilizar un parámetro de suavización medio (e.g., $\mathrm{n}=0.25$ ), sin desmerecer los resultados.

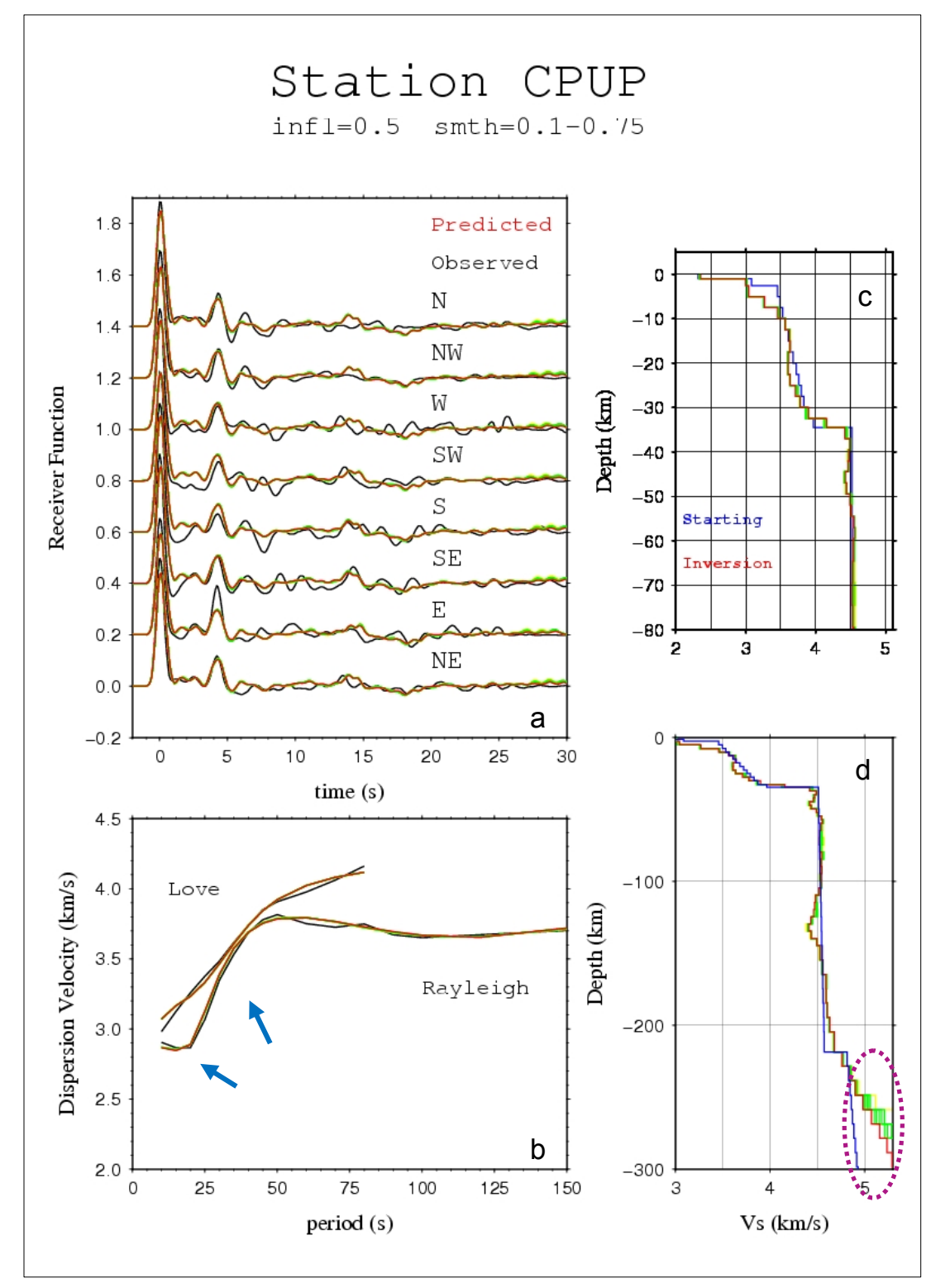

Figura 4.7: Resultados finales de la inversión conjunta para CPUP utilizando $\mathrm{p}$ (infl) de 0.5 y $\mathrm{n}$ (smth) variable entre 0.10 y 0.75 . Los datos sintéticos o modelados se graficaron utilizando trazo amarillo para $\mathrm{n}$ de 0.10 , trazo verde para $\mathrm{n}$ entre 0.20 y 0.50 , trazo rojo para $\mathrm{n}$ de 0.75 . a) FRs

observadas (trazo negro) y sintéticas b) Curvas de dispersión observadas (trazo negro) y modeladas. c) y d) Modelo final de velocidad en comparación al modelo inicial (trazo azul). Las flechas azules indican las mejoras en los ajustes. La elipse indica las diferencias obtenidas en los modelos para los distintos valores de $n$. 


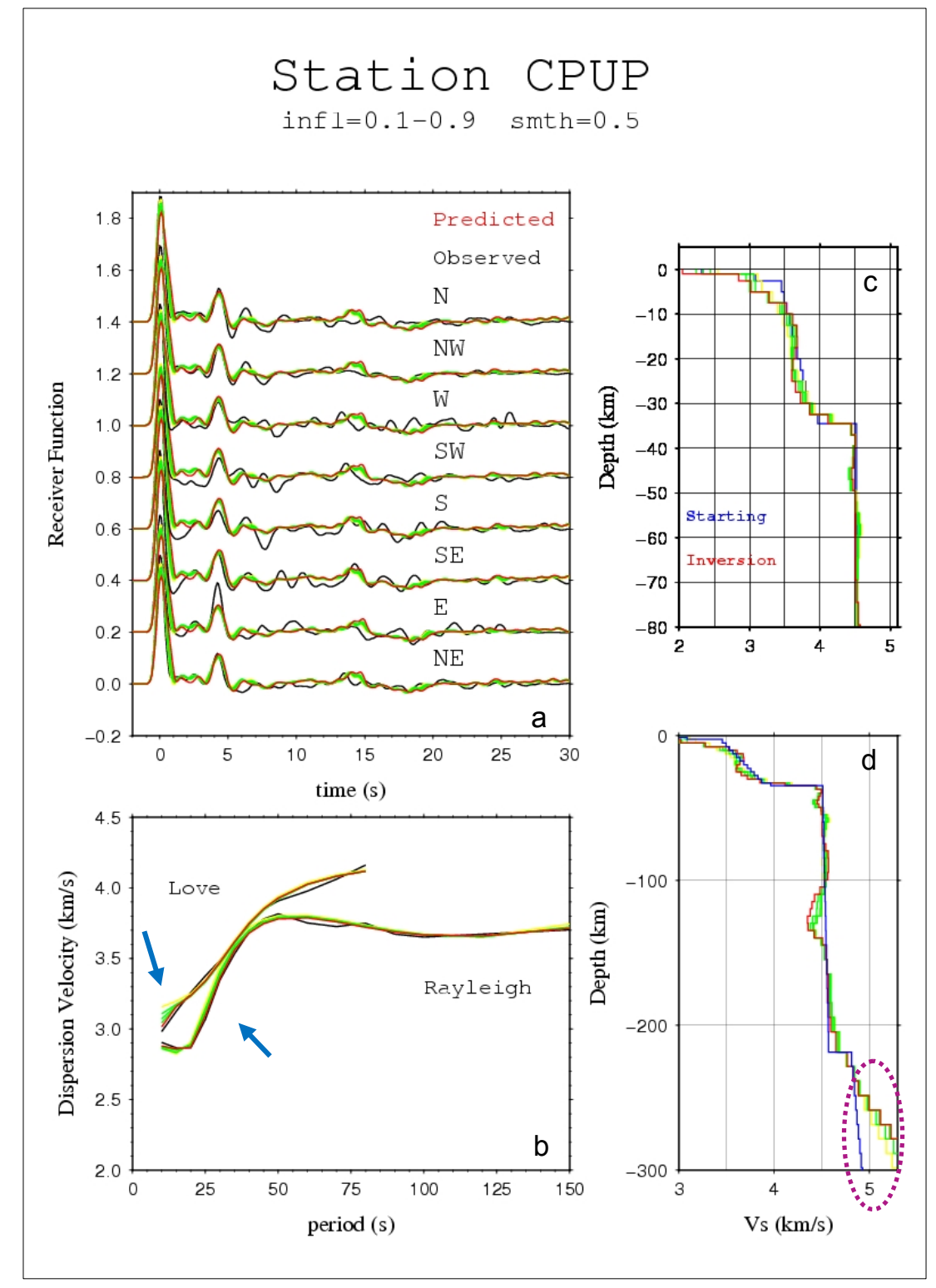

Figura 4.8: Resultados finales de la inversión conjunta para CPUP utilizando $\mathrm{p}$ (infl) variando entre 0.1 y 0.9 y $\mathrm{n}$ (smth) de 0.5 . Los datos sintéticos o modelados se graficaron utilizando trazo amarillo para $\mathrm{p}$ de 0.1 , trazo verde para $\mathrm{p}$ entre 0.30 y 0.70 , trazo rojo para $\mathrm{p}$ de 0.9 . a) FRs observadas (trazo negro) y sintéticas. b) Curvas de dispersión observadas (trazo negro) y modeladas. c) y d) Modelo final de velocidad en comparación al modelo inicial (trazo azul). Las flechas azules indican las mejoras en los ajustes. La elipse indica las diferencias obtenidas en los modelos para los distintos valores de $\mathrm{p}$.

A partir del análisis realizado sobre los modelos iniciales y sobre los parámetros de la inversión y luego de haber efectuado diversas pruebas, se escogió un modelo final mediante inspección visual de los resultados y con énfasis 
en la sencillez del mismo, que ajusta satisfactoriamente ambos conjuntos de observaciones (Fig. 4.11)

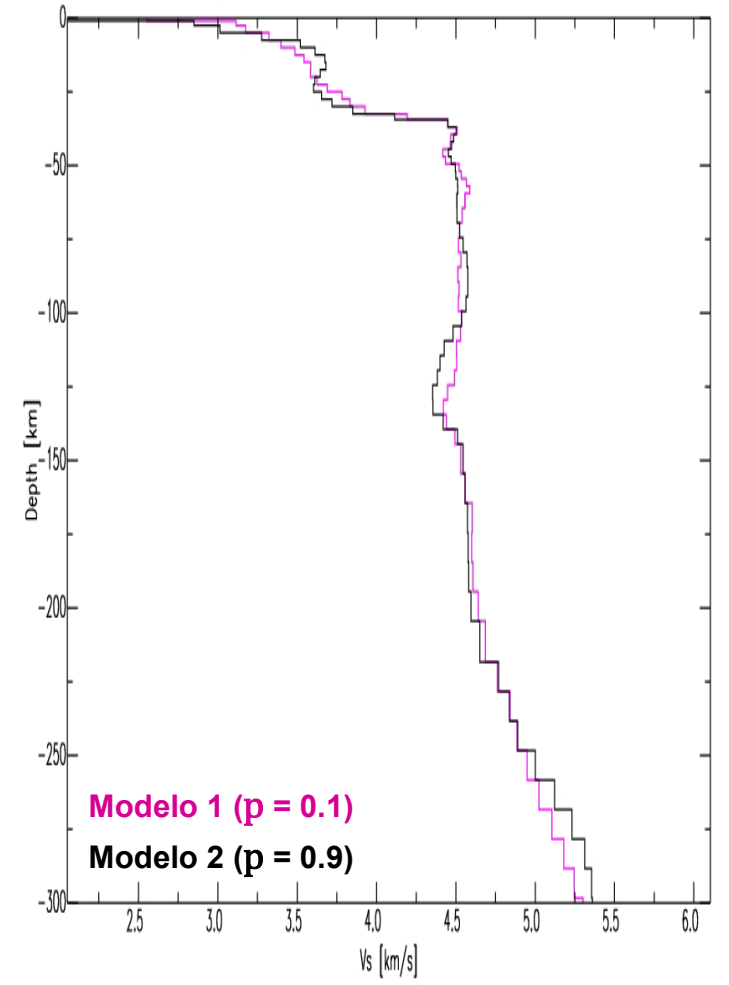

Figura 4.9: Modelos finales de la inversión para $\mathrm{n}$ fijo y $\mathrm{p}$ variando en los extremos.

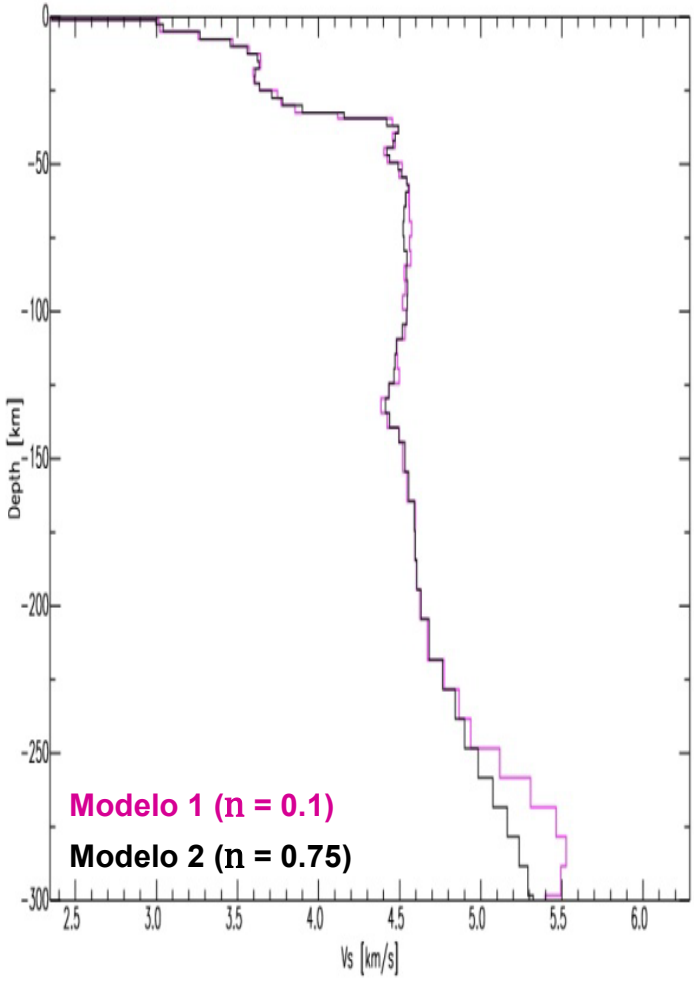

Figura 4.10: Modelos finales de la inversión para $\mathrm{p}$ fijo y $\mathrm{n}$ variando en los extremos.

El modelo final presenta una capa de $1 \mathrm{~km}$ de espesor con $V_{P}=4.11 \mathrm{~km} / \mathrm{s}$, velocidad característica de sedimentos consolidados en plataformas precámbricas y paleozoicas (Artemieva, 2002). Las velocidades de las ondas de corte aumentan gradualmente con la profundidad, de $\sim 3 \mathrm{~km} / \mathrm{s}$ bajo los sedimentos hasta $4.12 \mathrm{~km} / \mathrm{s}$ en la base de la corteza inferior, sin cambios bruscos. La discontinuidad de Mohorovicic queda evidenciada a los $34.5 \mathrm{~km}$ por el cambio de velocidad de 4.12 $\mathrm{km} / \mathrm{s}$ en la base de la corteza a $4.44 \mathrm{~km} / \mathrm{s}$ en el manto, con una Pn de $8.03 \mathrm{~km} / \mathrm{s}$. Este valor es típico de rocas peridotitas.

A $125 \mathrm{~km}$ de profundidad hay una disminución de la velocidad de corte que podría indicar la presencia de una astenósfera débil por debajo de una litósfera espesa. Comúnmente los cratones ubicados en el hemisferio sur presentan litósferas relativamente delgadas con un valor promedio del espesor cortical de 35 


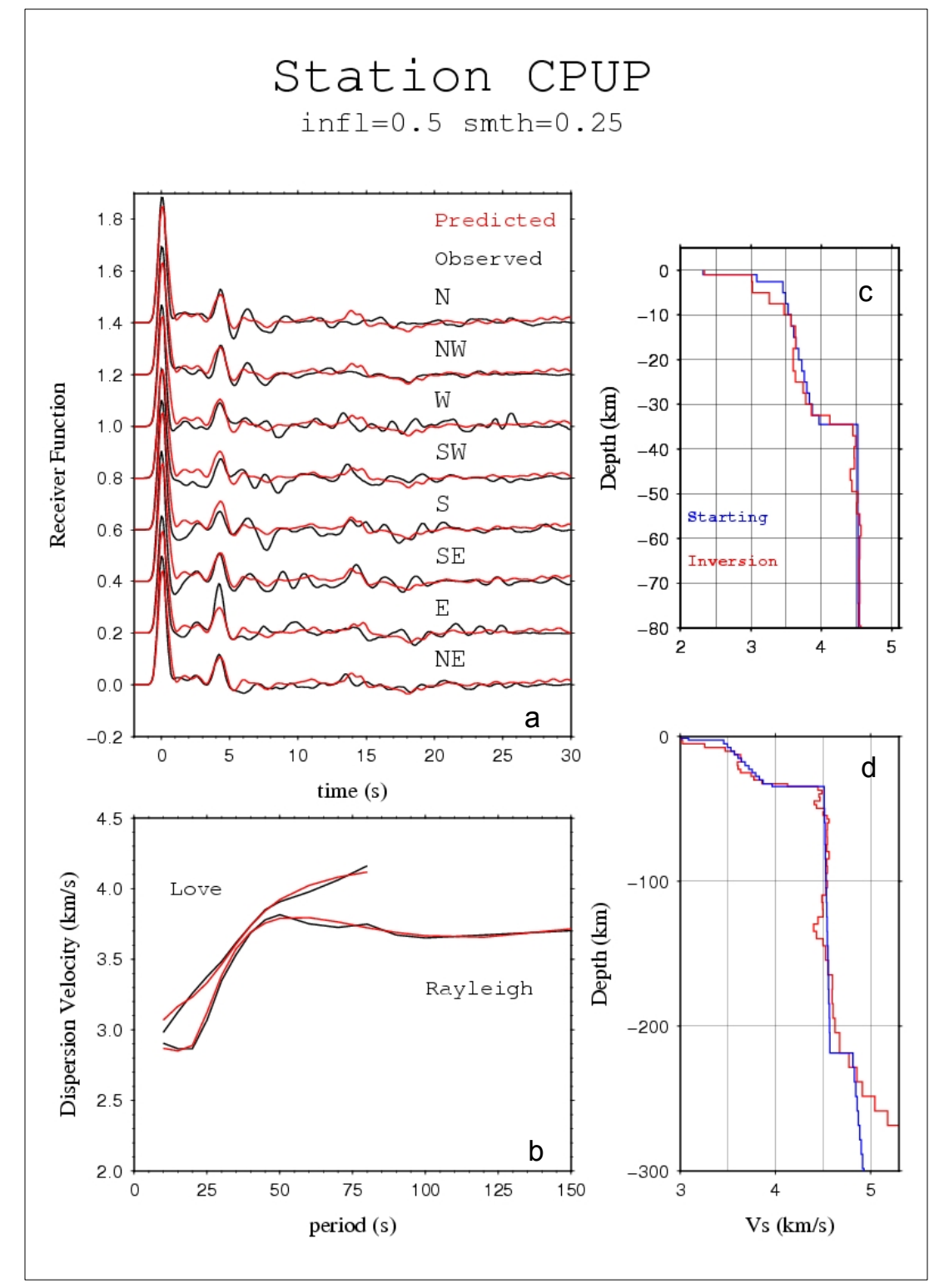

Figura 4.11: Resultados de la inversión conjunta para CPUP utilizando p (infl) de 0.5 y $\mathrm{n}$ (smth) de 0.25. a) FRs observadas (trazo negro) y sintéticas (trazo rojo). b) Curvas de dispersión observadas (trazo negro) y modeladas (trazo rojo). c) y d) Modelo final de velocidad para corteza y manto superior (trazo rojo) seleccionado para CPUP correspondiente al mejor ajuste en comparación al modelo inicial (trazo azul).

km (Artemieva and Mooney, 2001) comparado con otros cratones cuyos LAB (lithospheric-asthenospheric boundary) se pueden hallar entre los 150 y los $300 \mathrm{~km}$ de profundidad. Sin embargo este límite que tiende a ser más difuso en cratones que en otros escenarios tectónicos (Eaton et al., 2009), no está bien definido, ya que a esa profundidad el perfil de velocidad depende principalmente de las curvas de dispersión de la onda Rayleigh. Las FRs de onda P no son sensibles al LAB. En 
cambio las FRs de onda S tienen mayor potencial para encontrar ese límite con mejor resolución, ya que llegan antes de la fase directa $S$ y por lo tanto no interfieren con las reflexiones múltiples como si ocurre para las FRs de onda $P$. Heit et al. (2007) encontraron un valor de LAB de $80 \mathrm{~km}$ y una Moho de $35 \mathrm{~km}$ para la estación CPUP a partir del análisis de FRs de onda S.

Las velocidades de dispersión de la onda Love modeladas son mayores a las obtenidas con la tomografía para periodos menores a 20 s y entre 50 y 70 s. Para la onda Rayleigh el ajuste es más suave, salvo entre 55 y 75 s. Esto podría quedar justificado porque los datos de dispersión de onda Love restringen a velocidades de corteza demasiado altas. Cuando se usan ambos tipos de datos de dispersión, las velocidades en la superficie y en la corteza superior están afectadas por el ajuste a las velocidades de corto período en la curva de dispersión de onda Love. La discrepancia entre las ondas Love y Rayleigh se resuelve generalmente asumiendo isotropía transversal en la capa superior del manto, considerando que las variaciones acimutales se promedian por el gran número de observaciones (Julià et al., 2003).

Las FRs sintéticas ajustan las observaciones para las fases $\mathrm{P}$ directa y Ps convertida en todas las direcciones. Sin embargo algunas FRs no ajustan la amplitud de la Ps, ni la fase negativa que sigue a la P directa. Se podría plantear realizar una nueva inversión para esos grupos considerando conveniente ampliar el set de datos observados para asegurar un buen resultado.

El valor del espesor cortical obtenida para la estación CPUP a partir de la inversión conjunta, concuerda con el valor inferido mediante el análisis de HK stacking realizada en el capítulo 3.

Las incertezas fueron evaluadas a partir de realizar inversiones reiteradas usando un rango de parámetros y restricciones, omitiendo selectivamente las observaciones cuestionables. Esto se debe a la dificultad en evaluar los límites de confianza estadísticamente válidos para los parámetros del modelo de inversión conjunta, a través de las técnicas estándares de propagación de errores (Julià et al., 2000). Estas técnicas generalmente asumen una distribución normal de datos independientes y claramente los datos que generan las FRs o las curvas de dispersión no son independientes. Además cuantificar la dependencia en la 
información a priori del modelo y en las restricciones de suavización utilizadas en cada capa durante la inversión resulta altamente subjetivo.

\subsection{Inversión de velocidad en capas aplicada a la cuenca Chaco-Paraná}

La inversión de las curvas de dispersión de las ondas superficiales tuvo sus inicios en la década del 60 con el desarrollo de las técnicas numéricas. Aún continúa siendo una herramienta poderosa para investigar la estructura terrestre ya que las velocidades de dispersión resultan muy útiles para estimar las propiedades elásticas y sus variaciones verticales y horizontales. Un estudio de dispersión proporciona una mejor determinación de la estructura de la velocidad de corte comparado con un estudio de refracción sísmica.

Los mapas tomográficos representan un promedio local espacial de velocidad de grupo o de fase en cada punto del mapa y resumen gran cantidad de información de dispersión de ondas superficiales en una forma que es muy conveniente y fácil de interpretar. Esta información puede ser utilizada en la inversión 3D para estimar la distribución de la velocidad de corte.

La inversión de las velocidades de grupo para una estructura multicapa presenta dos aspectos importantes. El primero es la resolución que permite recuperar los parámetros del medio y el otro aspecto es la no unicidad que supone que diferentes modelos pueden ajustar los mismos datos de dispersión.

Existen diversos métodos para estimar la estructura multicapa de velocidad. Uno de ellos es el método de búsqueda de grilla que realiza una inversión calculando el problema directo varias veces y comparando los datos calculados con los observados. Este método fue empleado con éxito con modelos de pocos parámetros por Pasyanos et al. (2001), Tkalcic et al. (2006), Pasyanos and Nyblade (2007), Lodge and Helffrich (2009) y Pasyanos (2010).

En el capítulo 2 se obtuvieron los mapas tomográficos 2D para Sudamérica. En esta etapa se modelará la estructura cortical en la región de la cuenca Chaco- 
Paraná mediante una inversión de velocidad en capas. Esta etapa puede ser considerada una inversión 3D.

La cuenca de Chaco-Paraná está ubicada en la región sur suroeste de la plataforma Sudamericana (Fig. 1.2 y 1.5), desarrollándose principalmente en el noreste de Argentina. Su estructura sísmica en la corteza y el manto superior permanece poco caracterizada a lo largo de la región.

\subsubsection{Metodología}

Para determinar la estructura de la velocidad de corte a partir de la velocidad de grupo de las ondas superficiales se aplicó un método de búsqueda de grilla basado en el procedimiento aplicado por Pasyanos et al. (2001). Este método utiliza pocos parámetros de inversión, realiza una serie de cálculos progresivos siendo un poco más lento y presenta una única curva de dispersión para cada modelo de prueba. Puede ser utilizado para mapear el espacio del modelo a partir del mejor ajuste obtenido en cada punto de la grilla.

El procedimiento consiste en construir una curva de dispersión para cada celda de la grilla de inversión, tomando los resultados de la inversión 2D para todos los períodos en un mismo punto de la grilla. Las curvas de dispersión resultantes serán invertidas usando un modelo de velocidad que minimiza los residuos.

Se utiliza un modelo simple para parametrizar la estructura cortical, que consiste de una capa sedimentaria, dos capas corticales y un semiespacio, hasta los $200 \mathrm{~km}$ de profundidad. A partir de los $200 \mathrm{~km}$, los valores de velocidad son adoptados del modelo ak135 (Kennett et al., 1995). Es importante establecer que este modelo sencillo no permite resolver detalles en la variación de la velocidad o la relación de Poisson en corteza y manto superior. Las velocidades en el manto, Pn y Sn, se resuelven juntas, ya que la relación de Poisson es fija. De igual manera, no se permite ninguna capa adicional o variación de velocidad, en la corteza, más allá de las parametrizadas.

Para cada punto de la grilla en el mapa, se buscan los siguientes parámetros: el espesor de los sedimentos $(h)$, el espesor cortical $(H)$, la velocidad promedio de la onda $\mathrm{P}$ en corteza $\left(\mathrm{V}_{\mathrm{P}}\right)$ y la velocidad de la onda $\mathrm{P}$ en el manto 
superior $(P n)$ hasta los $200 \mathrm{~km}$. Se asume una $V_{P} / V_{S}=1.73$, para corteza y manto superior. Los parámetros del modelo se varían creando un conjunto de miles de nuevos modelos que dependen de sus combinaciones. El rango de variación de los parámetros se selecciona de acuerdo a los valores de velocidad y espesor sugeridos por Christensen and Mooney (1995). Para cada nuevo modelo generado se calculan los valores de dispersión, en cada punto de la grilla. Finalmente estos valores se comparan con los valores de dispersión de la inversión 2D, seleccionando los mejores ajustes.

\subsubsection{Resultados y discusión}

Se modeló la región de la cuenca Chaco-Paraná a intervalos regulares de $1^{\circ} \times 1^{\circ}$, sobre una región comprendida entre $19^{\circ}$ y $34^{\circ}$ de latitud sur y entre $53^{\circ}$ y $68^{\circ}$ de longitud oeste. Para la inversión se utilizaron las ondas Rayleigh entre 10 y $150 \mathrm{~s}$ y las ondas Love entre 10 y $90 \mathrm{~s}$, obtenidas de la regionalización tomográfica, considerando los dos criterios de suavización ( $1^{\text {er }}$ y $2^{\text {da }}$ derivada).

Como el menor período analizado para ambas ondas es $10 \mathrm{~s}$, no hay buena resolución para determinar las características de la capa sedimentaria. Por tal motivo se fijó $V_{S}$ para los sedimentos en $2.5 \mathrm{~km} / \mathrm{s}$ y $V_{P} / V_{S}$ en 1.81 . Este valor se encuentra en el rango de valores de $V_{S}(2.2-3.2 \mathrm{~km} / \mathrm{s})$ obtenido por funciones receptoras en la cuenca de Paraná por Julià et al. (2008).

Se varió el espesor de los sedimentos entre 0 y $7 \mathrm{~km}$, con un paso de $1 \mathrm{~km}$. Los valores del espesor de la corteza variaron entre 25 y $70 \mathrm{~km}$ con un paso de 5 $\mathrm{km}$ o entre 24 y $70 \mathrm{~km}$ con un paso variable de 2 a $5 \mathrm{~km}$. La velocidad promedio de la onda $P$ en corteza varió entre 6.2 y $6.7 \mathrm{~km} / \mathrm{s}$ y $P n$ varió entre 7.3 y $8.3 \mathrm{~km} / \mathrm{s}$, ambas velocidades con un paso de $0.1 \mathrm{~km} / \mathrm{s}$. $V_{\mathrm{P}} / \mathrm{V}_{\mathrm{S}}$ se fijó en 1.73 . La corteza se dividió en dos capas, superior e inferior, en donde las velocidades fueron $0.95 \mathrm{y}$ 1.05 de la velocidad promedio de la onda $P$ y las densidades de 2.8 y $3.0 \mathrm{~g} / \mathrm{cm}^{3}$, respectivamente.

El espacio de parámetros, dependiendo de las combinaciones, generó entre 5280 y 9504 nuevos modelos, con sus correspondientes curvas de dispersión sintéticas. Para cada punto en el mapa, se eligió el modelo con el mejor ajuste, o 
sea aquél con la curva de dispersión que mejor ajustaba. La Fig. 4.12a muestra un ejemplo del ajuste de las curvas de dispersión sintéticas (líneas enteras) y observadas (líneas de puntos) para ambas ondas, para un punto sobre la cuenca en $\left(-29^{\circ},-59^{\circ}\right)$. El modelo correspondiente a las curvas sintéticas que presentan mejor ajuste (Fig. 4.12b), tiene un residuo $\mathrm{rms}$ de $0.044 \mathrm{~km} / \mathrm{s}$. La familia de curvas grises que se observan en las Figs. $4.12 a$ y $4.12 b$ corresponde al rango de modelos aceptables y sus correspondientes curvas de dispersión sintéticas, definidos por residuos rms menores a $0.067 \mathrm{~km} / \mathrm{s}$, siendo este valor aproximadamente equivalente al $90 \%$ del intervalo de confianza, utilizando una distribución $\mathrm{F}$ o distribución de probabilidad continua. Los histogramas de la figura muestran la distribución de valores de los espesores sedimentario y cortical de los distintos modelos.

La anisotropía transversal en el manto superior (con ondas $S_{H}$ viajando más rápido que $S_{V}$ ) puede causar diferencias en las velocidades de las ondas Love y Rayleigh para períodos mayores que $50 \mathrm{~s}$. Esto podría resolverse considerando por separado $S_{H}$ y $S_{V}$ para el manto superior. Sin embargo, las velocidades de la onda Love que se obtuvieron por tomografía, son menos confiables que las Rayleigh y no hay resolución para poder invertir por separado $S_{H}$ y $S_{V}$. Las ondas Love de períodos menores que 50 s son importantes para restringir las velocidades en la corteza. Asimismo, también se realizaron pruebas de inversión usando sólo ondas Rayleigh. En el caso de la inversión realizada a partir de ambas ondas, los valores obtenidos de $\mathrm{Sn}$ deben ser considerados un promedio de $\mathrm{S}_{\mathrm{H}} \mathrm{y} \mathrm{S}_{\mathrm{V}}$.

La Tabla 4.2 resume la información de los modelos de inversión. Por ejemplo el modelo 1 corresponde a un modelo de los 9504 generados a partir de la combinación de los parámetros $\mathrm{h}, \mathrm{H}, \mathrm{V}_{\mathrm{P}}$ y $\mathrm{Pn}$, que mejor ajusta las ondas Rayleigh entre 10 y 150 s y las ondas Love entre 20 y 90 s obtenidas de la regionalización con un criterio de suavización de $1^{\mathrm{er}}$ derivada y un factor de peso $(\lambda)$ igual a 2 para todos los períodos. 

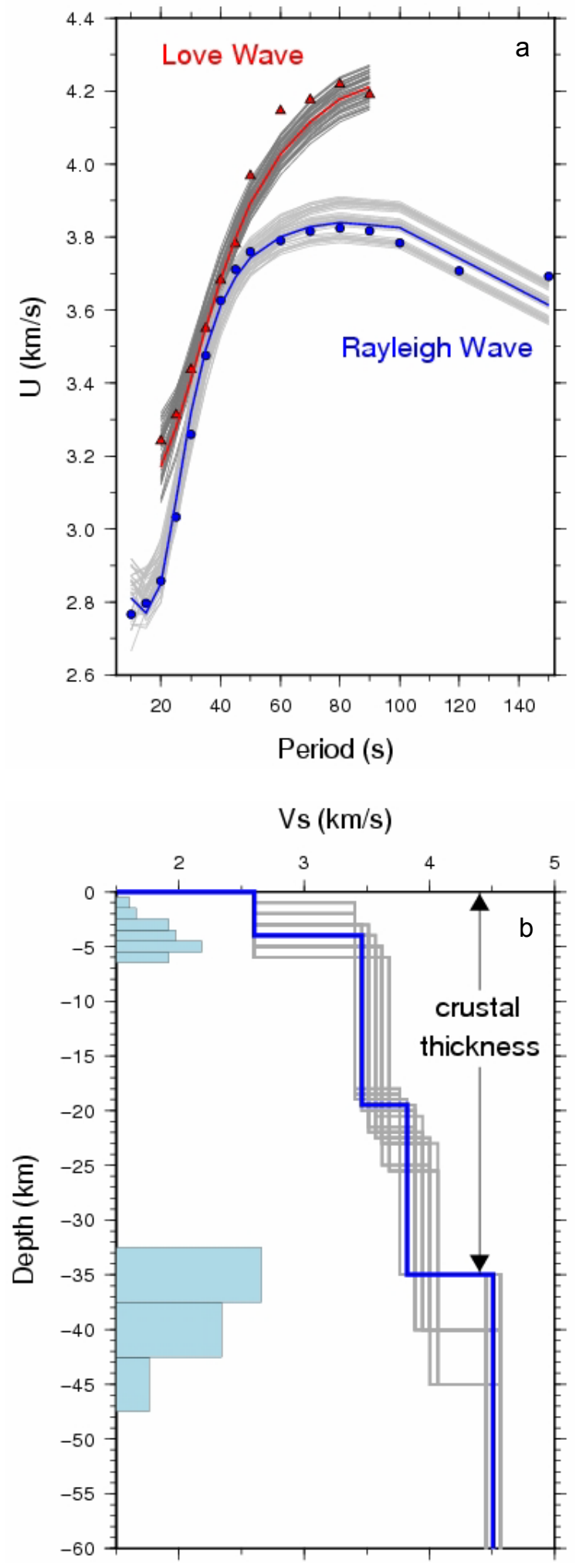

Figura 4.12: a) Ejemplo de la inversión 1D para la velocidad de grupo de las ondas Rayleigh (azul) y Love (rojo) para un punto en $\left(-29^{\circ},-59^{\circ}\right)$. Las curvas sintéticas están trazadas en línea entera, las curvas observadas en líneas punteadas. (b) Modelo de velocidad correspondiente al mejor ajuste (línea azul) con un rms de 0.044. En gris, modelos aceptables con rms $<0.067$, equivalentes a un intervalo de confianza del $90 \%$ y sus correspondientes curvas sintéticas. 
En esta tabla sólo se detallan los valores del espesor cortical $\mathrm{H}$, ya que no se consideró el mismo paso de variación ni el mismo rango de valores en todos los casos. El resto de los parámetros $\left(h, V_{P}\right.$ y $\left.P n\right)$ variaron siempre de igual forma, según se mencionó anteriormente.

\begin{tabular}{|c|c|c|c|c|c|c|c|}
\hline Modelo & Suavizado & $\mathrm{T}$ (Ray) & $\mathrm{T}$ (Love) & $\begin{array}{c}\text { Factor peso } \lambda \\
\text { (Ray) }\end{array}$ & $\begin{array}{c}\text { Factor peso } \lambda \\
\quad \text { (Love) }\end{array}$ & Espesor Cortical $(\mathrm{H})$ & $\begin{array}{c}\mathrm{N}^{\mathrm{o}} \mathrm{de} \\
\text { modelos }\end{array}$ \\
\hline 1 & $\begin{array}{c}1^{\text {er }} \\
\text { derivada }\end{array}$ & $10-150$ & $20-90$ & $2(\mathrm{~T}=10-150)$ & $2(\mathrm{~T}=20-90)$ & $\begin{array}{c}24-26-28-30-32-34-36-38-40-43-45- \\
50-55-60-65-70\end{array}$ & 9504 \\
\hline 2 & $\begin{array}{c}2^{\mathrm{da}} \\
\text { derivada }\end{array}$ & $10-150$ & $20-90$ & $\begin{array}{c}4(\mathrm{~T}=10-90) \\
5(\mathrm{~T}=100) \\
8(\mathrm{~T}=120) \\
10(\mathrm{~T}=150)\end{array}$ & $\begin{array}{c}4(\mathrm{~T}=20-60) \\
6(\mathrm{~T}=70) \\
8(\mathrm{~T}=80-90)\end{array}$ & $\begin{array}{c}24-26-28-30-32-34-36-38-40-43-45- \\
50-55-60-65-70\end{array}$ & 9504 \\
\hline 3 & $\begin{array}{c}1^{\mathrm{er}} \\
\text { derivada }\end{array}$ & $10-150$ & $10-90$ & $2(\mathrm{~T}=10-150)$ & $2(\mathrm{~T}=10-90)$ & $25-30-35-40-45-50-55-60-65-70$ & 5280 \\
\hline 4 & $\begin{array}{c}2^{\mathrm{da}} \\
\text { derivada }\end{array}$ & $10-150$ & $10-90$ & $2(\mathrm{~T}=10-150)$ & $2(\mathrm{~T}=10-90)$ & $25-30-35-40-45-50-55-60-65-70$ & 5280 \\
\hline 5 & $\begin{array}{c}2^{\mathrm{da}} \\
\text { derivada }\end{array}$ & $10-150$ & $10-90$ & $\begin{array}{c}4(\mathrm{~T}=10-90) \\
5(\mathrm{~T}=100) \\
8(\mathrm{~T}=120) \\
10(\mathrm{~T}=150)\end{array}$ & $\begin{array}{c}4(\mathrm{~T}=10-60) \\
6(\mathrm{~T}=70) \\
8(\mathrm{~T}=80-90)\end{array}$ & $25-30-35-40-45-50-55-60-65-70$ & 5280 \\
\hline 6 & $\begin{array}{c}1^{\mathrm{er}} \\
\text { derivada }\end{array}$ & $10-150$ & $20-90$ & $2(\mathrm{~T}=10-150)$ & $2(\mathrm{~T}=20-90)$ & $25-30-35-40-45-50-55-60-65-70$ & 5280 \\
\hline 7 & $\begin{array}{c}2^{\text {da }} \\
\text { derivada }\end{array}$ & $10-150$ & $20-90$ & $\begin{array}{c}4(\mathrm{~T}=10-90) \\
5(\mathrm{~T}=100) \\
8(\mathrm{~T}=120) \\
10(\mathrm{~T}=150)\end{array}$ & $\begin{array}{c}4(\mathrm{~T}=20-60) \\
6(\mathrm{~T}=70) \\
8(\mathrm{~T}=80-90)\end{array}$ & $25-30-35-40-45-50-55-60-65-70$ & 5280 \\
\hline 8 & $\begin{array}{c}1^{\mathrm{er}} \\
\text { derivada }\end{array}$ & $10-150$ & - & $2(\mathrm{~T}=10-150)$ & - & $25-30-35-40-45-50-55-60-65-70$ & 5280 \\
\hline 9 & $\begin{array}{c}2^{\text {da }} \\
\text { derivada }\end{array}$ & $10-150$ & - & $2(\mathrm{~T}=10-150)$ & - & $25-30-35-40-45-50-55-60-65-70$ & 5280 \\
\hline 10 & $\begin{array}{c}2^{\text {da }} \\
\text { derivada }\end{array}$ & $10-150$ & - & $\begin{array}{c}4(\mathrm{~T}=10-90) \\
5(\mathrm{~T}=100) \\
8(\mathrm{~T}=120) \\
10(\mathrm{~T}=150)\end{array}$ & - & $25-30-35-40-45-50-55-60-65-70$ & 5280 \\
\hline
\end{tabular}

Tabla 4.2: Modelos de inversión correspondientes a los mejores ajustes para ondas Rayleigh y Love obtenidas de la regionalización con criterios de suavización de $1^{\mathrm{er}}$ y $2^{\mathrm{da}}$ derivada y factores de peso $\lambda$ variables, generados a partir de la combinación de los parámetros $h, H, V_{P}$ y $P n$. 
La inversión 1D de las curvas de dispersión, incluso para unos pocos parámetros del modelo, puede ser sensible a pequeños errores en las velocidades de grupo. Además las curvas de dispersión regionalizadas dependen de la elección del criterio de suavizado ( $1^{\mathrm{er}} \circ 2^{\mathrm{da}}$ derivada), de la selección de datos (dispersión de Rayleigh o de Rayleigh y Love), del rango de período, etc. Por ello se analizan diferentes modelos tomográficos para determinar las características comunes, presumiblemente las más sólidas, en los modelos de inversión. La Fig. 4.13 muestra los resultados de tres perfiles E-W que atraviesan la cuenca ChacoParaná, ubicados a los $22^{\circ}, 26^{\circ}$ y $30^{\circ}$ de latitud sur, obtenidos a partir de los 10 modelos que figuran en la Tabla 4.2. En los perfiles están representados los valores de la topografía, el espesor sedimentario, el espesor cortical, la velocidad promedio en corteza $V_{S}$ y la velocidad $S n$ en el manto, correspondientes a los mejores ajustes para cada situación.

Se observa que todos los modelos presentan en general características comunes que indican la solidez de los resultados. Para ayudar en la discusión, se muestran ejemplos de mapas de espesor sedimentario, espesor total de la corteza y velocidad de $\mathrm{Sn}$ en el manto. Los resultados correspondientes a todos los modelos se encuentran disponibles en el Apéndice B.

Si bien el espesor de los sedimentos no está bien limitado debido a nuestro conjunto de datos (período mínimo de $10 \mathrm{~s}$ ), todos los modelos presentan valores altos en la región centro y norte de la cuenca (Fig. 4.13a y b), con valores que superan los $6 \mathrm{~km}$ en la región noroeste, tendiendo a disminuir hacia el Alto de Asunción, a valores menores a $3 \mathrm{~km}$, y aumentando nuevamente hacia las cuencas de Pantanal y Paraná. En la región sur los modelos no presentan diferencias tan significativas a través de la cuenca.

En la Fig. 4.14 se muestran mapas de espesores sedimentarios obtenidos a partir de la regionalización tomográfica con criterios de suavización de $1^{\text {er }}$ y $2^{\text {da }}$ derivada para ondas Rayleigh y Love (Fig. 4.14a y b) y para ondas Rayleigh (Fig. 4.14c y d). Se observa que los resultados obtenidos son relativamente independientes del criterio de suavización. Sin embargo aparecen pequeñas diferencias en los mapas cuando sólo se consideran datos de ondas Rayleigh (Fig. $4.14 \mathrm{c} \mathrm{y} \mathrm{d}$ ). Los mapas con datos de ondas Love son más inestables debido a la 
influencia de rasgos someros de pequeña escala y a la menor cobertura de las trayectorias, en particular en la región este sudeste de la cuenca (ver Fig. 2.24b).

Profile A (lat $\left.=22^{\circ} \mathrm{S}\right)$

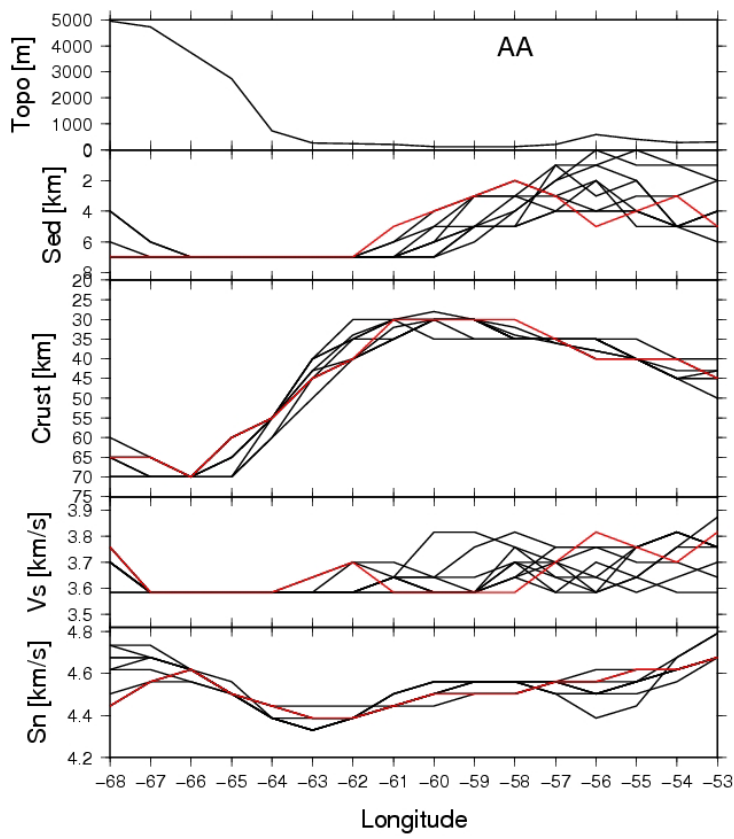

Profile B (lat $\left.=26^{\circ} \mathrm{S}\right)$

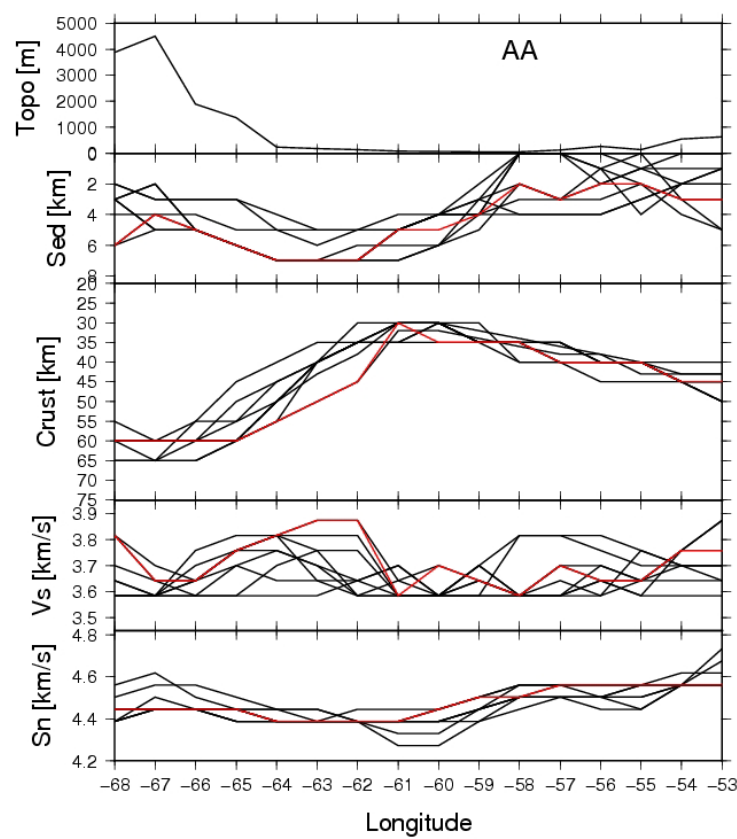

Profile C (lat $\left.=30^{\circ} \mathrm{S}\right)$

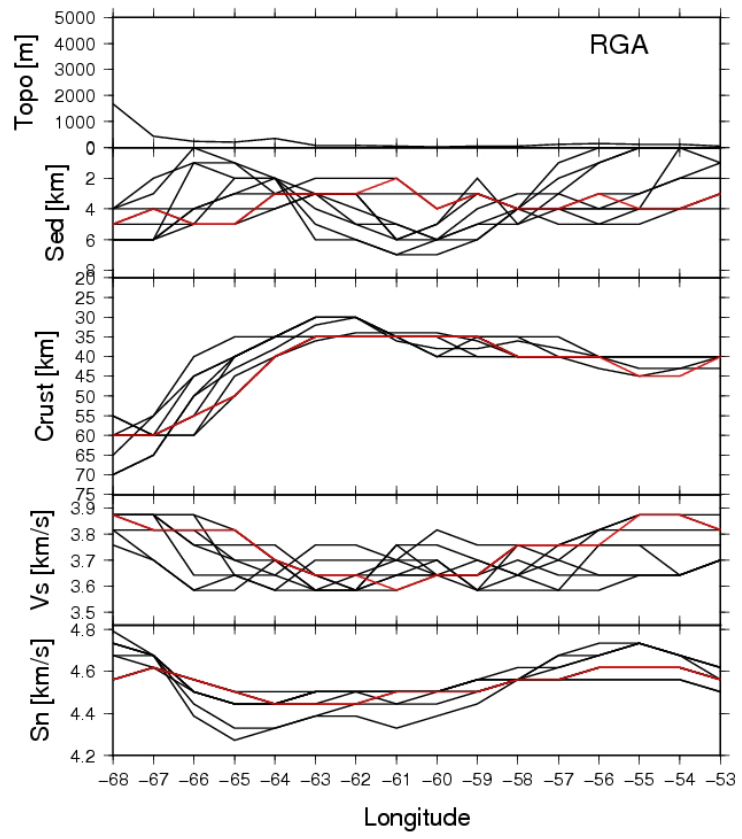

Figura 4.13: Perfiles E-W del espesor sedimentario (“Sed"), el espesor cortical (“Crust”), la velocidad promedio en corteza ("V') y la velocidad de $\mathrm{S}$ en el manto ("Sn") para un conjunto de diferentes modelos de inversión (analizados en la Tabla 4.2) en (a) $22^{\circ} \mathrm{S}$, (b) $26^{\circ} \mathrm{S}$ y (c) $30^{\circ} \mathrm{S}$. Los modelos de inversión mostrados en las Figs. 4.14, 4.16 y 4.17 corresponden al modelo de trazo rojo. AA representa el arco de Asunción y RGA el arco de Rio Grande (Fig. 1.5). 

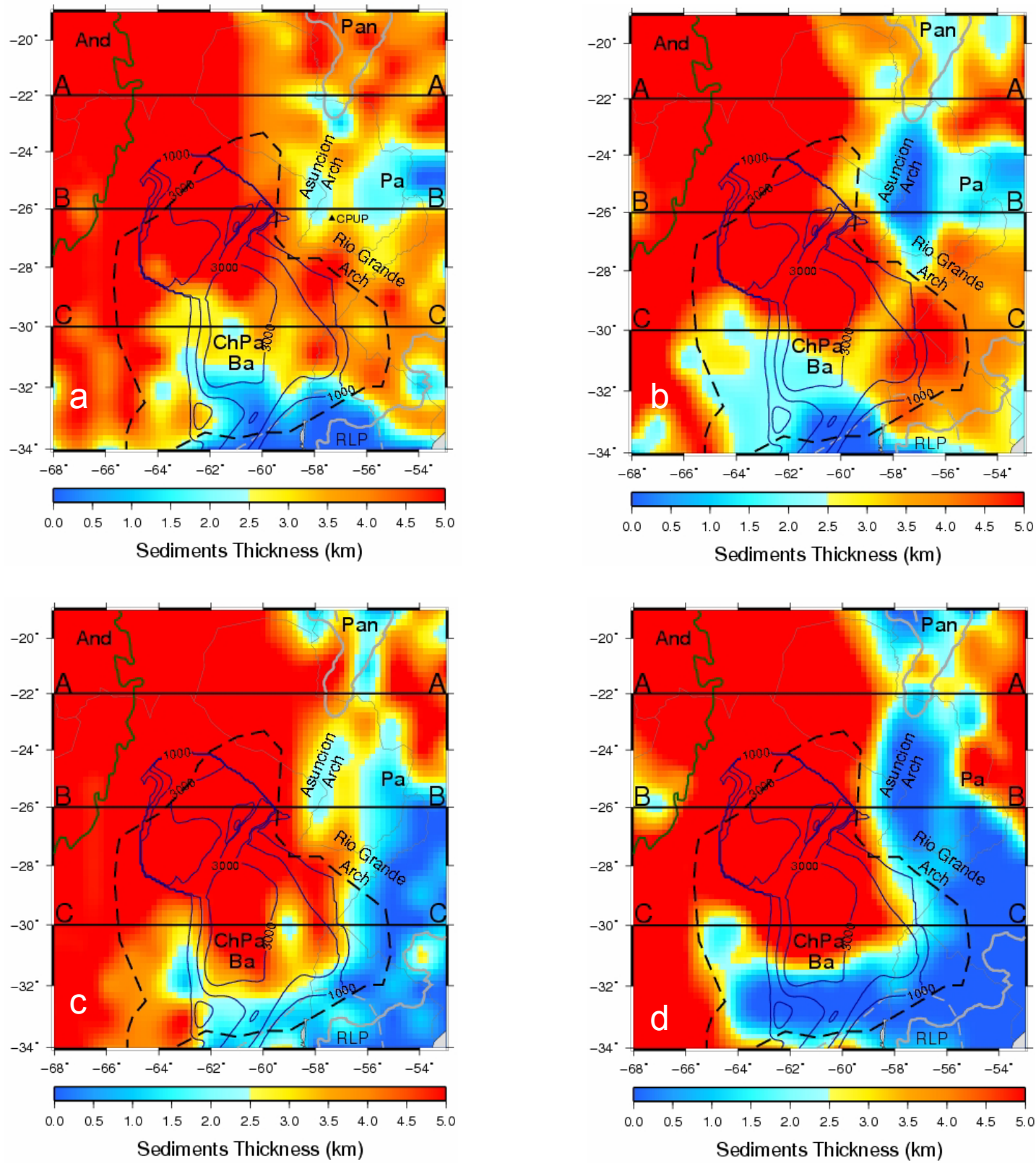

Figura 4.14: Mapas de espesores sedimentarios a partir de la regionalización tomográfica con criterios de suavización de $1^{\text {er }}$ derivada y $2^{\text {da }}$ derivada para ondas Rayleigh y Love (Fig. 4.14a y b) y para ondas Rayleigh (Fig. 4.14c y d). Las provincias geológicas corresponden a $\mathrm{ChPa}=$ cuenca Chaco-Paraná, $\mathrm{Pa}=$ cuenca de Paraná, And = región andina, $\mathrm{Pan}=$ cuenca de Pantanal, $\mathrm{RLP}=$ cratón del Río de la Plata. AA, BB y CC son los tres perfiles verticales de la Fig. 4.13. Los límites de la cuenca Chaco-Paraná (línea punteada) y los contornos del espesor sedimentario (línea azul) corresponden a Dragone et al. (2012).

Si se comparan los mapas de espesores sedimentarios de la Fig. 4.14 con el mapa de espesores obtenido con datos gravimétricos (Fig. 4.15) por Dragone (2013) se observa que los resultados para la región centro y noroeste de la cuenca 
se asemejan. Sin embargo sería necesario contar con datos de períodos menores a $10 \mathrm{~s}$, para las ondas superficiales, que nos permitieran realizar un mejor análisis.

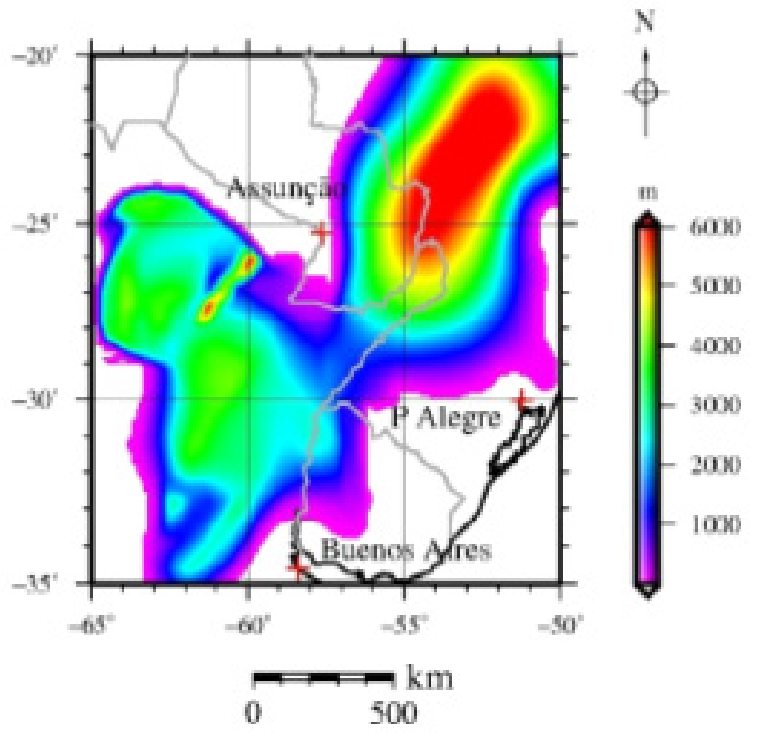

Figura 4.15: Espesor de sedimentos obtenidos con datos gravimétricos por Dragone (2013).

Los resultados obtenidos para los modelos de espesor de la corteza son muy similares e independientes del criterio de suavización y del tipo de datos (ondas Rayleigh u ondas Rayleigh y Love) como se observa en los perfiles de la Fig. 4.13. En la Fig. 4.16 se muestra un ejemplo del mapa de espesor cortical correspondiente al modelo 6 (Tabla 4.2) de trazo rojo en la Fig. 4.13.

La corteza debajo de la cuenca Chaco-Paraná es delgada, variando entre 33 y $38 \mathrm{~km}$, en promedio. Este resultado está en concordancia con los valores del espesor medio de la corteza (32-35 km) sugeridos por Snoke and James (1997); los espesores delgados obtenidos por Yuan et al. (2000) en la llanura chaqueña (aproximadamente $30 \mathrm{~km}$ ) y el espesor cortical más delgado que $35 \mathrm{~km}$ obtenido por Assumpção et al. (2013) mediante la compilación más actualizada de espesores corticales, entre los que incluye datos de Feng et al. (2007) y Lloyd et al. (2010). Al oeste de $64^{\circ} \mathrm{W}$ de longitud, la corteza se engrosa, siguiendo la topografía andina más alta, en concordancia con datos de la literatura (Assumpção et al., 2013; Ammirati et al., 2015). 


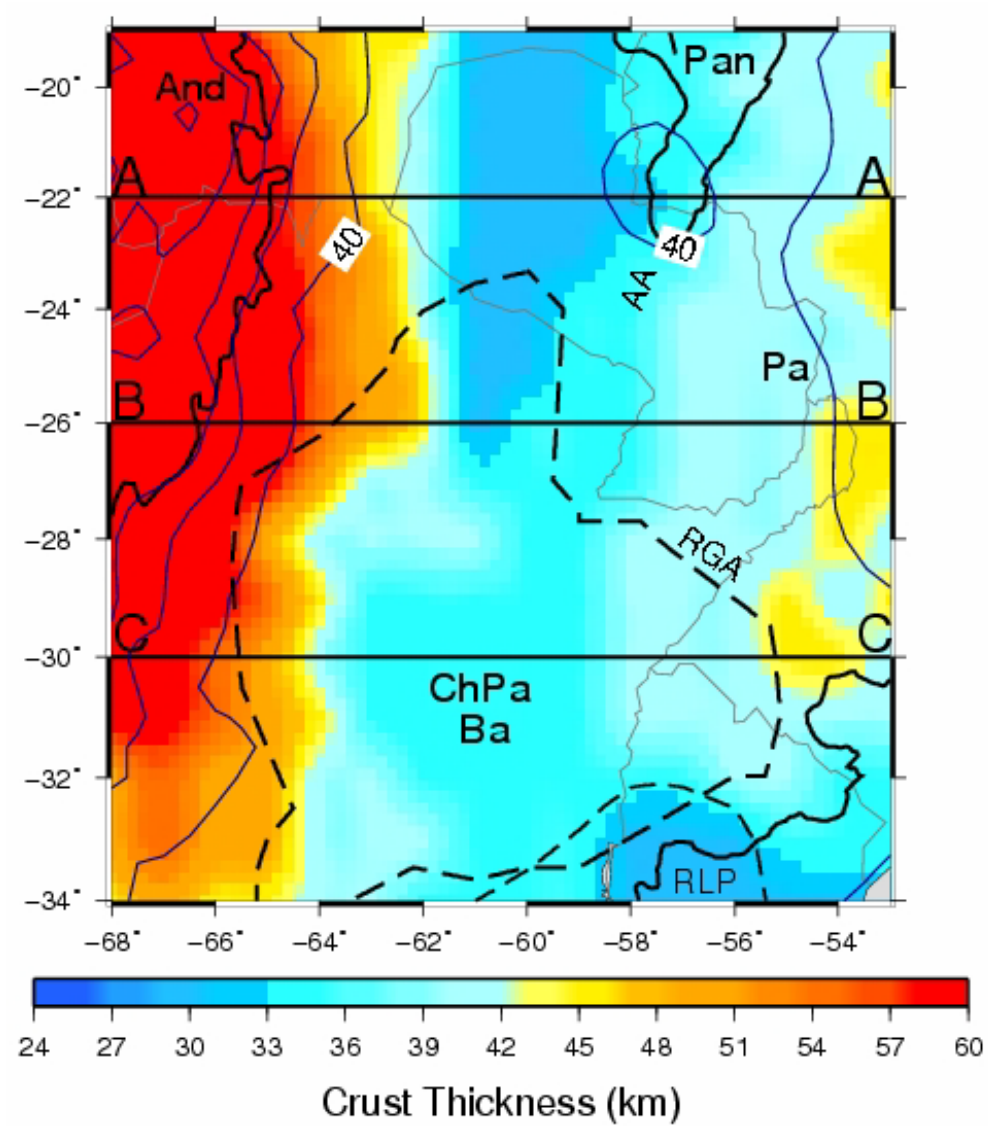

Figura 4.16: Mapa del espesor cortical total. Las provincias geológicas y los perfiles son iguales a la Fig. 4.14.

Una característica interesante es la existencia de una corteza más delgada en la región norte de la cuenca, que se extiende al NNE, hacia la cuenca de Pantanal (Fig. 4.13A y Fig. 4.16). Para poder analizar esta particularidad se realizó una inversión variando el espesor $\mathrm{H}$ entre 24 y $70 \mathrm{~km}$ pero con un paso menor, que permitió una mayor variación, generando los modelos 1 y 2 (Tabla 4.2), que se muestran en la Fig. 4.17.

Ambos modelos presentaron un espesor cortical para esa región de unos 28 a $30 \mathrm{~km}$. Esta corteza más delgada, al este de la meseta del Altiplano, en la Puna, fue observada también mediante funciones receptoras (Assumpção et al., 2013) y se estimó mediante modelado de datos satelitales de gravedad (Van der Meijde et al., 2013), pero no fue indicada por Chulick et al. (2013) que presentaron un mapa de contornos de espesor cortical, con espesores del orden de $30 \mathrm{~km}$ en el centro de la cuenca aumentando hacia el NNE según se observa en la Fig. 1.11. 

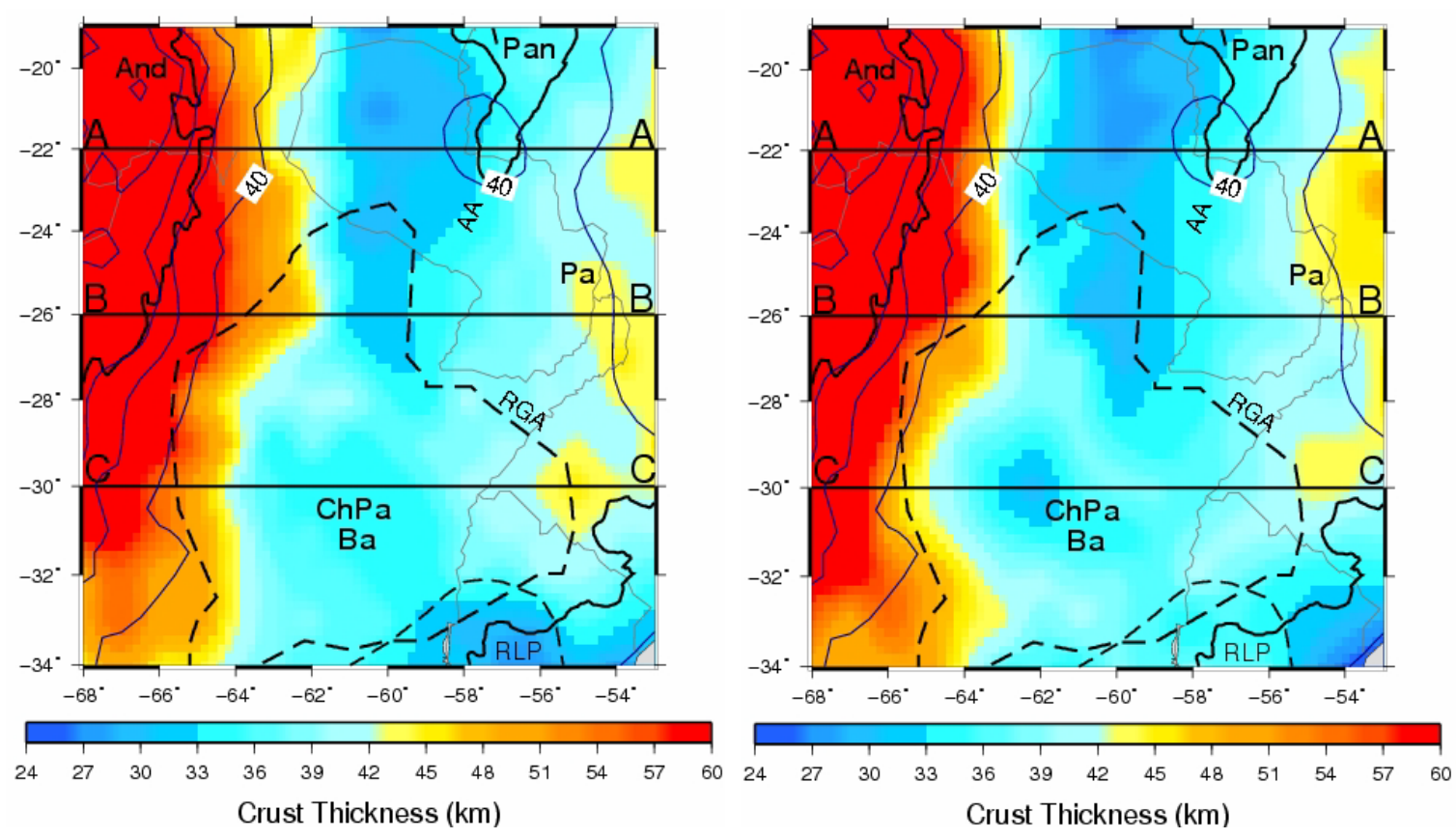

Figura 4.17: Mapas del espesor cortical total correspondientes a los modelos 1 (izquierda) y 2 (derecha) de la Tabla 4.2. Las provincias geológicas y los perfiles son iguales a la Fig. 4.14.

El menor espesor obtenido por Assumpção et al. (2013) para la cuenca se encuentra a $25^{\circ} \mathrm{S}$ de latitud y $60^{\circ} \mathrm{W}$ de longitud en la región del bajo Las Breñas (Fig. 4.18), mientras que los resultados obtenidos en todos los modelos

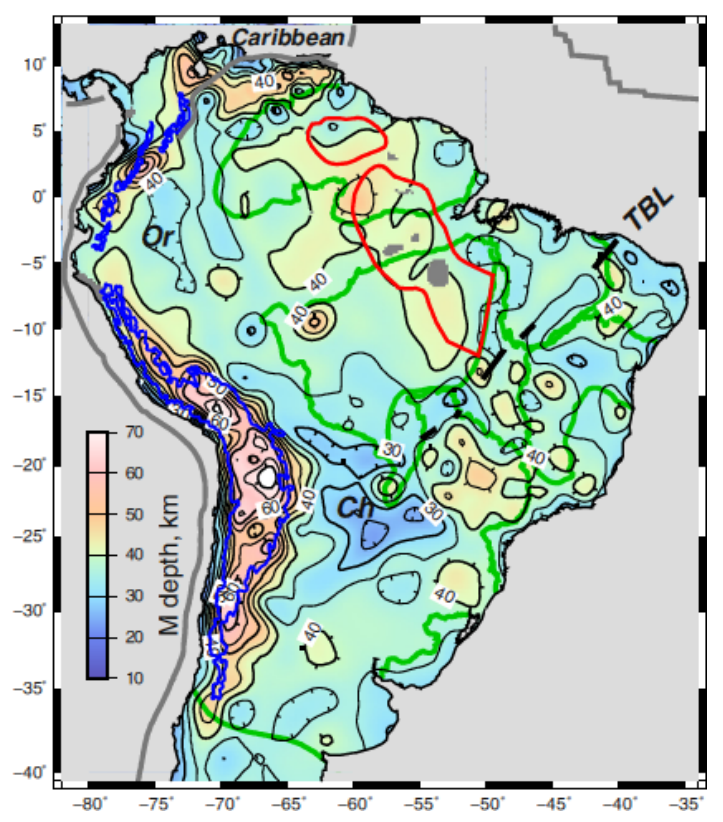

Figura 4.18: Modelo de profundidades de la Moho obtenido por Assumpção et al. (2013). 
presentados en este trabajo (Apéndice B) muestran que ese espesor delgado se extiende hacia el norte, más allá de los límites de la cuenca (Rosa et al., 2016).

Pasyanos and Walter (2002) demostraron que en regiones con buena cobertura de trayectorias se reducen las incertezas en el espesor cortical y en las velocidades. Los tests de resolución espacial para toda la cuenca Chaco-Paraná, mostraron resultados sólidos a partir de una mejor cobertura de trayectorias y una mejor distribución acimutal, comparando con estudios anteriores. Por lo tanto se puede sugerir que esta corteza muy delgada en la región norte de la cuenca es un resultado consistente y no un artilugio de la presente inversión.

Los mapas obtenidos para los modelos de velocidad de Sn en el manto son muy similares e independientes del criterio de suavización y del tipo de datos (ondas Rayleigh u ondas Rayleigh y Love) como se observa en los perfiles de la Fig. 4.13. En la Fig.4.19 se muestra un ejemplo correspondiente al modelo 6 (Tabla 4.2) de trazo rojo en la Fig.4.13.

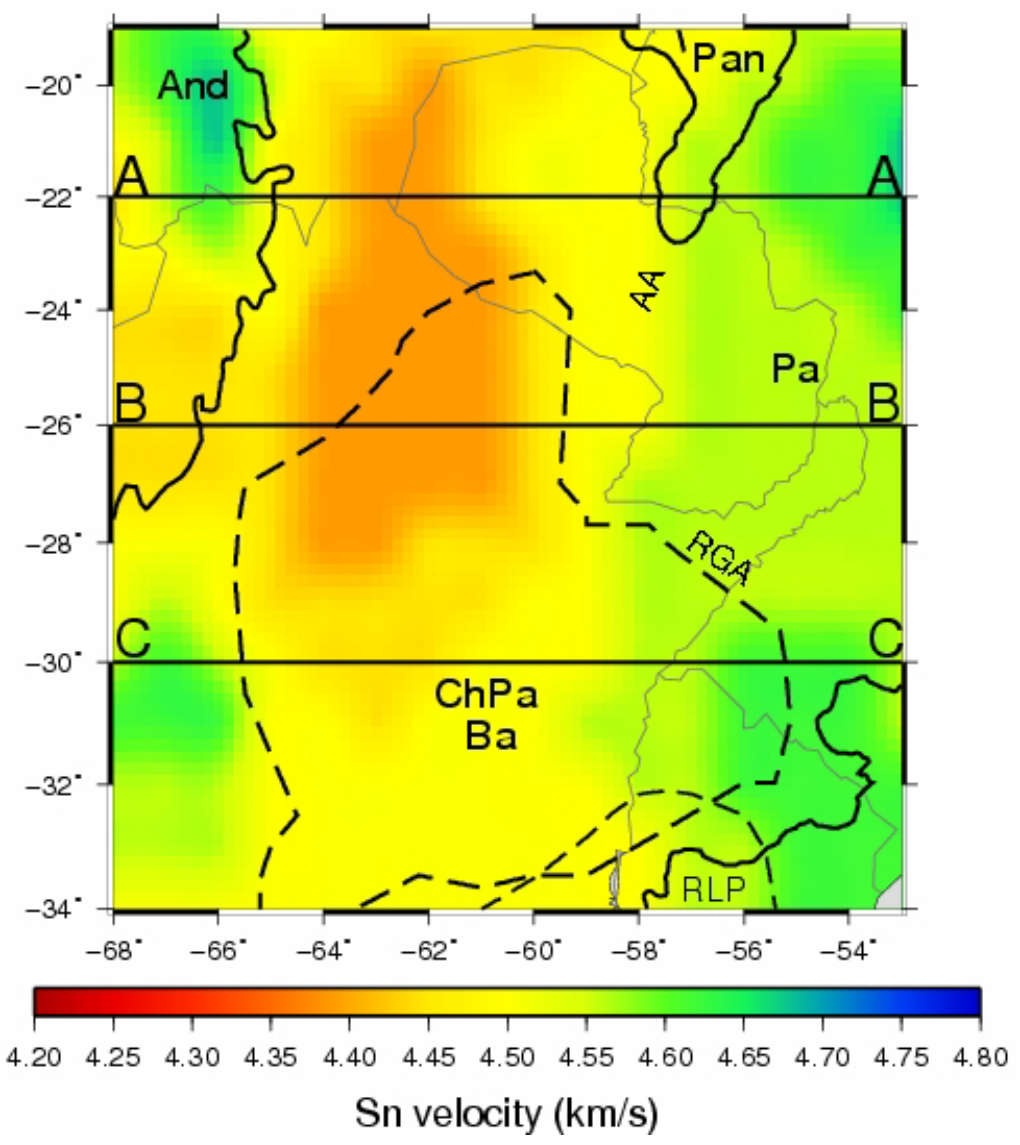

Figura 4.19: Mapa de la velocidad de Sn en el manto. Las provincias geológicas y los perfiles son iguales a la Fig. 4.14. 
La cuenca Chaco-Paraná presenta bajas velocidades (4.4 a $4.5 \mathrm{~km} / \mathrm{s}$ ) en comparación con la cuenca de Paraná (4,5 a 4,7 km/ s), como se observa en los perfiles de la Fig. 4.13. El mapa de velocidad de $\mathrm{Sn}$ en el manto muestra valores bajos ( 4.4 km / s) en la región norte (Fig. 4.13A y Fig. 4.19).

Esta anomalía de baja velocidad es consistente con los resultados hallados por otros autores como por ejemplo Snoke and James (1997) que encontraron velocidades en el manto superior de $4.2 \mathrm{~km} / \mathrm{s}$ aumentando solo a $4.3 \mathrm{~km} / \mathrm{s}$ a 150 $\mathrm{km}$ de profundidad. Van der Lee et al. (2001) indicaron esta anomalía de baja velocidad en su modelo SA99. Feng et al. $(2004 ; 2007)$ encontraron que esta anomalía se hallaba hasta aproximadamente los $150 \mathrm{~km}$, mientras que Heintz et al. (2005) la observaron hasta los $200 \mathrm{~km}$ de profundidad y Corchete (2012) mencionó la existencia de un canal de baja velocidad entre 180 y $280 \mathrm{~km}$ de profundidad. Esta anomalía sugiere la existencia de una astenósfera menos profunda y más caliente (o mayor contenido de agua en el manto superior en la región de la litósfera). Hacia el este de esta anomalía, se observan valores altos de Sn en la cuenca de Paraná señalados de manera consistente por todos los modelos (perfil AA en la Fig. 4.13), que se atribuyen a un bloque cratónico debajo de la cuenca (Cordani et al., 2000; Feng et al., 2007). Al oeste de la región central de la cuenca se observan velocidades relativamente altas en zona de subducción horizontal de las Sierras Pampeanas (Fig. 4.13C y Fig. 4.19), causadas posiblemente por la litósfera fría de Nazca.

Es fundamental mencionar que los modelos obtenidos para la cuenca Chaco-Paraná son el resultado de una mejora significativa en la cobertura y resolución de datos en comparación con estudios previos de la zona. La presente base de datos posee muchas más trayectorias y una mejor distribución acimutal, comparada con la de Feng et al. (2007). Por ejemplo el número de trayectorias correspondientes a la onda Rayleigh de 20 s se incrementó de 5935 a 9772 . Este incremento aproximado del $60 \%$ resultó en una mejor cobertura de la cuenca como se observa en la Fig.4.20.

Una de las limitaciones que presenta este método es la suposición de una única capa de sedimentos con velocidades de $\mathrm{P}$ y $\mathrm{S}$ únicas, dado que en la práctica existe una variación significativa en las velocidades sedimentarias. En trabajos futuros estas estimaciones podrán ser mejoradas con el aumento de datos 
de corto período para la onda Love. También se podrán mejorar las estimaciones de los espesores litosféricos incorporando más datos de largo período ( $T>120-150$ s). Se analizarán algunos cambios en la parametrización, generando modelos más complejos, considerando isotropía transversal en el manto, más capas corticales y una relación de Poisson variable en corteza y manto.

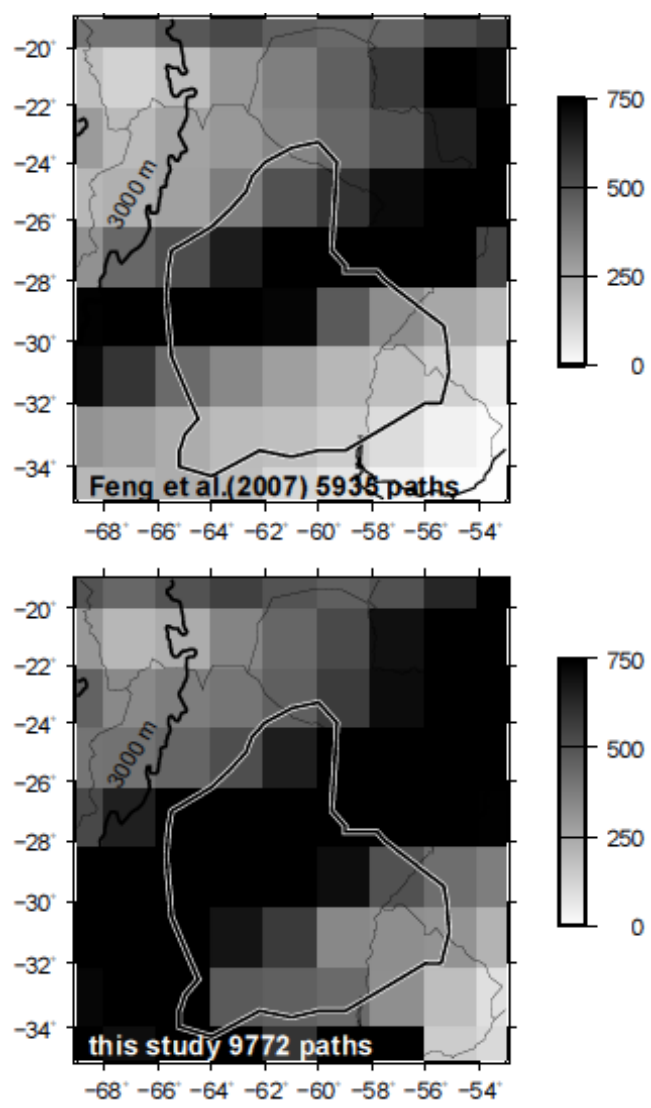

Figura 4.20: Comparación de la densidad de trayectorias entre un trabajo anterior y este trabajo. Se observa una mejora significativa en la cobertura y resolución de datos.

En esta última etapa se comparó para la estación CPUP, el modelo de velocidad de corte obtenido a partir de la inversión conjunta de ondas superficiales y funciones receptoras con el modelo obtenido a partir de la inversión de velocidad en capas mediante el método de búsqueda de grilla (Fig. 4.21).

A pesar de los diferentes métodos empleados, los resultados del modelo de velocidad de corte presentados en la Fig. 4.21 concuerdan en los valores del espesor cortical y los valores de la velocidad de corte para la región del manto superior. Sin embargo dadas las limitaciones que presenta el método de inversión 
de velocidad en capas, que fueran mencionadas anteriormente, no existe concordancia en los valores de velocidad para la región cortical. Por lo tanto se puede concluir que en regiones donde se cuenta con información de FRs y de tomografía, la inversión conjunta ha probado ser una buena técnica para poder determinar el modelo de velocidad de corte, mientras que en regiones donde sólo se cuenta con datos de ondas superficiales obtenidas mediante un estudio de tomografía, la inversión de velocidad en capas también ha probado ser un método eficaz para poder determinar un modelo de velocidad con ciertas restricciones, pero que permite describir las características de una región a través de mapas que reflejan la variación de estos parámetros.

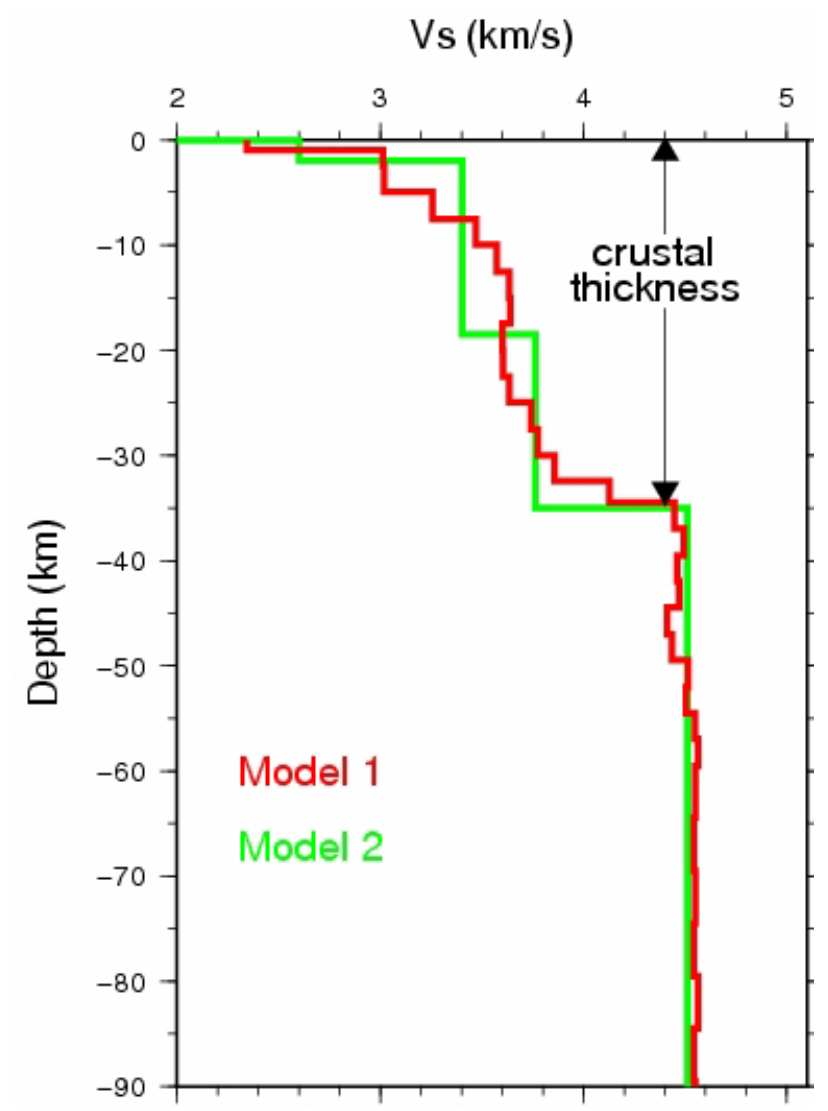

Figura 4.21: Modelos de la velocidad de la onda S para la estación CPUP, obtenidos a partir de la inversión conjunta de FRs y ondas superficiales (modelo en trazo rojo) y a partir de la inversión de velocidad en capas (modelo en trazo verde). 


\section{Capítulo 5}

\section{Conclusiones}

\subsection{Conclusiones}

A lo largo de la historia, la sismología se ha planteado el gran desafío de develar la estructura interna de la Tierra. La tomografía con ondas superficiales ha demostrado ser una técnica eficaz para lograrlo. Sin embargo la distribución desigual de los datos, provocada por la concentración de sismos en zonas de tectonismo activo y la distribución heterogénea de estaciones sismológicas, han limitado los resultados en regiones con escasa instrumentación.

El territorio central y oriental de Sudamérica es considerada una de las regiones menos estudiadas de la Tierra. El creciente número de estaciones de banda ancha instaladas en los últimos años y el desarrollo de nuevas técnicas han creado una oportunidad única y sin precedentes para evitar las limitaciones y poder determinar la estructura sísmica a lo ancho del continente.

En este trabajo de Tesis se realizó un estudio de tomografía con ondas superficiales en Sudamérica a partir de un conjunto ampliado de datos de sismos regionales registrados en diferentes estaciones, así como datos de correlación de ruido ambiental, que permitieron obtener y trabajar con una cobertura más densa de trayectorias y con una distribución acimutal más uniforme, produciendo imágenes tomográficas que mejoran la resolución especialmente en la región de la cuenca Chaco-Paraná. Estos nuevos mapas posibilitaron estimar con mayor precisión el modelo de velocidades de la corteza y manto superior en la región mediante una inversión 3D de las velocidades de grupo.

Aprovechando la instalación hace poco más de una década, de sensores banda ancha en dos estaciones sismológicas ubicadas en la provincia de Buenos Aires, al este de nuestro continente, se analizaron sus FRs. Asimismo, con el objetivo de estudiar en particular la cuenca Chaco-Paraná, se obtuvieron FRs en la estación banda ancha CPUP, y se determinaron los valores de la relación $V_{P} / V_{S} y$ el espesor cortical. Finalmente se obtuvieron modelos de velocidad de la onda $S$ 
para la estación cercana a la cuenca mediante la inversión conjunta de las funciones receptoras y las curvas de dispersión. Estos resultados aportaron información y fueron comparados con los resultados de la inversión a partir de la tomografía en la región, mostrando que la inversión conjunta resulta muy efectiva para poder determinar los modelos de velocidad en regiones donde se cuenta con información de funciones receptoras y datos de tomografía.

Los mapas de velocidad de grupo de las ondas superficiales mostraron variaciones laterales significativas, provocadas por las distintas características geológicas y tectónicas, fortaleciendo los resultados alcanzados en estudios previos. Las grandes cuencas sedimentarias del continente quedaron evidenciadas en los mapas de corto período, y los distintos espesores corticales correspondientes a regiones más o menos estables del continente, en los mapas de período intermedio. Para períodos mayores, las ondas superficiales revelaron las distintas anomalías de velocidad de la onda $S$ que permiten inducir el espesor de la litósfera en el manto superior.

El espesor cortical y la relación $V_{P} / V_{S}$ obtenidos para dos de las estaciones analizadas (TRQA y CPUP) mostraron valores acordes a la geología de la región. Para la tercera estación (LPA) se obtuvieron valores representativos del espesor y las características de los sedimentos, siendo éstos los primeros resultados obtenidos con técnicas sismológicas para la estructura local de esa estación.

Los modelos obtenidos en la cuenca Chaco-Paraná para la corteza y manto superior mostraron un espesor cortical entre 33 y $38 \mathrm{~km}$ y confirmaron la existencia de una zona de baja de velocidad de la onda $S$ en el manto superior, especialmente en la región norte de la cuenca, causada probablemente por una cuña astenosférica menos profunda y más caliente (o mayor contenido de agua en el manto superior en la región de la litósfera).

Otro resultado sustancial de este trabajo, es la confirmación de la existencia de un área de corteza delgada en la región norte de la cuenca, de aproximadamente 28 a $30 \mathrm{~km}$. Todos los modelos obtenidos considerando los distintos criterios, mostraron que esta región se extiende hacia el norte, más allá de los límites de la cuenca, siendo este resultado observado por primera vez. 
Los valores del espesor cortical han sido determinados a partir de una significativa mejora tanto en la cobertura de datos como en la resolución, por lo que se tornan más confiables que los estimados en estudios anteriores y por lo tanto deberían ser considerados como valiosas limitaciones para revisiones futuras del espesor cortical de la cuenca Chaco-Paraná.

\subsection{Publicaciones y presentaciones}

Este trabajo de investigación ya ha posibilitado publicar parte de sus resultados en revistas periódicas, nacional e internacional y en tres proceedings de conferencias, así como realizar diez presentaciones en congresos nacionales e internacionales:

Publicaciones en revistas periódicas:

- Thin crust beneath the Chaco-Paraná Basin by surface-wave tomography.

Rosa, M. L.; Collaço, B., Assumpção, M., Sabbione, N. and Sánchez, G. 2016. Journal of S. Am. Earth Sciences 66, 1-14.

doi:10.1016/j.jsames.2015.11.010

- Tomografía sísmica de la Cuenca de Chaco-Paraná mediante ondas superficiales.

Rosa, M. L.; Collaço, B., Assumpção, M. y Sabbione, N. 2015. Geoacta, Vol. 40, 2, pp. 1-10. ISSN1852-7744

Proceedings de conferencias:

- Crustal thickness beneath the Chaco-Paraná Basin, NE Argentina, using surface waves and ambient noise tomography.

Rosa, M. L., Collaço, B, Sánchez G., Assumpção, M., Sabbione, N. and Araujo, M. 2012. Libro digital de resúmenes expandidos del XVI Congreso Peruano de Geología y SEG 2012 Conference, SGPSEG081.

- Crustal structure of the Paraná Basin from ambient noise tomography.

Collaço, B., Sánchez, G., Rosa, M. L., Assumpção, M., Sabbione, N., Araujo, M. and Peres Rocha, M. 2012. Libro digital de resúmenes expandidos del XVI Congreso Peruano de Geología y SEG 2012 Conference, SGPSEG082. 
- Relación Vp/Vs y espesor cortical en Tornquist (TRQA), Pcia. de Buenos Aires, a partir de funciones receptoras.

Sabbione, N. y Rosa, M. L. 2009. Actas de la XXIV Reunión Científica de la Asociación Argentina de Geofísicos y Geodestas. Ciencias de la Tierra I, $1^{\circ}$ edición, pp. 320-326. ISBN 978-987-25291-1-6

\subsection{Trabajos a futuro}

Este trabajo de Tesis permite continuar y avanzar en varias líneas de investigación en sismología en nuestra Facultad. Además, a través de un proyecto de investigación en el que participan varias instituciones de nuestro país así como instituciones de Brasil, España, Inglaterra y otros; que se ha acreditado recientemente, y que tiene como objetivo analizar la estructura sísmica y evolución de la corteza y el manto superior en las cuencas de Paraná, Pantanal y ChacoParaná, se ha planeado la instalación de nuevas estaciones en la región. Esto permitirá no solo poder mejorar los resultados obtenidos a partir de nuevos datos, empleando las técnicas analizadas en esta Tesis, sino también implementar nuevas técnicas como por ejemplo, la obtención de las velocidades de fase mediante correlación de ruido ambiental para pares de estaciones, que permitirán mejorar los resultados de la tomografía de ruido ambiental.

Durante el desarrollo de la Tesis han surgido algunos temas con opción a futuros trabajos. Un ejemplo de esta situación es poder llevar a cabo un análisis más exhaustivo de las funciones receptoras para estaciones ubicadas sobre sedimentos, como LPA. Además, se espera implementar nuevos métodos de inversión de los datos de la regionalización, así como mejorar los resultados obtenidos con el método aplicado, a través del aumento de datos de corto período para mejorar las estimaciones del espesor de los sedimentos. También se podrán mejorar las estimaciones de los espesores litosféricos incorporando más datos de largo período, así como analizar algunos cambios en la parametrización, generando modelos más complejos, por ejemplo considerando isotropía transversal en el manto, más capas corticales y una relación de Poisson variable en corteza y manto. 


\section{Referencias Bibliográficas}

Aki, K. and Richards, P. 2002. Quantitative Seismology. 2nd ed., University Science Books, Sausalito, California, USA.

Almeida, F., Hasui, Y. and Britos Neves, B. 1976. The upper Precambrian of South America. Bol. Inst. Geoc., USP, 7, 45-80.

Almeida, F., Hasui, Y., Brito Neves, B. and Fuck, R. 1981. Brazilian structural provinces: an introduction. Earth-Science Reviews 17, 1e29.

Alvarado, P., Pardo, M., Gilbert, H., Miranda, S., Anderson, M., Saez, M. and Beck, S. 2009. Flatslab subduction and crustal models for the seismically active Sierras Pampeanas region of Argentina. En Kay, S., Ramos, V.A., Dickinson, W. (eds.), MWR204: Backbone of the Americas: Shallow subduction, plateau uplift, and ridge and terrane collision: Boulder, Colorado, Geological Society of America, 261-278.

Ammirati, J-B., Alvarado, P. and Beck, S. 2015. A lithospheric velocity model for the flat slab region of Argentina from joint inversion of Rayleigh wave phase velocity dispersion and teleseismic receiver functions. Geophys. J. Int. 202, 224-241.

Ammon, C., Randall, G. and Zandt, G. 1990. On the nonuniqueness of receiver function inversions. J. Geophys. Res. 95, 15303-15318.

Ammon, C. 1991. The isolation of receiver effects from teleseismic P waveforms. Bull. Seism. Soc. Am. 81, 6, 2504-2510.

Ammon, C. and Zandt, G. 1993. Receiver structure beneath the southern Mojave block, California. Bull. Seism. Soc. Am. 83, 737-755.

Ammon, C. 2006a. Downloading \& compiling the receiver function analysis computer programs. http://www.eqseis.geosc.psu.edu/ cammon/HTML/RftnDocs/thecodes01.html.

Ammon, C. 2006b. Isolating the receiver response Langston's source equalization procedure. http://www.eqseis.geosc.psu.edu/ cammon/HTML/RftnDocs/seq01.html.

An, M. and Assumpção, M. 2004. Multi-objective inversion of surface waves and receiver functions by competent genetic algorithm applied to the crustal structure of the Paraná Basin, SE Brazil. Geophys. Res. Lett. 31, L05615, doi:10.1029/2003GL019179.

Antayhua, Y. y Tavera, H. 2003. Volcanes y sismicidad en la región del volcán Sabancaya. Monografia. Instituto Geofísico de Perú.

Artemieva, I. and Mooney W. 2001. Thermal thickness and evolution of Precambrian lithosphere: A global study. J. Geophys. Res. 106 (B8), 16387-16414. 
Artemieva, I. 2002. Continental crust. UNESCO Encyclopedia EOLSS. http://www.eolss.net.

Assumpção, M., James, D. and Snoke, A. 2002. Crustal thicknesses in SE Brazilian Shield by receiver function analysis: Implications for isostatic compensation. J. Geophys. Res. 107, 10,1029 .

Assumpção, M., Feng, M., Tassara, A. and Julia, J. 2013. Models of crustal thickness for South America from seismic refraction, receiver functions and surface wave tomography. Tectonophysics 609, 82-96, doi:10.1016/j.tecto.2012.11.014.

Auge, M., Hirata, R. y López Vera, F. 2004. Vulnerabilidad a la contaminación por nitratos del acuífero Puelche en La Plata. Buenos Aires. Centro de Estudios de América Latina (CEAL), U.A.M., S.C.H. http://www.bfa.fcnym.unlp.edu.ar/catalogo/doc num.php?explnum id=239.

Barmin, M., Ritzwoller, M. and Levshin, A. 2001. A fast and reliable method for surface wave tomography. Pure appl. Geophys. 158, 1351-1375.

Barredo, S. y Stinco, L. 2010. Geodinámica de las cuencas sedimentarias: su importancia en la localización de sistemas petroleros en la Argentina. Petrotecnia, 48-68.

Bartel, A., Bidegain, J. y Sinito, A. 2005. Propiedades magnéticas de diferentes suelos del partido de La Plata, provincia de Buenos Aires. Revista de la Asociación Geológica Argentina, 60 (3), 591-598.

Bensen, G., Ritzwoller, M., Barmin, M., Levshin, A., Lin, F., Moschetti, M., Shapiron, M. and, Yang, Y. 2007. Processing seismic ambient noise data to obtain reliable broad-band surface wave dispersion measurements. Geophys. J. Int. 169, 1239-1260.

Beri, A., Martínez-Blanco, X. and Mourelle, D. 2010. A synthesis of palynological data from the Lower Permian Cerro Pelado Formation (Paraná Basin, Uruguay): A record of warmer climate stages during Gondwana glaciations. Geologica Acta 8, 419-429, doi:10.1344/105.000001580.

Cahill, T. and Isacks, B. 1992. Seismicity and shape of the subducted Nazca Plate. J. Geophys. Res. 97, 17503-17529.

Cassidy, J. 1992. Numerical experiments in broadband receiver function analysis. Bull. Seism. Soc. Am. 82, 1453-1474.

Cavallotto, J. 2002. Evolución holocena de la llanura costera del margen sur del Río de la Plata. Revista de la Asociación Geológica Argentina 57 (4), 376-388.

Chebli, G., Mozetic, M., Rossello, E. y Buhler, M. 1999. Cuencas sedimentarias de la Llanura Chacopampeana. Geología Argentina. Editor R. Caminos. Anales 29, 627-644, ISSN 03282325.

Christensen, N. and Mooney, W. 1995. Seismic velocity structure and composition of the continental crust: A global view. J. Geophys. Res. 100, 9761-9788, doi:10.1029/95JB00259 
Chulick, G., Detweiler, S. and Mooney, W. 2013. Seismic structure of the crust and uppermost mantle of South America and surrounding oceanic basins. J. South Am. Earth Sciences 42, 260-276, doi:10.1016/j.jsames.2012.06.002.

Cingolani, C. and Dalla Salda, L. 2000. Buenos Aires cratonic region. In: Cordani, U., Milani, E., Thomaz-Filho, A. and Campos, D. (Eds.), Tectonic Evolution of South America. $31^{\text {st }}$ International Geological Congress, Rio de Janeiro, 139-146.

Clitheroe, G., Gudmundsson, O. and Kennett, B. 2000. Sedimentary and upper crustal structure of Australia from receiver functions. Australian Journal of Earth Sciences 47, 209-216.

Collaço, B. 2014. Tomografia de Ruido Ambiental na Bacia do Paraná. Dissertação de mestrado, Universidade de São Paulo.

Collaço, B., Assumpçao, M., Rosa, M. and Sánchez, G. 2014. Crustal structure of the Paraná Basin from ambient noise tomography. Earth Sci. Res. Journal Proccedings 18, Special Issue, 238. ISSN1794-6190 e-ISSN2339-3459.

Corchete, V. 2012. Shear-wave velocity structure of South America from Rayleigh wave analysis. Terra Nova 24, 87-104, doi:10.1111/j.1365-3121.2011.01042.x.

Cordani, U. and Britos Neves, B. 1982. The geologic evolution of South America during the Archean and Early Proterozoic. Rev. Bras. Geoc. 12, 305-312.

Cordani, U. and Sato, K. 1999. Crustal evolution of the South American Platform, based on Nd isotopic systematics on granitoid rocks. Episodes 22, 167-173.

Cordani, U., Sato, K., Teixeira, W., Tassinari, C. and Basei, M. 2000. Crustal evolution of the South American Platform. In: Cordani, U., Milani, E., Thomaz-Filho, A. and Campos, D. (Eds.), Tectonic Evolution of South America. $31^{\text {st }}$ International Geological Congress, Rio de Janeiro, 19-40.

Crotwell, H., Owens, T. and Ritsema, J. 1999. The TauP toolkit: Flexible seismic travel-time and raypath utilities. Seismol. Res. Lett. 70, 154-160.

Crotwell, H. and Owens, T. 2005. Automated receiver function processing. Seism. Res. Lett. 76, 702-708.

Dalziel, I. 1986. Collision and cordilleran orogenesis: an Andean perspective. En Coward, M. y Ries, J. (eds.) Collision Tectonics, Geological Society, Special Publication 19, 389-404.

De Brito Neves, B. and Fuck, R. 2013. Neoproterozoic evolution of the basement of the SouthAmerican Platform. J. South Am. Earth Sciences 47, 72-89.

DeMets, C., Gordon, R., Stein, S. and Argus, D. 1990. Current plate motions. Geophys. J. Int.101, 425-478.

De Souza, J. and Mitchell, B. 1998. Lg Coda Q variations across South America and their relation to crustal evolution. Pure Appl. Geophys. 153, 587-612. 
Der, Z., Masse, R. and Landisman, M. 1970. Effects of observational errors on the resolution of surface waves at intermediate distances. J. Geophys. Res. 75, 3399-3415.

Dragone, G., Ussami, N. and Chaves, C. 2012. The Chaco-Paraná Basin from GOCE and integrated terrestrial/satellite gravity data: unraveling major lithosphere discontinuities. International Symposium on Gravity, Geoid and Height Systems, GGHS 2012.

http://www.iag-commission2.ch/GGHS2012/Session\%207/Gabriel\%20Dragone\%20\%5BP701\%5D.pdf.

Dragone, G. 2013. Estructura crustal da bacia do Chaco-Paraná a partir de dados gravimétricos. Dissertação de mestrado, Universidade de São Paulo.

Dragone, G., Lince Klinger, F., Alvarez, O., Ussami, N. and Gimenez, M. 2014. Integration of ChacoParaná and Paraná basins terrestrial gravity data using GOCE geopotential model: a major Proterozoic to Cambrian suture revealed. Actas XXVII Reunión Científica de la Asociación Argentina de Geofísicos y Geodestas, 497-498.

Dziewonski, A., Bloch, S. and Landisman, M. 1969. A technique for the analysis of transient seismic signals. Bull. Seism. Soc. Am. 59, 427-444.

Dziewonski, A. and Anderson, D. 1981. Preliminary reference Earth model. Phys. Earth Planet. Int. 25, 297-356.

Eaton, W., Darbyshire, F., Evans, R., Grutter, H., Jones, A. and Yuan, X. 2009. The elusive lithosphere-asthenosphere boundary (LAB) beneath cratons. Lithos 109, 1-22.

Efron, B. and Tibshirani, R. 1991. Statistical data analysis in the computer age. Science 253, 390395.

Engler, A. 2006. The geology of South America. Geology Vol IV. Encyclopedia of Life Support Systems (EOLSS). http://www.eolss.net/Eolss-sampleAllChapter.aspx.

Ewing, M. and Press, F. 1952. Crustal structure and surface wave dispersion, part II: Solomon Islands earthquake of July 29, 1950. Bull. Seism. Soc. Am. 42, 315-325.

Feng, M., Assumpção, M. and Van der Lee, S. 2004. Group-velocity tomography and lithospheric Svelocity structure of the South American continent. Phys. Earth Planet. Int. 147, 315-331, doi:10.1016/j.pepi.2004.07.008.

Feng, M., Van der Lee, S. and Assumpção, M. 2007. Upper mantle structure of South America from joint inversion of waveforms and fundamental-mode group velocities of Rayleigh waves. J. Geophys. Res. 112, doi:10.1029/2006JB004449.

Feng, M. and An, M. 2010. Lithospheric structure of the Chinese mainland determined from joint inversion of regional and teleseismic Rayleigh-wave group velocities. J. Geophys. Res. 115, B06317, doi:10.1029/2008JB005787.

Gansser, A. 1973. Facts and theories on the Andes, J. Geol. Soc. London 129, 93-131. 
Grahn, Y. 2003. Silurian and devonian chitinozoan assemblages from the Chaco-Paraná basin, northeastern Argentina and central Uruguay. Revista Española de Micropaleontología 35, 1-8.

Heintz, M., Debayle, E. and Vauchez, A. 2005. Upper mantle structure of the South American continent and neighboring oceans from surface wave tomography. Tectonophysics 406, 115 139, doi:10.1016/j.tecto.2005.05.006.

Heit, B., Sodoudi, F., Yuan, X., Bianchi, M. and Kind, R. 2007. An S receiver function analysis of the lithospheric structure in South America. Geophys. Res. Lett. 34, doi:10.1029/2007GL030317.

Herrin, E. and Goforth, T. 1977. Phase-matched filters: application to the study of Rayleigh waves. Bull. Seism. Soc. Am. 67, 1259-1275.

Herrmann, R. 1973. Some aspects of band-pass filtering of surface waves. Bull. Seism. Soc. Am. 63, 663-671.

Herrmann, R. 2013. Computer programs in seismology: An evolving tool for instruction and research. Seism. Res. Lett. 84, 1081-1088, doi:10.1785/0220110096.

James, D., Assumpção, M., Snoke, A., Ribotta, L. and Kuehnel, R. 1993. Seismic studies of continental lithosphere beneath SE Brazil. An. Acad. Bras. Cienc. 65 (Suppl. 2), 227-250.

Julià, J., Ammon, C., Herrmann, R. and Correig, A. 2000. Joint inversion of receiver function and surface wave dispersion observations. Geophys. J. Int. 143, 99-112.

Julià, J., Ammon, C. and Herrmann, R. 2003. Lithospheric structure of the Arabian Shield from the joint inversion of receiver functions and surface-wave group velocities. Tectonophysics 371, 121.

Julià, J. and Mejia J. 2004. Thickness and $V_{P} / V_{S}$ ratio variation in the Iberian crust. Geophys. J. Int. $156,59-72$.

Julià, J., Herrmann, R., Ammon, C. and Akinci, A. 2004. Evaluation of deep sediment velocity structure in the New Madrid Seismic Zone. Bull. Seism. Soc. Am. 94, 334-340.

Julià, J. 2007. Constraining velocity and density contrasts across the crust-mantle boundary with receiver function amplitudes. Geophys. J. Int. 171, 286-301.

Julià, J. 2007. Función receptora y estructura cortical. Material del curso de extensión universitaria realizado en la Universidad de São Paulo.

Julià, J., Assumpçao, M. and Rocha, M. 2008. Deep crustal structure of the Paraná basin from receiver functions and Rayleigh-wave dispersion: Evidence for a fragmented cratonic root. J. Geophys. Res. 113, doi:10.1029/2007JB005374.

Kennett, B., Engdahl, E. and Buland, R. 1995. Constraints on seismic velocities in the Earth from travel times. Geophys. J. Int. 122, 108-124.

Kikuchi, M. and Kanamori, H. 1982. Inversion of complex body waves. Bull. Seism. Soc. Am. 72, 491-506. 
Landisman, M., Dziewonski, A. and Sato, Y. 1969. Recent improvements in the analysis of surface wave observations. Geophys. J. R. Astron. Soc. 17, 369-403.

Langston, C. 1979. Structure under Mount Rainier, Washington, inferred from teleseismic body waves. J. Geophys. Res. 84, 4749-4762.

Langston, C. 1994. An integrated study of crustal structure and regional wave propagation for southeastern Missouri. Bull. Seism. Soc. Am. 84, 105-118.

Larson, E. and Ekstrom, G. 2001. Global models of surface wave group velocity. Pure Appl. Geophys. 158, 1377-1399.

Laurencena, P., Deluchi, M., Rojo, A. y Kruse, E. 2010. Influencia de la explotación de aguas subterráneas en un sector del área periurbana de La Plata. Revista de la Asociación Geológica Argentina 4 (66), 484-491.

Lawrence, J. and Wiens, D. 2004. Combined receiver-function and surface wave phase-velocity inversion using a niching genetic algorithm: application to Patagonia. Bull. Seism. Soc. Am. 94, 3, 977-987.

Lay, T. and Wallace, T. 1995. Modern global seismology. Academic Press.

Levshin, A., Pisarenko, V. and Pogrebinsky, G. 1972. On a frequency-time analysis of oscillations. Ann. Geophys. 28, 211-218.

Levshin, A., Ritzwoller, M. and Resovsky, J. 1999. Source effects on surface wave group travel times and group velocity maps. Phys. Earth Planet. Int. 115, 293-312.

Ligorría, J. and Ammon, C. 1999. Iterative deconvolution and receiver function estimation. Bull. Seism. Soc. Am. 89, 1395-1400.

Limarino, C. and Spalletti, L. 2006. Paleogeography of the upper Paleozoic basins of southern South America: An overview. J. South Am. Earth Sciences 22, doi:10.1016/j.jsames.2006.09.011.

Lin, F., Moschetti, M. and Ritzwoller, M. 2008. Surface wave tomography of the western United States from ambient seismic noise: Rayleigh and Love wave phase velocity maps. Geophys. J. Int. 173, 281-298.

Lloyd, S., Van der Lee, S., França, G., Assumpção, M. and Feng, M. 2010. Moho map of South America from receiver functions and surface waves. J. Geophys. Res. 115, doi:10.1029/2009JB006829.

Lobkis, O. and Weaver, R. 2001. On the emergence of the Greens function in the correlations of a diffuse field. Journal of the Acoustical Society of America 110, 894-903.

Lodge, A. and Helffrich, G. 2009. Grid search inversion of teleseismic receiver functions. Geophys. J. Int. 178, 513-523, doi:10.1111/j.1365-246X.2009.04176.x. 
Luz, R., Julià, J., Assumpção, M. and do Nascimento, A. 2014. Tomografia de ondas de superfície na América do Sul com ênfase na Província Borborema. Abstract da $47^{\circ}$ Congresso Brasileiro de Geologia, 21-26 September 2014, Brazil.

Luz, R., Julià, J. and do Nascimento, A. 2015. Crustal structure of the eastern Borborema Province, NE Brazil, from joint inversion of receiver functions and surface wave dispersion: Implications for plateau uplift. J. Geophys. Res. 120, doi: 10.1002/2015JB011872.

McQuarrie, N., Horton, B., Zandt, G., Beck, S. and DeCelles, P. 2005. Lithospheric evolution of the Andean fold-thrust belt, Bolivia, and the origin of the central Andean plateau. Tectonophysics 399, 15-37, doi:10.1016/j.tecto.2004.12.013.

Milani, E. e Ramos, V. 1998. Orogenias paleozoicas no domínio sul-ocidental do Gondwana e os ciclos de subsidência da Bacia do Paraná. Revista Brasileira de Geociências 28, 4, 473-484.

Milani, E. and Zalán, P. 1999. An outline of the geology and petroleum systems of the Paleozoic interior basins of South America. Episodes 22, 3, 199-205.

Milani, E. and Thomaz Filho, A. 2000. Sedimentary basins of South America. In: Cordani, U., Milani, E., Thomaz-Filho, A. and Campos, D. (Eds.), Tectonic evolution of South America. Rio de Janeiro: $31^{\text {st }}$ International Geological Congress Rio de Janeiro, 389-399.

Mejia, J. 2001. Lithospheric structure beneath the Tibetan Plateau using simultaneous inversion of surface wave dispersion and receiver functions. Ph. D. Thesis, Saint Louis University, EEUU.

Moschetti, M., Ritzwoller, M. and Shapiro N. 2007. Surface wave tomography of the western United States from ambient noise: Rayleigh wave group velocity maps. Geochemistry Geophysics Geosystems 8.

Nolet, G. 2008. A breviary of seismic tomography. Cambridge University Press.

Owens, T., Zandt, G. and Taylor, S. 1984. Seismic evidence for ancient rift beneath the Cumberland plateau, Tennessee: a detailed analysis of broadband teleseismic P waveforms. J. Geophys. Res. 89, 7783-7795.

Paige, C. and Saunders, M. 1982a. LSQR: An algorithm for sparse linear equations and sparse least squares. ACM TOMS 8, 43-71.

Paige, C. and Saunders, M. 1982b. Algorithm 583, LSQR: Sparse linear equations and leastsquares problems. ACM TOMS 8, 195-209.

Pasyanos, M., Walter, W. and Hazler, S. 2001. A surface wave dispersion study of the Middle East and North Africa for monitoring the Comprehensive Nuclear-Test-Ban Treaty. Pure Appl. Geophys. 158, 1445-1474.

Pasyanos, M. and Walter, W. 2002. Crust and upper-mantle structure of North Africa, Europe and the Middle East from inversion of surface waves. Geophys. J. Int. 149, 463-481, doi:10.1046/j.1365-246X.2002.01663.x. 
Pasyanos, M. 2005. A variable resolution surface wave dispersion study of Eurasia, North Africa, and surrounding regions. J. Geophys. Res. 110, doi:10.1029/2005JB003749.

Pasyanos, M. and Nyblade, A. 2007. A top to bottom lithospheric study of Africa and Arabia. Tectonophysics 444, 27-44, doi:10.1016/j.tecto.2007.07.008.

Pasyanos, M. 2010. Lithospheric thickness modeled from long-period surface wave dispersion. Tectonophysics $481,38-50$.

Pavlis, N., Holmes, S., Kenyon, S. and Factor, J. 2008. An Earth gravitational model to degree 2160: EGM2008. In: THE 2008 General Assembly of the European Geosciences Union, Austria.

Pezzi, E. y Mozetic, M. E. 1989 Cuencas Sedimentarias de la Región Chacoparanense. En: Cuencas Sedimentarias Argentinas. Chebli, G., Spalleti, I. (eds.). Universidad Nacional de Tucumán. Serie Correlación Geológica 6, 65-78.

Prezzi, C., Götze, H. and Schmidt, S. 2014. Andean foreland evolution and flexure in NW Argentina: Chaco-Paraná Basin. Tectonophysics 628, 228-243, doi:10.1016/j.tecto.2014.04.041.

Pirchiner, M., Collaço, B., Calhau, J., Assumpcao, M. and Dourado, J. 2011. Brazilian Seismographic Integrated Systems (BRASIS): infrastructure and data management. Annals of Geophysics 54, 17-22.

Ramesh, D., Kawakatsu, H., Watada, S. and Yuan, X. 2005. Receiver function images of the central Chugoku region in the Japanese islands using Hi-net data. Earth Planets Space 57, 271-280.

Ramos, V. 1988. Late Proterozoic-Early Paleozoic of South America. A collisional history. Episodes $11,168-175$.

Ramos, V. 1999. Las provincias geológicas del territorio Argentino. Geología Argentina. Editor R. Caminos. Anales 29, 41-96, ISSN 0328-2325.

Ramos, V. 2000. The Southern Central Andes. In: Cordani, U., Milani, E., Thomaz-Filho, A. and Campos, D. (Eds.), Tectonic Evolution of South America. $31^{\text {st }}$ International Geological Congress, Rio de Janeiro, 561-604.

Rapela, C. y Llambías, E. 1999. El magmatismo gondwánico y los ciclos fanerozoicos. Geología Argentina. Editor R. Caminos. Anales 29, 373-376, ISSN 0328-2325.

Rapela, C., Pankhurst, R., Casquet, C., Fanning, C., Baldo, E., González-Casado, J., Galindo, C. and Dahlquist, J. 2007. The Río de La Plata craton and the assembly of SW Gondwana. EarthScience Reviews 83, 49-82.

Rapela, C. 2008. La formación del continente sudamericano. Anales Academia Nacional de Ciencias Exactas, Físicas y Naturales 60, 25-31, ISSN: 0365-1185.

Rawlinson, N. and Sambridge M. 2003. Seismic traveltime tomography of the crust and lithosphere. Advances in Geophysics 46, 81-197. 
Rawlinson, N., Pozgay, S. and Fishwick S. 2010. Seismic tomography: A window into deep Earth. Phys. Earth Planet. Int 178, 101-135.

Ritzwoller, M. and Levshin, A. 1998. Eurasian surface wave tomography: Group velocities. J. Geophys. Res. 103, 4839-4878, doi:10.1029/97JB02622.

Ritzwoller, M. 2000. Introductory lectures in surface wave seismology. Fifth Workshop on three dimensional modelling of seismic waves generation, propagation and their Inversion, 1-186.

Ritzwoller, M., Shapiro, N., Barmin, M. and Levshin, A. 2002. Global surface wave diffraction tomography. J. Geophys. Res. 107, doi:10.1029/2002JB001777.

Rosa, M., Collaço, B., Assumpção, M., Sabbione, N. and Sanchez, G. 2016. Thin crust beneath the Chaco-Paraná Basin by surface-wave tomography. J. South Am. Earth Sciences 66, 1-14, doi:10.1016/j.jsames.2015.11.010.

Russo, A., Archangelshy, S., Andreis, R. y Cuerda, A. 1986. Cuenca Chacoparanense. En: El sistema Carbonifero en la República Argentina. Archangelsky, S. (Ed.). Córdoba, Academia Nacional de Ciencias, 197-212.

Sabbione, N. y Rosa, M. 2009. Relación Vp/Vs y espesor cortical en Tornquist (TRQA), Pcia. de Buenos Aires, a partir de funciones receptoras. Actas de la XXIV Reunión Científica de la Asociación Argentina de Geofísicos y Geodestas. Ciencias de la Tierra I, $1^{\circ}$ edición, 320-326, ISBN 978-987-25291-1-6.

Schmitz, M., Lessel, K., Giese, P., Wigger, P., Araneda, M., Bribach, J., Graeber, F., Grunewald, S., Haberland, C., Lüth, S., Röwer, P., Ryberg, T. and Schulze, A. 1999. The crustal structure beneath the Central Andean forearc and magmatic arc as derived from seismic studies - the PISCO 94 experiment in northern Chile $\left(21^{\circ}-23^{\circ} \mathrm{S}\right)$. J. South Am. Earth Sciences 12, 237-260, doi:10.1016/S0895-9811(99)00017-6.

Shapiro, N. and Campillo, M. 2004. Emergence of broadband Rayleigh waves from correlations of the ambient seismic noise. Geophys. Res. Lett. 31 (7), L07614.

Shapiro, N., Campillo, M., Stehly, L. and Ritzwoller, M. 2005. High resolution surface wave tomography from ambient seismic noise. Science 307, 1615-1618.

Shearer, P. 2009. Introduction to Seismology. Cambridge University Press.

Snoke, A. and James, D. 1997. Lithospheric struture of the Chaco and Paraná Basins of South America from surface-wave inversion. J. Geophys. Res. 102, doi:10.1029/96JB03180.

Stein, S. and Wysession, M. 2003. An Introduction to Seismology, Earthquakes, and Earth Structure. Blackwell Publishing.

Takeuchi, H. and Saito, M. 1972. Seismic surface waves. Methods of computational Physics, 217295, Bolt, B., Academic Press, New York. 
Tapley, W. and Tull, J. 2000. SAC2000, Seismic Analysis Code. Lawrence Livermore National Laboratory. http://www-ep.es.llnl.gov/tvp/sac.html.

Tassinari, C., Bettencourt, J., Geraldes, M., Macambira, M. and Lafon, J. 2000. The Amazon craton. In: Cordani, U., Milani, E., Thomaz Filho, A. and Campos, D. (Eds), Tectonic Evolution of South America. $31^{\text {st }}$. International Geological Congress, Rio de Janeiro, 41-95.

Tkalčić, H., Pasyanos, M., Rodgers, A., Gök, R., Walter, W. and Al-Amri, A. 2006. A multi-step approach in joint modeling of surface wave dispersion and teleseismic receiver functions: Implications for lithospheric structure of the Arabian peninsula. J. Geophys. Res 111, B11311, doi:10.1029/2005JB004130.

Torra, R. 2006. A stratigraphical-geochemical study on the Chaco Paraná continental rift basin. An approach study based on regional sedimentology and drill-hole core analyses, South America. Chinese Journal of Geochemistry 25, 3.

Turner, S., Regelous, M., Kelley, S., Hawkesworth, C. and Mantovani, M. 1994. Magmatism and continental break-up in the South Atlantic: high precision 40 Ar-39 geochronology. Earth Planet. Sci. Lett. 121, 333-348.

Udias, A. y Mezcua, J. 1997. Fundamentos de Sismología. Volumen 25 Colección textos universitarios. UCA Editores. $2^{\circ} \mathrm{Ed}$.

Udías, A. 1999. Principles of Seismology. Cambridge Univ. Press.

Urien, C. y Zambrano, J. 1996. Estructura del margen continental. Geología y recursos naturales de la plataforma continental argentina. Editores: V. Ramos and M. Turic. Relatorio 3, 29-65.

Van der Lee, S. and Nolet, G. 1997. Upper mantle S velocity structure of North America. J. Geophys. Res. 102, doi:10.1029/97JB01168.

Van der Lee, S., James, D. and Silver, P. 2001. Upper-mantle S-velocity structure of central and western South America. J. Geophys. Res. 106, doi:10.1029/2001JB000338.

Van der Meijde, M., Julia, J. and Assumpção, M. 2013. Gravity derived Moho for South America. Tectonophysics 609, 456-467, doi:10.1016/j.tecto.2013.03.023.

Vdovin, O., Rial, J., Levshin, A. and Ritzwoller, M. 1999. Group velocity tomography of South America and the surrounding oceans. Geophys. J. Int. 136, 324-340, doi:10.1046/j.1365246X.1999.00727.x

Vitorello, I., Ussami, N., Padilha A., Braitenberg, C., Pádua, M. and Bologna, M. 2011. Lithospheric investigations of the intra-cratonic Paraná and Chaco-Paraná basins integrating terrestrial gravitry, satellite gravity gradiometry, geomagnetic and electromagnetic soundings. Geophysical Research Abstracts Vol. 13, EGU2011-4601, EGU General Assembly 2011.

Wapenaar, K. 2004. Retrieving the elastodynamic Green's function of an arbitrary inhomogeneous medium by cross-correlation. Phys. Rev. Lett. 93, doi:10.1103/PhysRevLett.93.254301. 
Winn, R. and Steinmetz, J. 1998. Upper Paleozoic strata of the Chaco-Paraná basin, Argentina, and the great Gondwana glaciation. J. South Am. Earth Sciences 11, 153-168, doi:10.1016/S08959811(98)00007-8.

Yeck, W. Sheehan, A. and Schulte Pelkum, V. 2013. Sequential H-Stacking to obtain accurate crustal thicknesses beneath sedimentary basins. Bull. Seism. Soc. Am. 103, 2142-2150, doil:10.1785/0120120290.

Yoo, H., Herrmann, R., Cho, K. and Lee, K. 2007. Imaging the three-dimensional crust of the Korean Peninsula by joint inversion of surface-wave dispersion and teleseismic receiver functions. Bull. Seism. Soc. Am., 97, 1002-1011.

Yuan, X., Sobolev, S., Kind, R., Oncken, O., Bock, G., Asch, G., Schurr, B., Graeber, F., Rudloff, A., Hanka, W., Wylegalla, K., Tibi, R., Haberland, C., Rietbrock, A., Giese, P., Wigger, P., Röwer, P., Zandt, G., Beck, S., Wallace, T., Pardo, M. and Comte, D. 2000. New constraints on subduction and collision processes in the Central Andes from P-to-S converted seismic phases. Nature 408, 958-961, doi:10.1038/35050073.

Zandt, G. and Ammon, C. 1995. Continental crust composition constrained by measurements of crustal Poisson's ratio. Nature 374, 152-154.

Zhang, J. and Langston, C. 1995. Constraints on oceanic lithosphere structure from deep-focus regional receiver function inversions. J. Geophys. Res. 100, doi:10.1029/95JB02512.

Zhu, L. and Kanamori, H. 2000. Moho depth variation in southern California from teleseismic receiver functions. J. Geophys. Res. 105, 2969-2980. 


\section{Apéndice $A$}

\section{Resultados de la tomografía}

Se presentan los mapas de tomografía de las ondas Rayleigh y Love calculados con los dos criterios de suavización ( $1^{\text {er }}$ derivada y $2^{\text {da }}$ derivada) para los distintos períodos y los mapas de las trayectorias (líneas azules), sismos (círculos amarillos) y estaciones sismológicas (triángulos rojos).

Las variaciones laterales significativas que presentan los mapas tomográficos pueden atribuirse a las características geológicas y tectónicas de la región. A pesar de los distintos métodos de suavización utilizados, los mapas de velocidad de grupo para un mismo período se asemejan y muestrean las mismas estructuras (Rosa et al., 2015).

En todos los mapas analizados, la mayor resolución se obtuvo en la región central de Sudamérica (en particular en el área de las cuencas de Paraná y ChacoParaná), donde se cuenta con una gran cantidad de trayectorias y la distribución acimutal de las mismas es óptima, dada la configuración de datos disponibles.
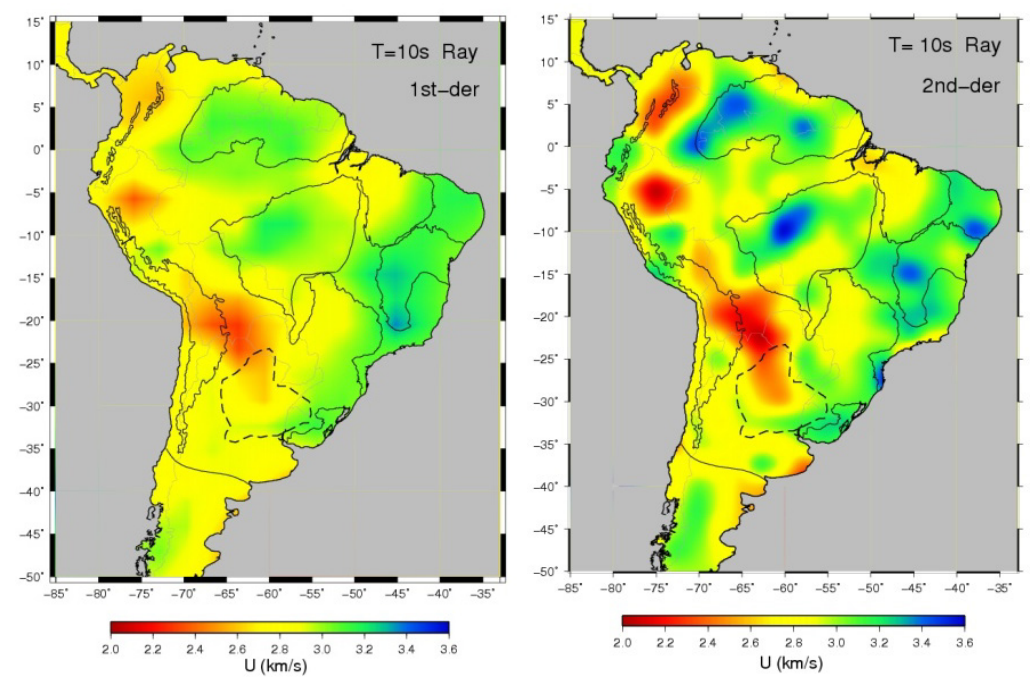

Figura A1: Mapa de velocidad de grupo de onda Rayleigh (10s) con suavizado de $1^{\text {er }}$ y $2^{\text {da }}$ derivada. 


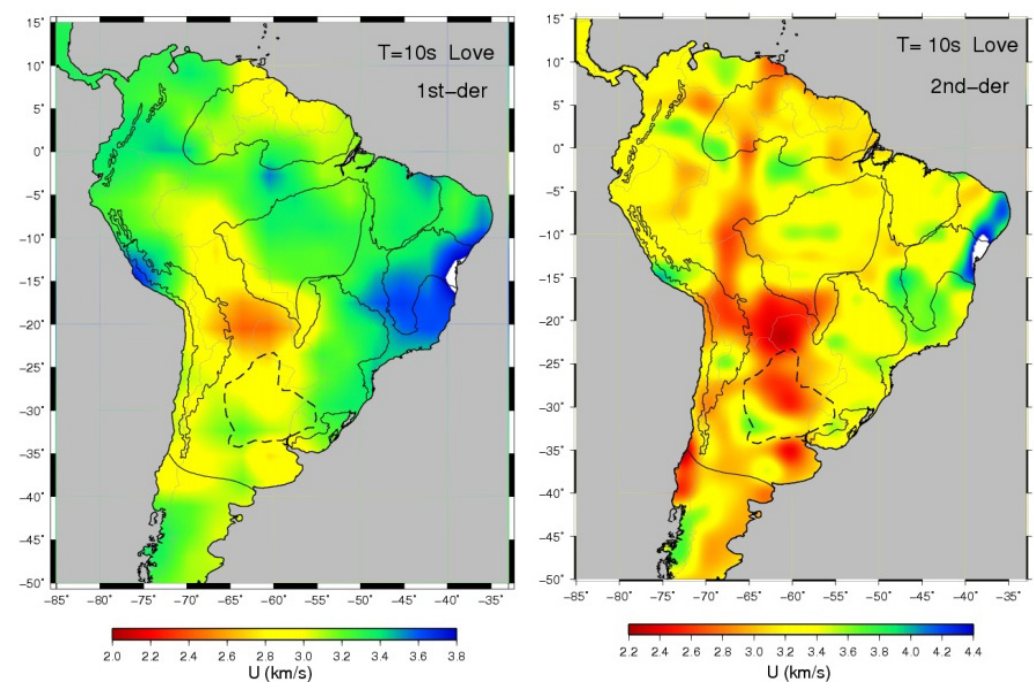

Figura A2: Mapa de velocidad de grupo de onda Love (10s) con suavizado de $1^{\text {er }}$ y $2^{\text {da }}$ derivada.

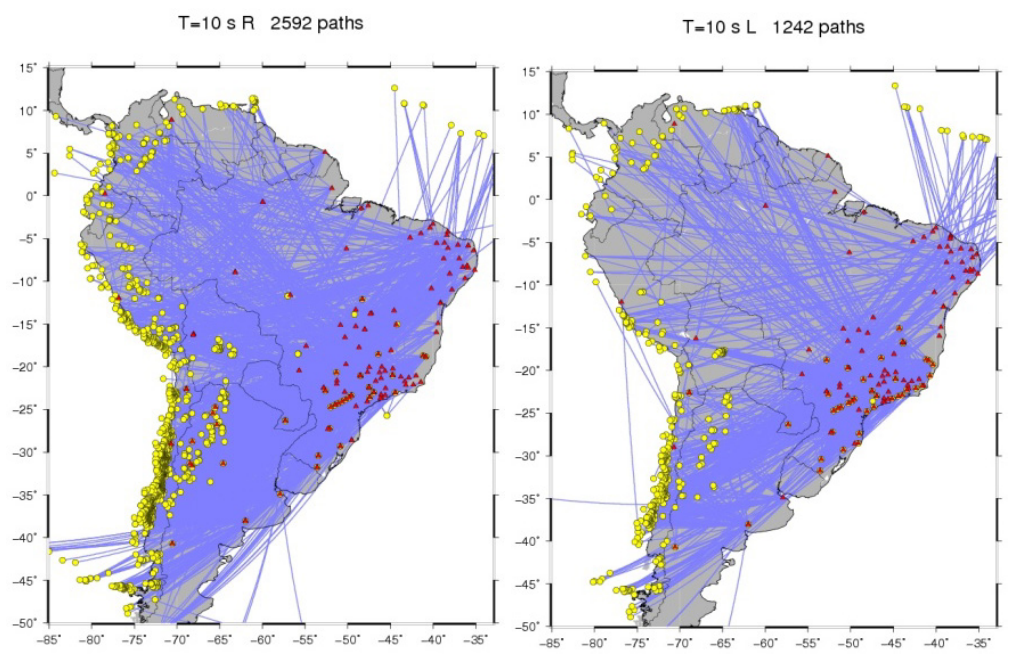

Figura A3: Mapa de trayectorias para las ondas Rayleigh (10s) y Love (10s).

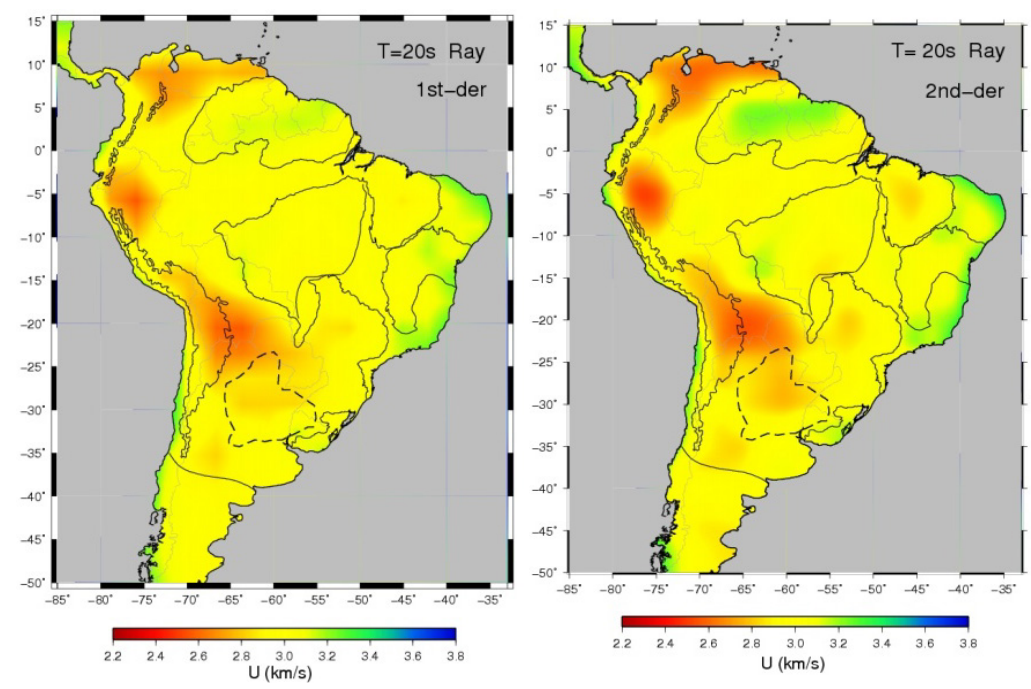

Figura A4: Mapa de velocidad de grupo de onda Rayleigh (20s) con suavizado de $1^{\text {er }}$ y $2^{\text {da }}$ deriv. 

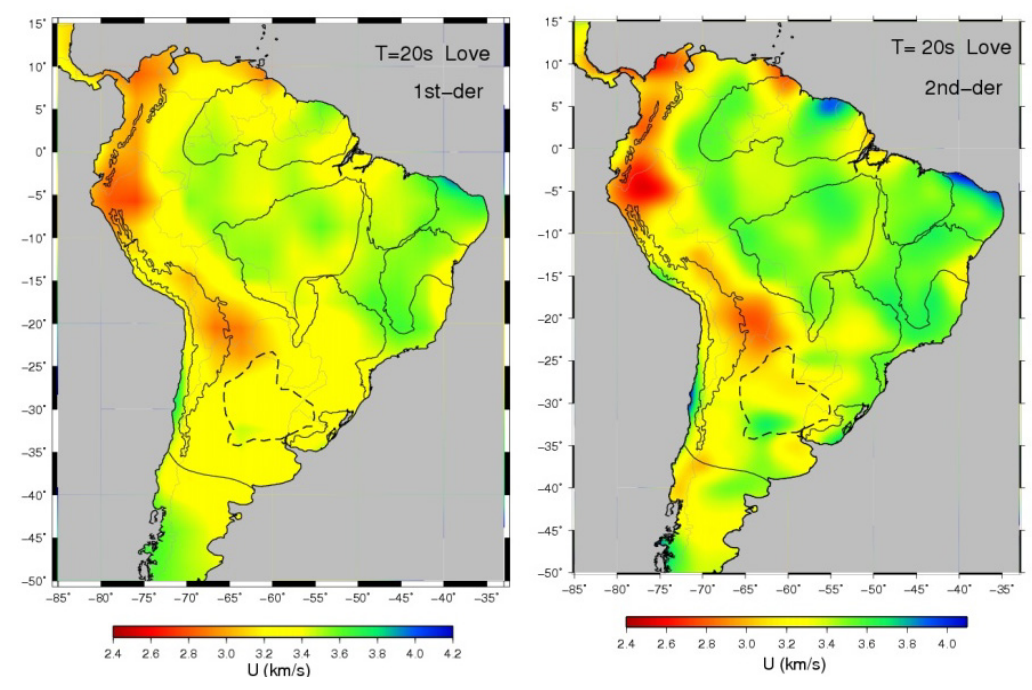

Figura A5: Mapa de velocidad de grupo de onda Love (20s) con suavizado de $1^{\text {er }}$ y $2^{\text {da }}$ deriv.
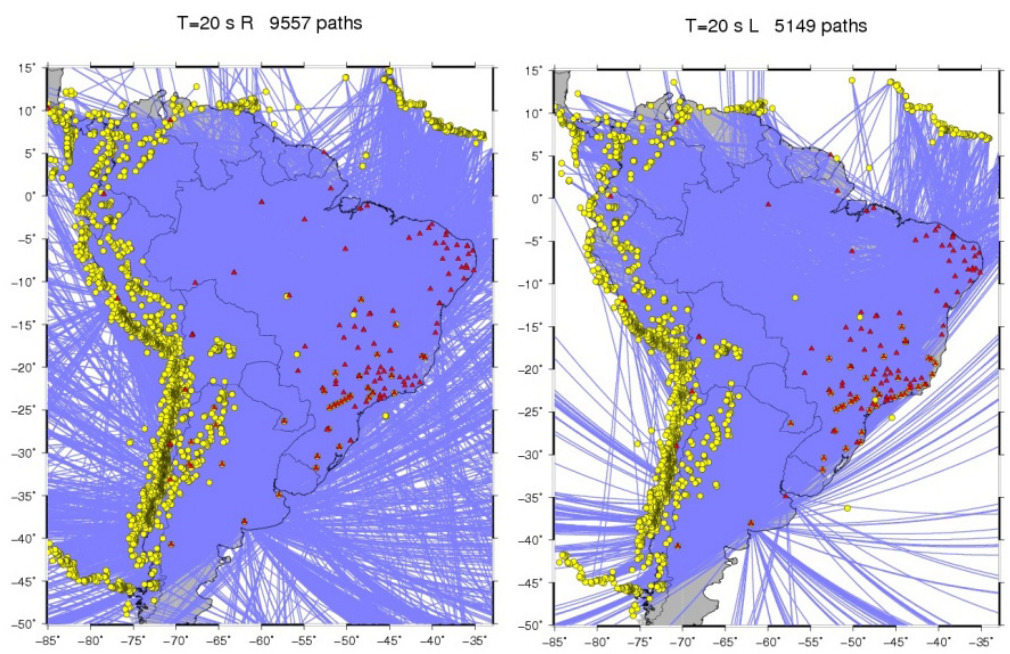

Figura A6: Mapa de trayectorias para las ondas Rayleigh (20s) y Love (20s).

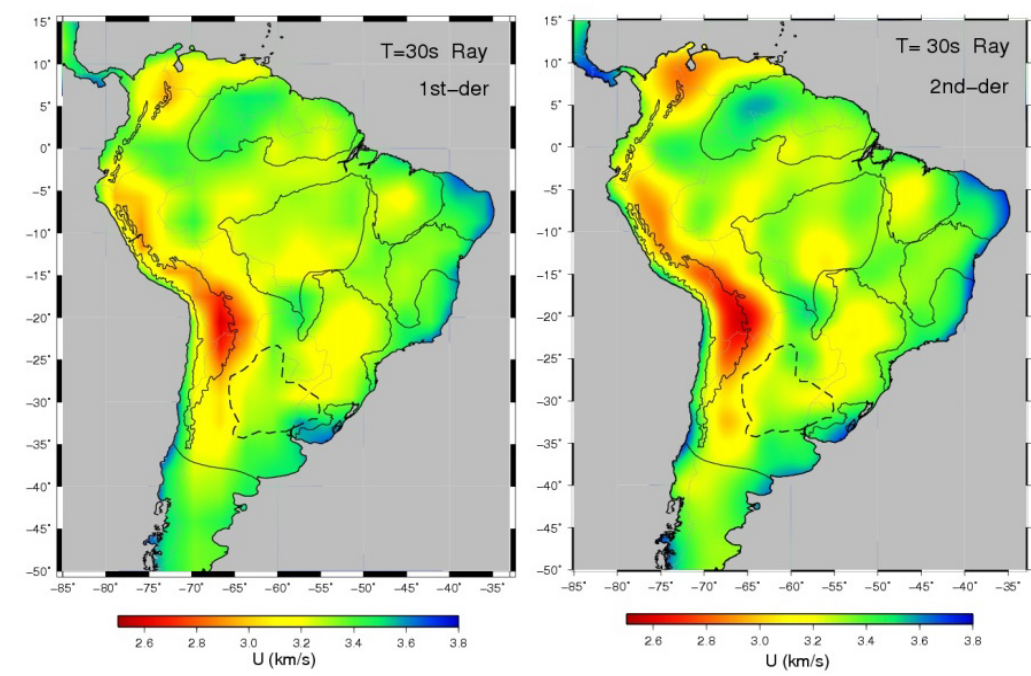

Figura A7: Mapa de velocidad de grupo de onda Rayleigh (30s) con suavizado de $1^{\text {er }}$ y $2^{\text {da }}$ deriv. 


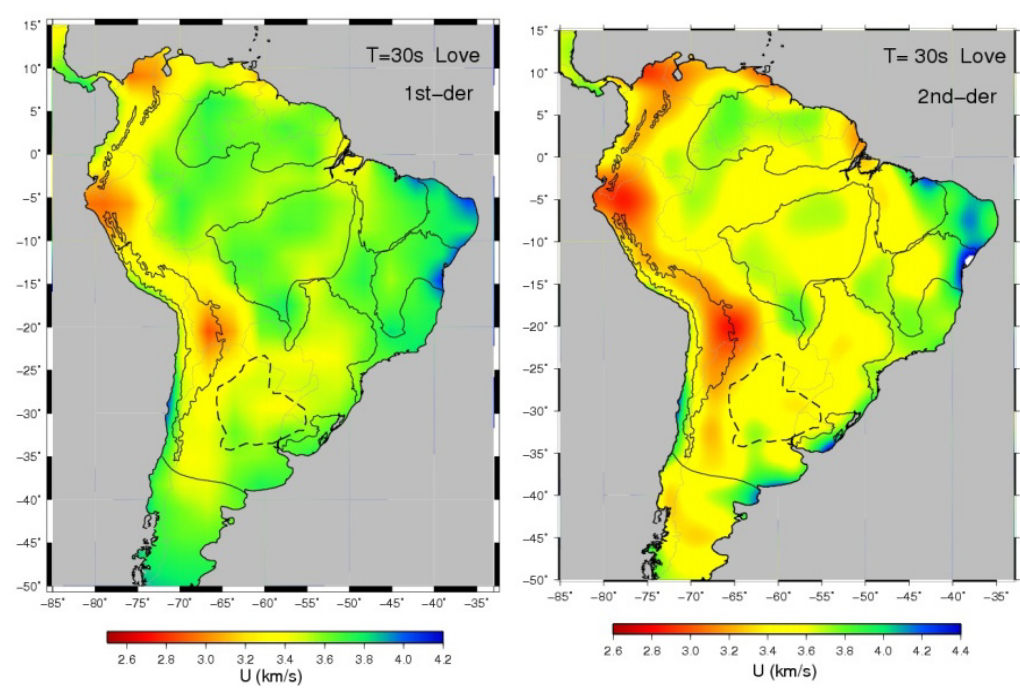

Figura A8: Mapa de velocidad de grupo de onda Love (30s) con suavizado de $1^{\text {er }}$ y $2^{\text {da }}$ deriv.
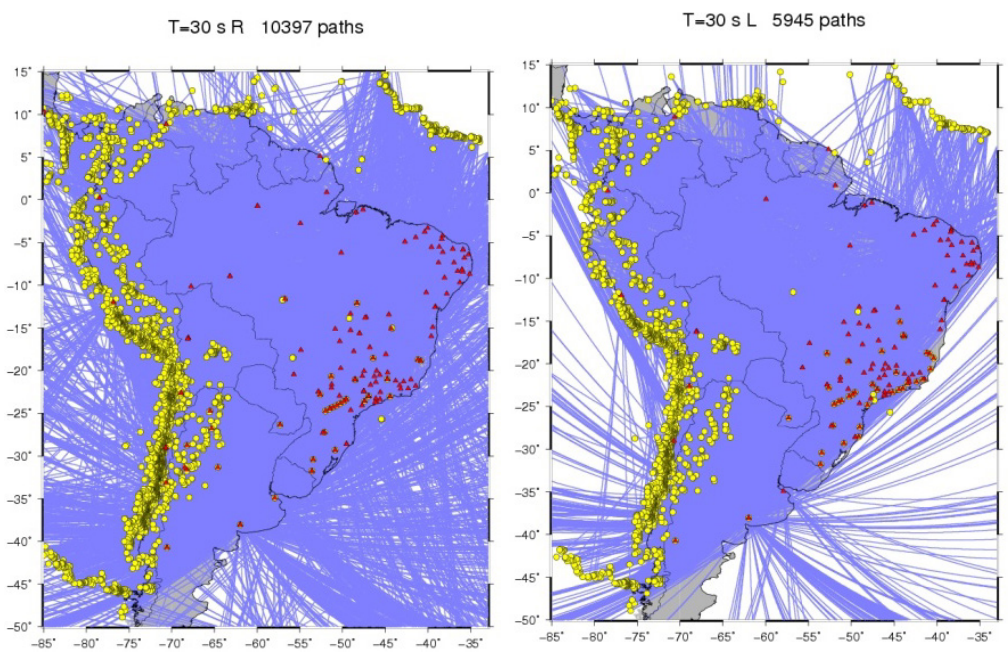

Figura A9: Mapa de trayectorias para las ondas Rayleigh (30s) y Love (30s).

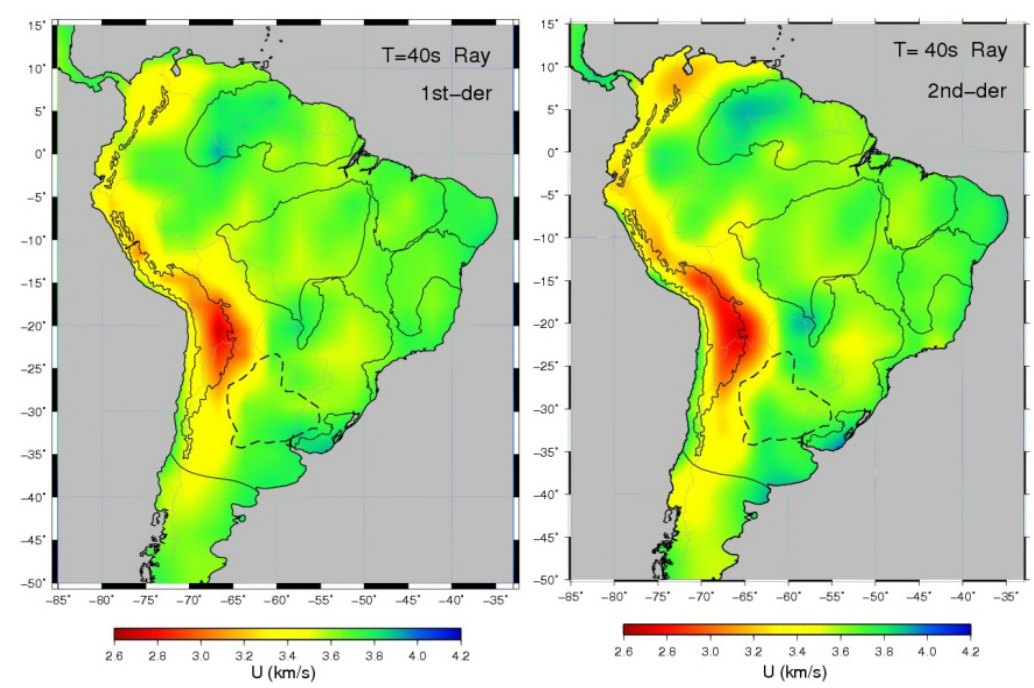

Figura A10: Mapa de velocidad de grupo de onda Rayleigh (40s) con suavizado de $1^{\text {er }}$ y $2^{\text {da }}$ deriv. 


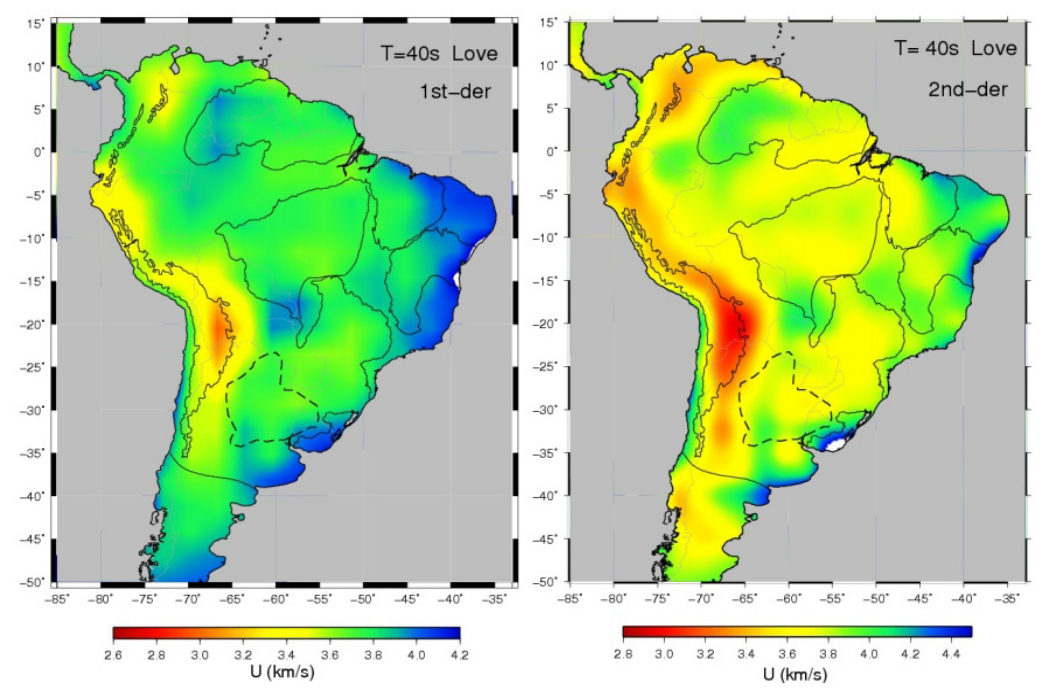

Figura A11: Mapa de velocidad de grupo de onda Love (40s) con suavizado de $1^{\text {er }}$ y $2^{\text {da }}$ deriv.

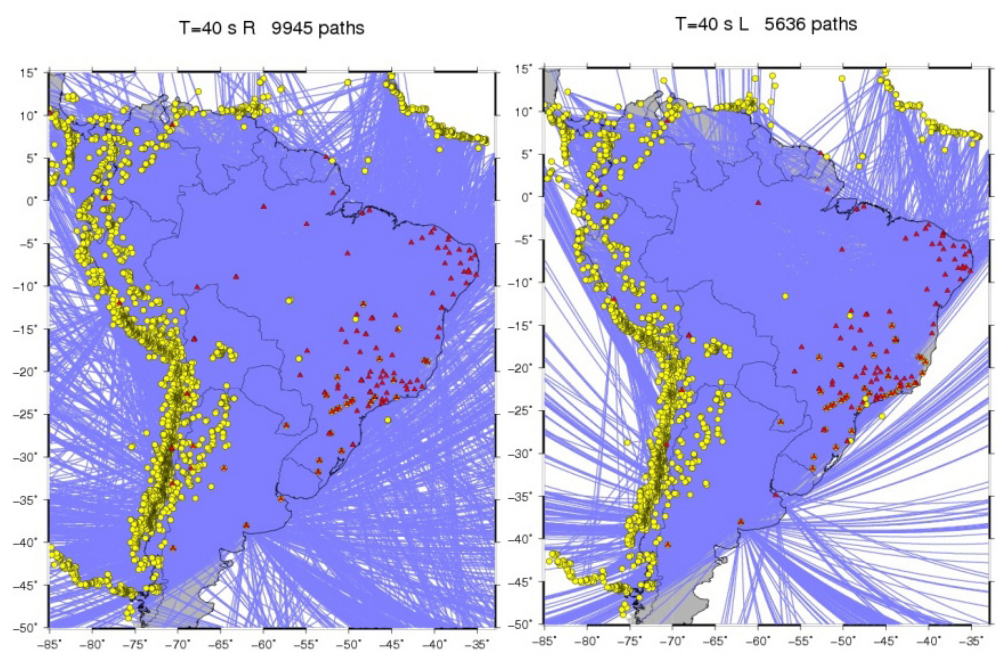

Figura A12: Mapa de trayectorias para las ondas Rayleigh (40s) y Love (40s).
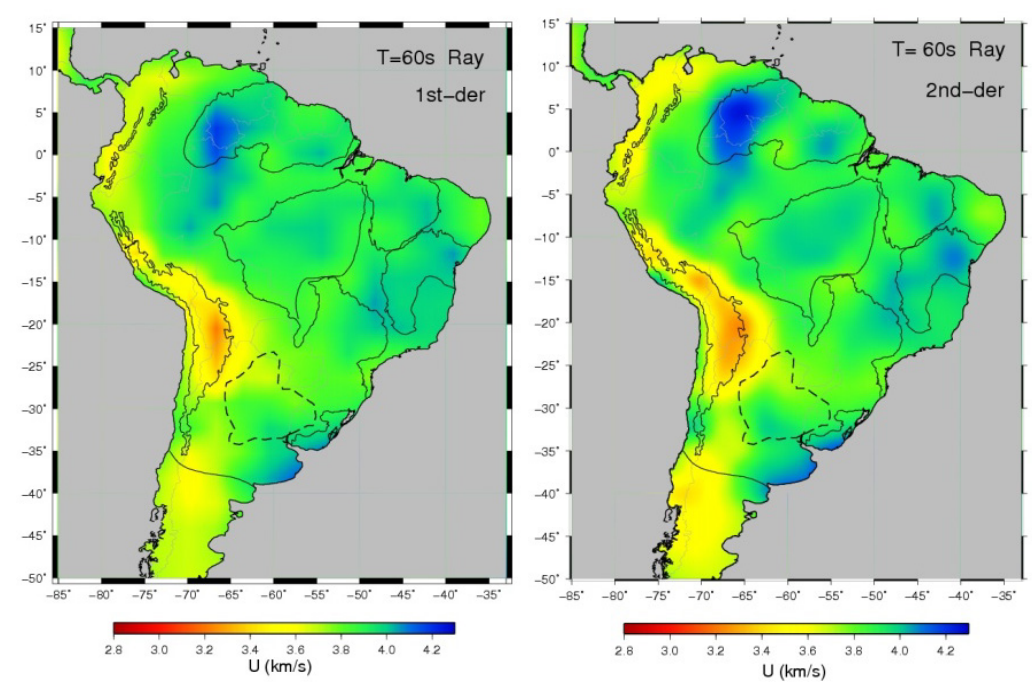

Figura A13: Mapa de velocidad de grupo de onda Rayleigh (60s) con suavizado de $1^{\text {er }}$ y $2^{\text {da }}$ deriv. 


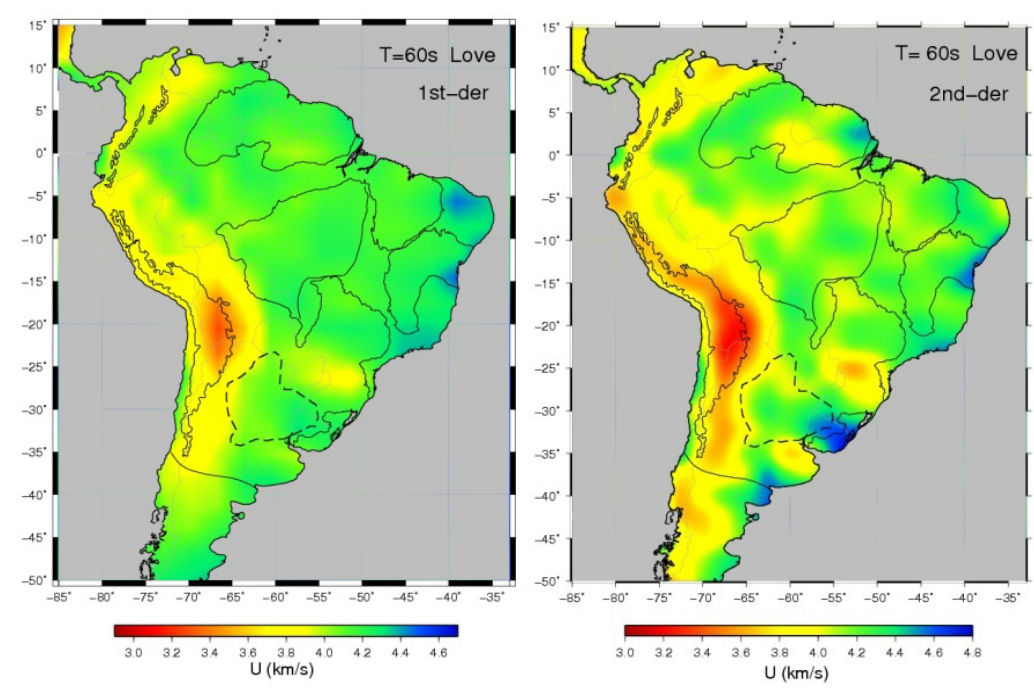

Figura A14: Mapa de velocidad de grupo de onda Love (60s) con suavizado de $1^{\text {er }}$ y $2^{\text {da }}$ deriv.
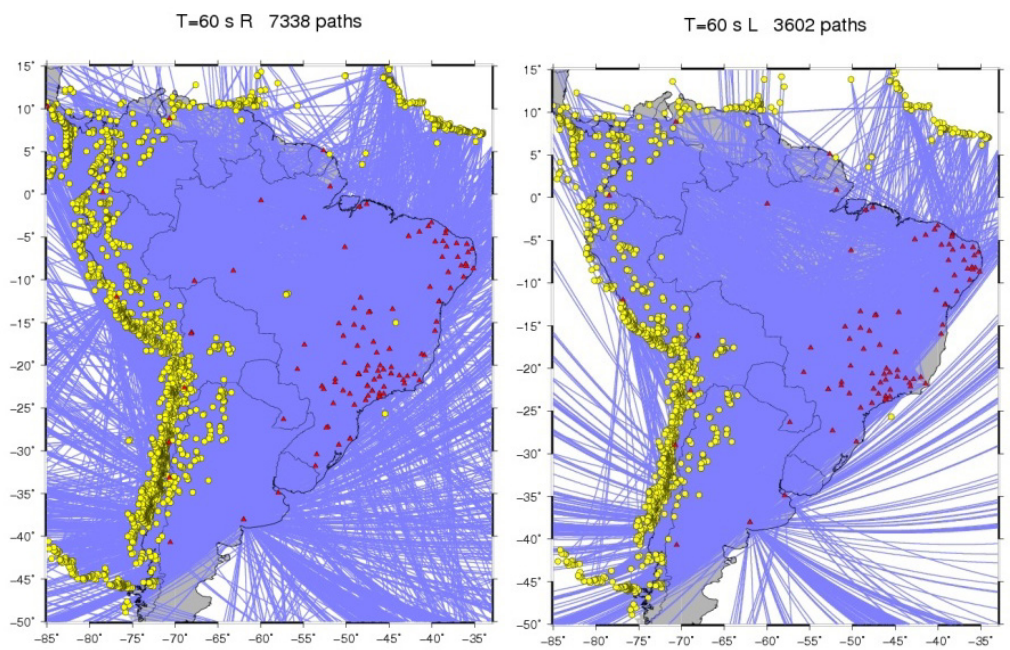

Figura A15: Mapa de trayectorias para las ondas Rayleigh (60s) y Love (60s).
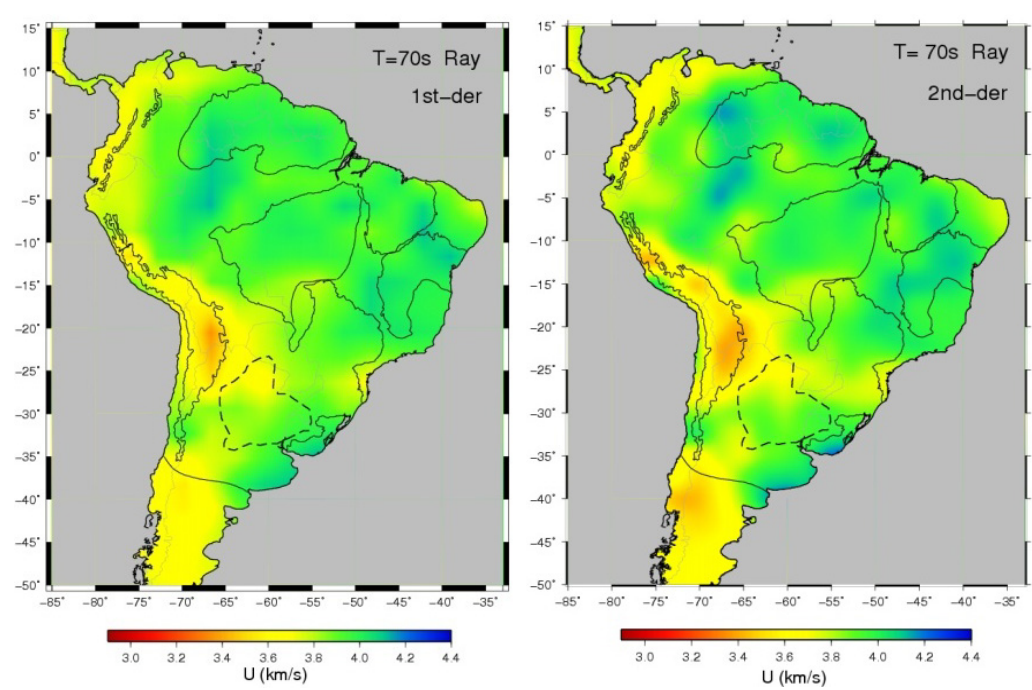

Figura A16: Mapa de velocidad de grupo de onda Rayleigh (70s) con suavizado de $1^{\mathrm{er}}$ y $2^{\text {da }}$ deriv. 


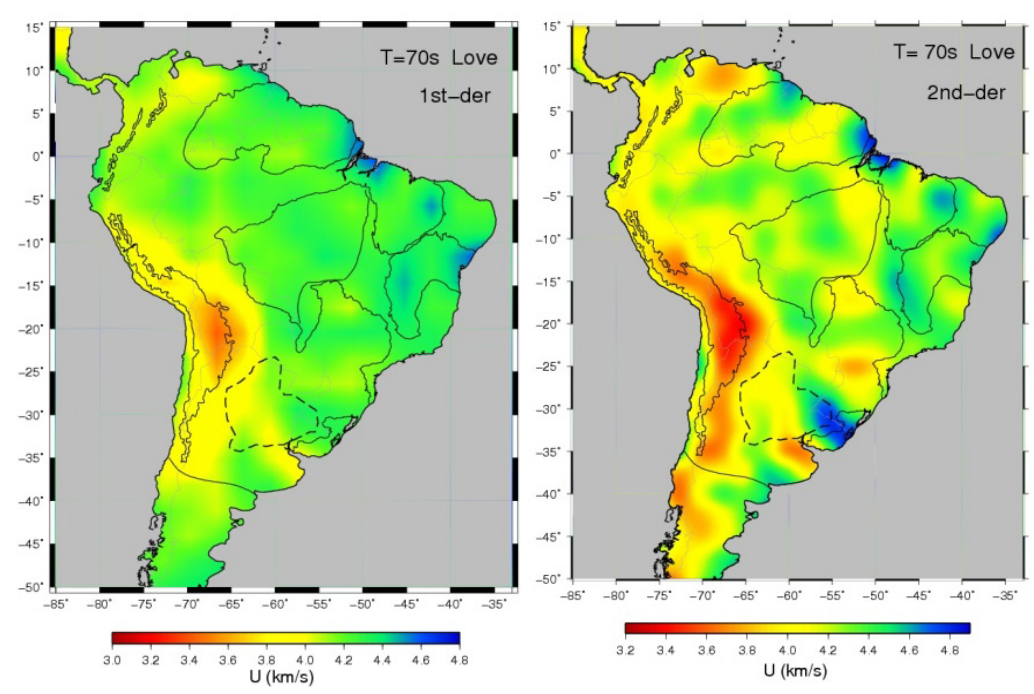

Figura A17: Mapa de velocidad de grupo de onda Love (70s) con suavizado de $1^{\text {er }}$ y $2^{\text {da }}$ deriv.

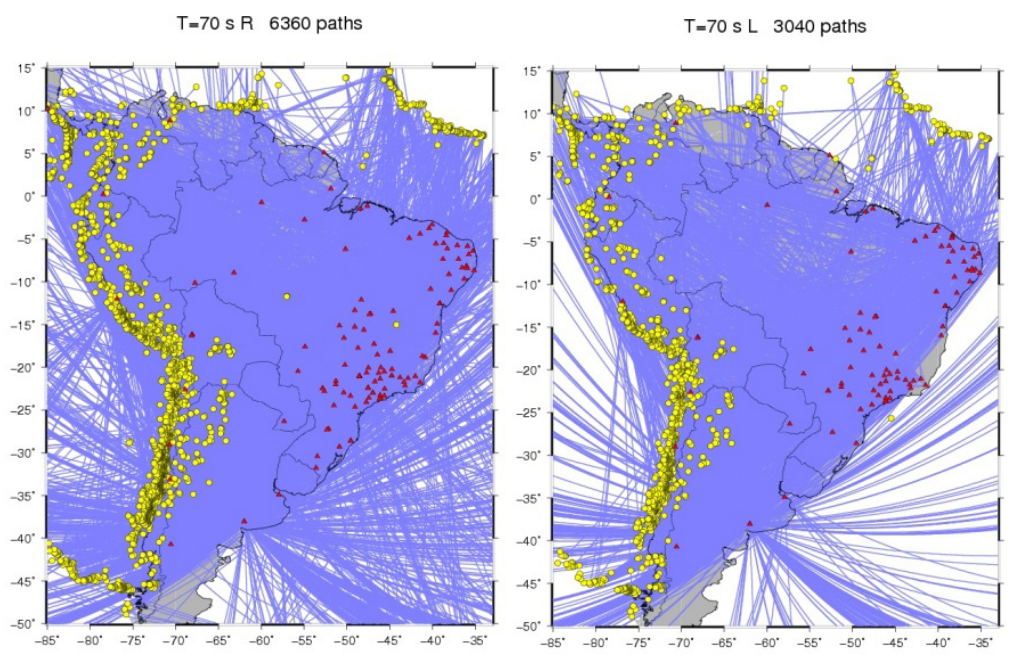

Figura A18: Mapa de trayectorias para las ondas Rayleigh (70s) y Love (70s).

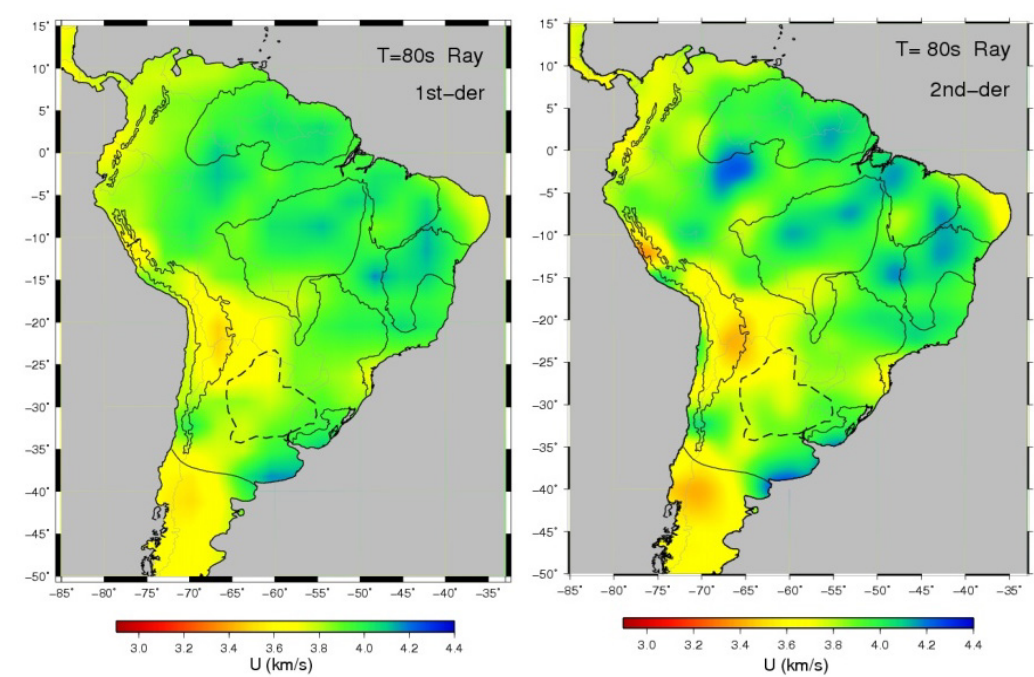

Figura A19: Mapa de velocidad de grupo de onda Rayleigh (80s) con suavizado de $1^{\text {er }}$ y $2^{\text {da }}$ deriv. 


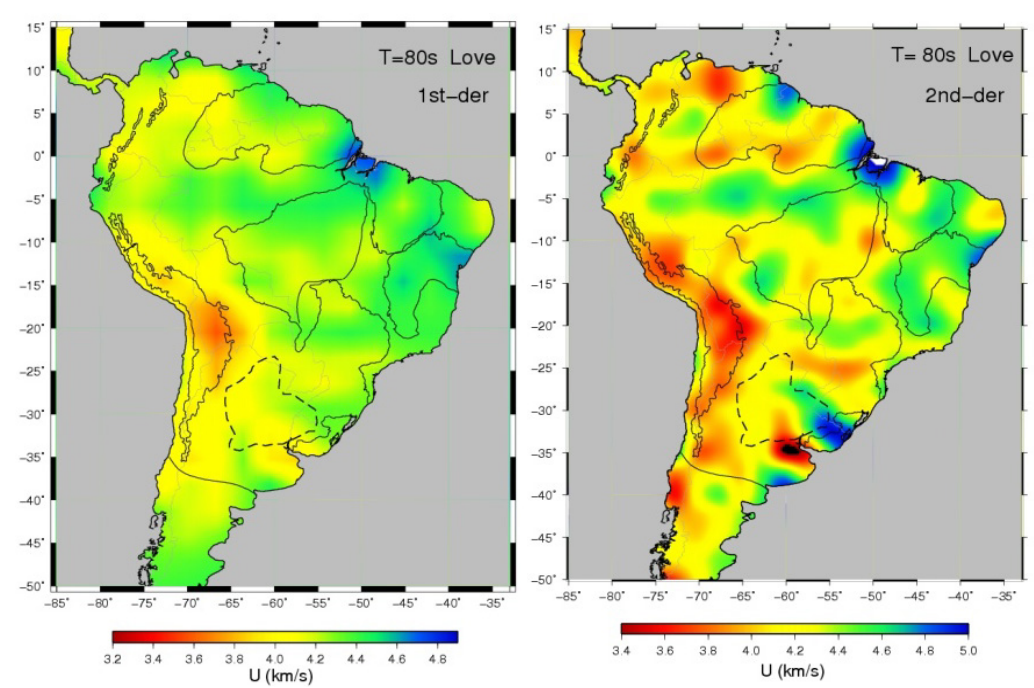

Figura A20: Mapa de velocidad de grupo de onda Love (80s) con suavizado de $1^{\text {er }}$ y $2^{\text {da }}$ deriv.

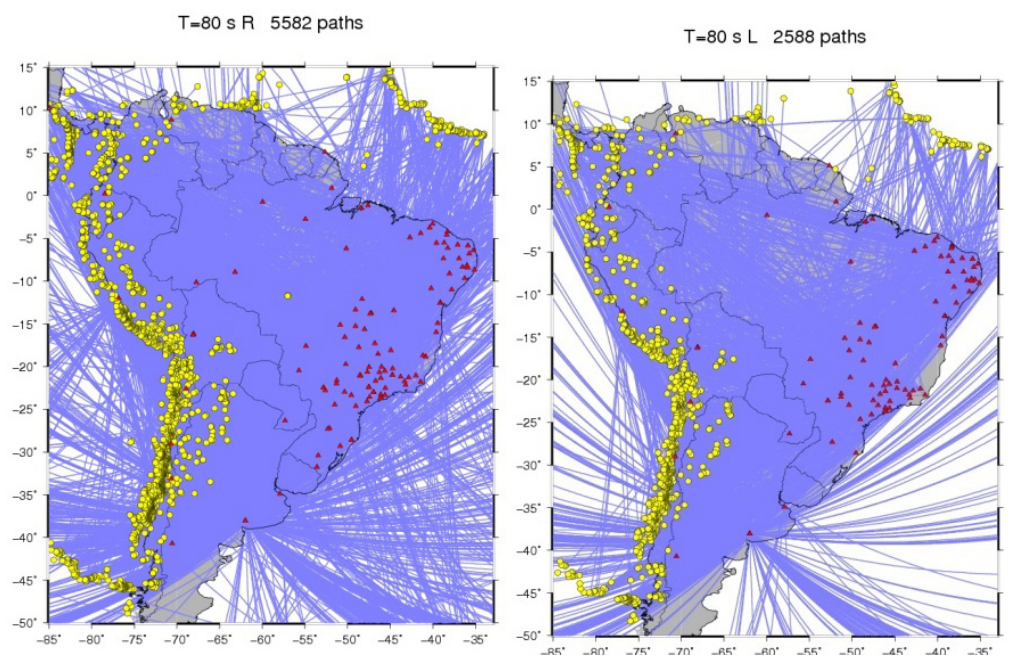

Figura A21: Mapa de trayectorias para las ondas Rayleigh (80s) y Love (80s).

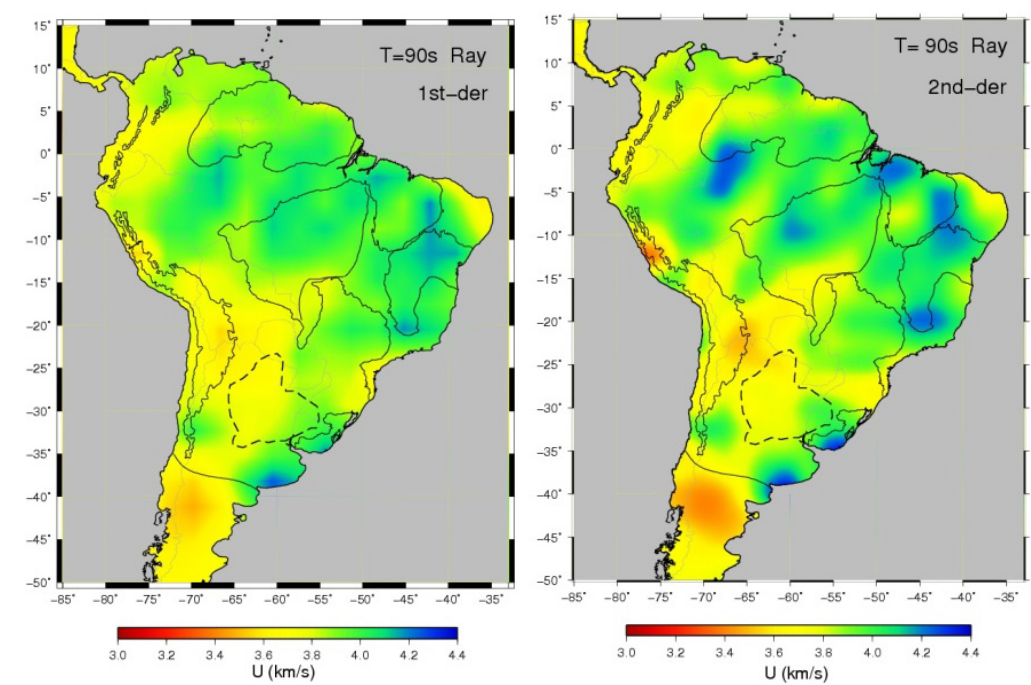

Figura A22: Mapa de velocidad de grupo de onda Rayleigh (90s) con suavizado de $1^{\text {er }}$ y $2^{\text {da }}$ deriv. 


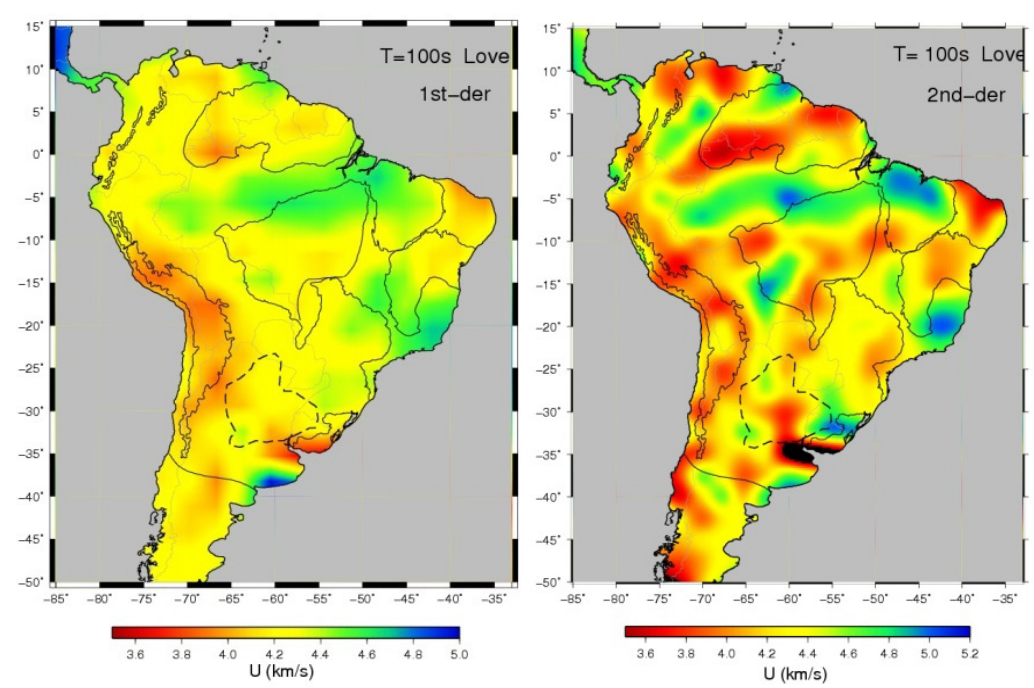

Figura A23: Mapa de velocidad de grupo de onda Love (100s) con suavizado de $1^{\text {er }}$ y $2^{\text {da }}$ deriv.
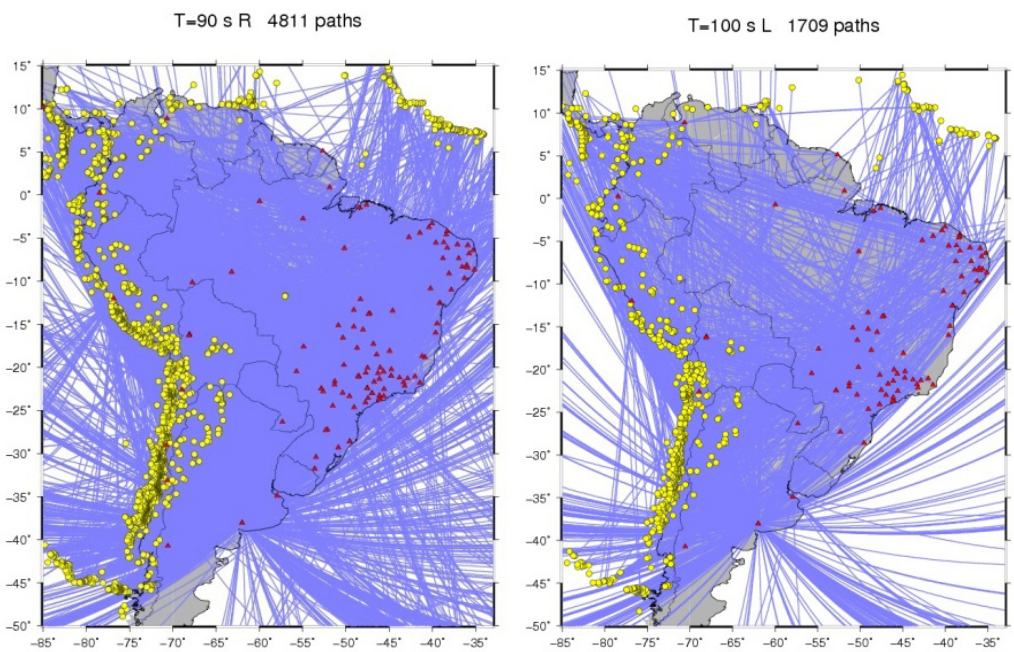

Figura A24: Mapa de trayectorias para las ondas Rayleigh (90 s) y Love (100 s).
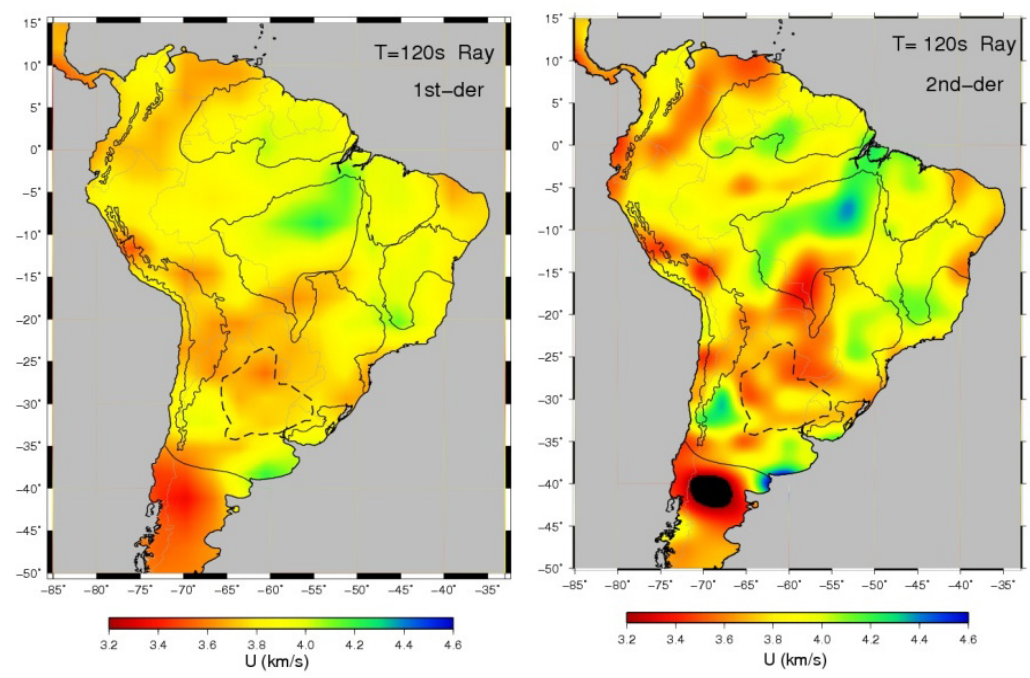

Figura A25: Mapa de velocidad de grupo de onda Rayleigh (120s) con suavizado de $1^{\text {er }}$ y $2^{\text {da }}$ deriv. 


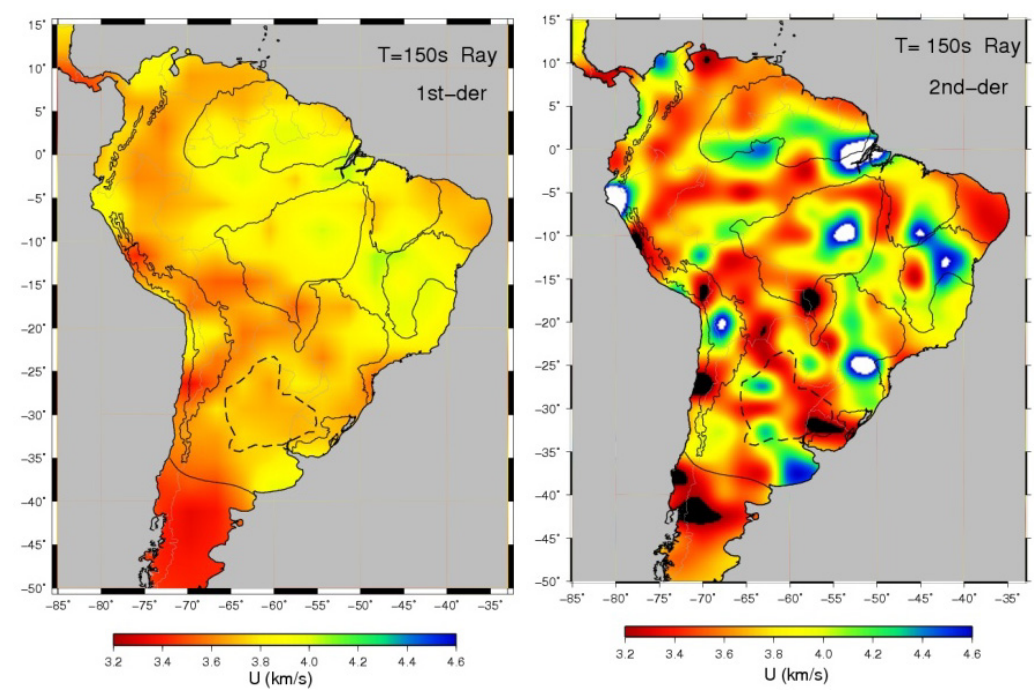

Figura A26: Mapa de velocidad de grupo de onda Rayleigh (150s) con suavizado de $1^{\text {er }}$ y $2^{\text {da }}$ deriv.

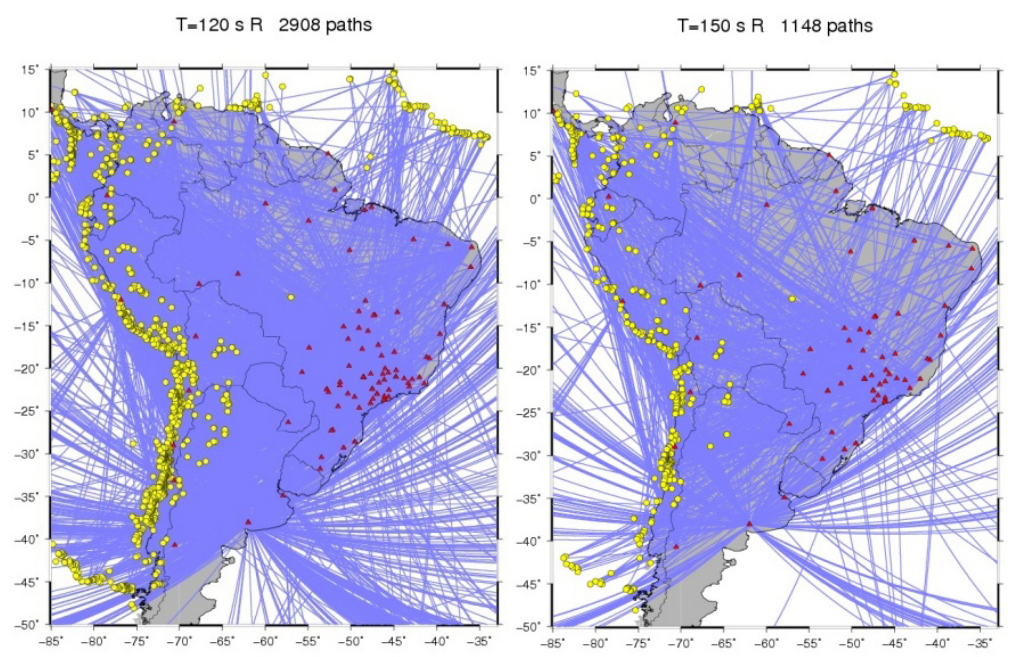

Figura A27: Mapa de trayectorias para las ondas Rayleigh (120s) y Rayleigh (150 s). 


\section{Apéndice B}

\section{Resultados de la inversión de velocidad en capas aplicada a la cuenca Chaco-Paraná}

Se presentan los resultados de los modelos de inversión correspondientes a los mejores ajustes para las ondas Rayleigh y Love obtenidas de la regionalización con criterios de suavización de $1^{\mathrm{er}}$ y $2^{\text {da }}$ derivada. Se observa que todos los modelos presentan en general características comunes que indican la solidez de los resultados.

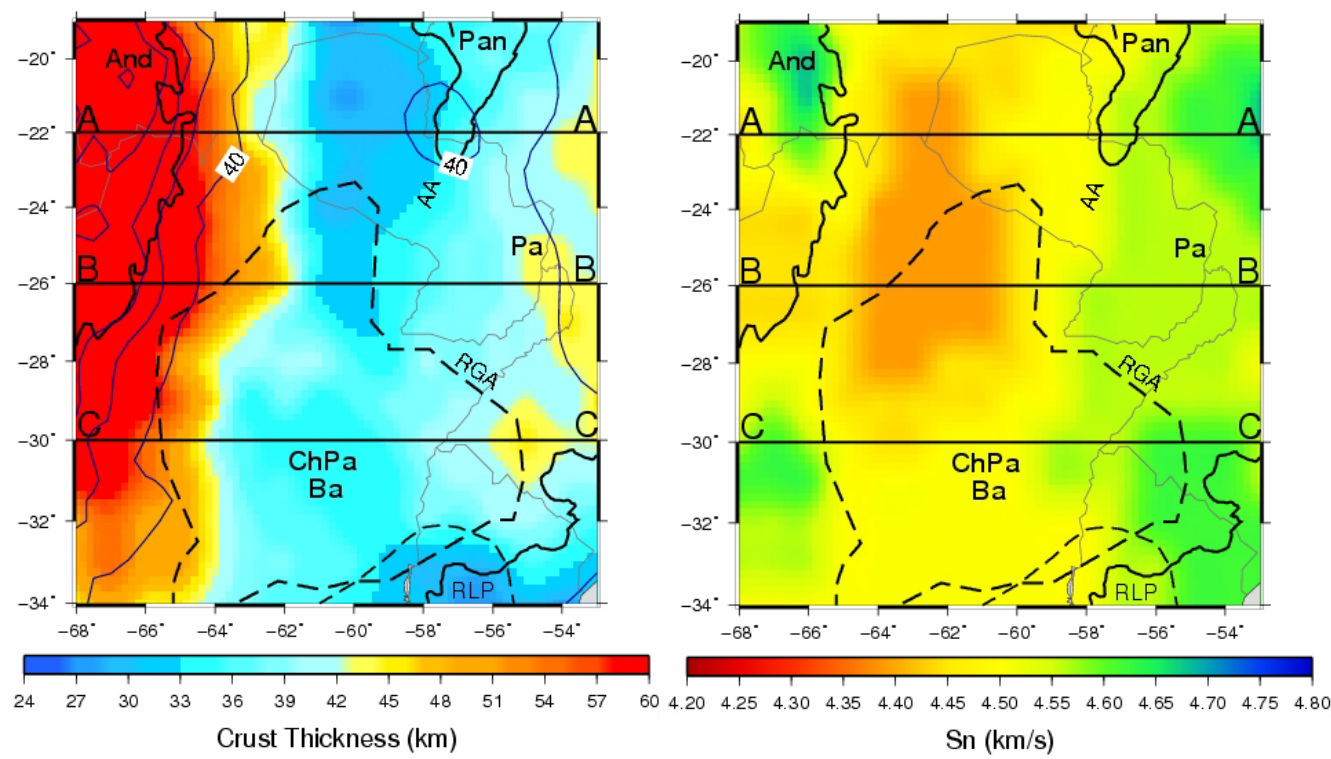

Figura B1: Mapas del espesor cortical total y la velocidad de Sn en el manto correspondientes al Modelo 1 de la tabla 4.2, obtenidos a partir de la regionalización tomográfica para ondas superficiales. Las provincias geológicas corresponden a $\mathrm{ChPa}=$ cuenca Chaco-Paraná, $\mathrm{Pa}=$ cuenca de Paraná, And = región andina, $P$ an = cuenca de Pantanal, $R L P=$ cratón del Río de la Plata. AA, BB y CC son los tres perfiles verticales de la Fig. 4.13. Los límites de la cuenca ChacoParaná (línea punteada) corresponden a Dragone et al. (2012). 


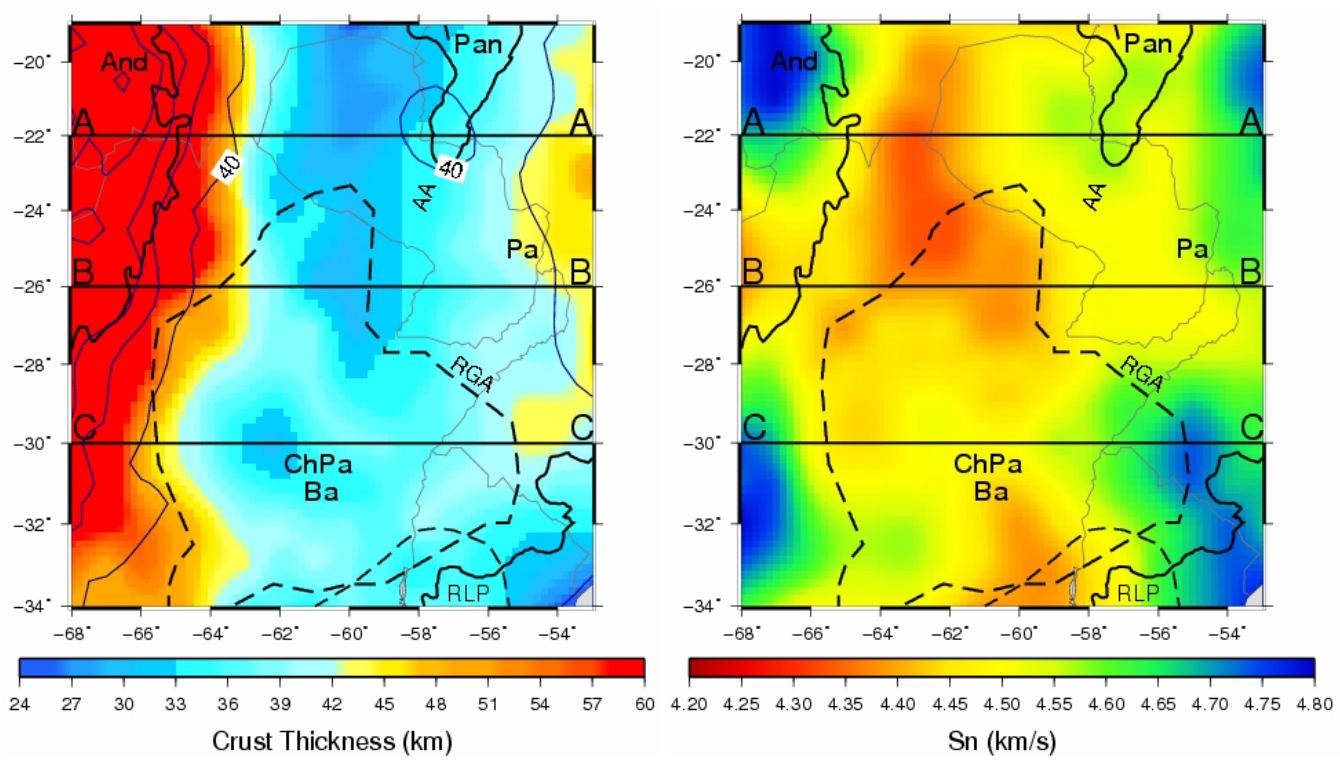

Figura B2: Mapas del espesor cortical total y la velocidad de Sn en el manto correspondientes al Modelo 2 de la tabla 4.2. Las provincias geológicas y los perfiles son iguales a la Fig. B1.

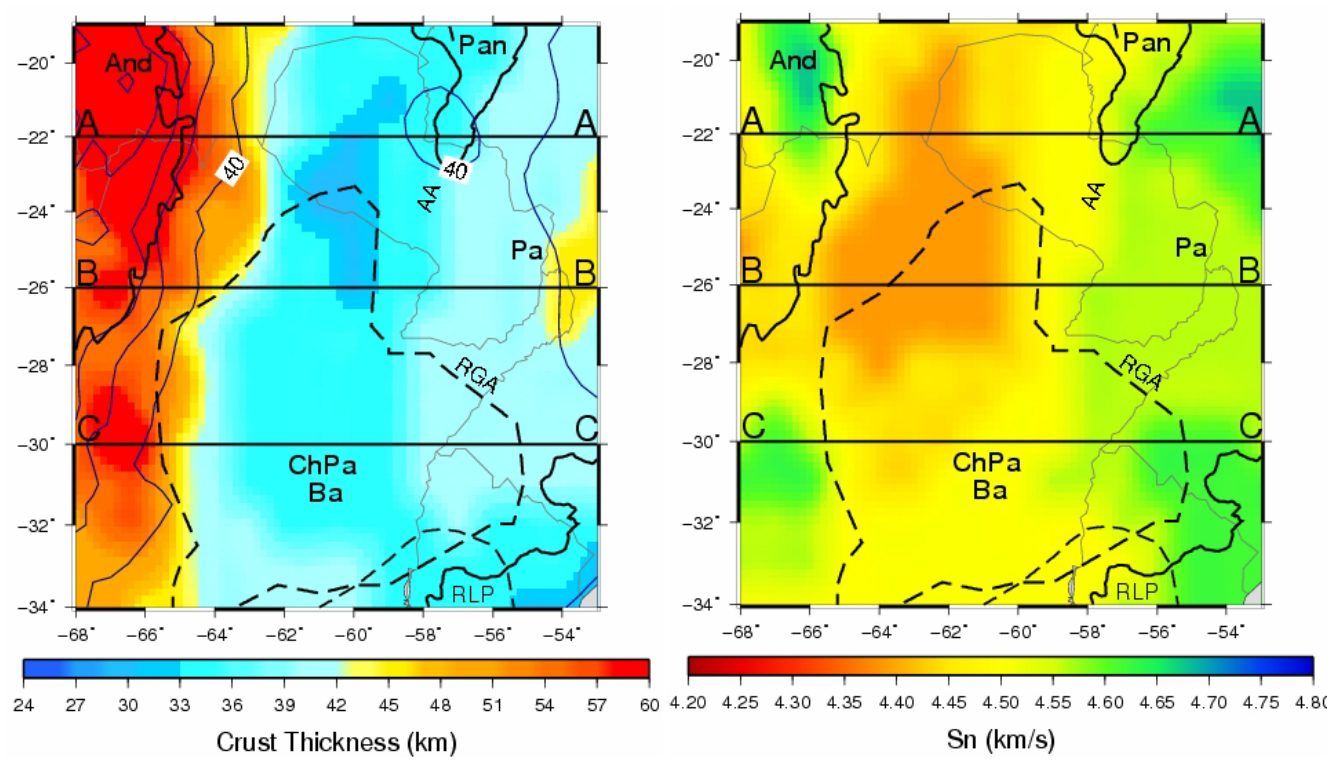

Figura B3: Mapas del espesor cortical total y la velocidad de $\mathrm{Sn}$ en el manto correspondientes al Modelo 3 de la tabla 4.2. Las provincias geológicas y los perfiles son iguales a la Fig. B1. 


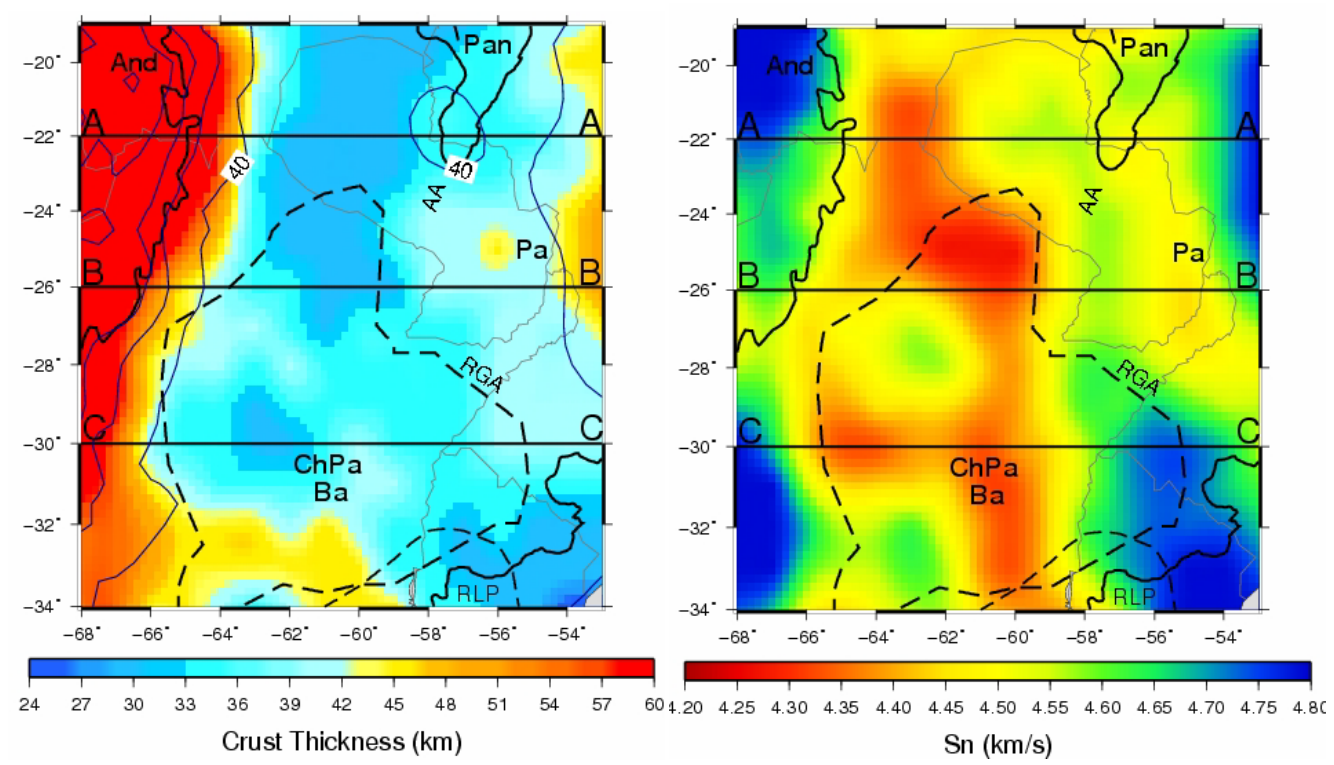

Figura B4: Mapas del espesor cortical total y la velocidad de Sn en el manto correspondientes al Modelo 4 de la tabla 4.2. Las provincias geológicas y los perfiles son iguales a la Fig. B1.

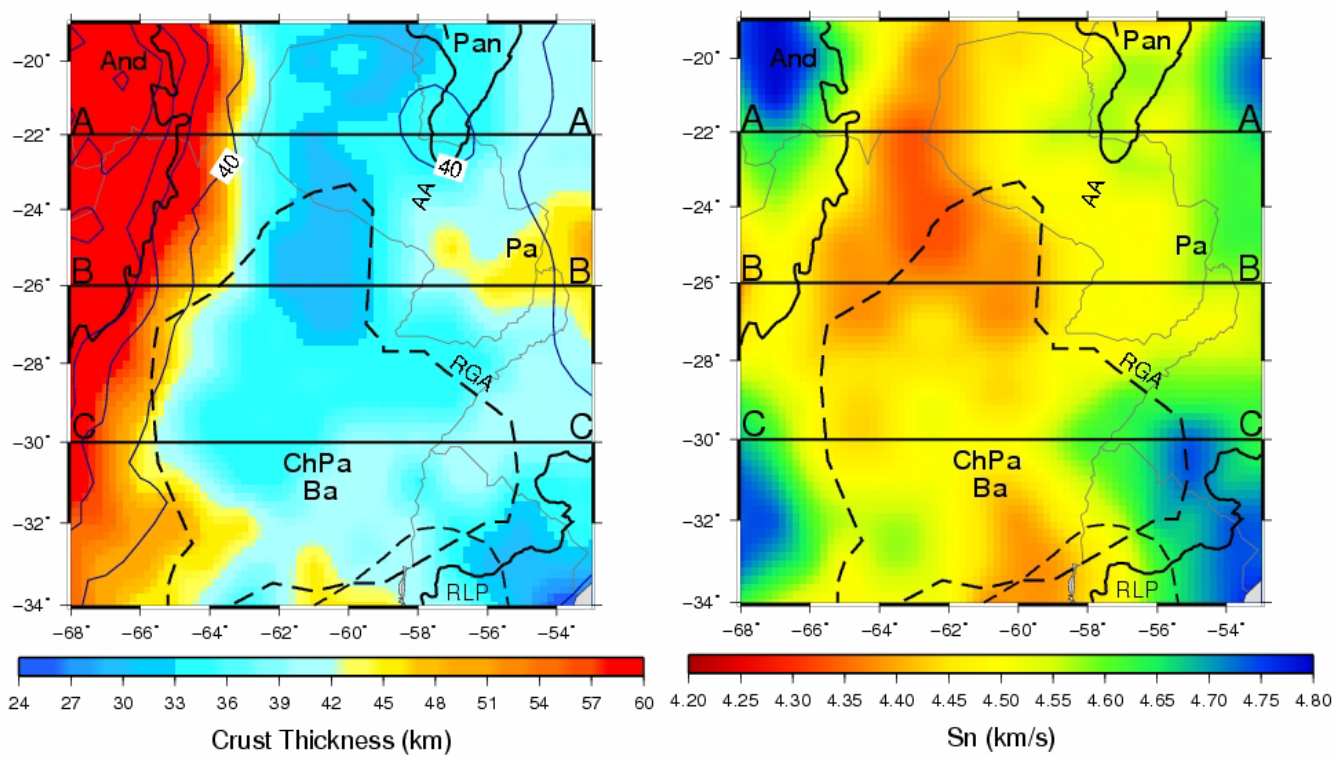

Figura B5: Mapas del espesor cortical total y la velocidad de Sn en el manto correspondientes al Modelo 5 de la tabla 4.2. Las provincias geológicas y los perfiles son iguales a la Fig. B1. 


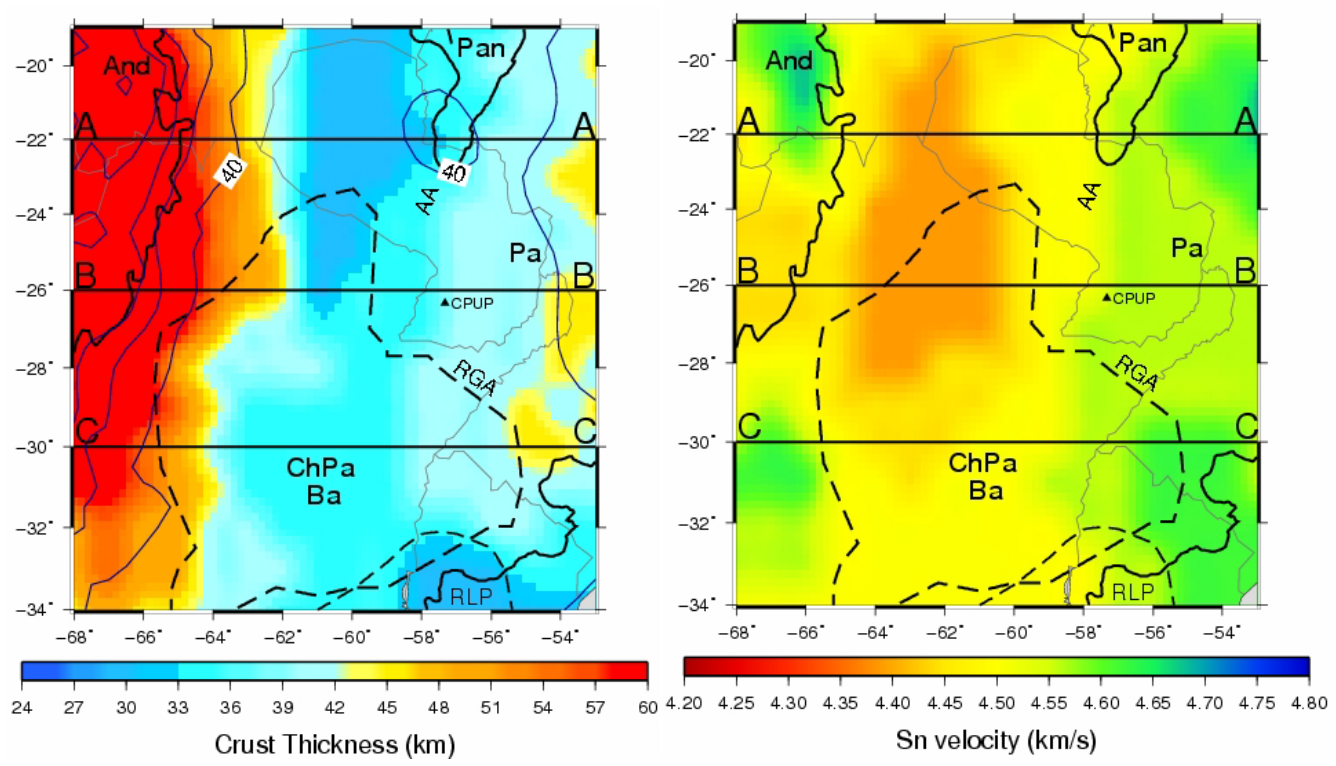

Figura B6: Mapas del espesor cortical total y la velocidad de Sn en el manto correspondientes al Modelo 6 de la tabla 4.2. Las provincias geológicas y los perfiles son iguales a la Fig. B1.

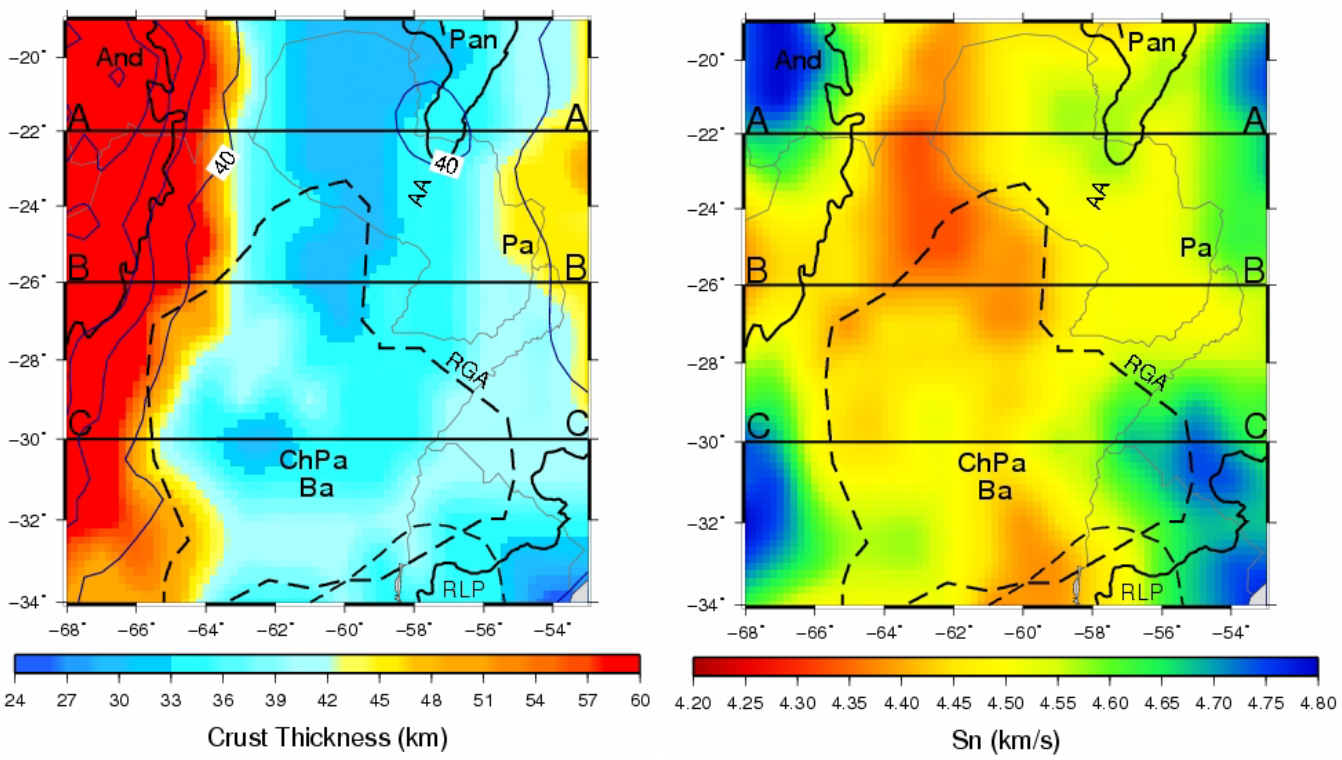

Figura B7: Mapas del espesor cortical total y la velocidad de Sn en el manto correspondientes al Modelo 7 de la tabla 4.2. Las provincias geológicas y los perfiles son iguales a la Fig. B1. 


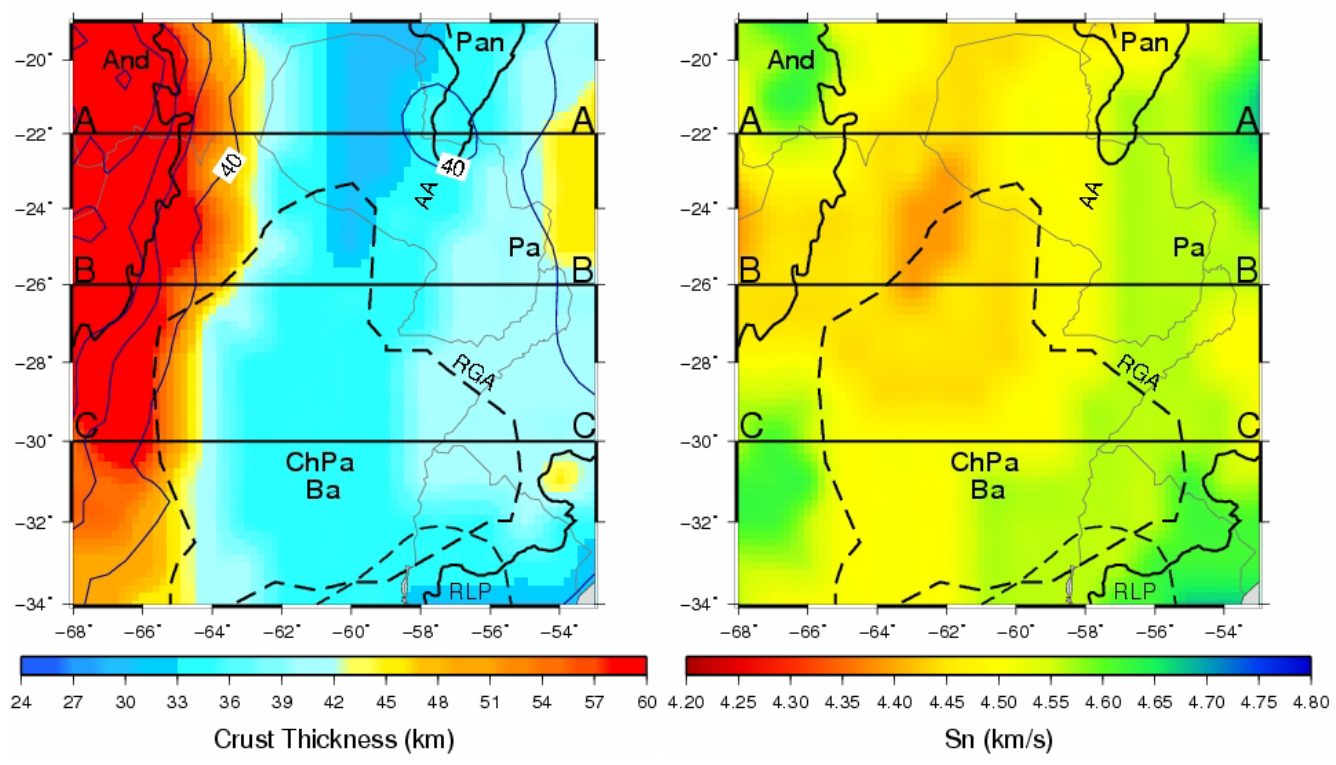

Figura B8: Mapas del espesor cortical total y la velocidad de Sn en el manto correspondientes al Modelo 8 de la tabla 4.2. Las provincias geológicas y los perfiles son iguales a la Fig. B1.

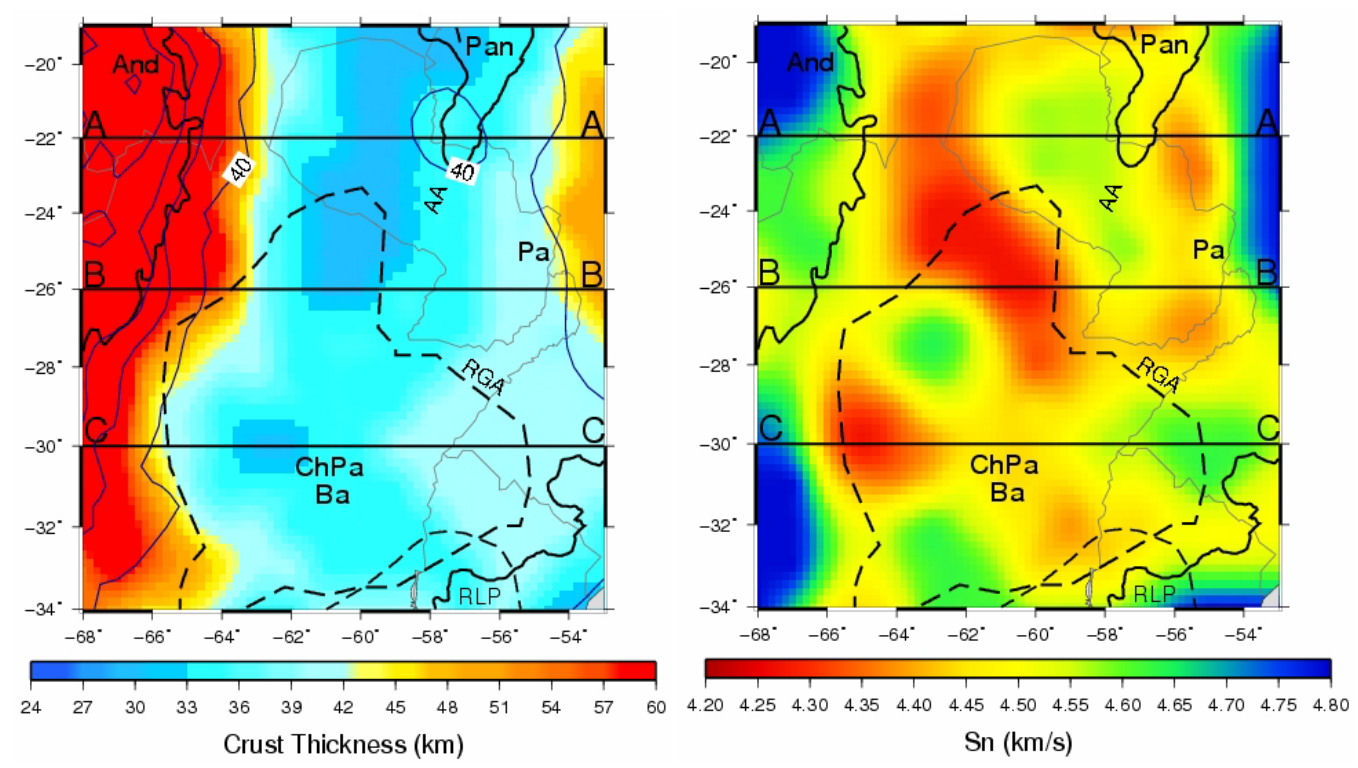

Figura B9: Mapas del espesor cortical total y la velocidad de Sn en el manto correspondientes al Modelo 9 de la tabla 4.2. Las provincias geológicas y los perfiles son iguales a la Fig. B1. 


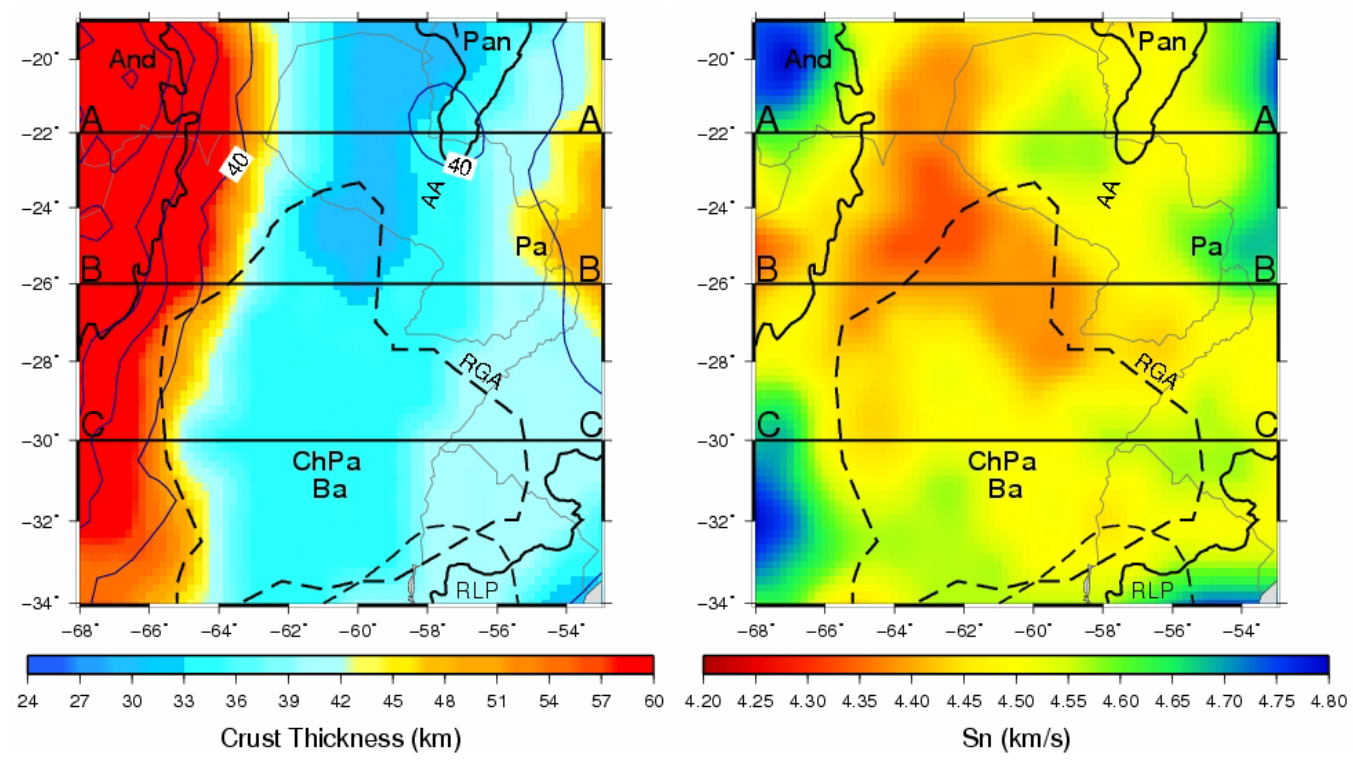

Figura B10: Mapas del espesor cortical total y la velocidad de Sn en el manto correspondientes al Modelo 10 de la tabla 4.2. Las provincias geológicas y los perfiles son iguales a la Fig. B1. 